\title{
Alpha-dicarbonyl stress
}

Citation for published version (APA):

Maessen, D. E. M. (2017). Alpha-dicarbonyl stress: implications for obesity and type 2 diabetes? .

[Doctoral Thesis, Maastricht University]. Maastricht University. https://doi.org/10.26481/dis.20170217dm

Document status and date:

Published: 01/01/2017

DOI:

10.26481/dis.20170217dm

Document Version:

Publisher's PDF, also known as Version of record

\section{Please check the document version of this publication:}

- A submitted manuscript is the version of the article upon submission and before peer-review. There can be important differences between the submitted version and the official published version of record.

People interested in the research are advised to contact the author for the final version of the publication, or visit the DOI to the publisher's website.

- The final author version and the galley proof are versions of the publication after peer review.

- The final published version features the final layout of the paper including the volume, issue and page numbers.

Link to publication

\footnotetext{
General rights rights.

- You may freely distribute the URL identifying the publication in the public portal. please follow below link for the End User Agreement:

www.umlib.nl/taverne-license

Take down policy

If you believe that this document breaches copyright please contact us at:

repository@maastrichtuniversity.nl

providing details and we will investigate your claim.
}

Copyright and moral rights for the publications made accessible in the public portal are retained by the authors and/or other copyright owners and it is a condition of accessing publications that users recognise and abide by the legal requirements associated with these

- Users may download and print one copy of any publication from the public portal for the purpose of private study or research.

- You may not further distribute the material or use it for any profit-making activity or commercial gain

If the publication is distributed under the terms of Article $25 \mathrm{fa}$ of the Dutch Copyright Act, indicated by the "Taverne" license above, 


\section{ALPHA-DICARBONYL STRESS:}

Implications for obesity and type $\mathbf{2}$ diabetes? 
(C) Dionne Maessen, Maastricht 2016

No part of this book may be reproduced or transmitted in any form or by any means, without prior permission in writing by the author, or when appropriate, by the publishers of the publications.

Layout: Dionne Maessen

Cover design: Jean Scheijen | www.vierdrie.nl

Production: Ipskamp Drukkers B.V., Enschede

ISBN: 978-94-028-0476-8 


\section{ALPHA-DICARBONYL STRESS: \\ Implications for obesity and type 2 diabetes?}

PROEFSCHRIFT

ter verkrijging van de graad van doctor aan de Universiteit Maastricht, op gezag van de Rector Magnificus, Prof. dr. Rianne M. Letschert, volgens het besluit van het College van Decanen, in het openbaar te verdedigen

op vrijdag 17 februari 2017 om 14.00 uur

door

Dionne Esther Marcelle Maessen 


\section{Promotores}

Prof. dr. C.G. Schalkwijk

Prof. dr. C.D.A. Stehouwer

\section{Copromotor}

Dr. N.M.J. Hanssen

\section{Beoordelingscommissie}

Prof. dr. H.A.J. Struijker-Boudier (voorzitter)

Prof. dr. E.E. Blaak

Prof. dr. ir. P.C. Dagnelie

Prof. dr. A.J. Smit (UMC Groningen)

Prof. dr. C.C.J. Tack (Radboud UMC Nijmegen)

The research presented in this thesis was conducted at the CARIM school for Cardiovascular Diseases, Maastricht University, Maastricht, The Netherlands.

Financial support by the Dutch Heart Foundation for the publication of this thesis is gratefully acknowledged. 


\section{Contents}

$\begin{array}{lll}\text { CHAPTER } 1 \text { General introduction } & 7\end{array}$

CHAPTER 2 The role of methylglyoxal and the glyoxalase system in 31 diabetes and other age-related diseases

PART I

ALPHA-DICARBONYL STRESS IN OBESITY AND INSULIN RESISTANCE

CHAPTER 3 Higher plasma concentrations of the methylglyoxal metabolite D-lactate are independently associated with insulin resistance: the CODAM study

CHAPTER 4 Extracellular methylglyoxal induces muscle insulin resistance by modification of the insulin molecule and not by intramuscular accumulation

CHAPTER 5 Delayed intervention with pyridoxamine improves metabolic 105 function and prevents adipose tissue inflammation and insulin resistance in high-fat diet-induced obese mice

CHAPTER 6 Glyoxalase-1 overexpression inhibits body weight gain and glucose intolerance in mice with high-fat diet-induced obesity

PART II POSTPRANDIAL ALPHA-DICARBONYL STRESS IN TYPE 2 DIABETES

CHAPTER 7 Post-glucose load $\alpha$-dicarbonyl concentrations are increased 149 in individuals with impaired glucose metabolism and type 2 diabetes: the CODAM study

CHAPTER 8 Energy restriction and Roux-en- $Y$ gastric bypass reduce 169 postprandial $\alpha$-dicarbonyl stress in obese women with type 2 diabetes

CHAPTER 9 General discussion

VALORISATION ADDENDUM 

GENERAL INTRODUCTION 


\section{Introduction}

The burden of obesity is one of the major health problems in modern-time society and has reached epidemic proportions worldwide. Since 1980, the incidence of obesity has doubled and at present, over 600 million adults are clinically obese. ${ }^{1}$ Overweight and obesity are related to an increased risk of developing insulin resistance and type 2 diabetes, thereby reducing life expectancy and increasing the social economic burden of obesity. ${ }^{2,3}$ Most recent estimates indicate that $8.3 \%$ of the adult population worldwide - 382 million people - has diabetes, and its prevalence is set to rise beyond 592 million within a generation. It is the fourth or fifth leading cause of death in highincome countries and there is increasing evidence that it has become an epidemic disease in many economically developing and newly industrialized countries. ${ }^{4}$

However, how obesity contributes to the development of insulin resistance and type 2 diabetes is yet not well understood. There is now emerging evidence that advanced glycation endproducts (AGEs) play a key role in these etiologies. Particularly precursors of AGEs, the so-called $\alpha$-dicarbonyls, are being considered as important players in the development of insulin resistance, diabetes and diabetic complications. Taking into account that $\alpha$-dicarbonyls are mainly formed under hyperglycemic and hyperlipidemic conditions, it is tempting to speculate that both obesity and hyperglycemia contribute to increased formation of $\alpha$-dicarbonyls and AGEs. Therefore, in this thesis, the impact of AGEs, with a focus on $\alpha$-dicarbonyls, is studied in obesity and hyperglycemia. This general introduction provides background on AGE formation in obesity and insulin resistance. In addition, this introduction elaborates on postprandial hyperglycemia since increasing evidence highlights postprandial hyperglycemia as an independent risk factor for cardiovascular disease and $\alpha$ dicarbonyls possibly mediate this association. Finally, at the end of this general introduction, knowledge gaps in this research field are indicated and aims of this thesis are formulated. 


\section{The glycation pathway}

Glycation is a non-enzymatic, post-translational modification of proteins, resulting from a condensation reaction of glucose and other reducing sugars with amino acids in proteins. ${ }^{5,6}$ The formation of AGEs is complex and may arise from distinct metabolic pathways (Figure 1.1).

\section{Formation of AGEs via the Maillard reaction}

The formation of AGEs was first described in the early 1900s by Louis Camille Maillard. ${ }^{7}$ The Maillard reaction can be divided into three main stages. The early stage consists of a non-enzymatic condensation reaction of the carbonyl group of glucose or other reducing sugars with the N-terminus of free amino acids of proteins, but also nucleic acids and lipids, resulting in the rapid formation of a reversible Schiff base. In the intermediate stage of the Maillard reaction, Schiff bases undergo structural rearrangements to form more stable, but still reversible Amadori products. Finally, only a small proportion of these Amadori products are further rearranged, dehydrated and condensated to form irreversible AGEs. ${ }^{8,9}$ This entire reaction occurs slowly over a period of months, and therefore, AGEs derived from the Maillard reaction are formed predominantly on long-lived extracellular proteins such as collagen and lens proteins. $^{7}$

\section{Intracellular formation of AGEs via a-dicarbonyls}

It is now well established that glucose-derived glycolytic intermediates are much more potent glycating agents compared to glucose itself, which has the slowest glycation rate of all naturally available sugars. Intracellular formation of AGEs is much faster and is therefore believed to be of more importance in vivo than AGE formation via the Maillard reaction. The glucose-derived glycolytic intermediate glucose-6-phosphate, the triose phosphates dihydroxyacetonephosphate (DHAP) and glyceraldehyde-3phosphate (G3P), and predominantly the $\alpha$-dicarbonyls methylglyoxal (MGO), glyoxal (GO) and 3-deoxyglucosesone (3-DG) play an important role in the rapid intracellular formation of AGEs. ${ }^{10-13}$ In addition, the sorbitol pathway generates reactive intermediates such as fructose, fructose-3-phosphate and 3-DG, which may also react with protein residues and substantially contribute to AGE formation. ${ }^{14}$ 


\section{Formation of AGEs via lipid peroxidation}

In addition to formation of AGEs via glucose or glucose-derived glycolytic intermediates, AGEs can also be formed via peroxidation of polyunsaturated fatty acids. ${ }^{15,16}$ The resulting dicarbonyl compounds include both dicarbonyls identical to those formed during glucose metabolism (e.g. MGO and GO), but also lipid-specific compounds such as malondialdehyde and 4-hydroxynonenal. ${ }^{16,17}$ Modification of amino acid residues with these compounds are often referred to as advanced lipid peroxidation endproducts (ALEs), of which $\mathrm{N}^{\varepsilon}$-(carboxymethyl)lysine $(\mathrm{CML})$ and $\mathrm{N}^{\varepsilon}$ (carboxyethyl)lysine (CEL) are the best known examples.

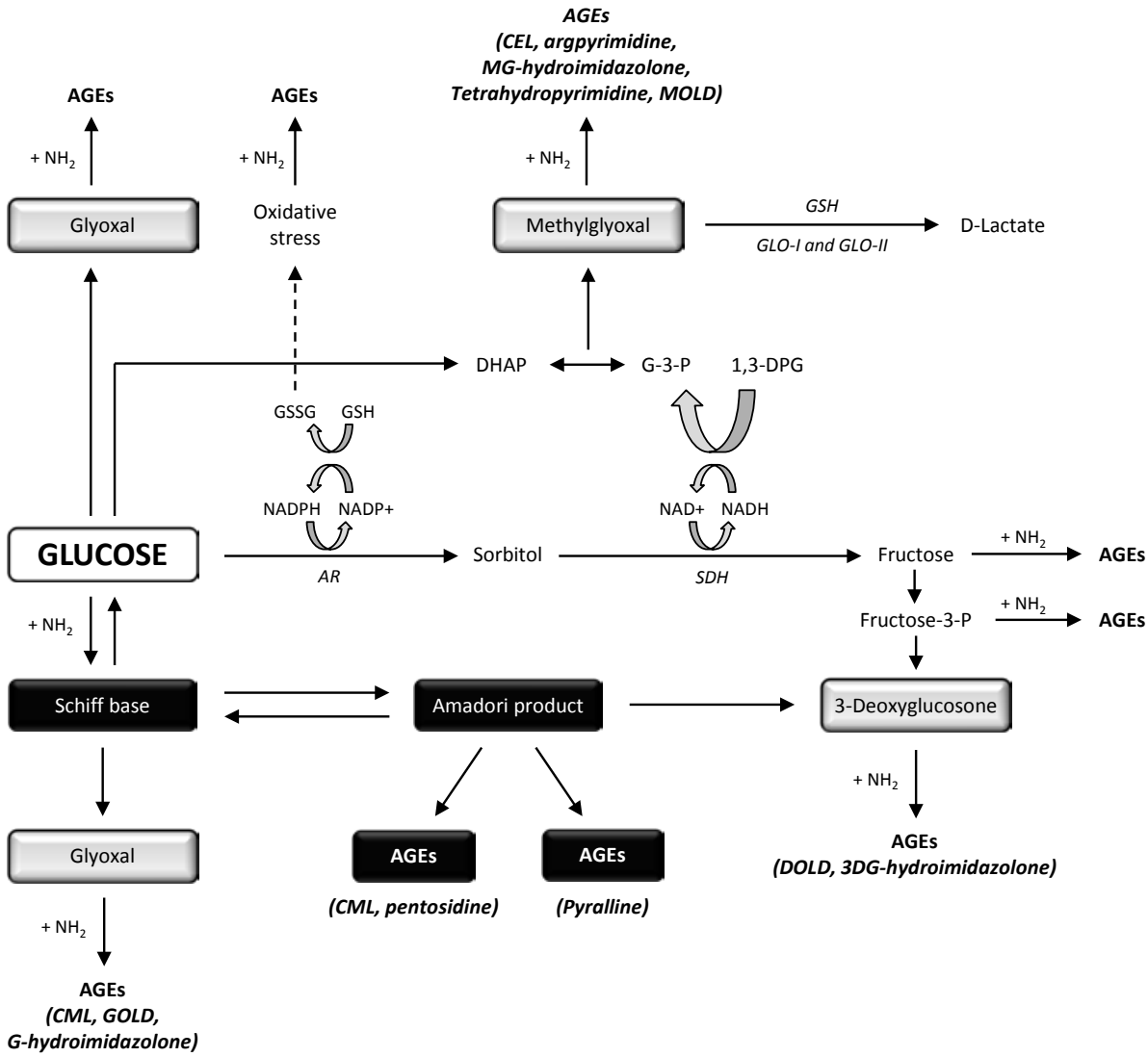

Figure 1.1 - The formation of advanced glycation endproducts via glucose. The classical pathway of the Maillard reaction is indicated in black boxes. In addition to the classical pathway, reactive $\alpha$-dicarbonyl precursors such as MGO, GO and 3-DG play an important role in the rapid formation of AGEs. MGO is formed by non-enzymatic fragmentation of the triose phosphates glyceraldehyde-3-phosphate (G-3-P) and dihydroxyacetonphosphate (DHAP). MGO reacts further with lysine and arginine residues in proteins to form AGEs including CEL, argpyrimidine, MGO-derived hydroimidazolones and cross-link structures such as MGO-derived lysine dimer (MOLD). In the pathogenesis of diabetes, hyperglycaemia results in high cellular glucose levels, which results in an overflow of the glycolysis pathway. Excess amount of glucose is 
metabolized by the enzyme aldose reductase (AR) to sorbitol, which is later oxidized to fructose by sorbitol dehydrogenase (SDH). This process of reducing high intracellular glucose to sorbitol is accompanied by oxidation of the cofactor NADPH to NADP+. NADPH is an essential cofactor for regenerating the intracellular antioxidant reduced glutathione (GSH). By decreasing the amount of GSH, this polyol pathway increases oxidative stress and this contributes to the formation of AGEs. Sorbitol is then further oxidized to fructose. This reaction causes an increase in the NADH/NAD+ ratio, which subsequently inhibits the glyceraldehyde3-phosphate dehydrogenase (GAPDH) and increases the triose phosphates and the formation of MGO. An additional and indirect effect of the polyol pathway is the inhibition of the glyoxalase (GLO)-1 enzyme, which uses GSH and has a detoxification function by converting MGO to D-lactate. Therefore, this pathway may further increase MGO levels. Fructose and its derivative fructose-3-phosphate (fructose-3-P) are also potent glycating agents and can lead to the formation of AGEs as well. Fructose-3-P can be further metabolized into 3-DG, which rapidly reacts with amino groups to form 3-DG-imidazolone and 3-DG-derived lysine dimer (DOLD). AGEs may also be formed directly from the intracellular auto-oxidation of free glucose to GO, without the formation of Amadori intermediates. In this pathway, known as autoxidative glycosylation or the Wolff pathway, reactive oxygen species (ROS) such as hydrogen peroxide are important catalysts of the autoxidation of sugars. GO further reacts with lysine and arginine residues to form AGEs including CML, GO-derived hydroimidazolones, and the cross-link GO-derived lysine dimer (GOLD).

\section{Biological effects of advanced glycation endproducts}

When $\alpha$-dicarbonyl formation exceeds the capacity for endogenous detoxification, $\alpha$ dicarbonyls may accumulate intracellularly. As a result, they may modify a wide variety of proteins, causing damage to cells and tissues. At least three important mechanisms by which AGEs damage cells and tissues have been proposed (Figure 1.2). ${ }^{18}$ First, modification of extracellular matrix proteins by $\alpha$-dicarbonyls causes abnormal interactions with other matrix components and with cellular receptors for matrix proteins (integrins). Aberrant cross-linking of extracellular matrix proteins due to AGE accumulation results in a decrease of elasticity and increase in thickness and rigidity of blood vessels, and may finally lead to arterial stiffness. ${ }^{19,}{ }^{20}$ As a consequence, permeability and cellular motility of the blood vessel become impaired. ${ }^{19}$ Second, intracellular proteins may be modified by $\alpha$-dicarbonyls. ${ }^{21}$ Due to the fast glycation rate of $\alpha$-dicarbonyls, AGEs often accumulate intracellularly. Of the three main $\alpha$-dicarbonyls, MGO is considered as the most reactive one in AGE formation ${ }^{22}$ and is discussed in detail in chapter 2. $\alpha$-Dicarbonyls are implicated in the activation of intracellular signaling pathways, as well as the modification of intracellular proteins, changing the original function of the protein and thereby contributing to diabetic vascular complications. ${ }^{18,}{ }^{19}$ Third, $\alpha$-dicarbonyls may diffuse out of cells and subsequently modify circulating proteins. Binding of circulating AGEs to AGE receptors such as RAGE on multiple cell types activates key cell signaling pathways including the nuclear transcription factor $\mathrm{KB}$ (NFKB) pathway via production of reactive oxygen species (ROS). ${ }^{21}$ This results in induction of mRNA expression of target genes such as inflammatory cytokines and growth factors, contributing to development of insulin resistance and diabetic complications. ${ }^{10,21}$ 


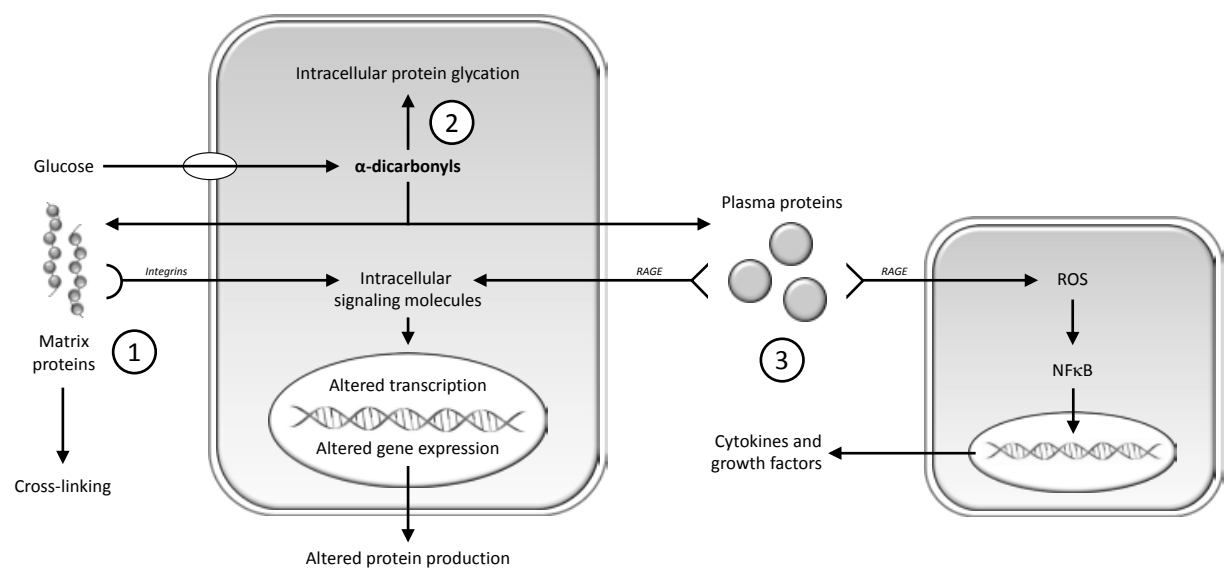

Figure 1.2 - Mechanisms by which $\alpha$-dicarbonyls exert their biological effects. 1) Glycation of extracellular matrix proteins by $\alpha$-dicarbonyls causes abnormal interactions with other proteins and integrins. 2) Modification of intracellular proteins changes the structure and function of the proteins, affecting cellular function. 3) Glycated plasma proteins may bind to receptor for AGEs (RAGE) at the cell membrane, resulting in activation of intracellular pathways such as the NFKB pathway. (Figure adapted from Brownlee et al. Nature 2001). ${ }^{18}$

\section{Advanced glycation endproducts in diabetic vascular complications}

The effect of AGEs on diabetic complications has been studied extensively. Chronic elevation of blood glucose levels results in damage to the vasculature, which can be roughly divided into microvascular disease (due to damage of small blood vessels) and macrovascular disease (due to damage of large arteries).

The major microvascular complications of diabetes comprise nephropathy, retinopathy and neuropathy. Diabetic nephropathy is the main cause of end-stage renal disease in Western society, affecting about $30 \%$ of the diabetes population. It is characterized as the appearance of persistence clinical albuminuria and a subsequent decline in glomerular filtration rate. ${ }^{23}$ This process is often associated with increasing blood pressure. Hypertension and proteinuria may accelerate the decline in the glomerular filtration rate and the progression to end-stage renal disease. ${ }^{24}$ In addition, nephropathy is an important risk factor for the development of cardiovascular disease in diabetic individuals. ${ }^{25}$ Retinopathy is the second main microvascular complication of diabetes and is characterized by a spectrum of lesions within the retina. It is identified in a third of people with diabetes and in 2010 diabetic retinopathy was responsible for $40 \%$ of all cases of blindness in Europe. ${ }^{26}$ Importantly, also retinopathy increases the risk of cardiovascular disease in individuals with diabetes. ${ }^{27}$ The third main microvascular complication is diabetic neuropathy, affecting eventually more than half of all individuals with diabetes and accompanied by a $15 \%$ risk of amputation of 
one or more of the lower extremities. ${ }^{23}$ Diabetic neuropathy affects both somatic and autonomic divisions of the peripheral nervous system and is the main initiating factor for foot ulceration. ${ }^{28}$ Diabetic macrovascular complications include cardiovascular diseases such as angina, myocardial infarction, stroke, peripheral artery disease and congestive heart failure. ${ }^{4}$ The risk of cardiovascular disease in individuals with diabetes is increased up to a level of a nondiabetic individual with previous myocardial infarction. ${ }^{29}$ Cardiovascular disease accounts for $50 \%$ or more deaths due to diabetes. ${ }^{4}$ Figure 1.3 summarizes a variety of vascular diabetic complications with corresponding studies describing the relationship between glycation and vascular disease.

\section{Inhibitors of advanced glycation endproducts}

To prevent accumulation of $\alpha$-dicarbonyls, they can be detoxified by both endogenous pathways and by exogenous compounds. Under physiological circumstances, GO and predominantly MGO can be detoxified by the glyoxalase system, which is active in the cytoplasm of all mammalian cells. This system converts MGO to D-lactate via the intermediate product S-D-lactoylglutathione. In mammals, the glyoxalase system consists of the rate-limiting enzyme glyoxalase-1 (GLO1) and glyoxalase-2 (GLO2). ${ }^{30}$ The glyoxalase system is explained in more detail in chapter 2 and overexpression of the GLO1 enzyme as a potential intervention in obesity is investigated in chapter 5 . Exogenous AGE inhibitors such as aminoguanidine ${ }^{31}$ and the crosslink-breaker alagebrium $^{32}$ have shown beneficial results in experimental studies, ${ }^{33-37}$ but their safety and efficacy in clinical studies is poor. ${ }^{38-43}$ In addition, metformin was shown to detoxify $\alpha$-dicarbonyls in a similar way as aminoguanidine, but data suggest that the AGE-lowering properties of metformin are mainly due to its improvement of glycemic control. ${ }^{44-46}$ Numerous studies also showed the AGE-inhibiting effects of vitamin B6 analogues (pyridoxamine), ${ }^{37,47}$ vitamin B1 (thiamine) ${ }^{37}$ and synthetic derivates of vitamin B1 (benfotiamine) ${ }^{37,48}$ and of angiotensin receptor blockers (ARBs). ${ }^{37}$ An intervention in obesity with pyridoxamine is described in chapter 5 . 


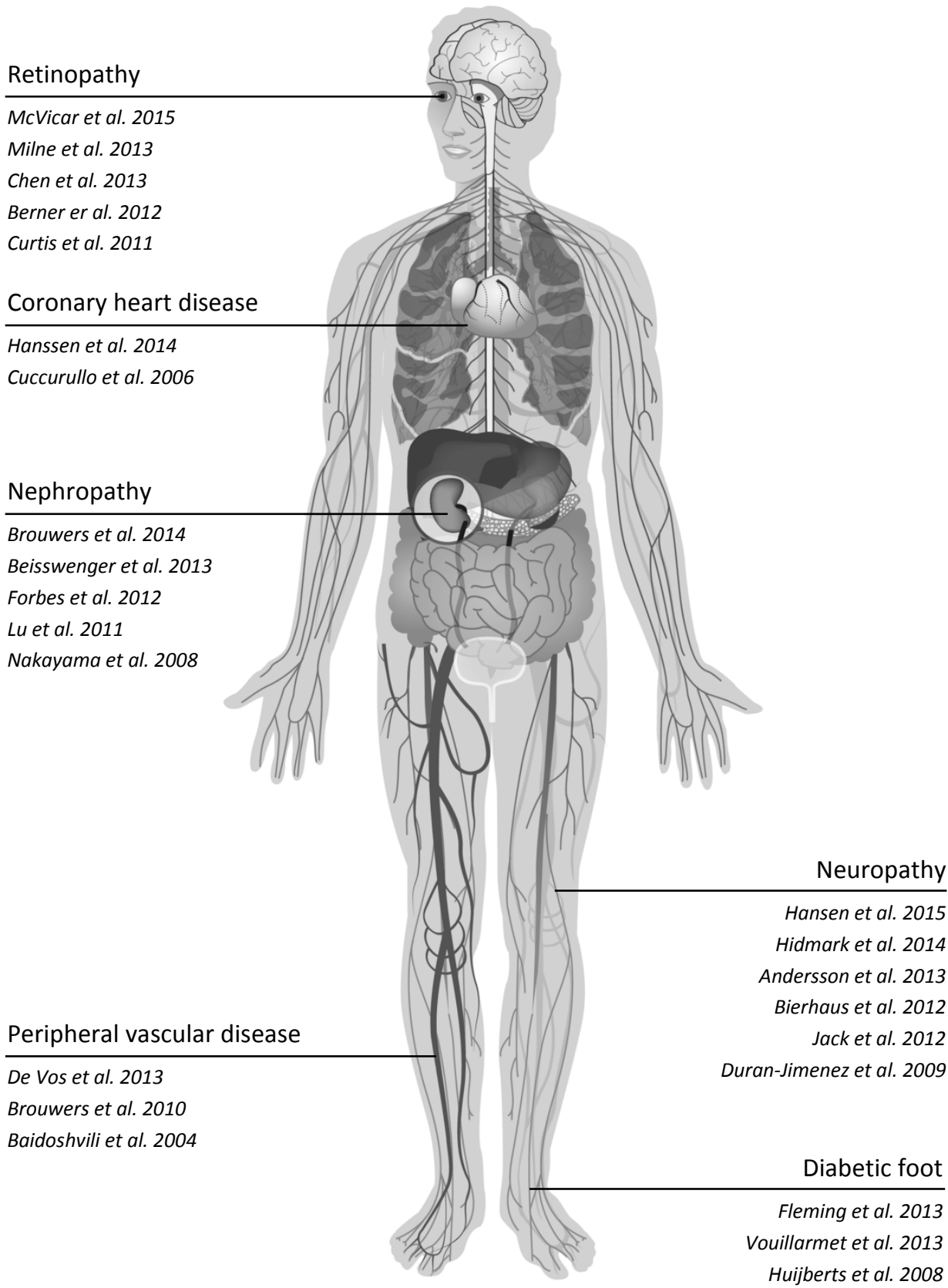

Figure 1.3 - Involvement of $\alpha$-dicarbonyls and advanced glycation endproducts in diabetic vascular disease. References in the figure are referring to studies describing the association between $\alpha$-dicarbonyls and AGEs, and the respective diabetic vascular complications. Figure adapted from the IDF Diabetes Atlas ( $6^{\text {th }}$ Edition). ${ }^{49}$ 


\section{Advanced glycation endproducts in obesity}

Hyperlipidemia is an important condition contributing to the formation of $\alpha$ dicarbonyls and subsequently AGEs. This may have consequences for the development of obesity-related complications such as insulin resistance. In recent years, the role of the adipose tissue is emerging this process.

\section{The dual function of adipose tissue}

Adipose tissue is a complex and highly active metabolic organ and represents the body's largest energy reservoir. ${ }^{21,50}$ Traditionally, the primary role of adipose tissue was regarded to be storage of triacylglycerol during periods of caloric excess and to mobilize fat reserves when energy expenditure exceeds intake. ${ }^{21}$ However, in 1987, adipose tissue was additionally identified as a major site for production of the secretory protein adipsin. ${ }^{51}$ Subsequent identification and characterization of leptin in 1994 firmly established the endocrine role of adipose tissue. ${ }^{52}$ Around the same time, several research groups described a new protein that was synthesized by the adipocyte, which later became known as adiponectin. ${ }^{53-56}$ Since then, many other proteins have been described as secretory proteins. ${ }^{57}$ Collectively, this variety of bioactive peptides produced and secreted specifically by the adipocyte is known as the family of adipocytokines or adipokines, which act at both the local (autocrine/paracrine) and systemic (endocrine) level. ${ }^{21}$ In addition to the adipocyte, the adipose tissue consists of many other secretory cell types such as precursor cells, endothelial cells, macrophages, foam cells, neutrophils, lymphocytes and fibroblasts. ${ }^{57}$ Thus, in addition to the adipocyte-specific adipokines, the adipose tissue secretes many other secretory proteins including complement proteins, proteins of the fibrinolytic system, angiotensinogen and cytokines. ${ }^{57}$ Although cytokines such as tumor necrosis factor alpha (TNF $\alpha$ ), interleukins (IL) and monocyte chemotactic protein-1 (MCP-1) are not adipose-tissue specific, they are often referred to as adipokines when secreted by the adipose tissue. By using these adipokines as communication tools, the adipose tissue can crosstalk with a large number of other tissues, such as the liver, muscle, the brain and the vasculature. ${ }^{58}$ Under normal conditions, the production and secretion of adipokines is strictly regulated, contributing to the regulation of appetite and satiety, fat distribution, insulin secretion and sensitivity, energy expenditure, endothelial function, inflammation, blood pressure, and hemostasis. ${ }^{57}$ However, in obesity, the adipokine profile becomes dysregulated, predisposing the obese individual to a variety of complications. 


\section{Dysregulated adipokine secretion in obesity}

The inability of obese individuals to increase adipose tissue mass by adipocyte hyperplasia may induce hypertrophy of the individual adipocyte, leading to dysfunction of the adipose tissue. ${ }^{52}$ Adipocyte size is an important determinant of adipokine secretion. ${ }^{59}$ Individuals with larger adipocytes typically have elevated levels of pro-inflammatory markers such as leptin, IL-6, IL-8 and MCP-1, and reduced levels of adiponectin and anti-inflammatory IL-10. ${ }^{57}$ In addition, obesity is associated with infiltration of macrophages into adipose tissue, contributing to increased formation of inflammatory adipokines. ${ }^{60}$ This adverse adipokine profile may lead to further adipose tissue inflammation and secondary organ damage in target tissues. ${ }^{57}$ Therefore, the chronically altered adipokine secretion not only reflects adipose tissue dysfunction, but also contributes to the development of obesity-related complications such as type 2 diabetes, cardiovascular disease and inflammatory diseases. ${ }^{57}$ Recent evidence indicates that AGEs are involved in the dysregulation of adipokine secretion in obesity. $^{61}$

\section{Advanced glycation endproducts and a-dicarbonyls in obesity}

Peroxidation of lipids in obesity leads to the formation of $\alpha$-dicarbonyls. Accelerated formation of both CML and MGO in obesity has been described in several studies. ${ }^{62-64}$ CML accumulation has been found in fatty livers of obese individuals, and progressively increased with the grade of steatosis. ${ }^{62}$ Increased accumulation of CML was also described in skeletal muscles of obese individuals and was associated with weight gain. ${ }^{63}$ With regard to $\alpha$-dicarbonyls, MGO has been shown to be increased in serum of obese Zucker rats. ${ }^{64}$ In addition, MGO accumulated in adipose tissue of these rats, mediating adipocyte proliferation by enhancing Akt1 phosphorylation. The implication of AGEs in obesity has also been demonstrated by two independent studies, showing that knockout of the AGE receptor RAGE inhibits body weight gain and dysregulation of adipokine secretion in mouse models of obesity. ${ }^{61,65}$ In this mouse model, RAGE was demonstrated to be involved in CML trapping in adipose tissue, providing a possible mechanism for increased accumulation of $C M L$ in adipose tissue of obese individuals. ${ }^{61}$ Evidence for this phenomenon has been enhanced by recent findings which describe an inverse association between plasma CML levels and central obesity. ${ }^{66}$ Furthermore, knockout of RAGE prevented the development of insulin resistance in a mouse model of obesity. ${ }^{61}$ The AGE-RAGE axis opens new windows for treatment of insulin resistance, which is a major complication in individuals with obesity. 


\section{Advanced glycation endproducts in insulin resistance}

Insulin resistance is often a precursor for the development of type 2 diabetes and is part of the major hallmarks of type 2 diabetes. Insulin resistance can manifest at the level of metabolism and the vasculature. This thesis focuses on metabolic insulin resistance, which is characterized by impaired glucose uptake by tissues including the muscle, liver and adipose tissue. Due to AGE accumulation under hyperglycemic conditions, AGEs may play an important role in the etiology of insulin resistance and type 2 diabetes. To evaluate the contribution of AGEs to impaired insulin sensitivity, physiological functioning of the insulin pathway for glucose uptake in the muscle is discussed first.

\section{The insulin signaling pathway}

A schematic overview of the insulin signaling pathway, with a focus on the PI3K-AKT pathway, is shown in Figure 1.4. Binding of insulin to the insulin receptor, predominantly on muscle cells, triggers phosphorylation of insulin receptor substrate, which subsequently forms a docking site for phosphatidylinositol 3-kinase (PI3K) at the inner cell membrane. ${ }^{67}$ Once docked, the catalytic subunit of PI3K phosphorylates the lipid phosphatidylinositol 4,5-biphosphate $\left(\mathrm{PIP}_{2}\right)$. This reaction yields phosphatidylinositol 3,4,5-triphosphate ( $\left.\mathrm{PIP}_{3}\right)$, which functions as a second messenger that activates phosphoinositide-dependent protein kinase 1 (PDK1) and recruits AKT to the cell membrane. ${ }^{68}$ In contrast, the lipid phosphatase PTEN (phosphatase and tensin homolog) dephosphorylates $\mathrm{PIP}_{3}$, making less $\mathrm{PIP}_{3}$ available to recruit AKT to the cell membrane. The high affinity interaction between $\mathrm{PIP}_{3}$ and AKT causes conformational changes in the AKT protein and exposure of the phosphorylation sites threonine $308\left(\mathrm{Thr}^{308}\right)$ in the kinase domain and serine $437\left(\mathrm{Ser}^{437}\right)$ in the C-terminal domain. Subsequent phosphorylation of the AKT substrate of $160 \mathrm{kDa}$ (AS160) by AKT itself causes it to dissociate from the glucose transporter GLUT4, facilitating translocation of the intracellular GLUT4 vesicle to the cell membrane. ${ }^{69}$ The role of AS160 in GLUT4 translocation is mediated by its GTPase activating domain and interactions with Rab proteins in vesicle formation, increasing GLUT4 translocation when its GTPase activity is inhibited by AKT phosphorylation. ${ }^{69}$ The Rab-interacting protein Rip11 is finally responsible for fusion of the GLUT4 vesicle with the cell membrane. ${ }^{70}$ As a result, GLUT4 at the cell membrane creates an opening for glucose to enter the cell. We hypothesize that AGEs interfere with the insulin signaling pathway at one or more specific points, contributing to insulin resistance. 


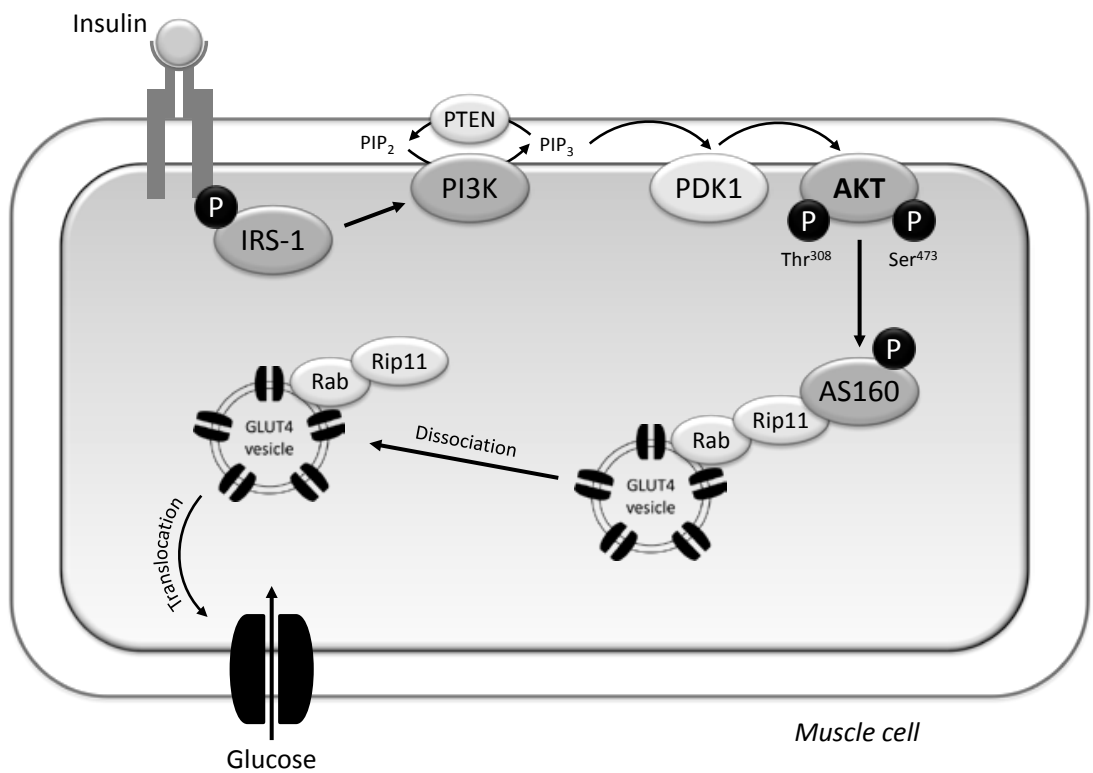

Figure 1.4 - Schematic overview of the PI3K-AKT insulin signaling pathway in the muscle cell. Phosphorylation of IRS1 upon insulin binding to its receptor results in docking of PI3K at the cell membrane. PI3K phosphorylates $\mathrm{PIP}_{2}$ into $\mathrm{PIP}_{3}$, which is a second messenger activating PDK1 with subsequent recruitment of AKT to the cell membrane. Interaction between AKT and $\mathrm{PIP}_{3}$ exposes the phosphorylation sites $\mathrm{Thr}^{308}$ and $\mathrm{Ser}^{473}$ at the AKT protein, which then phosphorylates AS160. This results in dissociation from the Rib/Rab complex at the GLUT4 vesicle and translocation of the vesicle to the cell membrane, creating an opening for glucose to enter the cell.

\section{Insulin resistance}

The most critical factor in the development of insulin resistance is obesity. ${ }^{71}$ The adipose tissue is involved in the regulation of whole body metabolism by releasing non-esterified fatty acids (NEFAs) and glycerol, hormones, and cytokines. ${ }^{58,72,73}$ In obese individuals, the production of many of these compounds is increased, contributing to the development of insulin resistance. For example, retinol-binding protein-4 (RBP4) induces insulin resistance through a reduction in PI3K activity in the muscle. $^{74}$ In contrast, increased adiponectin levels in obesity stimulate fatty acid oxidation. ${ }^{58,75}$ In addition, release of other adipokines such as TNF $\alpha$ and IL-6 play a role in obesity-induced insulin resistance. ${ }^{72,76}$ Increased release of NEFAs by the adipose tissue of obese individuals is probably the most critical factor in modulating insulin sensitivity. ${ }^{77}$ Acute increases in plasma NEFAs already cause the development of insulin resistance. ${ }^{78} \mathrm{~A}$ possible mechanism via which NEFAs contribute to insulin resistance may by via enhancement of diacylglycerol, fatty acid-coenzyme $A$ and ceramide production, products which subsequently inhibit the insulin signaling cascade. $^{79}$ 


\section{Advanced glycation endproducts in insulin resistance}

Since $\alpha$-dicarbonyls and AGEs are mainly formed during metabolism of glucose, it is likely that their formation is increased under hyperglycemic conditions. Several clinical studies have reported associations between higher serum AGE and $\alpha$-dicarbonyl levels, and higher values of the homeostatic model assessment of insulin resistance (HOMA-IR), independently of putative confounders. ${ }^{80-82}$ Structural and functional abnormalities of the insulin molecule by glycation and methylglyoxal may contribute to the pathogenesis of insulin resistance. In addition, it is likely that AGEs interfere in the insulin signaling pathway and as such in insulin resistance. Evidence for mechanistic links between AGEs and insulin resistance has been provided by results of both in vitro and in vivo experiments. ${ }^{83}$

\section{Glycation of insulin}

One possible mechanism via which glycation may contribute to insulin resistance is by glycation of the insulin molecule, changing its properties. Although insulin has a very short half-life of 5 to 10 minutes, a substantial proportion of insulin and proinsulin is glycated in the pancreatic $\beta$-cells during insulin synthesis and storage. Glycated insulin has been measured in the pancreas of various animal models of type 2 diabetes and in both isolated islets and clonal $\beta$-cells exposed to elevated glucose concentrations in tissue culture. ${ }^{84-86}$ In addition, plasma measurements in diabetic obese hyperglycemic $o b / o b$ mice revealed raised concentrations of glycated insulin in the circulation. ${ }^{87}$ These observations in animal models have been confirmed and extended with a sensitive immunoassay for glycated insulin, demonstrating that $\sim 9 \%$ of the insulin fraction in individuals with type 2 diabetes circulates in the glycated form. ${ }^{88}$ Infusion of glycated insulin in mice reduced plasma glucose levels to a much lesser extent compared to non-glycated insulin. ${ }^{89}$ In addition, glycated insulin was $20 \%$ less effective in mediating glucose uptake, glucose oxidation, and glycogen production in isolated abdominal muscle compared with the non-glycated form of insulin. ${ }^{89}$ When glycated insulin was tested in a two-step euglycemic-hyperinsulinemic clamp, the exogenous glucose infusion rates required to maintain euglycemia during steady state were significantly lower compared to non-glycated insulin and $\sim 70 \%$ more glycated insulin was required to induce a similar rate of insulin-mediated glucose uptake. ${ }^{90}$ In vitro, MGO modification of insulin reduced glucose uptake in 3T3-L1 adipocytes and L8 skeletal muscle cells. ${ }^{91}$ It has also been shown that MGO modification of insulin blocked IRS tyrosine phosphorylation and PI3K activation in the INS- 1 pancreatic $\beta$-cell line, ${ }^{92}$ demonstrating that MGO modification of insulin affects insulin signaling directly. 


\section{Glycation of distinct proteins}

Glycation of albumin, as a pre-stage of AGE adducts on albumin, has been demonstrated to increase the production of TNF $\alpha$, which is involved in insulin resistance via induction of pro-inflammatory cascades. ${ }^{93}$ More directly, glycated albumin may be involved in the modulation of insulin signaling and hence in the generation of insulin resistance in skeletal muscle cells. Miele et al. demonstrated that Amadori formation on albumin selectively inhibits the PI3K/AKT part of the insulin signaling pathway in L6 skeletal muscle cells, while leaving the MAPK pathway and mitogenic action of the hormone unaltered. ${ }^{94}$ The effect on PI3K/AKT inhibition was dependent on a PKC-mediated serine/threonine phosphorylation of IRS-1/2 proteins, but independent of ROS production. In addition, glycated albumin induced Srcmediated activation of protein kinase C- $\alpha$ and suppressed IRS-1 action in a RAGEdependent way. ${ }^{95}$

\section{Inhibition of glycation in vivo to prevent insulin resistance}

Several studies have investigated whether anti-glycating agents reduce or prevent the development of insulin resistance in hyperglycemic animal models. ${ }^{83}$ Unoki-Kubota et al. supplemented KK-A(y) mice, a mouse model of obesity and type 2 diabetes, with pyridoxamine and found decreased fasting insulin levels and a dose-dependent improvement in insulin sensitivity. ${ }^{96}$ In addition, MGO administration via drinking water to Sprague-Dawley rats for 4 weeks induced insulin resistance. However, when rats were additionally treated with the antioxidant $\mathrm{N}$-acetyl cysteine or the AGEinhibitor TM2002, MGO-induced insulin resistance was completely prevented. Similar effects were achieved by the AGE-inhibitor aminoguanidine. ${ }^{97}$ In this study, chronic exposure to hyperglycemia resulted in decreased glucose-stimulated insulin secretion by pancreatic islets of DBA/2 mice, due to reduced glucokinase activity. When these islets were co-incubated with aminoguanidine, levels of glucokinase increased, suggesting that chronic glucose-mediated increases in AGEs could participate in pancreatic islet dysfunction. More recently, the contribution of AGEs to the development of insulin resistance has been demonstrated in obese hyperglycemic ob/ob mice. ${ }^{61}$ This study showed that RAGE-mediated CML trapping in adipose tissue contributed to obesity-induced insulin resistance. Altogether, these data reinforce the hypothesis that hyperglycemia-induced AGE formation plays a pivotal role in the development of insulin resistance. 


\section{Advanced glycation endproducts in hyperglycemia}

A wealth of studies in both type 1 and type 2 diabetes, including the landmark Diabetes Control and Complications Trial (DCCT) and the United Kingdom Prospective Diabetes Study (UKPDS), have shown that chronic hyperglycemia is an important risk factor for the development of diabetic complications. ${ }^{98-100}$ Based on these studies, the primary focus in the management of hyperglycemia has been on lowering glycosylated hemoglobin $\left(\mathrm{HbA}_{1 \mathrm{C}}\right) \cdot{ }^{101}$ Although strategies aimed at lowering $\mathrm{HbA}_{1 \mathrm{C}}$ have led to reductions in cardiovascular risk, a key caveat of $\mathrm{HbA}_{1 \mathrm{c}}$ is that it does not include information about glucose fluctuations. ${ }^{102}$ Increasing evidence highlights postprandial hyperglycemia as a major risk factor for diabetic complications. ${ }^{101,103}$

\section{Postprandial hyperglycemia}

Under physiological circumstances, postprandial hyperglycemia occurs as a transient increase in blood glucose levels after ingestion of food and is restrained by rapid secretion of insulin and inhibition of glucagon secretion to suppress hepatic glucose production. ${ }^{104-106}$ In addition, glucose uptake is stimulated in hepatic and peripheral tissues. $^{104}$ In individuals with diabetes, food intake and the subsequent rise in postprandial glucose levels elicit a delayed and blunted insulin response, accompanied by impaired inhibition of glucagon secretion and reduced glucose uptake by the liver and other tissues. ${ }^{101,105}$ This results in prolonged postprandial hyperglycemia, which is known to be associated with increased risk of diabetic vascular complications. ${ }^{101,103,}$ 107, 108 Importantly, it has been postulated that postprandial glucose fluctuations may contribute even more to the development of complications in diabetes than $\mathrm{HbA}_{1 \mathrm{c}}{ }^{102}$ Several studies showed that blood glucose levels after an oral glucose tolerance test have a higher predictive value for cardiovascular events compared to fasting blood glucose levels. ${ }^{109-115}$ In addition, postprandial glucose excursions constitute a risk factor for cardiovascular disease in diabetes. ${ }^{35,108}$ To date, it is unknown how postprandial glucose excursions contribute to the development of diabetic vascular complications. Due to their rapid formation under hyperglycemic conditions and their link to diabetic complications, $\alpha$-dicarbonyls and AGEs may have a pivotal role in this process. However, knowledge about postprandial formation of $\alpha$-dicarbonyls and AGEs is scarce, and until now, this has only been investigated in a single study in type 1 diabetes. ${ }^{116}$ Therefore, in this thesis, the presence of postprandial $\alpha$-dicarbonyl stress in type 2 diabetes is investigated (chapter 7 and 8). 


\section{Knowledge gaps}

Although it is well established that obesity is an important contributor to the burden of insulin resistance, type 2 diabetes and cardiovascular disease, many unresolved questions remain about the underlying mechanisms. A possible mechanism by which excessive adipose tissue contributes to obesity-related complications is the dysregulated secretion of adipokines, which are known to play an important role in the pathogenesis of insulin resistance. Recent evidence indicates a role for AGEs in this process. In addition, AGEs are also thought be key players in diabetes and diabetes-related complications. Theoretically, $\alpha$-dicarbonyl formation during postprandial hyperglycemia in diabetes may contribute to the development of diabetic complications.

A better understanding about the role of $\alpha$-dicarbonyls and AGEs in obesity-induced insulin resistance and type 2 diabetes is needed to address whether the glycation pathway is a promising treatment target. In this thesis, the association between glycation and insulin resistance and type 2 diabetes is investigated using several approaches including cohort studies, in vivo studies and in vitro experiments. In addition, intervention studies are performed to establish the role of AGEs and $\alpha$ dicarbonyls in obesity.

\section{Aims and outline of this thesis}

The central aim of this thesis is to identify the detailed role of $\alpha$-dicarbonyl stress and AGEs in the etiology of obesity, insulin resistance and type 2 diabetes. This thesis will mainly focus on the most reactive $\alpha$-dicarbonyl MGO and the glyoxalase system. To highlight the importance of MGO and the glyoxalase system, chapter 2 reports a detailed review about the role of MGO and the glyoxalase system in diabetes and other AGE-related diseases including obesity and insulin resistance. This thesis is divided into two parts. Part $I$ of this thesis focuses on $\alpha$-dicarbonyls and AGEs in obesity and insulin resistance. Part // of this thesis focuses on postprandial $\alpha$ dicarbonyl stress in type 2 diabetes.

Part I consists of four research chapters. Chapter $\mathbf{3}$ makes the first suggestive link between MGO and insulin resistance in humans, describing a positive association between the plasma MGO metabolite D-lactate and HOMA-IR, as a measure of insulin resistance. The study described in chapter 4 focuses on underlying mechanisms through which $\alpha$-dicarbonyls, and particularly MGO, contribute to the development of insulin resistance in the muscle. In chapter 5, we investigate the effect of quenching 
$\alpha$-dicarbonyl compounds with the compound pyridoxamine on insulin resistance, obesity and associated complications in a mouse model of obesity. Chapter 6 reports a similar study, but in this animal model of obesity, $\alpha$-dicarbonyls, specifically MGO and GO, are reduced by an overexpression of the GLO1 enzyme.

In part // of this thesis, the existence of postprandial $\alpha$-dicarbonyl stress in type 2 diabetes is investigated and described in chapter 7 and 8 . In chapter 7, $\alpha$-dicarbonyl stress is investigated after an oral glucose load in individuals with impaired glucose metabolism and type 2 diabetes. In line, chapter 8 describes increased $\alpha$-dicarbonyl stress after a mixed meal in obese individuals with type 2 diabetes and additionally, weight loss interventions are tested in this study to be functional in reducing postprandial $\alpha$-dicarbonyl stress. The combined results from cohort studies, in vivo studies and in vitro experiments from this thesis and their clinical relevance are discussed in the general discussion in chapter 9. Figure 1.5 illustrates a schematic representation of the studies investigated in this thesis.

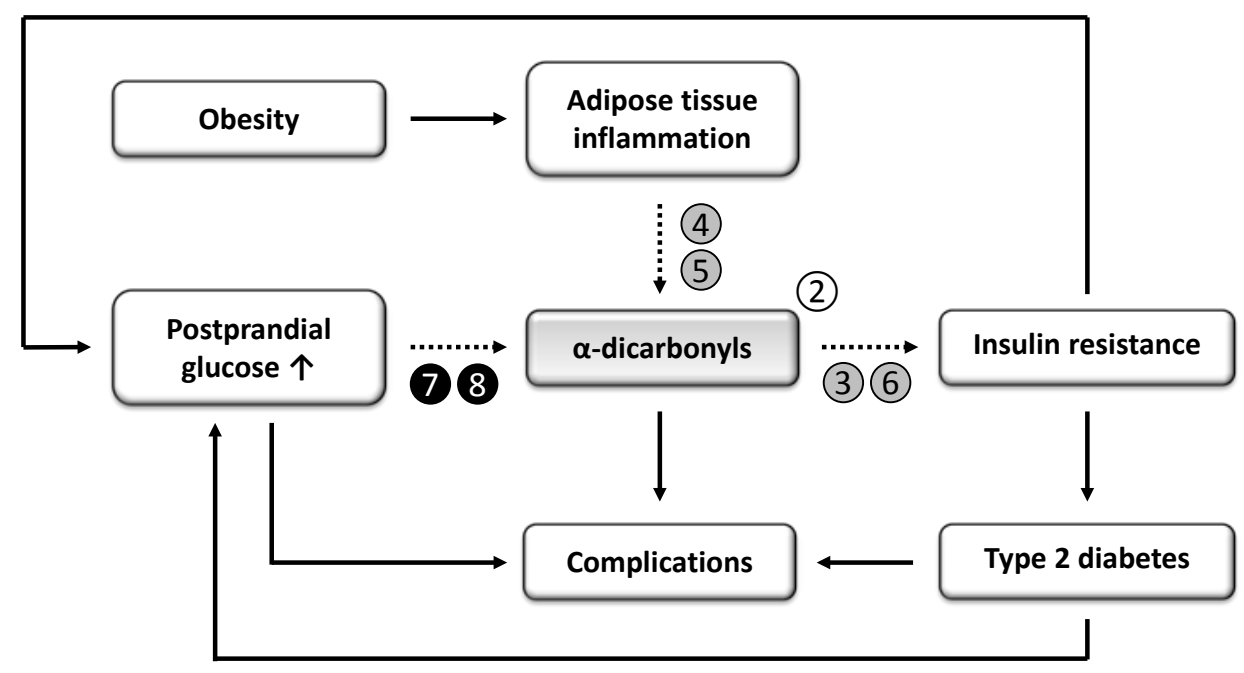

Figure 1.5 - Schematic representation of the studies investigated in this thesis. Dashed lines represent relations investigated and numbers 2-8 indicate the corresponding chapters, where grey numbers indicate chapters of part I and black numbers indicate chapters of part II. Chapter 2 comprises a review article about the biochemistry of MGO and the glyoxalase system, and their role in diabetes and other age-related diseases. 


\section{References}

1. World, Health, Organization. Fact sheet obesity and overweight. 2015

2. James WPT, Jackson-Leach R, Ni Mhurchu C, E K, Shayegi M, Rigby NJ, Nishida C, A R. Overweight and obesity (high body mass index). Comparative quantification of health risks: Global and regional burden of disease attributable to selected major risk factors. Geneva: WHO; 2004:959-1108.

3. Haslam DW, James WP. Obesity. Lancet. 2005; 366:1197-1209

4. The IDF. Idf diabetes atlas 6th edition. 2013.

5. Brownlee M. Advanced protein glycosylation in diabetes and aging. Annu Rev Med. 1995; 46:223-234

6. Monnier VM. Nonenzymatic glycosylation, the maillard reaction and the aging process. J Gerontol. 1990; 45:B105-111

7. Maillard LC. Action des acides amines sur les sucres: Formation des mélanoïdines par voie méthodique. Compte-rendu de l'Académie des sciences. 1912:66-68

8. Singh R, Barden A, Mori T, Beilin L. Advanced glycation end-products: A review. Diabetologia. 2001; 44:129-146

9. Brownlee $\mathrm{M}$, Vlassara $\mathrm{H}$, Cerami A. Nonenzymatic glycosylation and the pathogenesis of diabetic complications. Ann Intern Med. 1984; 101:527-537

10. Thornalley PJ, Langborg A, Minhas HS. Formation of glyoxal, methylglyoxal and 3-deoxyglucosone in the glycation of proteins by glucose. Biochem J. 1999; 344 Pt 1:109-116

11. Glomb MA, Monnier VM. Mechanism of protein modification by glyoxal and glycolaldehyde, reactive intermediates of the maillard reaction. J Biol Chem. 1995; 270:10017-10026

12. Goldin A, Beckman JA, Schmidt AM, Creager MA. Advanced glycation end products: Sparking the development of diabetic vascular injury. Circulation. 2006; 114:597-605

13. Thornalley PJ, Jahan I, Ng R. Suppression of the accumulation of triosephosphates and increased formation of methylglyoxal in human red blood cells during hyperglycaemia by thiamine in vitro. $J$ Biochem. 2001; 129:543-549

14. Schalkwijk CG, Stehouwer CD, van Hinsbergh VW. Fructose-mediated non-enzymatic glycation: Sweet coupling or bad modification. Diabetes Metab Res Rev. 2004; 20:369-382

15. Fu MX, Requena JR, Jenkins AJ, Lyons TJ, Baynes JW, Thorpe SR. The advanced glycation end product, nepsilon-(carboxymethyl)lysine, is a product of both lipid peroxidation and glycoxidation reactions. $J$ Biol Chem. 1996; 271:9982-9986

16. Baynes JW, Thorpe SR. Glycoxidation and lipoxidation in atherogenesis. Free Radic Biol Med. 2000; 28:1708-1716

17. Januszewski AS, Alderson NL, Jenkins AJ, Thorpe SR, Baynes JW. Chemical modification of proteins during peroxidation of phospholipids. J Lipid Res. 2005; 46:1440-1449

18. Brownlee M. Biochemistry and molecular cell biology of diabetic complications. Nature. 2001; 414:813-820

19. Schalkwijk CG. Vascular age-ing by methylglyoxal: The past, the present and the future. Diabetologia. 2015; 58:1715-1719

20. Bierhaus A, Hofmann MA, Ziegler R, Nawroth PP. Ages and their interaction with age-receptors in vascular disease and diabetes mellitus. I. The age concept. Cardiovasc Res. 1998; 37:586-600

21. Fruhbeck G, Gomez-Ambrosi J, Muruzabal FJ, Burrell MA. The adipocyte: A model for integration of endocrine and metabolic signaling in energy metabolism regulation. Am J Physiol Endocrinol Metab. 2001; 280:E827-847

22. Westwood ME, Thornalley PJ. Molecular characteristics of methylglyoxal-modified bovine and human serum albumins. Comparison with glucose-derived advanced glycation endproduct-modified serum albumins. J Protein Chem. 1995; 14:359-372

23. Forbes JM, Cooper ME. Mechanisms of diabetic complications. Physiol Rev. 2013; 93:137-188

24. Remuzzi G, Schieppati A, Ruggenenti P. Nephropathy in patients with type 2 diabetes. New England Journal of Medicine. 2002; 346:1145-1151

25. Groop PH, Thomas MC, Moran JL, Waden J, Thorn LM, Makinen VP, Rosengard-Barlund M, Saraheimo M, Hietala K, Heikkila O, Forsblom C. The presence and severity of chronic kidney disease predicts allcause mortality in type 1 diabetes. Diabetes. 2009; 58:1651-1658

26. Bourne RR, Jonas JB, Flaxman SR, Keeffe J, Leasher J, Naidoo K, Parodi MB, Pesudovs K, Price H, White RA, Wong TY, Resnikoff S, Taylor HR. Prevalence and causes of vision loss in high-income countries and in eastern and central europe: 1990-2010. Br J Ophthalmol. 2014; 98:629-638 
27. Cheung N, Mitchell P, Wong TY. Diabetic retinopathy. Lancet. 2010; 376:124-136

28. Abbott CA, Malik RA, van Ross ER, Kulkarni J, Boulton AJ. Prevalence and characteristics of painful diabetic neuropathy in a large community-based diabetic population in the u.K. Diabetes Care. 2011; 34:2220-2224

29. Haffner SM, Lehto S, Ronnemaa T, Pyorala K, Laakso M. Mortality from coronary heart disease in subjects with type 2 diabetes and in nondiabetic subjects with and without prior myocardial infarction. N Engl J Med. 1998; 339:229-234

30. Thornalley PJ. The glyoxalase system in health and disease. Mol Aspects Med. 1993; 14:287-371

31. Brownlee M, Vlassara H, Kooney A, Ulrich P, Cerami A. Aminoguanidine prevents diabetes-induced arterial wall protein cross-linking. Science. 1986; 232:1629-1632

32. Vasan S, Foiles $P$, Founds $H$. Therapeutic potential of breakers of advanced glycation end productprotein crosslinks. Arch Biochem Biophys. 2003; 419:89-96

33. Soulis-Liparota T, Cooper M, Papazoglou D, Clarke B, Jerums G. Retardation by aminoguanidine of development of albuminuria, mesangial expansion, and tissue fluorescence in streptozocin-induced diabetic rat. Diabetes. 1991; 40:1328-1334

34. Soulis T, Cooper ME, Vranes D, Bucala R, Jerums G. Effects of aminoguanidine in preventing experimental diabetic nephropathy are related to the duration of treatment. Kidney Int. 1996; 50:627-634

35. Hammes HP, Martin S, Federlin K, Geisen K, Brownlee M. Aminoguanidine treatment inhibits the development of experimental diabetic retinopathy. Proc Natl Acad Sci U S A. 1991; 88:11555-11558

36. Kihara M, Schmelzer JD, Poduslo JF, Curran GL, Nickander KK, Low PA. Aminoguanidine effects on nerve blood flow, vascular permeability, electrophysiology, and oxygen free radicals. Proc Natl Acad Sci U S A. 1991; 88:6107-6111

37. Engelen L, Stehouwer CD, Schalkwijk CG. Current therapeutic interventions in the glycation pathway: Evidence from clinical studies. Diabetes Obes Metab. 2013; 15:677-689

38. Bolton WK, Cattran DC, Williams ME, Adler SG, Appel GB, Cartwright K, Foiles PG, Freedman BI, Raskin P, Ratner RE, Spinowitz BS, Whittier FC, Wuerth JP. Randomized trial of an inhibitor of formation of advanced glycation end products in diabetic nephropathy. Am J Nephrol. 2004; 24:32-40

39. Freedman BI, Wuerth JP, Cartwright K, Bain RP, Dippe S, Hershon K, Mooradian AD, Spinowitz BS. Design and baseline characteristics for the aminoguanidine clinical trial in overt type 2 diabetic nephropathy (action ii). Control Clin Trials. 1999; 20:493-510

40. Kass DA, Shapiro EP, Kawaguchi M, Capriotti AR, Scuteri A, deGroof RC, Lakatta EG. Improved arterial compliance by a novel advanced glycation end-product crosslink breaker. Circulation. 2001; 104:1464-1470

41. Hartog JW, Willemsen S, van Veldhuisen DJ, Posma JL, van Wijk LM, Hummel YM, Hillege HL, Voors AA. Effects of alagebrium, an advanced glycation endproduct breaker, on exercise tolerance and cardiac function in patients with chronic heart failure. Eur J Heart Fail. 2011; 13:899-908

42. Zieman SJ, Melenovsky V, Clattenburg L, Corretti MC, Capriotti A, Gerstenblith G, Kass DA. Advanced glycation endproduct crosslink breaker (alagebrium) improves endothelial function in patients with isolated systolic hypertension. J Hypertens. 2007; 25:577-583

43. Little WC, Zile MR, Kitzman DW, Hundley WG, O'Brien TX, Degroof RC. The effect of alagebrium chloride (alt-711), a novel glucose cross-link breaker, in the treatment of elderly patients with diastolic heart failure. J Card Fail. 2005; 11:191-195

44. Ruggiero-Lopez D, Lecomte M, Moinet G, Patereau G, Lagarde M, Wiernsperger N. Reaction of metformin with dicarbonyl compounds. Possible implication in the inhibition of advanced glycation end product formation. Biochem Pharmacol. 1999; 58:1765-1773

45. Beisswenger PJ, Howell SK, Touchette AD, Lal S, Szwergold BS. Metformin reduces systemic methylglyoxal levels in type 2 diabetes. Diabetes. 1999; 48:198-202

46. Kender Z, Fleming T, Kopf S, Torzsa P, Grolmusz V, Herzig S, Schleicher E, Racz K, Reismann P, Nawroth PP. Effect of metformin on methylglyoxal metabolism in patients with type 2 diabetes. Exp Clin Endocrinol Diabetes. 2014; 122:316-319

47. Voziyan PA, Hudson BG. Pyridoxamine as a multifunctional pharmaceutical: Targeting pathogenic glycation and oxidative damage. Cell Mol Life Sci. 2005; 62:1671-1681

48. Hammes HP, Du X, Edelstein D, Taguchi T, Matsumura T, Ju Q, Lin J, Bierhaus A, Nawroth P, Hannak D, Neumaier M, Bergfeld R, Giardino I, Brownlee M. Benfotiamine blocks three major pathways of hyperglycemic damage and prevents experimental diabetic retinopathy. Nat Med. 2003; 9:294-299

49. The international diabetes federation. Idf diabetes atlas 6th edition. 2013 
50. Kershaw EE, Flier JS. Adipose tissue as an endocrine organ. J Clin Endocrinol Metab. 2004; 89:25482556

51. Cook KS, Min HY, Johnson D, Chaplinsky RJ, Flier JS, Hunt CR, Spiegelman BM. Adipsin: A circulating serine protease homolog secreted by adipose tissue and sciatic nerve. Science. 1987; 237:402-405

52. Zhang Y, Proenca R, Maffei M, Barone M, Leopold L, Friedman JM. Positional cloning of the mouse obese gene and its human homologue. Nature. 1994; 372:425-432

53. Scherer PE, Williams S, Fogliano M, Baldini G, Lodish HF. A novel serum protein similar to c1q, produced exclusively in adipocytes. J Biol Chem. 1995; 270:26746-26749

54. Hu E, Liang P, Spiegelman BM. Adipoq is a novel adipose-specific gene dysregulated in obesity. J Biol Chem. 1996; 271:10697-10703

55. Maeda K, Okubo K, Shimomura I, Funahashi T, Matsuzawa Y, Matsubara K. Cdna cloning and expression of a novel adipose specific collagen-like factor, apm1 (adipose most abundant gene transcript 1). Biochem Biophys Res Commun. 1996; 221:286-289

56. Nakano Y, Tobe T, Choi-Miura NH, Mazda T, Tomita M. Isolation and characterization of gbp28, a novel gelatin-binding protein purified from human plasma. J Biochem. 1996; 120:803-812

57. Fasshauer M, Bluher M. Adipokines in health and disease. Trends Pharmacol Sci. 2015; 36:461-470

58. Scherer PE. Adipose tissue: From lipid storage compartment to endocrine organ. Diabetes. 2006; 55:1537-1545

59. Skurk T, Alberti-Huber C, Herder C, Hauner H. Relationship between adipocyte size and adipokine expression and secretion. J Clin Endocrinol Metab. 2007; 92:1023-1033

60. Nagareddy PR, Kraakman M, Masters SL, Stirzaker RA, Gorman DJ, Grant RW, Dragoljevic D, Hong ES, Abdel-Latif A, Smyth SS, Choi SH, Korner J, Bornfeldt KE, Fisher EA, Dixit VD, Tall AR, Goldberg IJ, Murphy AJ. Adipose tissue macrophages promote myelopoiesis and monocytosis in obesity. Cell Metab. 2014; 19:821-835

61. Gaens KH, Goossens GH, Niessen PM, van Greevenbroek MM, van der Kallen CJ, Niessen HW, Rensen SS, Buurman WA, Greve JW, Blaak EE, van Zandvoort MA, Bierhaus A, Stehouwer CD, Schalkwijk CG. Nepsilon-(carboxymethyl)lysine-receptor for advanced glycation end product axis is a key modulator of obesity-induced dysregulation of adipokine expression and insulin resistance. Arterioscler Thromb Vasc Biol. 2014; 34:1199-1208

62. Gaens KH, Niessen PM, Rensen SS, Buurman WA, Greve JW, Driessen A, Wolfs MG, Hofker MH, Bloemen JG, Dejong CH, Stehouwer CD, Schalkwijk CG. Endogenous formation of nepsilon(carboxymethyl)lysine is increased in fatty livers and induces inflammatory markers in an in vitro model of hepatic steatosis. J Hepatol. 2012; 56:647-655

63. de la Maza MP, Uribarri J, Olivares D, Hirsch S, Leiva L, Barrera G, Bunout D. Weight increase is associated with skeletal muscle immunostaining for advanced glycation end products, receptor for advanced glycation end products, and oxidation injury. Rejuvenation Res. 2008; 11:1041-1048

64. Jia X, Chang T, Wilson TW, Wu L. Methylglyoxal mediates adipocyte proliferation by increasing phosphorylation of akt1. PLoS One. 2012; 7:e36610

65. Song F, Hurtado del Pozo C, Rosario R, Zou YS, Ananthakrishnan R, Xu X, Patel PR, Benoit VM, Yan SF, Li H, Friedman RA, Kim JK, Ramasamy R, Ferrante AW, Jr., Schmidt AM. Rage regulates the metabolic and inflammatory response to high-fat feeding in mice. Diabetes. 2014; 63:1948-1965

66. Gaens KH, Ferreira I, van de Waarenburg MP, van Greevenbroek MM, van der Kallen CJ, Dekker JM, Nijpels G, Rensen SS, Stehouwer CD, Schalkwijk CG. Protein-bound plasma nepsilon(carboxymethyl)lysine is inversely associated with central obesity and inflammation and significantly explain a part of the central obesity-related increase in inflammation: The hoorn and codam studies. Arterioscler Thromb Vasc Biol. 2015; 35:2707-2713

67. Saltiel AR, Kahn CR. Insulin signalling and the regulation of glucose and lipid metabolism. Nature. 2001; 414:799-806

68. Taniguchi CM, Emanuelli B, Kahn CR. Critical nodes in signalling pathways: Insights into insulin action. Nat Rev Mol Cell Biol. 2006; 7:85-96

69. Sakamoto K, Holman GD. Emerging role for as160/tbc1d4 and tbc1d1 in the regulation of glut4 traffic. Am J Physiol Endocrinol Metab. 2008; 295:E29-37

70. Welsh GI, Leney SE, Lloyd-Lewis B, Wherlock M, Lindsay AJ, McCaffrey MW, Tavare JM. Rip11 is a rab11- and as160-rabgap-binding protein required for insulin-stimulated glucose uptake in adipocytes. J Cell Sci. 2007; 120:4197-4208

71. Kahn SE, Hull RL, Utzschneider KM. Mechanisms linking obesity to insulin resistance and type 2 diabetes. Nature. 2006; 444:840-846 
72. Wellen KE, Hotamisligil GS. Inflammation, stress, and diabetes. J Clin Invest. 2005; 115:1111-1119

73. Shoelson SE, Lee J, Goldfine AB. Inflammation and insulin resistance. J Clin Invest. 2006; 116:17931801

74. Yang Q, Graham TE, Mody N, Preitner F, Peroni OD, Zabolotny JM, Kotani K, Quadro L, Kahn BB. Serum retinol binding protein 4 contributes to insulin resistance in obesity and type 2 diabetes. Nature. 2005; 436:356-362

75. Kadowaki T, Yamauchi T, Kubota N, Hara K, Ueki K, Tobe K. Adiponectin and adiponectin receptors in insulin resistance, diabetes, and the metabolic syndrome. J Clin Invest. 2006; 116:1784-1792

76. Fain JN, Madan AK, Hiler ML, Cheema P, Bahouth SW. Comparison of the release of adipokines by adipose tissue, adipose tissue matrix, and adipocytes from visceral and subcutaneous abdominal adipose tissues of obese humans. Endocrinology. 2004; 145:2273-2282

77. Boden G. Role of fatty acids in the pathogenesis of insulin resistance and niddm. Diabetes. 1997; 46:3-10

78. Roden M, Price TB, Perseghin G, Petersen KF, Rothman DL, Cline GW, Shulman GI. Mechanism of free fatty acid-induced insulin resistance in humans. J Clin Invest. 1996; 97:2859-2865

79. Shulman GI. Cellular mechanisms of insulin resistance. J Clin Invest. 2000; 106:171-176

80. Tan KC, Shiu SW, Wong Y, Tam X. Serum advanced glycation end products (ages) are associated with insulin resistance. Diabetes Metab Res Rev. 2011; 27:488-492

81. Tahara N, Yamagishi S, Matsui T, Takeuchi M, Nitta Y, Kodama N, Mizoguchi M, Imaizumi T. Serum levels of advanced glycation end products (ages) are independent correlates of insulin resistance in nondiabetic subjects. Cardiovasc Ther. 2012; 30:42-48

82. Sarkar P, Kar K, Mondal MC, Chakraborty I, Kar M. Elevated level of carbonyl compounds correlates with insulin resistance in type 2 diabetes. Ann Acad Med Singapore. 2010; 39:909-904

83. Song F, Schmidt AM. Glycation and insulin resistance: Novel mechanisms and unique targets? Arterioscler Thromb Vasc Biol. 2012; 32:1760-1765

84. Abdel-Wahab YH, O'Harte FP, Ratcliff H, McClenaghan NH, Barnett CR, Flatt PR. Glycation of insulin in the islets of langerhans of normal and diabetic animals. Diabetes. 1996; 45:1489-1496

85. Abdel-Wahab YH, O'Harte FP, Barnett CR, Flatt PR. Glycation of insulin in a cultured insulin-secreting cell line. Biochem Soc Trans. 1997; 25:128S

86. Abdel-Wahab YH, O'Harte FP, Barnett CR, Flatt PR. Characterization of insulin glycation in insulinsecreting cells maintained in tissue culture. J Endocrinol. 1997; 152:59-67

87. Abdel-Wahab YH, O'Harte FP, Boyd AC, Barnett CR, Flatt PR. Glycation of insulin results in reduced biological activity in mice. Acta Diabetol. 1997; 34:265-270

88. Lindsay JR, McKillop AM, Mooney MH, O'Harte FP, Bell PM, Flatt PR. Demonstration of increased concentrations of circulating glycated insulin in human type 2 diabetes using a novel and specific radioimmunoassay. Diabetologia. 2003; 46:475-478

89. Boyd AC, Abdel-Wahab YH, McKillop AM, McNulty H, Barnett CR, O'Harte FP, Flatt PR. Impaired ability of glycated insulin to regulate plasma glucose and stimulate glucose transport and metabolism in mouse abdominal muscle. Biochim Biophys Acta. 2000; 1523:128-134

90. Hunter SJ, Boyd AC, O'Harte FP, McKillop AM, Wiggam MI, Mooney MH, McCluskey JT, Lindsay JR, Ennis CN, Gamble R, Sheridan B, Barnett CR, McNulty H, Bell PM, Flatt PR. Demonstration of glycated insulin in human diabetic plasma and decreased biological activity assessed by euglycemichyperinsulinemic clamp technique in humans. Diabetes. 2003; 52:492-498

91. Jia X, Olson DJ, Ross AR, Wu L. Structural and functional changes in human insulin induced by methylglyoxal. Faseb J. 2006; 20:1555-1557

92. Fiory F, Lombardi A, Miele C, Giudicelli J, Beguinot F, Van Obberghen E. Methylglyoxal impairs insulin signalling and insulin action on glucose-induced insulin secretion in the pancreatic beta cell line ins1e. Diabetologia. 2011; 54:2941-2952

93. Naitoh T, Kitahara M, Tsuruzoe N. Tumor necrosis factor-alpha is induced through phorbol ester--and glycated human albumin-dependent pathway in thp-1 cells. Cell Signal. 2001; 13:331-334

94. Miele C, Riboulet A, Maitan MA, Oriente F, Romano C, Formisano P, Giudicelli J, Beguinot F, Van Obberghen E. Human glycated albumin affects glucose metabolism in 16 skeletal muscle cells by impairing insulin-induced insulin receptor substrate (irs) signaling through a protein kinase $c$ alphamediated mechanism. J Biol Chem. 2003; 278:47376-47387 
95. Cassese A, Esposito I, Fiory F, Barbagallo AP, Paturzo F, Mirra P, Ulianich L, Giacco F, ladicicco C, Lombardi A, Oriente F, Van Obberghen E, Beguinot F, Formisano P, Miele C. In skeletal muscle advanced glycation end products (ages) inhibit insulin action and induce the formation of multimolecular complexes including the receptor for ages. J Biol Chem. 2008; 283:36088-36099

96. Unoki-Kubota H, Yamagishi S, Takeuchi M, Bujo H, Saito Y. Pyridoxamine, an inhibitor of advanced glycation end product (age) formation ameliorates insulin resistance in obese, type 2 diabetic mice. Protein Pept Lett. 2010; 17:1177-1181

97. Kooptiwut S, Kebede M, Zraika S, Visinoni S, Aston-Mourney K, Favaloro J, Tikellis C, Thomas MC, Forbes JM, Cooper ME, Dunlop M, Proietto J, Andrikopoulos S. High glucose-induced impairment in insulin secretion is associated with reduction in islet glucokinase in a mouse model of susceptibility to islet dysfunction. J Mol Endocrinol. 2005; 35:39-48

98. The effect of intensive treatment of diabetes on the development and progression of long-term complications in insulin-dependent diabetes mellitus. The diabetes control and complications trial research group. N Engl J Med. 1993; 329:977-986

99. Intensive blood-glucose control with sulphonylureas or insulin compared with conventional treatment and risk of complications in patients with type 2 diabetes (ukpds 33). Uk prospective diabetes study (ukpds) group. Lancet. 1998; 352:837-853

100. Smith-Palmer J, Brandle M, Trevisan R, Orsini Federici M, Liabat S, Valentine W. Assessment of the association between glycemic variability and diabetes-related complications in type 1 and type 2 diabetes. Diabetes Res Clin Pr. 2014; 105:273-284

101. Madsbad S. Impact of postprandial glucose control on diabetes-related complications: How is the evidence evolving? J Diabetes Complications. 2016; 30:374-385

102. Brownlee M, Hirsch IB. Glycemic variability: A hemoglobin a1c-independent risk factor for diabetic complications. Jama. 2006; 295:1707-1708

103. Cavalot F, Petrelli A, Traversa M, Bonomo K, Fiora E, Conti M, Anfossi G, Costa G, Trovati M. Postprandial blood glucose is a stronger predictor of cardiovascular events than fasting blood glucose in type 2 diabetes mellitus, particularly in women: Lessons from the san luigi gonzaga diabetes study. J Clin Endocrinol Metab. 2006; 91:813-819

104. Moore MC, Coate KC, Winnick JJ, An Z, Cherrington AD. Regulation of hepatic glucose uptake and storage in vivo. Adv Nutr. 2012; 3:286-294

105. Rizza RA. Pathogenesis of fasting and postprandial hyperglycemia in type 2 diabetes: Implications for therapy. Diabetes. 2010; 59:2697-2707

106. Bansal P, Wang Q. Insulin as a physiological modulator of glucagon secretion. Am J Physiol Endocrinol Metab. 2008; 295:E751-761

107. Ryden L, Grant PJ, Anker SD, Berne C, Cosentino F, Danchin N, Deaton C, Escaned J, Hammes HP, Huikuri H, Marre M, Marx N, Mellbin L, Ostergren J, Patrono C, Seferovic P, Uva MS, Taskinen MR, Tendera M, Tuomilehto J, Valensi P, Zamorano JL, Achenbach S, Baumgartner H, Bax JJ, Bueno $\mathrm{H}$, Dean V, Erol C, Fagard R, Ferrari R, Hasdai D, Hoes AW, Kirchhof $P$, Knuuti J, Kolh $P$, Lancellotti $P$, Linhart A, Nihoyannopoulos P, Piepoli MF, Ponikowski P, Sirnes PA, Tamargo JL, Torbicki A, Wijns W, Windecker S, De Backer G, Ezquerra EA, Avogaro A, Badimon L, Baranova E, Betteridge J, Ceriello A, Funck-Brentano C, Gulba DC, Kjekshus JK, Lev E, Mueller C, Neyses L, Nilsson PM, Perk J, Reiner Z, Sattar N, Schachinger V, Scheen A, Schirmer H, Stromberg A, Sudzhaeva S, Viigimaa M, Vlachopoulos $C$, Xuereb RG. Esc guidelines on diabetes, pre-diabetes, and cardiovascular diseases developed in collaboration with the easd: The task force on diabetes, pre-diabetes, and cardiovascular diseases of the european society of cardiology (esc) and developed in collaboration with the european association for the study of diabetes (easd). Eur Heart J. 2013; 34:3035-3087

108. Hanefeld M, Fischer S, Julius U, Schulze J, Schwanebeck U, Schmechel H, Ziegelasch HJ, Lindner J. Risk factors for myocardial infarction and death in newly detected niddm: The diabetes intervention study, 11-year follow-up. Diabetologia. 1996; 39:1577-1583

109. Ceriello A. Postprandial hyperglycemia and diabetes complications: Is it time to treat? Diabetes. 2005; 54:1-7

110. de Vegt F, Dekker JM, Ruhe HG, Stehouwer CD, Nijpels G, Bouter LM, Heine RJ. Hyperglycaemia is associated with all-cause and cardiovascular mortality in the hoorn population: The hoorn study. Diabetologia. 1999; 42:926-931

111. Donahue RP, Abbott RD, Reed DM, Yano K. Postchallenge glucose concentration and coronary heart disease in men of japanese ancestry. Honolulu heart program. Diabetes. 1987; 36:689-692 
112. Lowe LP, Liu K, Greenland P, Metzger BE, Dyer AR, Stamler J. Diabetes, asymptomatic hyperglycemia, and 22-year mortality in black and white men. The chicago heart association detection project in industry study. Diabetes Care. 1997; 20:163-169

113. Glucose tolerance and mortality: Comparison of who and american diabetes association diagnostic criteria. The decode study group. European diabetes epidemiology group. Diabetes epidemiology: Collaborative analysis of diagnostic criteria in europe. Lancet. 1999; 354:617-621

114. Coutinho M, Gerstein HC, Wang Y, Yusuf S. The relationship between glucose and incident cardiovascular events. A metaregression analysis of published data from 20 studies of 95,783 individuals followed for 12.4 years. Diabetes Care. 1999; 22:233-240

115. Balkau B, Shipley M, Jarrett RJ, Pyorala K, Pyorala M, Forhan A, Eschwege E. High blood glucose concentration is a risk factor for mortality in middle-aged nondiabetic men. 20-year follow-up in the whitehall study, the paris prospective study, and the helsinki policemen study. Diabetes Care. 1998; 21:360-367

116. Beisswenger PJ, Howell SK, O'Dell RM, Wood ME, Touchette AD, Szwergold BS. Alpha-dicarbonyls increase in the postprandial period and reflect the degree of hyperglycemia. Diabetes Care. 2001; 24:726-732 
30 Chapter 1 


\section{THE ROLE OF METHYLGLYOXAL AND THE GLYOXALASE SYSTEM IN DIABETES AND OTHER AGE-RELATED DISEASES}

DIONNE E.M. MAESSEN, COEN D.A. STEHOUWER AND CASPER G. SCHALKWIJK 


\section{Abstract}

The formation and accumulation of advanced glycation endproducts (AGEs) are related to diabetes and other age-related diseases. Methylglyoxal (MGO), a highly reactive dicarbonyl compound, is the major precursor in the formation of AGEs. MGO is mainly formed as a byproduct of glycolysis. Under physiological circumstances, MGO is detoxified by the glyoxalase system into D-lactate, with glyoxalase I (GLO1) as the key enzyme in the anti-glycation defense. New insights indicate that increased levels of MGO and the major MGO-derived AGE methylglyoxal-derived hydroimidazolone 1 (MG-H1), and dysfunctioning of the glyoxalase system, are linked to several age-related health problems, such as diabetes, cardiovascular disease, cancer and disorders of the central nervous system. This review summarizes the mechanisms through which MGO is formed, its detoxification by the glyoxalase system, and its effect on biochemical pathways in relation to the development of agerelated diseases. Although several scavengers of MGO have been developed over the years, therapies to treat MGO-associated complications are not yet available for application in clinical practice. Small bioactive inducers of GLO1 can potentially form the basis for new treatment strategies for age-related disorders in which MGO plays a pivotal role. 


\section{Introduction}

The Maillard reaction is a process in which reducing sugars react spontaneously with amino residues in proteins, lipids and nucleic acids, to form advanced glycation endproducts (AGEs). Although elevated levels of glucose have been thought to play a primary role in the Maillard reaction, glucose is among the least reactive sugars in biological systems. ${ }^{1}$ The formation of AGEs is now believed to result mainly from the action of various reactive metabolites other than glucose, such as methylglyoxal (MGO). ${ }^{2}$ It has become increasingly clear that the highly reactive glucose-derived metabolite MGO is the most potent glycating agent in the very fast generation of glycation adducts on cellular and short-lived extracellular proteins, lipids, and DNA. ${ }^{3}$ In the glycation reaction, MGO is up to 20,000 -fold more reactive than glucose. MGO is mainly formed in cells by the non-enzymatic degradation of the triose phosphates glyceraldehyde-3-phosphate (G3P) and dihydroxyacetone-phosphate (DHAP), derived from glycolysis. ${ }^{4} \mathrm{MGO}$ reacts primarily with arginine residues of proteins, forming the AGE methylglyoxal-derived hydroimidazolone 1 (MG-H1). ${ }^{5}$ Arginine residues are thus hotspots for MGO modifications. Since arginine residues are often present in the functional domains of proteins, such modifications by MGO contribute to alterations in cellular proteins and dysfunctioning of cells, and can subsequently lead to health problems. Emerging evidence indicates that MGO is not only important for diabetic complications, but also plays a role in the development of other age-related diseases such as obesity, ${ }^{6}$ atherosclerosis, ${ }^{7}$ cancer $^{8}$ and neurodegenerative disorders. ${ }^{9}$ The awareness that MGO can initiate potentially deleterious changes leading to protein dysfunction has raised concern in relation to healthy living. The harmful effects of MGO are counteracted in organisms by means of an enzymatic glyoxalase defense system, which converts MGO to D-lactate. In this process, glyoxalase I (GLO1) is the most crucial enzyme. ${ }^{10}$ GLO1 is a key regulator of MGO levels, which means that alterations in GLO1 levels influence MGO production, and hence have an effect on the development of health problems. To further highlight the potential importance of MGO and GLO1 for human health, we will focus below on the glycation reaction, paying special attention to the role that MGO and GLO1 play in the development of disease. In this review, biochemical mechanisms and the significant extent to which MGO and GLO1 contribute to protein glycation and age-related diseases will be surveyed. 


\section{Metabolism of methylglyoxal}

MGO can be formed in several ways. It modifies proteins and nucleic acids, and is detoxified by several enzymatic pathways (Figure 2.1).

\section{Formation of methylglyoxal}

Endogenous MGO is derived from metabolic intermediates of carbohydrates, proteins and fatty acids. ${ }^{11}$ Most MGO is formed as a by-product from glycolysis by the nonenzymatic degradation of G3P and DHAP., ${ }^{40}$ This pathway results in the formation of MGO in all cells and organisms, with a formation rate of circa $120 \mu \mathrm{M} /$ day under normoglycaemic conditions. ${ }^{4,12}$ Although this production constitutes only $0.1 \%$ of the glucotriose flux, its biological effect is important because of the high reactivity of MGO with proteins and nucleic acids. Minor sources of MGO are autoxidation of glucose and degradation of glycated proteins, ${ }^{13}$ and also oxidation of acetone in the catabolism of ketone bodies during diabetic ketoacidosis, ${ }^{14}$ catabolism of threonine ${ }^{15}$ and lipid peroxidation ${ }^{16}$ (Figure 2.1).

Although concentrations of MGO have frequently been measured in tissues and plasma of various species, providing a reliable estimate of MGO levels is a challenging task. Published estimates of MGO concentrations in plasma and tissues vary by more than a factor of $1,000 .{ }^{17}$ As recently reviewed by Kalapos, ${ }^{18}$ plasma MGO can originate from various sources, including in situ formation from glycated proteins, formation and release or outflow from cells and exogenous sources. Under physiological circumstances, an important source of plasma MGO seems to be in situ formation, while under pathophysiological circumstances, such as diabetes, increased intracellular formation of MGO and leakage from cells also significantly contribute to plasma MGO levels. Although MGO is also present in several daily consumed products, ${ }^{19}$ exogenous sources of MGO are not likely to be significant for plasma MGO levels. In literature, plasma concentrations of MGO have been measured ranging from circa $100 \mathrm{nM}$ to $400 \mu \mathrm{M} .^{20-22}$ These variations most likely reflect the different analytical methods used, however. In particular, the formation of MGO during preanalytical processing can lead to an overestimation of its concentration. ${ }^{17}$ During sample processing, MGO may be formed by degradation of monosaccharides, glycated proteins, glycolytic intermediates, conditions of high temperature or $\mathrm{pH}$, oxidizing conditions, and peroxidase activity. ${ }^{17}$ To minimize the formation of MGO during sample processing, such conditions should therefore be avoided. The current state-of-the art technique for the measurement of MGO is ultra-performance liquid chromatography tandem mass spectrometry (UPLC-MS/MS), as recently described in 
detail. ${ }^{17,22}$ By taking such precautionary measures and applying UPLC-MS/MS, plasma levels of MGO in healthy individuals have been estimated at circa $132 \mathrm{nM}^{17}$ In subjects with type 2 diabetes, plasma MGO concentrations are about 1.3-fold higher than in healthy subjects. ${ }^{22}$ Importantly, plasma MGO levels increase during the postprandial period in type 1 diabetic patients and reflect the degree of hyperglycaemia. ${ }^{23}$ In patients with renal disease, up to 3.7-fold higher plasma levels of MGO have been reported; these levels increase with the stage of disease. ${ }^{24,25}$ Cellular MGO levels have been estimated at 1-5 $\mu \mathrm{M} \mathrm{MGO} .^{26,27}$

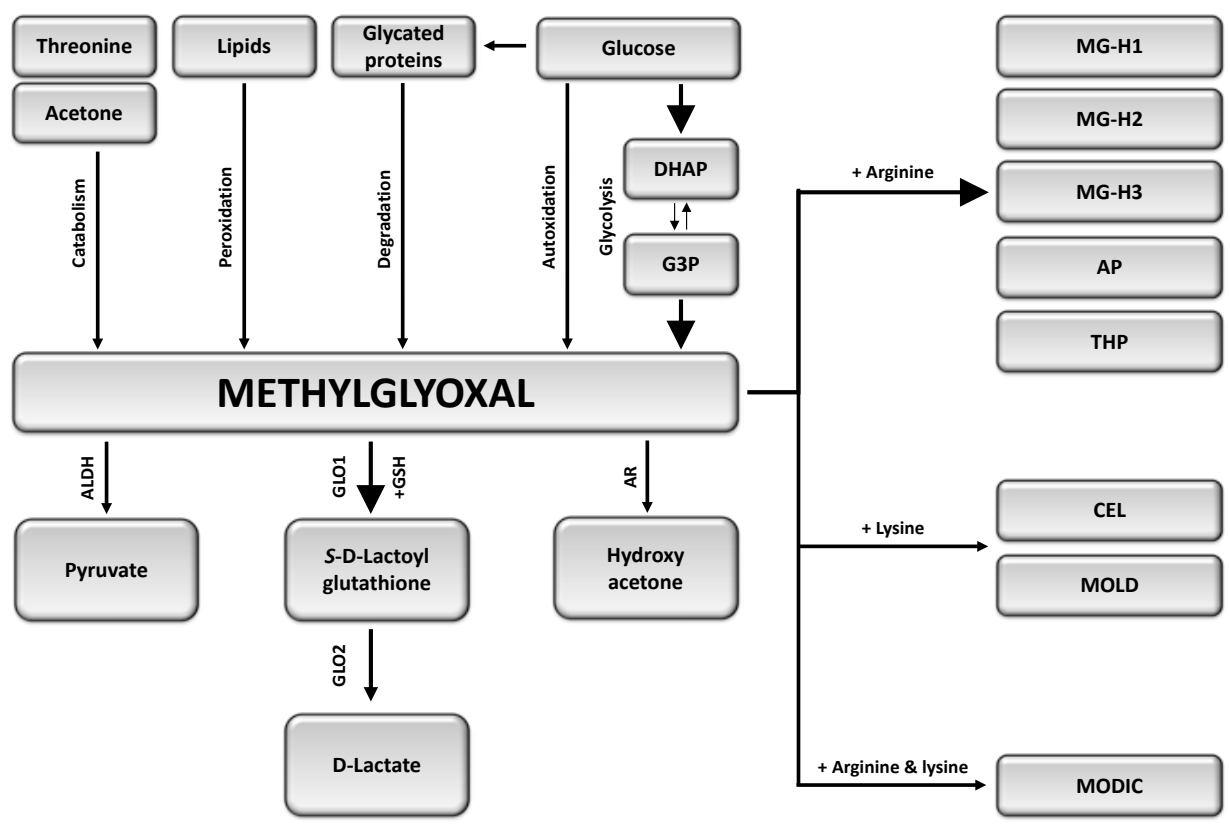

Figure 2.1 - Biology of methylglyoxal. Methylglyoxal (MGO) is mainly formed as a by-product from glycolysis and from autoxidation of glucose. Other sources of MGO are catabolism of threonine and acetone, lipid peroxidation and degradation of glycated proteins. Increased levels of MGO are predominantly detoxified by the glyoxalase system, which converts MGO into its end product D-lactate, via the formation of the intermediate S-D-lactoylglutathione. In addition, ALDH and AR comprise minor pathways of MGO detoxification. If MGO production exceeds the detoxification capacity, MGO can modify arginine residues to form MG-H1, $-\mathrm{H} 2$ and $-\mathrm{H} 3$, AP, and THP. When MGO reacts with lysine, it forms CEL and MOLD, whereas it forms MODIC when it forms a dimer crosslink with arginine and lysine. ALDH, aldehyde dehydrogenase; $A P$, argpyrimidine; $A R$, aldose reductase; CEL, N $\varepsilon$-(1-carboxyethyl)lysine; DHAP, dihydroxyacetone-phosphate; G3P, glyceraldehyde-3-phosphate; GLO, glyoxalase; MG-H, methylglyoxalderived hydroimidazolone; MGO, methylglyoxal; MODIC, 2-ammonio-6-((2-[(4-ammonio-5-oxido-5oxopentyl)amino]-4-methyl-4,5-dihydro-1H-imidazol-5 ylidene)amino)hexanoate; MOLD, 1,3-di(NE-lysino)4-methyl-imidazolium; THP, tetrahydropyrimidine. 


\section{Detoxification of methylglyoxal}

To prevent accumulation of MGO, it can be detoxified by various pathways (Figure 2.1). The most important enzymatic detoxification system is the glyoxalase system (Figure 2.2). This system, which is active in the cytoplasm of all mammalian cells, converts MGO to D-lactate via the intermediate product S-D-lactoylglutathione. In mammals, the glyoxalase system involves two major enzymes, namely, glyoxalase I (GLO1, lactoylglutathione methylglyoxallyase) and glyoxalase II (GLO2, hydroxyacylglutathione hydrolase). It also requires a catalytic amount of reduced glutathione (GSH). ${ }^{28}$ Under normal conditions, more than $99 \%$ of MGO is metabolized via the glyoxalase system. ${ }^{29}$ Minor pathways of MGO detoxification include aldehyde dehydrogenase (ALDH) and aldose reductase (AR). ${ }^{30-32}$ ALDH catalyzes the oxidation of MGO into pyruvate, ${ }^{30}$ whereas AR metabolizes MGO mainly by means of the formation of hydroxyacetone. ${ }^{31,32}$

Methylglyoxal

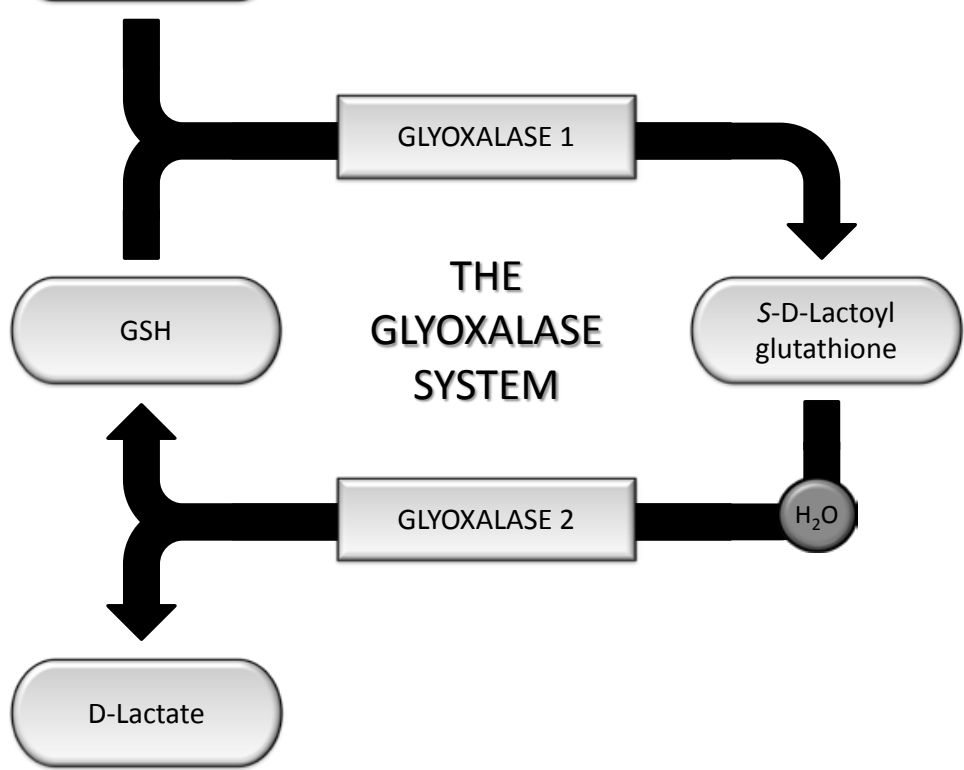

Figure 2.2 - The glyoxalase system. Methylglyoxal (MGO) forms a hemithioacetal with reduced glutathione (GSH), serving as a substrate for glyoxalase-1 (GLO1). GLO1 catalyzes the conversion of the MGO-GSH hemithioacetal to the thioester S-D-lactoylglutathione. The GLO2 enzyme catalyzes the hydrolysis of S-Dlactoylglutathione to form the end product D-lactate. During this reaction, glutathione (GSH) is recycled. 


\section{Targets of methylglyoxal}

The two most important targets of MGO are protein residues and nucleic acids. Modification of these targets results in the formation of, respectively, MGO-derived AGEs and DNA adducts.

\section{Modification of proteins by methylglyoxal and its functional} consequences

MGO is believed to be the most important precursor of AGEs. By way of modification of protein residues, MGO leads to the formation of MGO-derived AGEs (Figure 2.1). MGO-derived AGEs result from modification of the amino acids arginine and, to a much lesser extent, lysine. ${ }^{33}$ In an irreversible reaction with arginine, MGO mainly leads to the formation of methylglyoxal-derived hydroimidazolones (MG-H). These cyclic hydroimidazolones are formed as three structural isoforms, MG-H1, MG-H2 and MG-H3. MG-H1 is the most important MGO-derived AGE, as it accounts for more than $90 \%$ of all MGO adducts, equivalent to MG-H1 residues in 1 to $5 \%$ of all proteins. $5,31,34$ Peptide mapping by mass spectrometry has identified protein-specific MG-H1 hotspots. For example, Arg-410 has been identified as the major MG-H1 hotspot on human serum albumin. Minor hotspots are Arg-114, Arg-186, Arg-218, and Arg-428. These modifications of albumin lead to the inhibition of antioxidant capacity, esterase activity and decreased drug-binding affinity. ${ }^{35-37}$ MGO-modified albumin also increases the synthesis and secretion of pro-inflammatory markers such as tumor necrosis factor $\alpha$ (TNF $\alpha)$ and interleukin-1 $($ IL-1 $\beta)$ in monocytes and stimulates receptormediated endocytosis and degradation of proteins. ${ }^{38-42}$ Other important MG-H1 modified proteins are collagen, ${ }^{27,43}$ hemoglobin, ${ }^{44}$ and lens proteins. ${ }^{5}$

It has been estimated that MG-H1 modifications have the greatest physiological consequences when they increase by a factor of 2 to 3 on, for instance, vascular type IV collagen. ${ }^{27}$ This modification of type IV collagen leads to decreased integrin binding, detachment of endothelial cells from the vascular wall and inhibition of angiogenesis. ${ }^{27}$ Similar increases of MG-H1 modifications of mitochondrial proteins have been linked to a 2 to 3 -fold increase in oxidative stress, most probably as a result of electron leakage from the electron transport chain. ${ }^{45} \mathrm{MG}-\mathrm{H} 1$ modification of $20 \mathrm{~S}$ proteasomal subunit proteins decreases proteasome activity. ${ }^{46}$ Moreover, heat shock protein 27 (HSP27) is an important MG-H1 modified protein, whose hydroimidazolone modification results in the enhancement of chaperone function, a factor which may play an important role in the reduction of protein aggregation in the lens during ageing and cataract formation. ${ }^{47}$ Recently, it has been described that MG-H1 also 
serves as a ligand for the receptor of AGEs (RAGE), resulting in signal transduction, which could play a role in the development of various health problems. ${ }^{48}$

In addition to the hydroimidazolones, modification of arginine by MGO results in the formation of $\mathrm{N} \delta$-(5-hydroxy-4,6-dimethylpyramidine-2-yl)-L-ornithine argpyrimidine $(\mathrm{AP}){ }^{49}$ and N $\delta$-(4-carboxy-4,6-dimethyl-5,6-dihydroxy-1,4,5,6-tetrahydropyrimidine-2$\mathrm{yl}$ )-L-ornithine tetrahydropyrimidine (THP). ${ }^{50}$ Modification of HSP27 by AP also leads to heightened chaperone activity and lower apoptotic activity in lens epithelial cells, probably because it inhibits reactive oxygen species (ROS) generation and caspase activity. ${ }^{51,52}$ AP-modified HSP27 in lens epithelial cells may therefore cope better with stress conditions that induce apoptosis during ageing and cataract conditions. AP modifications of HSP27 have also been detected in endothelial ${ }^{53}$ and cardiac cells. ${ }^{54}$ Furthermore, Van Eupen et al. have recently described THP modifications in atherosclerotic lesions and increased plasma levels of THP in patients with type 1 diabetes, which is associated with the endothelial dysfunction marker soluble vascular cell adhesion molecule 1 (sVCAM1), ${ }^{55}$ strengthening the evidence that THP may be involved in the development of vascular disease. Finally, MGO can react irreversibly with lysine residues to form $\mathrm{N} \varepsilon$-(1-carboxyethyl)lysine (CEL) ${ }^{56}$ and the lysine dimer 1,3di(Ne-lysino)-4-methyl-imidazolium (MOLD). ${ }^{57}$ MGO can also cross-link arginine and lysine residues to form the adduct 2-ammonio-6-((2-[(4-ammonio-5-oxido-5oxopentyl)amino]-4-methyl-4,5-dihydro-1H-imidazol-5-ylidene)amino)hexanoate (MODIC)..$^{58}$

\section{Modification of DNA by methylglyoxal and its functional consequences}

DNA is susceptible to glycation by MGO as well. Under physiological conditions, deoxyguanosine (dG) is the most reactive nucleotide to link with MGO. In vivo, DNA glycation products were described for the first time by Pischetsrieder, ${ }^{59}$ who identified $\mathrm{N}^{2}$-carboxyethyl-2'-deoxyguanosine (CEdG) in human urine samples with an antibody. More sensitive methods, such as quantitative liquid chromatography electrospray ionization tandem mass spectrometry are now being developed, which allow screening for DNA glycation products in vivo. ${ }^{60}$ These methods have helped to identify the imidazopurinone 3-(2'-deoxyribosyl)-6,7-dihydro-6,7-dihydroxy-6/7methylimidazo-[2,3-b]purin-9(8)one (MGdG) as the major nucleotide AGE. ${ }^{61}$ Up to 1 in 100,000 nucleotides in DNA is an MGdG adduct ${ }^{61}$. Modification of DNA by MGO results in higher numbers of DNA strand breaks, ${ }^{61}$ nucleotide transversions, ${ }^{62}$ DNADNA crosslinks, ${ }^{63}$ DNA-protein crosslinks, ${ }^{64}$ and glycation of the nucleosomal protein histone H2A. ${ }^{65}$ Although the biological consequences of MGO-derived DNA adducts have not yet been fully established, the non-enzymatic glycation of DNA by MGO may have severe implications for various pathological conditions, such as age-related complications. 


\section{The glyoxalase system}

The glyoxalase system, as discovered in 1913, is the main system involved in the detoxification of MGO. It involves the rate-limiting enzyme GLO1 and the GLO2 enzyme. Moreover, glyoxalase III (GLO3) has been identified in Escherichia coli (E. coli).

\section{Glyoxalase I}

GLO1 catalyzes the conversion of the MGO-GSH hemithioacetal to the thioester S-Dlactoylglutathione. ${ }^{10}$ Under physiological conditions, the fragmentation of the hemithioacetal to MGO and GSH is about 1,000 times faster than the isomerizationrate of the hemithioacetal catalyzed by GLO1. ${ }^{31}$ Other substrates of GLO1 include glutathione-derived hemithioacetals, which are formed from different $\alpha$-dicarbonyls, such as glyoxal, hydroxypyruvaldehyde, or phenylglyoxal. ${ }^{66,67}$

The GLO1 gene is ubiquitously expressed in all tissues of prokaryotic and eukaryotic organisms, with about $0.2 \mu \mathrm{g}$ GLO1 per gram of protein. ${ }^{68}$ The human GLO1 enzyme is a homodimeric $\mathrm{Zn}^{2+}$-dependent isomerase, of which the two monomers are formed by means of non-covalent bonds. Based on gel filtration, the dimer has a molecular mass of $46 \mathrm{kDa}$ (based on sequence analysis, the molecular mass of GLO1 is $42 \mathrm{kDa}$ ) and exists as three alloenzymes, GLO1-1, GLO1-2 and GLO2-2. ${ }^{68}$ These phenotypes represent the homozygous and heterozygous expression of a diallelic gene on an autosomal locus, respectively, $\mathrm{GLO}^{1}$ and $\mathrm{GLO}^{2}$. The GLO1 locus is located on chromosome 6 and the gene promoter of GLO1 contains an insulin and metal response element. $^{69}$

The mechanisms regulating GLO1 activity may be complex, comprising both regulation of gene expression and post-translational modifications of the enzyme. Although $\mathrm{N}$ acetylation and oxidation do not affect GLO1 activity, S-glutathionylation strongly inhibits GLO1 activity. $^{70}$ In addition, GLO1 has been described as a nitric oxideresponsive protein ${ }^{71}$. GLO1 is also modified by phosphorylation of threonine residue107 and nitrosylation of cysteine residue-139. ${ }^{70,72}$ TNF $\alpha$-induced modulation of GLO1 activity through phosphorylation by PKA results in caspase-independent cell death, accompanied by increased production of ROS. $^{73}$ Since the TNF $\alpha$-induced phosphorylation of GLO1 is not involved in the detoxification pathway of MGO, the real biological function of phosphorylated GLO1 remains to be determined.

In quiescent cells, the activity of GLO1 lies in the range of $0.06-1.10 \mathrm{U} / \mathrm{mg}$ protein, increasing in proliferating cells to $1.12-2.69 \mathrm{U} / \mathrm{mg}$ protein. $^{74}$ In fetal tissues, GLO1 activity is about 3 times higher than in corresponding adult tissues. ${ }^{68}$ In cases of 
obesity or diabetes, contrary findings have been reported on the activity of GLO1: both increased and decreased GLO1 activities have been found in various tissues. In red blood cells of leptin-deficient obese ob/ob mice, GLO1 activity increases to a level of 50 to $60 \%$ higher than in lean controls. However, whole blood concentration of MGO also increases, by a factor of $14 .^{75}$ Moreover, in leptin receptor mutated obese $\mathrm{db} / \mathrm{db}$ mice, GLO1 protein has been shown to increase by circa $50 \%$ in the glomeruli, whereas the enzyme activity of GLO1 decreases. ${ }^{76}$ Hanssen et al. have established that incubation of monocytes with TNF $\alpha$ or hypoxia results in a decrease in enzymatic activity of GLO1. ${ }^{77}$ Also during the process of ageing, the activity of GLO1 has been shown to decrease. ${ }^{45}$

Genetically, the GLO1 gene is a hotspot for copy number variation. ${ }^{78}$ Approximately $2 \%$ of the human population has copy number increases of the GLO1 gene. These copy numbers are often linked to an increased risk of obesity and diabetes, and to ageing. ${ }^{78}$ The additional copies are mostly functional, resulting in a two- to four-fold increase in the expression and activity of GLO1. ${ }^{78}$ In addition, various single nucleotide polymorphisms (SNPS) of GLO1 have been identified. Previous results show a significant link between the minor alleles rs1130534 (G124G) and rs1049346 (5'-UTR) and decreased enzyme activity. ${ }^{79}$ A large epidemiological study demonstrated that nine tag SNPs which cover the common GLO1 gene variation are not associated with the prevalence of hypertension, markers of atherosclerosis, or renal function. ${ }^{80}$ However, another SNP in GLO1, Ala111Glu, has been identified as a susceptibility marker for the development of autism, most likely because it influences the accumulation of MGO, which in turn forms AGEs that induce the expression of RAGE during neuronal development. ${ }^{81-83}$ Because of this pathway, it is believed that GLO1 is of crucial influence on the pathology of autism. It has been suggested that the same SNP is also associated with panic disorder, although this has only been demonstrated in patients without agoraphobia. ${ }^{84}$

\section{Glyoxalase II and III}

GLO2 is the second enzyme in the glyoxalase system. GLO2 catalyzes the hydrolysis of S-D-lactoylglutathione, to form GSH and D-lactate. ${ }^{74}$ Like GLO1, GLO2 is present in nearly all living organisms, although it has been reported to be absent in certain mammals. ${ }^{85,86}$ The human GLO2 enzyme is a monomer with a molecular weight of 23 $\mathrm{kDa},{ }^{74}$ and is encoded by the hydroxyacylglutathione hydrolase (HAGH) gene. Genetic polymorphisms of GLO2 are extremely rare. The glutathione moiety of the hemithioacetal is a highly specific target for the GLO2 enzyme, although it can also react with other thioesters. ${ }^{10}$ 
In E. coli, glyoxalase III (GLO3) has been identified as an enzyme catalyzing the conversion of MGO into D-lactate, without GSH or any other co-factors being needed. ${ }^{87}$ In this reaction, the intermediate S-D-lactoylglutathione is not formed. Although GLO3 has so far only been identified in bacteria, results from a human study describe the activity of a DJ-1 homologue that is able to convert MGO into lactic acid without GSH being needed. ${ }^{88}$ However, further research is necessary for the identification of a human GLO3 enzyme.

\section{Methylglyoxal and glyoxalase in disease}

Increased levels of MGO and/or dysfunction of the glyoxalase system have frequently been found in relation to ageing and age-related diseases. Here, we will summarize the role of MGO and the glyoxalase system in diabetes and its related vascular complications, cardiovascular disease, cancer, disorders of the central nervous system, ageing and epigenetics (Figure 2.3).

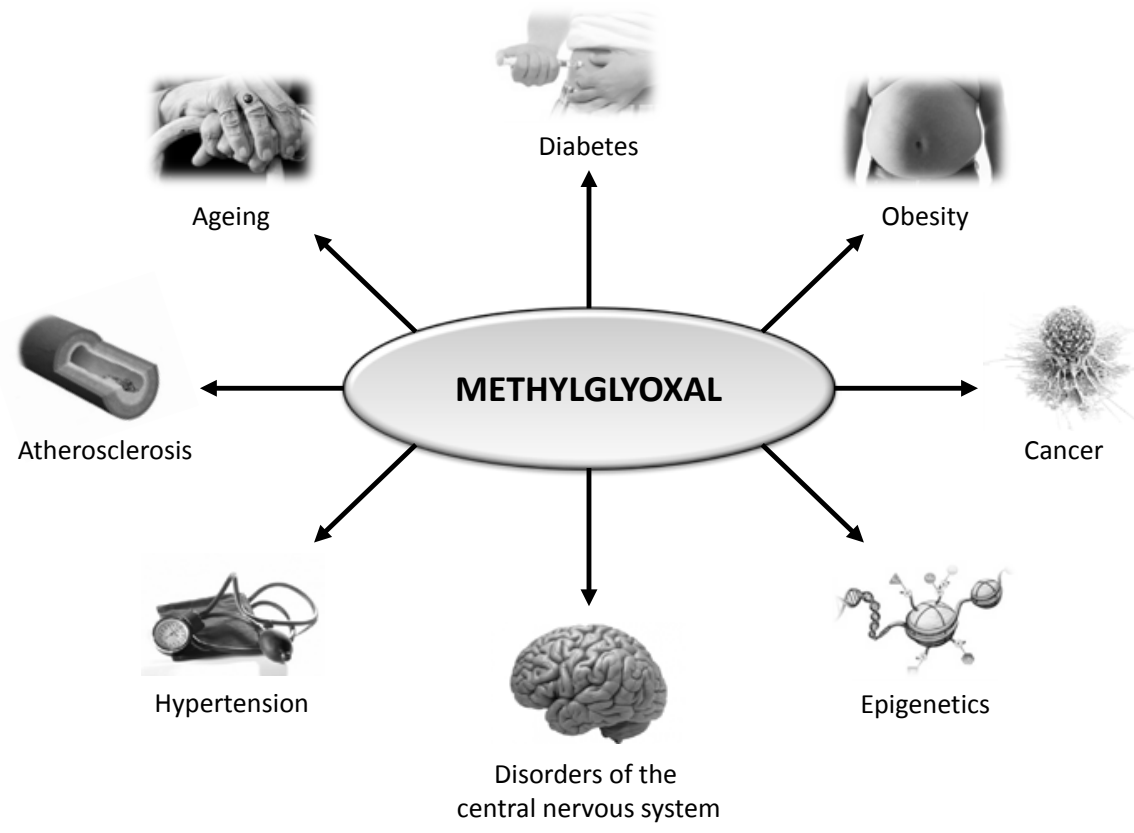

Figure 2.3 - Methylglyoxal and disease. Methylglyoxal (MGO) plays an important role in the process of ageing, but also in the pathogenesis of several age-related diseases, such as diabetes, obesity, cancer, disorders of the central nervous system, hypertension and atherosclerosis. MGO is also involved in epigenetics. 


\section{Diabetes and its vascular complications}

Diabetes has become a major 21st century epidemic, and is currently one of the largest health problems in the world, affecting almost $10 \%$ of the adult population in $2011 .^{89}$ After the discovery that high glucose concentrations in vitro result in the formation of MGO and cellular dysfunction, ${ }^{12,53,90}$ subsequent studies have reinforced the importance of MGO in diabetes and diabetes-associated complications. Indeed, both patients with type 1 and type 2 diabetes have higher plasma levels of MGO and MGO-derived AGEs. ${ }^{20,55}$ Dysfunctioning of the vascular endothelium is regarded as an important factor in the pathogenesis of diabetic micro- and macroangiopathy. In this section, we will describe the role of MGO in diabetes-related endothelial dysfunction and in micro- and macrovascular complications. In addition, the role of MGO will be discussed in obesity and insulin resistance, i.e. the major risk factors of diabetes.

\section{Endothelial dysfunction in diabetes}

The endothelium, a single layer of endothelial cells, is essential for the control of vascular functions. Dysfunctioning of the vascular endothelium in diabetes is regarded as an important initial factor in the pathogenesis of diabetic micro- and macroangiopathy. ${ }^{91}$ Diabetes-related endothelial dysfunction is characterized by changes in vasoregulation, increased levels of oxidative stress, inflammation, and altered barrier function of the endothelium. ${ }^{92}$ Metabolic alterations in endothelial cells are not harmless, but mediate dysfunction. In this respect, it is important to note that endothelial cells rely primarily on glycolysis for ATP production, with GLUT-1 as the main route for glucose uptake. ${ }^{93}$ In contrast to, for instance, smooth muscle cells, glucose transport into endothelial cells takes place by means of facilitated diffusion, independent of insulin. An increase in blood glucose concentrations will thus lead to a rise in the intracellular accumulation of glucose and its metabolites, including MGO. ${ }^{94}$ The importance of MGO for endothelial dysfunction in diabetes has recently been investigated in a rat study, which showed that GLO1 overexpression improved diabetes-induced impairment of nitric oxide-mediated relaxation. ${ }^{95}$ In vivo, exogenous administration of MGO to rats induces diabetes-like microvascular changes ${ }^{96}$ and impairment of endothelial function. ${ }^{97}$ Overexpression of GLO1 prevents impairment of angiogenesis in human endothelial cells ${ }^{98}$ and endothelial dysfunction in diabetic rats. $^{99}$ Moreover, overexpression of GLO1 completely prevents hyperglycaemiainduced AGE formation, ${ }^{90}$ indicating that $\mathrm{MGO}$ is indeed the most important AGE precursor in endothelial cells.

Several mechanisms to explain the effect of MGO on endothelial function have been investigated. In human aortic endothelial cells, it has been established that MGO 
induces mitochondrial oxidative stress by stimulating superoxide production and nitric oxide synthase. ${ }^{100}$ Likewise, overexpression of GLO1 in Caenorhabditis Elegans (C. Elegans) decreases the modification of mitochondrial proteins by MGO, thereby reducing mitochondrial ROS production. ${ }^{45}$

Multiple in vitro studies have investigated the effect of MGO on cellular damage ${ }^{6}$. MGO causes induction of oxidative stress, ${ }^{101,102}$ genotoxicity $^{103,104}$ and apoptosis. ${ }^{105-107}$ More specifically for endothelial cells, MGO modulates endothelial nitric oxide synthase (eNOS)-associated functions and NADPH oxidase activity. ${ }^{108,}{ }^{109}$ In addition, exposure of vascular smooth muscle cells (VSMCs) to MGO also causes oxidative stress $^{110,111}$ and decreased hydrogen sulfide levels. ${ }^{112}$ Hydrogen sulfide levels are usually responsible for ATP-sensitive $\mathrm{K}^{+}\left(\mathrm{K}_{\text {ATP }}\right)$ channel activation and disruption of the $\mathrm{K}_{\text {ATP }}$ channels results in abnormalities of contractility and dysfunctioning of responses to local vasoactive regulators. ${ }^{113}$ Thus, direct effects of MGO on endothelial cells and VSMCs mainly involve dysregulation of vasorelaxation. It should be emphasized, however, that in some of these studies high and unphysiological concentrations of MGO were used from commercial stock solutions, which are often contaminated with formaldehyde and other substances. ${ }^{17}$ For this reason, studies with high concentrations of commercial batches of MGO that do not include the preparation of high-purity MGO should be interpreted with care.

Nevertheless, there is sufficient evidence that MGO plays an important role in the pathogenesis of endothelial dysfunction in diabetes.

\section{Microvascular complications in diabetes}

Results from both experimental and clinical studies of diabetes have demonstrated that hyperglycaemia-induced MGO plays an important role in the pathogenesis of microvascular complications.

\section{Diabetic nephropathy}

Diabetic nephropathy is the major cause of end-stage renal disease in Western societies, and it affects circa $30 \%$ of all people with diabetes. Clinically, this condition is characterized by the development of proteinuria and a decline in glomerular filtration rate. ${ }^{114}$ Diabetic nephropathy progresses over a long period of time, and is a major risk factor for the development of macrovascular complications in diabetes. ${ }^{114}$ Multiple studies demonstrated that high plasma levels of MGO are associated with the prevalence of diabetic nephropathy. ${ }^{115-117}$ Moreover, the MGO-derived AGEs MG$\mathrm{H} 1$ and CEL are shown to be early indicators of progression of important diabetic nephropathy lesions, with MG-HI as a significant independent predictor of glomerular basement membrane increase. ${ }^{118}$ Experimental studies in cultured cells and kidneys 
from diabetic mice have demonstrated that high glucose levels induced MGO modification of the co-repressor $\mathrm{mSin} 3 \mathrm{~A}$, resulting in enhanced angiopoietin-2 expression, sensitizing microvascular endothelial cells to the pro-inflammatory effects of TNF $\alpha .{ }^{119}$ Moreover, it has been reported that MGO inhibits the electron respiratory chain in renal cells, leading to mitochondrial dysfunction, which may play an important role in renal cellular toxicity and the development of diabetic nephropathy. $^{120}$

In line, it has been demonstrated that overexpression of GLO1 in streptozotocininduced diabetic rats improves renal function and protects against albuminuria. ${ }^{99,}{ }^{121}$, ${ }^{122}$ The importance of GLO1 for normal kidney functioning has been confirmed as well by a recent study in non-diabetic mice, in which a reduction in GLO1 by small interfering RNA (siRNA) was found to increase MG-H1 residues in proteins of renal glomeruli and tubules, accompanied by the development of albuminuria and mesengial expansion. ${ }^{123}$ Moreover, a study in rats has shown that overexpression of GLO1 ameliorates renal ischemia-reperfusion injury via reduction of MGO accumulation in tubular cells. ${ }^{124}$

Taken together, these data demonstrate that MGO plays an important role in the pathogenesis of diabetic nephropathy. Loss of podocytes in the glomerulus may be a mechanism that potentially explains the contribution of MGO to the development of such complications. ${ }^{99}$

\section{Diabetic retinopathy}

Retinopathy is a second common microvascular complication of diabetes and is characterized by a spectrum of lesions within the retina, leading to increased vascular permeability, capillary microaneurysms, capillary degeneration, and neovascularization. ${ }^{114}$ In 2010, 40\% of all cases of blindness in Europe were caused by diabetic retinopathy, ${ }^{125}$ which is associated in its turn with increased risk of lifethreatening systemic vascular complications, such as stroke, coronary heart disease, or heart failure. ${ }^{126}$

Results from clinical studies have demonstrated that in both type $1^{127}$ and type 2 diabetes ${ }^{128}$ increased serum levels of MG-H1 are associated with the development of diabetic retinopathy. Moreover, it has been shown that serum MG-H1 levels are higher in patients with proliferative retinopathy than in patients with nonproliferative retinopathy. In rats, retinal levels of MG-H1 increased by $279 \%$ within 24 weeks of diabetes. ${ }^{129}$

To understand the involvement of MGO in diabetic retinopathy, several studies focused on pathways via which MGO contributes to retinal damage. Two experimental studies have demonstrated that culturing retinal endothelial cells under 
high glucose results in higher MGO levels, ${ }^{130,131}$ which subsequently leads to an imbalance in the ratio of vascular endothelial growth factor (VEGF) and angiopoietin 2. Consequently, capillary permeability and apoptosis increase and proliferation of retinal endothelial cells reduces. ${ }^{131}$ In line, seeding retinal pericytes on MGO-modified fibronectin triggers apoptosis through a combination of increased oxidative stress and a reduction of $\alpha \mathrm{B}$-crystallin. ${ }^{132}$

Overexpression of the GLO1 enzyme has been shown to protect against premature death of pericytes and endothelial cells under conditions of high glucose, ${ }^{133}$ supporting the hypothesis that increased MGO levels are involved in the pathogenesis of diabetic retinopathy. In addition, it has been found that GLO1 overexpression in diabetic rats prevents hyperglycaemia-induced formation of MGO-derived AGEs in neural retina, and protects against retinal capillary degeneration over 6 months of diabetes. ${ }^{46,134}$ It also prevents the dysfunctioning of Müller glia in the retina and the degeneration of retinal capillaries. Recently, it has been demonstrated that MGO increases the expression of CD74 in the retina, which is a marker of microglia activation, ${ }^{135}$ and that it induces mitochondrial dysfunction and oxidative DNA damage in human epithelial lens cells in vitro. ${ }^{136,137} \mathrm{MGO}$ has also been shown to induce cell death via nuclear factor $\mathrm{K}$ B (NFKB) activation in the diabetic lens. ${ }^{138}$

Together, these findings support the hypothesis that increased levels of MGO are involved in the pathogenesis of diabetic retinopathy, likely via activation of proapoptotic triggers such as the NFKB pathway, oxidative stress and mitochondrial dysfunction.

\section{Diabetic neuropathy}

Diabetic neuropathy is a syndrome which involves both somatic and autonomic divisions of the peripheral nervous system. The prevalence of neuropathy is about $50 \%$ in all individuals with diabetes, which is accompanied by a $15 \%$ risk of amputation being needed of one or more of the lower extremities. ${ }^{114}$ Numerous studies have confirmed the role played by glycation in diabetic neuropathy, ${ }^{139}$ although only few studies have focused specifically on the importance of MGO and glyoxalase until now. Previously, it has been shown that elevated plasma levels of MGO can discriminate between type 2 diabetes patients with or without neurological pain, ${ }^{140}$ and that skin MG-H1 is strongly associated with the progression of neuropathy in type 1 diabetes. ${ }^{141}$ In line, results from an experimental study have demonstrated that sciatic nerves have high levels of MGO; these levels are even higher in streptozotocin-induced diabetes. ${ }^{34}$ MGO causes depolarization of the sensory neurons, and induces post-translational modifications of the voltage-gated sodium channel $\mathrm{Na}(v) 1.8 .{ }^{140}$ Because of this, 
treatment with MGO evokes mechanical hyperalgesia, leading to increased blood flow to the brain regions that are involved in processing pain. ${ }^{140}$

In vitro, MGO has been identified to activate p38 MAPK in Schwann cells, leading to the induction of apoptosis. ${ }^{142}$ Moreover, MGO affects neuronal cell viability by deleterious effects on signal transducer and activator of transcription 3 (STAT3) signaling, resulting in down-regulation of the anti-apoptotic protein $\mathrm{Bcl} 2{ }^{143}$

MGO has also been described as a modifier of cysteine residues of the transient receptor potential channel subfamily A, member 1 (TPRA1). ${ }^{144-146}$ This modification results in slower conduction velocity in unmyelinated peripheral nerve fibers, and stimulation of proinflammatory neuropeptide release. ${ }^{147}$

Few studies investigated the effect of GLO1 on diabetic neuropathy. Diabetic mice with reduced GLO1 levels have been shown to have increased mechanical thresholds, indicative of the development of neuropathy, loss of epidermal fibers, and reduced activity of mitochondrial oxidative phosphorylation proteins. ${ }^{148}$

All in all, suggestive and divergent evidence of mechanistic links between MGO and diabetic neuropathy has been provided by several studies. Although extensive future research is required to confirm these results, data so far indicate that MGO contributes in a major way to the pathogenesis of diabetic neuropathy.

\section{Macrovascular complications in diabetes}

Cardiovascular disease (CVD) is a major cause of mortality in people with diabetes. ${ }^{149}$ In the majority of cases, the underlying process is atherosclerosis, a pathological condition characterized by the formation of atheromatous plaques in the intima of the arterial wall. ${ }^{150}$ Advanced atherosclerotic plaques consist of a necrotic core containing cholesterol and dead macrophages, which are covered by a fibrous cap consisting of smooth muscle cells and collagen. Ruptured plaques are defined as a disruption of the fibrous cap and a thrombus that is constantly present in the necrotic core, which may occlude an artery, creating a significant risk of cardiovascular disease which can result in myocardial infarction or stroke. ${ }^{151}$ Previous studies have proposed that high metabolic activity in atherosclerotic plaques can contribute to the development of plaque rupture. ${ }^{152}$ One aspect of increased metabolic activity is the formation of AGEs. ${ }^{153}$ Several studies have shown that the AGE $N(\varepsilon)$ (carboxymethyl)lysine (CML) indeed accumulates in human atherosclerotic plaques. $^{154,155}$ There is increasing evidence to suggest that MGO in particular could play a major role in the development of atherosclerosis. Administering MGO directly via the drinking water has been shown to increase atherosclerosis. ${ }^{156} \mathrm{MGO}$ has also been described as a predictor of intima-media thickening in type 2 diabetes. ${ }^{157}$ 
Low-density lipoprotein (LDL) plays a significant role in the enhancement, development, and progression of atherosclerosis, through a pathway that involves endothelial cell dysfunction, lipid oxidation and accumulation, foam cell formation and inflammatory responses. Research has demonstrated that LDL can be modified by MGO, resulting in a change in both the physiochemical and biological properties of LDL. $^{158-161}$ More specifically, MGO modifies arginine residues of the protein component of LDL, mainly apoB100, which results in the formation of MG-H1. ${ }^{159,} 162$ These modifications lead to the formation of a more atherogenic LDL particle, thus stimulating the development of atherosclerosis. In addition to LDL, high-density lipoprotein (HDL) can also be modified by MGO. Main HDL functions are esterification of cholesterol and reverse cholesterol transport; however, HDL has several other antiatherogenic effects, such as antioxidative, vasodilatory, and anti-inflammatory functions. ${ }^{163}$ In type 2 diabetes, $4.5 \%$ of all HDL is modified by MGO or related dicarbonyl compounds, ${ }^{164}$ resulting in a decrease of anti-oxidant and antiinflammatory activities of the HDL enzyme paraoxonase-1. ${ }^{165}$ Moreover, due to restructuring of the HDL protein, its stability and plasma half-life in vivo is decreased after modification by MGO. ${ }^{164}$ Whether these MGO-modified lipoprotein particles are indeed more atherogenic in vivo is not yet known.

Next to the crucial lipoproteins in atherosclerosis, also the platelet-derived growth factor receptor $\beta$ (PDGFR $\beta$ ) is known to be a target of MGO modification. PDGFR $\beta$ is involved in the proliferation of smooth muscle cells and MGO modification of this protein may lead to a fragile thin cap at the atherosclerotic lesion, creating a rupturevulnerable plaque. ${ }^{166}$

Surprisingly, overexpression of GLO1 does not lead to decreased atherosclerotic lesion size in streptozotocin-induced diabetic $\mathrm{ApoE}^{-/-}$mice. ${ }^{167}$ Comparable results have been obtained by Geoffrion et al., who found no effects on diabetic atherosclerosis of either GLO1 overexpression or GLO1 knockdown. ${ }^{121}$ In contrast, exposure to MGO, either from an exogeneous source or generated following inhibition of GLO1, is able to augment atherogenesis in $\mathrm{ApoE}^{-/-}$mice, with a similar magnitude to that observed in diabetic mice. ${ }^{156}$ Although future studies are needed to explain the seemingly contrasting results, it is likely that GLO1 overexpression may not protect against AGEformation in hyperlipidaemic conditions, such as in $\mathrm{ApoE}^{-/}$mice, because GLO1 does not come into sufficient contact with the AGE precursors derived from lipid oxidation. This seems a serious possibility, as GLO1 is present in the cytosol where glycolysis takes place, but not in the cellular membranes and lipid particles where lipid oxidation mainly occurs.

In addition to atherosclerosis, both experimental and human studies have shown that diabetes is also associated with the impairment of ischemia-driven neovascularization, 
increasing rates of lower limb amputations, heart failure and mortality after ischemic events. The direct modification of HIF1 $\alpha$ or its co-activator p300 by MGO and the reduced binding to relevant promoters of genes required for neovascularization has been described as one of the mechanisms involved in the defective ischemia-induced new vessel formation in diabetes. ${ }^{168,169}$ Another mechanism by which MGO induces macrovascular damage, is via reduction of sarco(endo)plasmic reticulum $\mathrm{Ca}^{2+}$-ATPase (SERCA2a), which normally translocates $\mathrm{Ca}^{2+}$ from the cytoplasm to the lumen of the sarco(endo)plasmic reticulum during cardiac relaxation. In a rat model of type 1 diabetes, it has been shown that MGO reduces the ability of SERCA2a to perform this translocation, resulting in diastolic dysfunction of the heart. ${ }^{170}$ Interestingly, the overexpression of GLO1 does attenuate mild oxidative damage in the diabetic rat heart, by reducing MGO levels. ${ }^{171}$

Thus, although GLO1 overexpression obviously is not capable in reducing the pathogenesis of atherosclerosis, findings so far provide strong evidence that higher levels of MGO are associated with the development of macrovascular complications in diabetes.

\section{Obesity}

The incidence of obesity has reached epidemic proportions, and contributes to the increasing prevalence of type 2 diabetes and cardiovascular disease. ${ }^{172}$ Excessive food consumption, low energy expenditure, hyperglycaemia and hyperlipidaemia can all augment the formation of MGO in obese individuals. It has been observed that, in obese Zucker rats, an accumulation of $\mathrm{MGO}$ in adipose tissue takes place, accompanied by an increase in serum levels of MGO. ${ }^{173}$ Cell proliferation experiments have shown that direct incubation of adipocytes with MGO results in an increased proliferation of these cells, suggesting that MGO may be involved in the expansion of the adipose tissue in obesity. ${ }^{173}$ In vivo, it has recently been demonstrated that longterm MGO administration (14 weeks) to normal rats leads to structural changes in the adipose tissue microvasculature, hypoadiponectinaemia, and lipolysis. These effects are associated with increased tissue glycation and impaired expression of apoptotic and angiogenic markers, but not with insulin resistance. ${ }^{174,175}$ In contrast, short-term MGO administration ( 8 weeks) causes much less severe effects, despite the fact that tissue accumulation of CEL takes place. ${ }^{176,177}$

In $\mathrm{db} / \mathrm{db}$ mice, an animal model of obesity, decreased activity of GLO1 has been found in the renal cortex. ${ }^{76}$ However, in red blood cells of obese mice, GLO1 activity was increased by 50 to $60 \%$ as compared to those of lean controls, and GLO2 activity rose by 20 to $30 \% .^{75}$ A proteomics study has demonstrated that GLO1 protein levels increase in the skeletal muscle of rats on a high-fat diet. ${ }^{178}$ Furthermore, increased 
mRNA expression and activity of the GLO1 enzyme has been linked to mice that prefer high carbohydrate diets. ${ }^{28}$ These contradictory results show that further study is needed to clarify the role of GLO1 in obesity.

Despite these contradictory results from multiple studies, these data have shown the importance of MGO and GLO1 during the development of obesity and adipose tissue dysfunction, suggesting their potential influence on the onset of type 2 diabetes. The underlying mechanism and the activity of GLO1 in obesity still have to be further elucidated.

\section{Insulin resistance}

Insulin resistance is characterized by a reduced responsiveness to the action of insulin on glucose uptake, metabolism or storage, and other targets of insulin signaling. ${ }^{179}$ Several studies have demonstrated that direct or indirect administration of MGO to Sprague-Dawley rats results in insulin resistance. ${ }^{180-183}$ There is increasing evidence from experimental studies that MGO may contribute to the pathogenesis of insulin resistance by means of direct functional modifications of the insulin molecule and interference in the complex molecular pathways of insulin signaling. Moreover, we recently demonstrated in a large cohort study that plasma D-lactate levels, as a reflection of plasma MGO concentrations, are independently associated with insulin resistance. $^{184}$

In vitro incubation of human insulin with MGO has been shown to yield attachment of MGO to an arginine residue of the insulin $\beta$-chain adducts, which is accompanied by functional changes. ${ }^{185}$ In comparison with the effect of native insulin in the same concentrations, a significant decrease of glucose uptake induced by MGO-modified insulin adducts has been observed in 3T3-L1 adipocytes and L8 skeletal muscle cells. Unlike native insulin, MGO-modified insulin adducts diminishes the feedback inhibition of insulin release from pancreatic beta-cells. The degradation of MGOmodified insulin through liver cells decreases as well. ${ }^{185}$ In this way, the formation of the MGO-insulin adduct reduces insulin-mediated glucose uptake, impairs autocrine control of insulin secretion, and decreases insulin clearance. Although these structural and functional abnormalities of the insulin molecule may contribute to the pathogenesis of insulin resistance, no data are available yet about the presence of MGO-insulin adducts in vivo.

In addition, MGO has been shown to modify activity of the insulin signaling pathway. A short exposure of $L 6$ muscle cells to MGO induces an inhibition of insulin-stimulated phosphorylation of protein kinase $B$ (PKB) and extracellular signal-regulated protein kinases $1 / 2$ (ERK1/2), without affecting insulin receptor tyrosine phosphorylation. ${ }^{186}$ Importantly, these harmful effects of MGO are independent of ROS, but appear to be 
a direct consequence of MGO-induced impairment of insulin-receptor-substrate-1 (IRS-1) tyrosine phosphorylation. Also in 3T3-L1 adipocytes, MGO impairs insulin signaling, as indicated by decreased insulin-induced IRS-1 tyrosine phosphorylation. ${ }^{181}$ Incubation of pancreatic beta INS-1E cells with MGO results in glycogen synthase kinase-3 (GSK-3)-mediated impairment of insulin secretion and action. ${ }^{187}$ As this shows, MGO can directly and significantly interrupt the insulin signaling pathway. In an animal model of insulin resistance, a close correlation has been established between the development of insulin resistance and elevated MGO levels in serum and adipose tissue. ${ }^{181}$ Both the insulin resistant state and elevated MGO levels are reversed by the major glutathione precursor $\mathrm{N}$-acetylcysteine (NAC). The ability of NAC to block MGO-impairment of phosphatidylinositol-4,5-bisphosphate 3-kinase (PI3K) activity and IRS-1 phosphorylation has further confirmed the role that MGO plays in the development of insulin resistance. In addition to the effect of insulin on glucose metabolism, insulin also exerts a direct effect on endothelial cells. MGO has recently been identified as an inducer of endothelial insulin resistance. ${ }^{188}$ It impairs the action of insulin on the endothelium both in vitro and in vivo, at least partly, through an ERK1/2-mediated mechanism.

In conclusion, the increase in endogenous MGO has been shown to impair the insulinsignaling pathway and to decrease insulin-stimulated glucose uptake in several tissues, both of which can contribute to the development of insulin resistance. These findings may be instrumental to further elucidate the role of MGO in the development of insulin resistance, and to develop new strategies for controlling insulin resistance.

\section{Cardiovascular disease}

Next to diabetes-related cardiovascular complications, MGO is also associated with non-diabetes-related cardiovascular disease. The two most described cardiovascular complications in relation to MGO and GLO1 are atherosclerosis and hypertension.

\section{Atherosclerosis}

As described above, MGO is an important factor influencing the pathogenesis of diabetes-associated atherosclerosis. However, $\mathrm{MGO}$ is also involved in the development of non-diabetes-associated atherosclerosis. ${ }^{2,97}$

We have recently demonstrated that the MGO-derived AGEs MG-H1 and THP can be found in atherosclerotic plaques, and that MG-H1 is associated with rupture-prone phenotypes of the plaque. ${ }^{55,77}$ Interestingly, no differences were found between diabetic and non-diabetic individuals, indicating that the metabolic dysfunction in atherosclerotic plaques has a greater influence on the accumulation of AGEs, 
including MG-H1, than the hyperglycaemic environment. Immunohistochemical staining has shown that the macrophage is the predominant cell type in the atherosclerotic plaque for MG-H1 accumulation. ${ }^{77}$ Macrophages are characterized by high activity of the glycolytic pathway, and the atherosclerotic environment of inflammation and hypoxia stimulate glucose uptake by macrophages, the latter probably resulting in enhanced MGO production. ${ }^{77,152,189}$ However, in addition to formation of MGO by glycolysis, MGO can also result from lipid oxidation. Indeed, higher lipid contents of the plaque are associated with higher MG-H1 levels. ${ }^{77}$

LDL is an important target for MGO modification in atherosclerosis. Glycation of LDL by $M G O$ results in decreased LDL particle size, increased atherogenicity, and reduced affinity for the LDL receptor. ${ }^{159,190}$ Because of this, less LDL can be cleared from the circulation, which means that higher amounts will become trapped in the vessel wall. As macrophages take up oxidized LDL in atherosclerotic lesions, MGO formation in macrophages is likely to play an important role in the process of atherosclerosis. ${ }^{77}$ Moreover, in the atherosclerotic plaque, MG-H1 levels co-localize with markers of inflammation, hypoxia, apoptosis, and oxidative stress, ${ }^{77}$ suggesting that an increase of MG-H1 in the plaque and consequent macrophage death can contribute to the transition of stable plaques to rupture-prone plaques.

Apart from increased prevalence in plaque macrophages, the detoxification of MGO by the glyoxalase system can also be impaired in atherosclerotic lesions. Indeed, mRNA, protein and activity levels of GLO1 are lower in ruptured plaques as compared to stable plaques, ${ }^{77}$ which confirms the finding of increased MGO levels in atherosclerosis. All in all, it can be said that MGO has been proven to be of influence on the development of atherosclerosis, either by increased formation or impaired detoxification by GLO1. As increased levels of MGO modifications in the plaque are associated with a rupture-prone phenotype, inhibition of MGO would not only prevent the development, but also the progression of atherosclerosis. Therefore, further insights into the molecular mechanisms at hand may help to improve the management of atherosclerotic lesions.

\section{Hypertension}

According to the World Health Organization (WHO), hypertension is responsible for almost $13 \%$ of all deaths worldwide, which makes it a major threat to public health. $A$ link between MGO accumulation and hypertension has been demonstrated in rats whose MGO levels in aortic and renal tissues were increased. ${ }^{183,191-193}$ Administering MGO to rats leads to a significant rise in systolic blood pressure ${ }^{194,195}$ and higher plasma levels of aldosterone, renin, angiotensin, and catecholamines. ${ }^{195}$ Similarly, a diet high in fructose - a precursor of MGO - induces hypertension and renal injury in 
rats. ${ }^{196,197}$ Although a dose of $1 \%$ MGO in drinking water did not induce hypertension in Sprague-Dawley rats, ${ }^{183}$ surprisingly enough, the same dose in combination with a high-salt diet induced hypertension and enhanced renal oxidative stress, ${ }^{183}$ suggesting that MGO causes hypertension only in rats with enhanced renal oxidative stress. Previous findings from a mouse study indicate that MGO-induced hypertension partially takes place via the angiotensin II type-1 receptor-mediated pathway. ${ }^{198}$ In addition, an increase in cytosolic [Ca2+] through MGO, resulting in vascular retention, has been suggested as an underlying mechanism to link MGO to hypertension. ${ }^{194}$ An improvement in blood pressure has been observed in rats after treatment with aminoguanidine, which is a scavenger of MGO. ${ }^{199,200}$

To conclude, MGO has been demonstrated to be of important influence on the development of hypertension. This suggests that it may be clinically useful as a biomarker or potential therapeutic target for combating hypertension. Indeed, in humans, multiple regression analysis has revealed that MGO is an independent risk factor for increased systolic blood pressure over a 5-year period. ${ }^{157}$

\section{Cancer}

Cancer is the leading cause of morbidity and mortality worldwide, with approximately 14 million new cases and 8.2 million cancer-related deaths in $2012 .{ }^{201}$ Cancer is a disease characterized by uncontrolled growth and proliferation of abnormal cells. As mentioned above, MGO plays an important role in the process of cell death. ${ }^{105-107}$ Due to lack of oxygen, tumors primarily rely on the anaerobic metabolism of glucose. To compensate for this inefficient energy supply, tumors show a higher rate of glucose uptake and glycolysis. An important consequence is intracellular formation of MGO. To survive, cancer cells with such a high glycolytic rate require a high rate of detoxification of MGO. The increased expression and activity of the GLO1 enzyme found in many tumors are therefore stimulating growth and avoiding MGO-induced apoptosis. The survival-promoting effects of GLO1 overexpression have been attributed to NFKB and activator protein-1 (AP-1), which results in activation of the PI3K/Akt pathway. ${ }^{202,203}$ In addition, GLO1 reduces intracellular MGO levels. As a consequence, activation of p38 mitogen-activated protein kinase (MAPK) is decreased and the NFKB pathway is induced, which leads to inhibition of the pro-apoptotic Bax and 553 proteins and enhanced expression of the anti-apoptotic $\mathrm{Bcl}-2$ protein. ${ }^{204,} 205$ Moreover, it was indicated that AP-modification of HSP27 in human lung squamous cell carcinomas could play a role in the inhibition of caspase activation, and thereby prevent apoptosis. ${ }^{206}$ Thus, these findings suggest that GLO1 plays a crucial role in the survival and proliferation of tumor cells by enhancing MGO detoxification. 
Overexpression of GLO1, commonly caused by GLO1 gene amplification, has been associated with multidrug resistance in chemotherapy. ${ }^{8}$ This was demonstrated for the first time in fibroblasts with an induced overexpression of GLO1, which protected the cells against the toxic effects of the anti-tumor agents mitomycin $\mathrm{C}$ and doxorubicin. ${ }^{207}$ Moreover, it was shown that inhibition of GLO1 in tumor cells with high GLO1 expression levels prevented multidrug resistance and increased sensitivity to anti-cancer therapies. One of the first developed GLO1 inhibiting agents in tumor cells is S-p-bromobenzylglutathione cyclopentyl diester (BBGD). ${ }^{208}$ This agent directly induces the activation of the stress-activated protein kinases cJun $\mathrm{NH}_{2}$-terminal kinase 1 (JNK1) and p38 MAPK, resulting in activation of caspases. Eventually, this leads to apoptosis in GLO1 overexpressing tumor cells. Moreover, inhibition of GLO1 promotes apoptosis indirectly via increasing intracellular MGO levels, leading to the release of cytochrome $\mathrm{C}$ from mitochondria and thereby inducing apoptosis by modifying the mitochondrial permeability transition pore. ${ }^{209}$ However, it has been demonstrated that BBGD does not directly inhibit the activity of GLO1, but that it requires hydrolysis by tumor non-specific esterase to exhibit GLO1 inhibitor activity. ${ }^{208}$ Nowadays, more potent GLO1 inhibitors have been described, such as methotrexate ${ }^{210}$ and polyphenols curcumin. ${ }^{211,212}$

In conclusion, overexpression of GLO1 in tumor cells promotes cell survival and proliferation through reduction of intracellular MGO levels. In addition, high levels of GLO1 are associated with multidrug resistance. Therefore, GLO1 is a potential molecular target to increase efficacy of anti-cancer therapy.

\section{Disorders of the central nervous system}

With respect to brain functioning, various studies have linked glycation to disorders of the central nervous system. In the next paragraphs, we describe the role of MGO and GLO1 in Alzheimer's disease, Parkinson's disease, schizophrenia and anxiety disorders.

\section{Alzheimer's disease}

Impaired activity of GLO1 and increased serum levels of MGO have been described as being associated with impaired cognitive function, in particular Alzheimer's disease (AD). ${ }^{213-216}$ In the cerebrospinal fluid (CSF) of AD patients, higher levels of MG-H1 and other glycation free adducts have been found compared to the CSF of healthy controls. ${ }^{217}$ Multiple studies have investigated the molecular mechanisms that might explain the role of MGO in AD. In vitro incubation of neuroblastoma cells with MGO increased the activity of the pro-apoptotic protein Bax and caused a decrease in the anti-apoptotic protein $\mathrm{Bcl} 2$. In combination, these processes resulted in more 
apoptotic cells, which are known to play a key role in the development of AD. ${ }^{218} \mathrm{High}$ levels of MGO also caused impairment of the oxidative status of brain mitochondria, ${ }^{219}$ which possibly contributes further to the pathogenesis of AD. ${ }^{220}$ Moreover, depletion of reduced GSH and subsequent inadequate functioning of the glyoxalase system may have a major effect. ${ }^{221,222}$ In line with this, an increased ratio of oxidized GSSH/reduced GSH in patients with $A D$ is associated with severity of the disease. $^{221}$

\section{Parkinson's disease}

Besides $A D$, there is also evidence that MGO plays a role in the development of Parkinson's disease (PD). PD is accompanied by increased protein glycation, ${ }^{223,224}$ and it has been found that a mutation of the DJ-1 gene is a risk factor for PD. DJ-1 normally controls the nuclear factor (erythroid-derived 2)-like 2 (Nrf2) transcription factor, which regulates the cellular response to oxidative stress, including the expression of GLO1. ${ }^{225}$ These data suggest that a change in the activity of GLO1 could play a role in $\mathrm{PD}$, possibly via elevation of MGO levels.

\section{Schizophrenia}

Few studies also report on the role of MGO and GLO1 in the pathogenesis of schizophrenia. Heterozygous frameshift mutations and the homozygous Ala111 phenotype in GLO1 have been described in association with low GLO1 activity and a concomitant increase in carbonyl stress in a subset of schizophrenia patients. ${ }^{226,227}$ However, sample sizes are very small and therefore, additional human or mouse genetic studies are needed to confirm the role of MGO and GLO1 in schizophrenia.

\section{Anxiety disorders}

In contrast, increased expression levels of GLO1 and, consequently, lower MGO concentrations in the brain have been reported in relation to anxiety. ${ }^{228-231}$ Direct MGO infusions into the brain of mice caused an anxiolytic effect, ${ }^{232}$ which was mediated by a decrease in $\mathrm{GABA}_{\mathrm{A}}$ receptor activation - a major known mediator of anxiety. ${ }^{233}$ This finding suggests that MGO and low levels of GLO1 enable the brain to put things and events into perspective, although additional studies are needed to confirm this hypothesis. 


\section{Ageing and epigenetics}

In addition to specific complications, MGO and GLO1 are also extensively described in relation to the ageing process and epigenetics, which could both give rise to a wide variety of diseases.

\section{Ageing}

During the ageing process, an increase in protein damage takes place as a result of non-enzymatic glycation. ${ }^{234}$ The physiological consequences of this non-enzymatic glycation and the aetiology of a range of important age-related diseases have been described in a number of excellent reviews. ${ }^{6,7,28,74,179,235}$

Several studies have demonstrated the effects of GLO1 during ageing, as described in the review by Xue et al. ${ }^{235}$ In 1960, a study on humans reported for the first time that GLO1 activity in human arterial tissue decreases with age, which suggests a potential link between a decline in glyoxalase activity and an increased risk of age-related cardiovascular disease. ${ }^{236}$ Later, McLellan and Thornalley described a decline in both GLO1 and GLO2 activity in old red blood cells during the ageing process. ${ }^{237}$ In older people's brains, smaller numbers of GLO1 expressing neurons are found than in the brains of younger individuals, ${ }^{238}$ which links GLO1 to age-related cognitive impairment, as described above. Thus, GLO1 seems to be directly involved in the ageing process. In addition, GLO1 has been described as an important player in life span regulation. It was shown that during ageing, the activity of GLO1 declines in the nematode C. Elegans. ${ }^{45}$ The downstream consequences of GLO1 reduction have been demonstrated by an overexpression of the GLO1 homologue in C. Elegans, resulting in an increase of the mean and maximum lifespan by circa $30 \%$; silencing the GLO1 homologue decreased the lifespan by circa $50 \% .{ }^{45,}{ }^{239}$ Similar findings have been described in the ageing model Podospora anserine. ${ }^{240}$ Moreover, elderly rats with an overexpression of GLO1 showed an amelioration of senescence, which was associated with protection against the age-dependent decline of renal functions. ${ }^{241}$ Together, these findings suggest that GLO1 belongs to the network of genes that influence longevity.

Multiple studies have also demonstrated a decreased activity of the glyoxalase system and subsequently accumulation of MGO-derived AGEs in the ageing human lens, which can potentially contribute to the development of age-dependent cataract. ${ }^{5,56 \text {, }}$ 57, 242-245 Age-related endothelial dysfunction is ameliorated by an overexpression of the GLO1 enzyme, as it leads to the inhibition of MGO and subsequent inhibition of eNOS phosphorylation. ${ }^{246}$ Moreover, Fleming et al. have recently shown that ageingassociated impairment of wound healing is related to decreased GLO1 transcription, 
expression, and activity. ${ }^{247}$ Treatment with the MGO scavenger aminoguanidine restores wound healing in elderly mice, suggesting a causative influence of MGO on the impairment of wound healing.

In conclusion, the balance between the production of MGO and its detoxification by GLO1 can significantly contribute to the ageing process; managing this balance is important for the prevention of age-related health problems.

\section{Epigenetics}

Epigenetics is the study of modifications in gene expression that concentrates on changes in gene expression that do not involve changes in DNA nucleotide sequences. ${ }^{248}$ Although epigenetics is not a disease in itself, it plays an important role in several age-related diseases. Modification in gene expression through DNA methylation and chromatin remodeling via histone modifications are believed to be the most important epigenetic changes. ${ }^{248}$ Although not much research has been done on MGO in epigenetics, a study from El-Osta et al. has described that MGO does play an important role in epigenetic changes. ${ }^{249}$ Transient hyperglycaemia leads to increased p65 gene expression and subsequent increased NFKB activation, resulting in inflammatory gene expression. This phenomenon can be attributed to the activation of methylation of histones associated with the p65 promoter, in particular monomethylation of lysine 4 of histone 3 (H3K4), which is mediated by histone methyltransferases (HMT). The mammalian HMT Set7 is known to methylate H3K4. GLO1 prevents the hyperglycaemia-induced increase in p65 expression, which points towards a significant influence of MGO on epigenetic DNA methylation. The same study has shown that, in a non-diabetic GLO1 knockdown mouse model, H3K4 Set7mediated monomethylation and subsequent p65 expression tends to increase. It has also been demonstrated that MGO can induce substantial modifications in secondary and tertiary structures of nucleosomal protein histone $\mathrm{H} 2 \mathrm{~A} .{ }^{65}$ Thus, since epigenetic changes form the basis of many diseases, management of MGO levels could be a major factor in the prevention of multiple complications.

\section{Scavengers of methylglyoxal}

Below, we will discuss the scavengers of MGO that have been studied most extensively in human studies, namely, aminoguanidine, alagebrium, metformin and pyridoxamine. Besides, we will briefly discuss the function of benfotiamine. 


\section{Aminoguanidine}

The AGE-lowering effects of aminoguanidine were first described by Brownlee et al. in 1986. ${ }^{250}$ Aminoguanidine is a scavenging agent of MGO and other $\alpha$-dicarbonyls; it consists of a nucleophilic hydrazine group and a dicarbonyl-directing guanidine group. $^{251}$ In experimental diabetes, aminoguanidine has been proven to be very effective in lowering AGE formation and preventing diabetic complications such as nephropathy, ${ }^{252,}{ }^{253}$ retinopathy, ${ }^{254}$ and neuropathy. ${ }^{255}$ However, the use of aminoguanidine in clinical trials has shown disappointing results. Two large doubleblind randomized controlled trials (RCTs) have studied the effects of aminoguanidine in patients with type $1^{256}$ and type 2 diabetes. ${ }^{257}$ In both studies, the primary end point was doubling time of serum creatinine. In type 1 diabetic individuals, 2-4 years of treatment with aminoguanidine did not significantly decrease this primary endpoint. The study in patients with type 2 diabetes was initially planned to continue for 2 years, but was terminated prematurely because of a lack of efficacy and safety concerns about gastrointestinal disturbance, lupus-like illness, abnormal liver function, flu-like symptoms, and vasculitis. For these reasons, aminoguanidine is at present not considered to be an effective treatment of diabetic complications.

\section{Alagebrium}

Although alagebrium (also known as ALT-711) has often been described as an AGE cross-link breaker, ${ }^{258}$ there is now overwhelming evidence that it is rather an inhibitor of AGE formation, ${ }^{259}$ with the inhibition of MGO as the likely underlying mechanism. In experimental studies, pharmacological intervention with alagebrium has proven efficient for the reduction of large artery stiffness, left ventricular mass, diastolic stiffness of the heart, atherosclerosis, and diabetic nephropathy. ${ }^{260}$ Clinical trials on alagebrium have shown mixed results. Whereas one RCT has found beneficial effects on cardiovascular variables in hypertensive individuals, ${ }^{261}$ another RCT has yielded no beneficial results. $^{262}$ Furthermore, two uncontrolled studies in hypertensive individuals have reported an improved aortic augmentation index and flow-mediated dilation after 8 weeks of alagebrium treatment, as well as improvements in the left ventricular mass and diastolic cardiac function after 16 weeks of treatment. ${ }^{263,264}$ No improvements were seen in other vascular parameters. Although the results from experimental studies have been promising, the efficacy of alagebrium in clinical trials has not met expectations. 


\section{Metformin}

Due to its beneficial effects on cardiovascular disease, metformin has become one of the most widely prescribed oral glucose-lowering agents for type 2 diabetes. The main blood glucose-lowering activity of metformin is believed to be that of suppression of hepatic gluconeogenesis and increasing cellular uptake of glucose, ${ }^{265}, 266$ most likely via inhibition of mitochondrial glycerophosphate dehydrogenase. ${ }^{267}$ It has been demonstrated that metformin is also able to trap MGO, ${ }^{268}$ which might explain the beneficial effect of metformin on cardiovascular complications in patients with type 2 diabetes. ${ }^{269}$ Indeed, it has been shown that metformin treatment is able to reduce systemic plasma MGO levels. ${ }^{20}$ The effect of metformin on MGO has recently been confirmed in a prospective non-randomized 24-week trial in patients with type 2 diabetes. ${ }^{270}$ However, the reduction in MGO is accompanied by a significant increase in the activity of GLO1 in circulating cells, indicating that the reduction of MGO is most likely not due to the scavenging properties of metformin, but due to the restoration of GLO1 activity. Other trials have also reported that metformin is effective in reducing glycation, but it has no additional effects in comparison with other antihyperglycaemic treatments. These data suggest that the AGE-inhibiting effects of metformin result from an improvement in glycaemic control or increased levels of GLO1, rather than from direct inhibition of MGO. ${ }^{260}$ The very low rate constant of metformin and MGO also indicates that quenching of MGO is not the primary effect by means of which metformin reduces systemic MGO concentrations. ${ }^{271}$

\section{Pyridoxamine}

The natural vitamin B6 analogue, pyridoxamine, has been described as an antiglycating agent, which operates via the quenching of reactive $\alpha$-dicarbonyl compounds such as MGO. ${ }^{272}$ Preclinical studies in animal models of diabetic nephropathy have reported the efficacy of oral pyridoxamine supplementation for preserving renal function. ${ }^{273-277}$ In a phase II clinical trial, pyridoxamine not only inhibited the formation of CML and CEL, but also improved kidney function in type 2 diabetes patients with overt nephropathy. ${ }^{278}$ However, a second placebo-controlled clinical trial found no beneficial effect of pyridoxamine on the reduction of creatinine levels, although it has been suggested that individuals with less advanced renal impairment might benefit. ${ }^{279}$ In a third clinical trial, treatment with pyridoxamine significantly decreased the formation of AGEs, inflammation and pain in patients with osteoarthritis. No adverse effects of pyridoxamine were found after 6 months of treatment. ${ }^{280}$ As pyridoxamine has a demonstrated beneficial effect on the treatment of diabetes-associated complications, and since it has a favorable safety profile with no adverse effects, it is currently being studied as a potential treatment for type 2 diabetes. 


\section{Benfotiamine}

Benfotiamine is commonly used as a treatment of diabetic neuropathy and activates transketolase, which directs glucose substrates to the pentose phosphate pathway. ${ }^{281}$ Therefore, benfotiamine blocks several hyperglycaemia-induced pathways, including formation of MGO. Although benfotiamine is thus not a direct scavenger of MGO, it can potentially decrease MGO levels by reducing its substrate.

\section{Glyoxalase I-inducing compounds}

Previous studies have shown that there are potentially several classes of compounds that can promote GLO1 expression and activity. It is not only synthetic drugs like candesartan ${ }^{282}$ that possess GLO1 stimulating properties, but more natural occurring compounds have a similar effect. Nagaraj et al. have shown that pyridoxamine not only quenches MGO, but can also increase GLO1 activity, an effect which they have demonstrated in the retina of diabetic rats. ${ }^{283}$ Furthermore, polyphenols like resveratrol and fisetine are known to up-regulate GLO1 expression. ${ }^{284,}{ }^{285}$ A class of interesting naturally occurring compounds are the isothiocyanates, which include phenethyl isothiocyanate and sulforaphane. ${ }^{286}$ These compounds, which can be found in cruciferous vegetables, are known to activate Nrf2. ${ }^{287} \mathrm{Nrf2}$ is a master switch in the protection against oxidative damage and mediates antioxidant responsive element (ARE)-dependent induction of anti-oxidant enzymes, such as heme oxygenase, catalase, and superoxide dismutase. ${ }^{288}$ GLO1 has an ARE responsive element in its promoter, and it has been shown that activators of Nrf2 increase the levels of GLO1 mRNA, protein, and activity, ${ }^{286}$ and thereby decrease MGO levels. ${ }^{289}$ Increased expression of GLO1 reduces cellular and extracellular concentrations of MGO, MGOderived protein adducts, mutagenesis and cell detachment. ${ }^{286}$ In concurrence with this, GLO1 mRNA and protein levels have been shown to decrease in the liver, brain, heart, kidney, and lung in $\mathrm{Nrf2}^{-/}$mice; urinary excretion of MGO and nucleotide adducts increase by some $100 \% .{ }^{286}$ These findings underline the importance of the regulatory increase of cell defenses against MGO via the Nrf2-ARE-GLO1 pathway. Another Nrf2-inducing compound is bardoxolone methyl, which has mainly been described as a potential treatment of chronic kidney disease. Although bardoxolone methyl has not been described in relation with GLO1 activation so far, its potential to induce Nrf2 may result in GLO1 induction. ${ }^{290-293}$

Based on these findings, bioactive inducers of GLO1 could thus be used for patients with age-related disorders in which MGO play a pivotal role. 


\section{Conclusions and future study}

There is much scientific evidence to suggest that the very reactive glycolytic intermediate MGO engenders the development of multiple health problems and complications. Although MGO can be detoxified endogenously by the glyoxalase system, increased levels of MGO under pathophysiological conditions result in the formation of ROS and AGEs. Accumulation of MGO, ROS, and AGEs in various tissues can subsequently contribute to age-related health problems such as diabetes, cardiovascular disease, cancer and disorders of the central nervous system. Despite the progress made in recent years, further research is needed to pinpoint the underlying mechanisms of how MGO contributes to the development of these diseases. Several pharmacological interventions have been developed to inhibit the accumulation of MGO, of which pyridoxamine is currently regarded as the most important MGO scavenger. From a clinical point of view, the reduction of the accumulation of MGO and the enhancement of GLO1 activity could provide new therapeutic opportunities aimed to reduce the pathophysiological modifications associated with increased levels of MGO. 


\section{References}

1. Singh R, Barden A, Mori T, Beilin L. Advanced glycation end-products: A review. Diabetologia. 2001;44:129-146

2. Brownlee M. Biochemistry and molecular cell biology of diabetic complications. Nature. 2001;414:813-820

3. Westwood ME, Thornalley PJ. Molecular characteristics of methylglyoxal-modified bovine and human serum albumins. Comparison with glucose-derived advanced glycation endproduct-modified serum albumins. J Protein Chem. 1995;14:359-372

4. Phillips SA, Thornalley PJ. The formation of methylglyoxal from triose phosphates. Investigation using a specific assay for methylglyoxal. Eur J Biochem. 1993;212:101-105

5. Ahmed N, Thornalley PJ, Dawczynski J, Franke S, Strobel J, Stein G, Haik GM. Methylglyoxal-derived hydroimidazolone advanced glycation end-products of human lens proteins. Invest Ophthalmol Vis Sci. 2003;44:5287-5292

6. Matafome P, Sena C, Seica R. Methylglyoxal, obesity, and diabetes. Endocrine. 2013;43:472-484

7. Hanssen NM, Stehouwer CD, Schalkwijk CG. Methylglyoxal and glyoxalase $\mathrm{i}$ in atherosclerosis. Biochemical Society transactions. 2014;42:443-449

8. Thornalley PJ, Rabbani N. Glyoxalase in tumourigenesis and multidrug resistance. Seminars in cell \& developmental biology. 2011;22:318-325

9. Srikanth V, Westcott B, Forbes J, Phan TG, Beare R, Venn A, Pearson S, Greenaway T, Parameswaran V, Münch G. Methylglyoxal, cognitive function and cerebral atrophy in older people. The journals of gerontology. Series A, Biological sciences and medical sciences. 2013;68:68-73

10. Sousa Silva M, Gomes RA, Ferreira AE, Ponces Freire A, Cordeiro C. The glyoxalase pathway: The first hundred years... And beyond. Biochem J. 2013;453:1-15

11. Kalapos MP. Methylglyoxal in living organisms: Chemistry, biochemistry, toxicology and biological implications. Toxicology letters. 1999;110:145-175

12. Thornalley PJ. Modification of the glyoxalase system in human red blood cells by glucose in vitro. Biochem J. 1988;254:751-755

13. Thornalley PJ, Langborg A, Minhas HS. Formation of glyoxal, methylglyoxal and 3-deoxyglucosone in the glycation of proteins by glucose. Biochem J. 1999;344 Pt 1:109-116

14. Reichard GA, Jr., Skutches CL, Hoeldtke RD, Owen OE. Acetone metabolism in humans during diabetic ketoacidosis. Diabetes. 1986;35:668-674

15. Lyles GA, Chalmers J. The metabolism of aminoacetone to methylglyoxal by semicarbazide-sensitive amine oxidase in human umbilical artery. Biochem Pharmacol. 1992;43:1409-1414

16. Baynes JW, Thorpe SR. Glycoxidation and lipoxidation in atherogenesis. Free Radic Biol Med. 2000;28:1708-1716

17. Rabbani N, Thornalley PJ. Measurement of methylglyoxal by stable isotopic dilution analysis Ic-ms/ms with corroborative prediction in physiological samples. Nat Protoc. 2014;9:1969-1979

18. Kalapos MP. Where does plasma methylglyoxal originate from? Diabetes Res Clin Pract. 2013;99:260271

19. Degen J, Hellwig M, Henle T. 1,2-dicarbonyl compounds in commonly consumed foods. Journal of agricultural and food chemistry. 2012;60:7071-7079

20. Beisswenger PJ, Howell SK, Touchette AD, Lal S, Szwergold BS. Metformin reduces systemic methylglyoxal levels in type 2 diabetes. Diabetes. 1999;48:198-202

21. Lapolla A, Flamini R, Lupo A, Arico NC, Rugiu C, Reitano R, Tubaro M, Ragazzi E, Seraglia R, Traldi P. Evaluation of glyoxal and methylglyoxal levels in uremic patients under peritoneal dialysis. Annals of the New York Academy of Sciences. 2005;1043:217-224

22. Scheijen JL, Schalkwijk CG. Quantification of glyoxal, methylglyoxal and 3-deoxyglucosone in blood and plasma by ultra performance liquid chromatography tandem mass spectrometry: Evaluation of blood specimen. Clin Chem Lab Med. 2014;52:85-91

23. Beisswenger P, Heine RJ, Leiter LA, Moses A, Tuomilehto J. Prandial glucose regulation in the glucose triad: Emerging evidence and insights. Endocrine. 2004;25:195-202

24. Nakayama K, Nakayama M, Iwabuchi M, Terawaki H, Sato T, Kohno M, Ito S. Plasma alphaoxoaldehyde levels in diabetic and nondiabetic chronic kidney disease patients. Am J Nephrol. 2008;28:871-878 
25. Lu J, Randell E, Han Y, Adeli K, Krahn J, Meng QH. Increased plasma methylglyoxal level, inflammation, and vascular endothelial dysfunction in diabetic nephropathy. Clinical biochemistry. 2011;44:307-311

26. Phillips SA, Mirrlees D, Thornalley PJ. Modification of the glyoxalase system in streptozotocin-induced diabetic rats. Effect of the aldose reductase inhibitor statil. Biochem Pharmacol. 1993;46:805-811

27. Dobler D, Ahmed N, Song L, Eboigbodin KE, Thornalley PJ. Increased dicarbonyl metabolism in endothelial cells in hyperglycemia induces anoikis and impairs angiogenesis by rgd and gfoger motif modification. Diabetes. 2006;55:1961-1969

28. Rabbani N, Thornalley PJ. Glyoxalase in diabetes, obesity and related disorders. Seminars in cell \& developmental biology. 2011;22:309-317

29. Rabbani N, Thornalley PJ. Dicarbonyl proteome and genome damage in metabolic and vascular disease. Biochemical Society transactions. 2014;42:425-432

30. Izaguirre G, Kikonyogo A, Pietruszko R. Methylglyoxal as substrate and inhibitor of human aldehyde dehydrogenase: Comparison of kinetic properties among the three isozymes. Comparative biochemistry and physiology. Part B, Biochemistry \& molecular biology. 1998;119:747-754

31. Rabbani N, Thornalley PJ. Methylglyoxal, glyoxalase 1 and the dicarbonyl proteome. Amino Acids. 2012;42:1133-1142

32. Baba SP, Barski OA, Ahmed Y, O'Toole TE, Conklin DJ, Bhatnagar A, Srivastava S. Reductive metabolism of age precursors: A metabolic route for preventing age accumulation in cardiovascular tissue. Diabetes. 2009;58:2486-2497

33. Lo TW, Westwood ME, McLellan AC, Selwood T, Thornalley PJ. Binding and modification of proteins by methylglyoxal under physiological conditions. A kinetic and mechanistic study with $\mathrm{n}$ alphaacetylarginine, $\mathrm{n}$ alpha-acetylcysteine, and $\mathrm{n}$ alpha-acetyllysine, and bovine serum albumin. $J$ Biol Chem. 1994;269:32299-32305

34. Thornalley PJ, Battah S, Ahmed N, Karachalias N, Agalou S, Babaei-Jadidi R, Dawnay A. Quantitative screening of advanced glycation endproducts in cellular and extracellular proteins by tandem mass spectrometry. Biochem J. 2003;375:581-592

35. Ahmed N, Thornalley PJ. Peptide mapping of human serum albumin modified minimally by methylglyoxal in vitro and in vivo. Annals of the New York Academy of Sciences. 2005;1043:260-266

36. Watanabe H, Tanase S, Nakajou K, Maruyama T, Kragh-Hansen U, Otagiri M. Role of arg-410 and tyr411 in human serum albumin for ligand binding and esterase-like activity. Biochem J. 2000;349 Pt 3:813-819

37. Faure $\mathrm{P}$, Troncy L, Lecomte $\mathrm{M}$, Wiernsperger $\mathrm{N}$, Lagarde $\mathrm{M}$, Ruggiero D, Halimi S. Albumin antioxidant capacity is modified by methylglyoxal. Diabetes Metab. 2005;31:169-177

38. Abordo EA, Thornalley PJ. Synthesis and secretion of tumour necrosis factor-alpha by human monocytic thp-1 cells and chemotaxis induced by human serum albumin derivatives modified with methylglyoxal and glucose-derived advanced glycation endproducts. Immunol Lett. 1997;58:139-147

39. Westwood ME, McLellan AC, Thornalley PJ. Receptor-mediated endocytic uptake of methylglyoxalmodified serum albumin. Competition with advanced glycation end product-modified serum albumin at the advanced glycation end product receptor. J Biol Chem. 1994;269:32293-32298

40. Fan X, Subramaniam R, Weiss MF, Monnier VM. Methylglyoxal-bovine serum albumin stimulates tumor necrosis factor alpha secretion in raw 264.7 cells through activation of mitogen-activating protein kinase, nuclear factor kappab and intracellular reactive oxygen species formation. Arch Biochem Biophys. 2003;409:274-286

41. Westwood ME, Thornalley PJ. Induction of synthesis and secretion of interleukin 1 beta in the human monocytic thp-1 cells by human serum albumins modified with methylglyoxal and advanced glycation endproducts. Immunol Lett. 1996;50:17-21

42. Westwood ME, Argirov OK, Abordo EA, Thornalley PJ. Methylglyoxal-modified arginine residues--a signal for receptor-mediated endocytosis and degradation of proteins by monocytic thp-1 cells. Biochimica et biophysica acta. 1997;1356:84-94

43. Monnier VM, Sell DR, Strauch C, Sun W, Lachin JM, Cleary PA, Genuth S. The association between skin collagen glucosepane and past progression of microvascular and neuropathic complications in type 1 diabetes. J Diabetes Complications. 2013;27:141-149

44. Bose T, Bhattacherjee A, Banerjee S, Chakraborti AS. Methylglyoxal-induced modifications of hemoglobin: Structural and functional characteristics. Arch Biochem Biophys. 2013;529:99-104 
45. Morcos M, Du X, Pfisterer F, Hutter H, Sayed AA, Thornalley P, Ahmed N, Baynes J, Thorpe S, Kukudov G, Schlotterer A, Bozorgmehr F, El Baki RA, Stern D, Moehrlen F, Ibrahim Y, Oikonomou D, Hamann A, Becker C, Zeier M, Schwenger V, Miftari N, Humpert P, Hammes HP, Buechler M, Bierhaus A, Brownlee M, Nawroth PP. Glyoxalase-1 prevents mitochondrial protein modification and enhances lifespan in caenorhabditis elegans. Aging Cell. 2008;7:260-269

46. Queisser MA, Yao D, Geisler S, Hammes HP, Lochnit G, Schleicher ED, Brownlee M, Preissner KT. Hyperglycemia impairs proteasome function by methylglyoxal. Diabetes. 2010;59:670-678

47. Nagaraj RH, Panda AK, Shanthakumar S, Santhoshkumar P, Pasupuleti N, Wang B, Biswas A. Hydroimidazolone modification of the conserved arg12 in small heat shock proteins: Studies on the structure and chaperone function using mutant mimics. PloS one. 2012;7:e30257

48. Xue J, Ray R, Singer D, Bohme D, Burz DS, Rai V, Hoffmann R, Shekhtman A. The receptor for advanced glycation end products (rage) specifically recognizes methylglyoxal-derived ages. Biochemistry. 2014;53:3327-3335

49. Shipanova IN, Glomb MA, Nagaraj RH. Protein modification by methylglyoxal: Chemical nature and synthetic mechanism of a major fluorescent adduct. Arch Biochem Biophys. 1997;344:29-36

50. Oya T, Hattori N, Mizuno Y, Miyata S, Maeda S, Osawa T, Uchida K. Methylglyoxal modification of protein. Chemical and immunochemical characterization of methylglyoxal-arginine adducts. J Biol Chem. 1999;274:18492-18502

51. Oya-Ito T, Liu BF, Nagaraj RH. Effect of methylglyoxal modification and phosphorylation on the chaperone and anti-apoptotic properties of heat shock protein 27. J Cell Biochem. 2006;99:279-291

52. Nagaraj RH, Oya-Ito T, Padayatti PS, Kumar R, Mehta S, West K, Levison B, Sun J, Crabb JW, Padival AK. Enhancement of chaperone function of alpha-crystallin by methylglyoxal modification. Biochemistry. 2003;42:10746-10755

53. Schalkwijk CG, van Bezu J, van der Schors RC, Uchida K, Stehouwer CD, van Hinsbergh VW. Heatshock protein 27 is a major methylglyoxal-modified protein in endothelial cells. FEBS letters. 2006;580:1565-1570

54. Gawlowski T, Stratmann B, Stork I, Engelbrecht B, Brodehl A, Niehaus K, Korfer R, Tschoepe D, Milting $\mathrm{H}$. Heat shock protein 27 modification is increased in the human diabetic failing heart. Horm Metab Res. 2009;41:594-599

55. van Eupen MG, Schram MT, Colhoun HM, Hanssen NM, Niessen HW, Tarnow L, Parving HH, Rossing $P$, Stehouwer CD, Schalkwijk CG. The methylglyoxal-derived age tetrahydropyrimidine is increased in plasma of individuals with type 1 diabetes mellitus and in atherosclerotic lesions and is associated with svcam-1. Diabetologia. 2013;56:1845-1855

56. Ahmed MU, Brinkmann Frye E, Degenhardt TP, Thorpe SR, Baynes JW. N-epsilon-(carboxyethyl)lysine, a product of the chemical modification of proteins by methylglyoxal, increases with age in human lens proteins. Biochem J. 1997;324 ( Pt 2):565-570

57. Frye EB, Degenhardt TP, Thorpe SR, Baynes JW. Role of the maillard reaction in aging of tissue proteins. Advanced glycation end product-dependent increase in imidazolium cross-links in human lens proteins. J Biol Chem. 1998;273:18714-18719

58. Lederer MO, Klaiber RG. Cross-linking of proteins by maillard processes: Characterization and detection of lysine-arginine cross-links derived from glyoxal and methylglyoxal. Bioorg Med Chem. 1999;7:2499-2507

59. Schneider M, Thoss G, Hubner-Parajsz C, Kientsch-Engel R, Stahl P, Pischetsrieder M. Determination of glycated nucleobases in human urine by a new monoclonal antibody specific for n2-carboxyethyl2'-deoxyguanosine. Chem Res Toxicol. 2004;17:1385-1390

60. Synold T, Xi B, Wuenschell GE, Tamae D, Figarola JL, Rahbar S, Termini J. Advanced glycation end products of DNA: Quantification of n2-(1-carboxyethyl)-2'-deoxyguanosine in biological samples by liquid chromatography electrospray ionization tandem mass spectrometry. Chem Res Toxicol. 2008;21:2148-2155

61. Thornalley PJ, Waris S, Fleming T, Santarius T, Larkin SJ, Winklhofer-Roob BM, Stratton MR, Rabbani $\mathrm{N}$. Imidazopurinones are markers of physiological genomic damage linked to DNA instability and glyoxalase 1-associated tumour multidrug resistance. Nucleic Acids Res. 2010;38:5432-5442

62. Murata-Kamiya N, Kamiya H, Kaji H, Kasai H. Methylglyoxal induces g: $\mathrm{C}$ to $\mathrm{c}: \mathrm{G}$ and g:C to t:A transversions in the supf gene on a shuttle vector plasmid replicated in mammalian cells. Mutat Res. 2000;468:173-182

63. Tu CY, Chen YF, Lii CK, Wang TS. Methylglyoxal induces DNA crosslinks in ecv304 cells via a reactive oxygen species-independent protein carbonylation pathway. Toxicol In Vitro. 2013;27:1211-1219 
64. Petrova KV, Millsap AD, Stec DF, Rizzo CJ. Characterization of the deoxyguanosine-lysine cross-link of methylglyoxal. Chem Res Toxicol. 2014;27:1019-1029

65. Mir AR, Uddin M, Alam K, Ali A. Methylglyoxal mediated conformational changes in histone h2ageneration of carboxyethylated advanced glycation end products. Int J Biol Macromol. 2014;69:260266

66. Vander Jagt DL, Daub E, Krohn JA, Han LP. Effects of ph and thiols on the kinetics of yeast glyoxalase i. An evaluation of the random pathway mechanism. Biochemistry. 1975;14:3669-3675

67. Vander Jagt DL, Han LP, Lehman CH. Kinetic evaluation of substrate specificity in the glyoxalase-icatalyzed disproportionation of -ketoaldehydes. Biochemistry. 1972;11:3735-3740

68. Thornalley PJ. Glyoxalase i--structure, function and a critical role in the enzymatic defence against glycation. Biochemical Society transactions. 2003;31:1343-1348

69. Ranganathan S, Ciaccio PJ, Walsh ES, Tew KD. Genomic sequence of human glyoxalase-i: Analysis of promoter activity and its regulation. Gene. 1999;240:149-155

70. Birkenmeier G, Stegemann C, Hoffmann R, Gunther R, Huse K, Birkemeyer C. Posttranslational modification of human glyoxalase 1 indicates redox-dependent regulation. PloS one. 2010;5:e10399

71. Mitsumoto A, Kim KR, Oshima G, Kunimoto M, Okawa K, Iwamatsu A, Nakagawa Y. Glyoxalase i is a novel nitric-oxide-responsive protein. Biochem J. 1999;344 Pt 3:837-844

72. de Hemptinne V, Rondas D, Toepoel M, Vancompernolle K. Phosphorylation on thr-106 and nomodification of glyoxalase $\mathrm{i}$ suppress the tnf-induced transcriptional activity of nf-kappab. Mol Cell Biochem. 2009;325:169-178

73. Van Herreweghe F, Mao J, Chaplen FW, Grooten J, Gevaert K, Vandekerckhove J, Vancompernolle K. Tumor necrosis factor-induced modulation of glyoxalase i activities through phosphorylation by pka results in cell death and is accompanied by the formation of a specific methylglyoxal-derived age. Proceedings of the National Academy of Sciences of the United States of America. 2002;99:949-954

74. Thornalley PJ. The glyoxalase system in health and disease. Molecular aspects of medicine. 1993;14:287-371

75. Atkins TW, Thornally PJ. Erythrocyte glyoxalase activity in genetically obese (ob/ob) and streptozotocin diabetic mice. Diabetes Res. 1989;11:125-129

76. Barati MT, Merchant ML, Kain AB, Jevans AW, McLeish KR, Klein JB. Proteomic analysis defines altered cellular redox pathways and advanced glycation end-product metabolism in glomeruli of db/db diabetic mice. Am J Physiol Renal Physiol. 2007;293:F1157-1165

77. Hanssen NM, Wouters K, Huijberts MS, Gijbels MJ, Sluimer JC, Scheijen JL, Heeneman S, Biessen EA, Daemen MJ, Brownlee M, de Kleijn DP, Stehouwer CD, Pasterkamp G, Schalkwijk CG. Higher levels of advanced glycation endproducts in human carotid atherosclerotic plaques are associated with a rupture-prone phenotype. Eur Heart J. 2014;35:1137-1146

78. Shafie A, Xue M, Thornalley PJ, Rabbani N. Copy number variation of glyoxalase i. Biochemical Society transactions. 2014;42:500-503

79. Peculis R, Konrade I, Skapare E, Fridmanis D, Nikitina-Zake L, Lejnieks A, Pirags V, Dambrova M, Klovins J. Identification of glyoxalase 1 polymorphisms associated with enzyme activity. Gene. 2013;515:140-143

80. Engelen L, Ferreira I, Brouwers O, Henry RM, Dekker JM, Nijpels G, Heine RJ, van Greevenbroek MM, van der Kallen CJ, Blaak EE, Feskens EJ, ten Cate H, Stehouwer CD, Schalkwijk CG. Polymorphisms in glyoxalase 1 gene are not associated with vascular complications: The hoorn and codam studies. $J$ Hypertens. 2009;27:1399-1403

81. Barua M, Jenkins EC, Chen W, Kuizon S, Pullarkat RK, Junaid MA. Glyoxalase i polymorphism rs2736654 causing the ala111glu substitution modulates enzyme activity--implications for autism. Autism Res. 2011;4:262-270

82. Junaid MA, Kowal D, Barua M, Pullarkat PS, Sklower Brooks S, Pullarkat RK. Proteomic studies identified a single nucleotide polymorphism in glyoxalase i as autism susceptibility factor. Am J Med Genet A. 2004;131:11-17

83. Gabriele S, Lombardi F, Sacco R, Napolioni V, Altieri L, Tirindelli MC, Gregorj C, Bravaccio C, Rousseau F, Persico AM. The glo1 c332 (ala111) allele confers autism vulnerability: Family-based genetic association and functional correlates. J Psychiatr Res. 2014

84. Politi P, Minoretti P, Falcone C, Martinelli V, Emanuele E. Association analysis of the functional ala111glu polymorphism of the glyoxalase $\mathrm{i}$ gene in panic disorder. Neuroscience letters. 2006;396:163-166 
85. Agar NS, Board PG, Bell K. Studies of erythrocyte glyoxalase ii in various domestic species: Discovery of glyoxalase ii deficiency in the horse. Animal blood groups and biochemical genetics. 1984;15:67-70

86. Valentine WN, Paglia DE, Neerhout RC, Konrad PN. Erythrocyte glyoxalase ii deficiency with coincidental hereditary elliptocytosis. Blood. 1970;36:797-808

87. Misra K, Banerjee AB, Ray S, Ray M. Glyoxalase iii from escherichia coli: A single novel enzyme for the conversion of methylglyoxal into d-lactate without reduced glutathione. Biochem J. 1995;305 ( Pt 3):999-1003

88. Lee JY, Song J, Kwon K, Jang S, Kim C, Baek K, Kim J, Park C. Human dj-1 and its homologs are novel glyoxalases. Human molecular genetics. 2012;21:3215-3225

89. Danaei G, Finucane MM, Lu Y, Singh GM, Cowan MJ, Paciorek CJ, Lin JK, Farzadfar F, Khang YH, Stevens GA, Rao M, Ali MK, Riley LM, Robinson CA, Ezzati M. National, regional, and global trends in fasting plasma glucose and diabetes prevalence since 1980: Systematic analysis of health examination surveys and epidemiological studies with 370 country-years and 2.7 million participants. Lancet. 2011;378:31-40

90. Shinohara M, Thornalley PJ, Giardino I, Beisswenger P, Thorpe SR, Onorato J, Brownlee M. Overexpression of glyoxalase-i in bovine endothelial cells inhibits intracellular advanced glycation endproduct formation and prevents hyperglycemia-induced increases in macromolecular endocytosis. J Clin Invest. 1998;101:1142-1147

91. Schalkwijk CG, Stehouwer CD. Vascular complications in diabetes mellitus: The role of endothelial dysfunction. Clin Sci (Lond). 2005;109:143-159

92. Eringa EC, Serne EH, Meijer RI, Schalkwijk CG, Houben AJ, Stehouwer CD, Smulders YM, van Hinsbergh VW. Endothelial dysfunction in (pre)diabetes: Characteristics, causative mechanisms and pathogenic role in type 2 diabetes. Rev Endocr Metab Disord. 2013;14:39-48

93. De Bock K, Georgiadou M, Carmeliet P. Role of endothelial cell metabolism in vessel sprouting. Cell Metab. 2013;18:634-647

94. Abebe W, Mozaffari M. Endothelial dysfunction in diabetes: Potential application of circulating markers as advanced diagnostic and prognostic tools. Epma J. 2010;1:32-45

95. Brouwers O, Niessen PM, Haenen G, Miyata T, Brownlee M, Stehouwer CD, De Mey JG, Schalkwijk CG. Hyperglycaemia-induced impairment of endothelium-dependent vasorelaxation in rat mesenteric arteries is mediated by intracellular methylglyoxal levels in a pathway dependent on oxidative stress. Diabetologia. 2010;53:989-1000

96. Berlanga J, Cibrian D, Guillen I, Freyre F, Alba JS, Lopez-Saura P, Merino N, Aldama A, Quintela AM, Triana ME, Montequin JF, Ajamieh H, Urquiza D, Ahmed N, Thornalley PJ. Methylglyoxal administration induces diabetes-like microvascular changes and perturbs the healing process of cutaneous wounds. Clin Sci (Lond). 2005;109:83-95

97. Sena CM, Matafome P, Crisostomo J, Rodrigues L, Fernandes R, Pereira P, Seica RM. Methylglyoxal promotes oxidative stress and endothelial dysfunction. Pharmacol Res. 2012;65:497-506

98. Ahmed U, Dobler D, Larkin SJ, Rabbani N, Thornalley PJ. Reversal of hyperglycemia-induced angiogenesis deficit of human endothelial cells by overexpression of glyoxalase 1 in vitro. Annals of the New York Academy of Sciences. 2008;1126:262-264

99. Brouwers O, Niessen PM, Miyata T, Ostergaard JA, Flyvbjerg A, Peutz-Kootstra CJ, Sieber J, Mundel PH, Brownlee M, Janssen BJ, De Mey JG, Stehouwer CD, Schalkwijk CG. Glyoxalase-1 overexpression reduces endothelial dysfunction and attenuates early renal impairment in a rat model of diabetes. Diabetologia. 2014;57:224-235

100. Miyazawa N, Abe M, Souma T, Tanemoto M, Abe T, Nakayama M, Ito S. Methylglyoxal augments intracellular oxidative stress in human aortic endothelial cells. Free Radic Res. 2010;44:101-107

101. Nagaraj RH, Oya-Ito T, Bhat M, Liu B. Dicarbonyl stress and apoptosis of vascular cells: Prevention by alphab-crystallin. Annals of the New York Academy of Sciences. 2005;1043:158-165

102. Chan WH, Wu HJ. Methylglyoxal and high glucose co-treatment induces apoptosis or necrosis in human umbilical vein endothelial cells. J Cell Biochem. 2008;103:1144-1157

103. Hou SM, Nori P, Fang JL, Vaca CE. Methylglyoxal induces hprt mutation and DNA adducts in human tlymphocytes in vitro. Environ Mol Mutagen. 1995;26:286-291

104. Kang Y, Edwards LG, Thornalley PJ. Effect of methylglyoxal on human leukaemia 60 cell growth: Modification of DNA g1 growth arrest and induction of apoptosis. Leuk Res. 1996;20:397-405

105. Chan WH, Wu HJ, Shiao NH. Apoptotic signaling in methylglyoxal-treated human osteoblasts involves oxidative stress, c-jun n-terminal kinase, caspase-3, and p21-activated kinase 2. J Cell Biochem. 2007;100:1056-1069 
106. Du J, Suzuki H, Nagase F, Akhand AA, Ma XY, Yokoyama T, Miyata T, Nakashima I. Superoxidemediated early oxidation and activation of ask1 are important for initiating methylglyoxal-induced apoptosis process. Free Radic Biol Med. 2001;31:469-478

107. Okado A, Kawasaki Y, Hasuike Y, Takahashi M, Teshima T, Fujii J, Taniguchi N. Induction of apoptotic cell death by methylglyoxal and 3-deoxyglucosone in macrophage-derived cell lines. Biochemical and biophysical research communications. 1996;225:219-224

108. Su Y, Qadri SM, Wu L, Liu L. Methylglyoxal modulates endothelial nitric oxide synthase-associated functions in ea.Hy926 endothelial cells. Cardiovasc Diabetol. 2013;12:134

109. Phalitakul S, Okada M, Hara Y, Yamawaki H. Vaspin prevents methylglyoxal-induced apoptosis in human vascular endothelial cells by inhibiting reactive oxygen species generation. Acta Physiol (Oxf). 2013;209:212-219

110. Chang $\mathrm{T}$, Wang $\mathrm{R}, \mathrm{Wu} \mathrm{L}$. Methylglyoxal-induced nitric oxide and peroxynitrite production in vascular smooth muscle cells. Free Radic Biol Med. 2005;38:286-293

111. Wang $\mathrm{H}$, Meng $\mathrm{QH}$, Chang $\mathrm{T}, \mathrm{Wu}$ L. Fructose-induced peroxynitrite production is mediated by methylglyoxal in vascular smooth muscle cells. Life sciences. 2006;79:2448-2454

112. Chang T, Untereiner A, Liu J, Wu L. Interaction of methylglyoxal and hydrogen sulfide in rat vascular smooth muscle cells. Antioxid Redox Signal. 2010;12:1093-1100

113. Yang Y, Li S, Konduru AS, Zhang S, Trower TC, Shi W, Cui N, Yu L, Wang Y, Zhu D, Jiang C. Prolonged exposure to methylglyoxal causes disruption of vascular katp channel by mrna instability. Am J Physiol Cell Physiol. 2012;303:C1045-1054

114. Forbes JM, Cooper ME. Mechanisms of diabetic complications. Physiol Rev. 2013;93:137-188

115. Lu J, Randell E, Han Y, Adeli K, Krahn J, Meng QH. Increased plasma methylglyoxal level, inflammation, and vascular endothelial dysfunction in diabetic nephropathy. Clinical biochemistry. 2011;44:307-311

116. Nakayama K, Nakayama M, Iwabuchi M, Terawaki H, Sato T, Kohno M, Ito S. Plasma alphaoxoaldehyde levels in diabetic and nondiabetic chronic kidney disease patients. Am J Nephrol. 2008;28:871-878

117. Beisswenger PJ, Drummond KS, Nelson RG, Howell SK, Szwergold BS, Mauer M. Susceptibility to diabetic nephropathy is related to dicarbonyl and oxidative stress. Diabetes. 2005;54:3274-3281

118. Beisswenger PJ, Howell SK, Russell GB, Miller ME, Rich SS, Mauer M. Early progression of diabetic nephropathy correlates with methylglyoxal-derived advanced glycation end products. Diabetes Care. 2013;36:3234-3239

119. Yao D, Taguchi T, Matsumura T, Pestell R, Edelstein D, Giardino I, Suske G, Rabbani N, Thornalley PJ, Sarthy VP, Hammes HP, Brownlee M. High glucose increases angiopoietin-2 transcription in microvascular endothelial cells through methylglyoxal modification of msin3a. J Biol Chem. 2007;282:31038-31045

120. Rosca MG, Monnier VM, Szweda LI, Weiss MF. Alterations in renal mitochondrial respiration in response to the reactive oxoaldehyde methylglyoxal. Am J Physiol Renal Physiol. 2002;283:F52-59

121. Geoffrion M, Du X, Irshad Z, Vanderhyden BC, Courville K, Sui G, D'Agati VD, Ott-Braschi S, Rabbani N, Thornalley PJ, Brownlee M, Milne RW. Differential effects of glyoxalase 1 overexpression on diabetic atherosclerosis and renal dysfunction in streptozotocin-treated, apolipoprotein e-deficient mice. Physiol Rep. 2014;2

122. Liu Y-WW, Zhu X, Zhang L, Lu Q, Wang J-YY, Zhang F, Guo H, Yin J-LL, Yin X-XX. Up-regulation of glyoxalase 1 by mangiferin prevents diabetic nephropathy progression in streptozotocin-induced diabetic rats. European journal of pharmacology. 2013;721:355-364

123. Giacco F, Du X, D'Agati VD, Milne R, Sui G, Geoffrion M, Brownlee M. Knockdown of glyoxalase 1 mimics diabetic nephropathy in nondiabetic mice. Diabetes. 2014;63:291-299

124. Kumagai T, Nangaku M, Kojima I, Nagai R, Ingelfinger JR, Miyata T, Fujita T, Inagi R. Glyoxalase i overexpression ameliorates renal ischemia-reperfusion injury in rats. Am J Physiol Renal Physiol. 2009;296:F912-921

125. Bourne RR, Jonas JB, Flaxman SR, Keeffe J, Leasher J, Naidoo K, Parodi MB, Pesudovs K, Price H, White RA, Wong TY, Resnikoff S, Taylor HR. Prevalence and causes of vision loss in high-income countries and in eastern and central europe: 1990-2010. Br J Ophthalmol. 2014;98:629-638

126. Cheung N, Mitchell P, Wong TY. Diabetic retinopathy. Lancet. 2010;376:124-136

127. Fosmark DS, Berg JP, Jensen A-BB, Sandvik L, Agardh E, Agardh C-DD, Hanssen KF. Increased retinopathy occurrence in type 1 diabetes patients with increased serum levels of the advanced glycation endproduct hydroimidazolone. Acta ophthalmologica. 2009;87:498-500 
128. Fosmark DS, Torjesen PA, Kilhovd BK, Berg TJ, Sandvik L, Hanssen KF, Agardh C-DD, Agardh E. Increased serum levels of the specific advanced glycation end product methylglyoxal-derived hydroimidazolone are associated with retinopathy in patients with type 2 diabetes mellitus. Metabolism: clinical and experimental. 2006;55:232-236

129. Karachalias N, Babaei-Jadidi R, Ahmed N, Thornalley PJ. Accumulation of fructosyl-lysine and advanced glycation end products in the kidney, retina and peripheral nerve of streptozotocin-induced diabetic rats. Biochemical Society transactions. 2003;31:1423-1425

130. Padayatti PS, Jiang C, Glomb MA, Uchida K, Nagaraj RH. High concentrations of glucose induce synthesis of argpyrimidine in retinal endothelial cells. Current eye research. 2001;23:106-115

131. Bento CF, Fernandes R, Matafome P, Sena C, Seiça R, Pereira P. Methylglyoxal-induced imbalance in the ratio of vascular endothelial growth factor to angiopoietin 2 secreted by retinal pigment epithelial cells leads to endothelial dysfunction. Experimental physiology. 2010;95:955-970

132. Liu B, Bhat M, Padival AK, Smith DG, Nagaraj RH. Effect of dicarbonyl modification of fibronectin on retinal capillary pericytes. Invest Ophthalmol Vis Sci. 2004;45:1983-1995

133. Miller AG, Smith DG, Bhat M, Nagaraj RH. Glyoxalase $i$ is critical for human retinal capillary pericyte survival under hyperglycemic conditions. J Biol Chem. 2006;281:11864-11871

134. Berner AK, Brouwers O, Pringle R, Klaassen I, Colhoun L, McVicar C, Brockbank S, Curry JW, Miyata T, Brownlee M, Schlingemann RO, Schalkwijk C, Stitt AW. Protection against methylglyoxal-derived ages by regulation of glyoxalase 1 prevents retinal neuroglial and vasodegenerative pathology. Diabetologia. 2012;55:845-854

135. Wang J, Lin J, Schlotterer A, Wu L, Fleming T, Busch S, Dietrich N, Hammes HP. Cd74 indicates microglial activation in experimental diabetic retinopathy and exogenous methylglyoxal mimics the response in normoglycemic retina. Acta Diabetol. 2014;51:813-821

136. Wang YH, Han YP, Yu HT, Pu XP, Du GH. Protocatechualdehyde prevents methylglyoxal-induced mitochondrial dysfunction and ages-rage axis activation in human lens epithelial cells. European journal of pharmacology. 2014;738:374-383

137. Kim J, Kim NH, Sohn E, Kim CS, Kim JS. Methylglyoxal induces cellular damage by increasing argpyrimidine accumulation and oxidative DNA damage in human lens epithelial cells. Biochemical and biophysical research communications. 2010;391:346-351

138. Kim J, Kim OS, Kim CS, Sohn E, Jo K, Kim JS. Accumulation of argpyrimidine, a methylglyoxal-derived advanced glycation end product, increases apoptosis of lens epithelial cells both in vitro and in vivo. Exp Mol Med. 2012;44:167-175

139. Sugimoto K, Yasujima M, Yagihashi S. Role of advanced glycation end products in diabetic neuropathy. Curr Pharm Des. 2008;14:953-961

140. Bierhaus A, Fleming T, Stoyanov S, Leffler A, Babes A, Neacsu C, Sauer SK, Eberhardt M, Schnölzer M, Lasitschka F, Lasischka F, Neuhuber WL, Kichko TI, Konrade I, Elvert R, Mier W, Pirags V, Lukic IK, Morcos M, Dehmer T, Rabbani N, Thornalley PJ, Edelstein D, Nau C, Forbes J, Humpert PM, Schwaninger M, Ziegler D, Stern DM, Cooper ME, Haberkorn U, Brownlee M, Reeh PW, Nawroth PP. Methylglyoxal modification of nav1.8 facilitates nociceptive neuron firing and causes hyperalgesia in diabetic neuropathy. Nature medicine. 2012;18:926-933

141. Genuth S, Sun W, Cleary P, Gao X, Sell DR, Lachin J, Monnier VM. Skin advanced glycation endproducts (ages) glucosepane and methylglyoxal hydroimidazolone are independently associated with long-term microvascular complication progression of type i diabetes. Diabetes. 2014

142. Fukunaga M, Miyata S, Liu BF, Miyazaki H, Hirota Y, Higo S, Hamada Y, Ueyama S, Kasuga M. Methylglyoxal induces apoptosis through activation of p38 mapk in rat schwann cells. Biochemical and biophysical research communications. 2004;320:689-695

143. Lee HK, Seo IA, Suh DJ, Lee HJ, Park HT. A novel mechanism of methylglyoxal cytotoxicity in neuroglial cells. Journal of neurochemistry. 2009;108:273-284

144. Ohkawara S, Tanaka-Kagawa T, Furukawa Y, Jinno H. Methylglyoxal activates the human transient receptor potential ankyrin 1 channel. The Journal of toxicological sciences. 2012;37:831-835

145. Andersson DA, Gentry C, Light E, Vastani N, Vallortigara J, Bierhaus A, Fleming T, Bevan S. Methylglyoxal evokes pain by stimulating trpa1. PloS one. 2013;8

146. Koivisto A, Hukkanen M, Saarnilehto M, Chapman H, Kuokkanen K, Wei H, Viisanen H, Akerman KE, Lindstedt K, Pertovaara A. Inhibiting trpa1 ion channel reduces loss of cutaneous nerve fiber function in diabetic animals: Sustained activation of the trpa1 channel contributes to the pathogenesis of peripheral diabetic neuropathy. Pharmacol Res. 2012;65:149-158 
147. Eberhardt MJ, Filipovic MR, Leffler A, de la Roche J, Kistner K, Fischer MJ, Fleming T, Zimmermann K, Ivanovic-Burmazovic I, Nawroth PP, Bierhaus A, Reeh PW, Sauer SK. Methylglyoxal activates nociceptors through transient receptor potential channel a1 (trpa1): A possible mechanism of metabolic neuropathies. J Biol Chem. 2012;287:28291-28306

148. Jack M, Wright D. Role of advanced glycation endproducts and glyoxalase $\mathrm{i}$ in diabetic peripheral sensory neuropathy. Translational research : the journal of laboratory and clinical medicine. 2012;159:355-365

149. Grundy SM, Benjamin IJ, Burke GL, Chait A, Eckel RH, Howard BV, Mitch W, Smith SC, Jr., Sowers JR. Diabetes and cardiovascular disease: A statement for healthcare professionals from the american heart association. Circulation. 1999;100:1134-1146

150. Ross R. Atherosclerosis--an inflammatory disease. N Engl J Med. 1999;340:115-126

151. Virmani R, Burke AP, Farb A, Kolodgie FD. Pathology of the vulnerable plaque. Journal of the American College of Cardiology. 2006;47:C13-18

152. Rudd JH, Warburton EA, Fryer TD, Jones HA, Clark JC, Antoun N, Johnstrom P, Davenport AP, Kirkpatrick PJ, Arch BN, Pickard JD, Weissberg PL. Imaging atherosclerotic plaque inflammation with [18f]-fluorodeoxyglucose positron emission tomography. Circulation. 2002;105:2708-2711

153. Basta G, Schmidt AM, De Caterina R. Advanced glycation end products and vascular inflammation: Implications for accelerated atherosclerosis in diabetes. Cardiovasc Res. 2004;63:582-592

154. Kume S, Takeya M, Mori T, Araki N, Suzuki H, Horiuchi S, Kodama T, Miyauchi Y, Takahashi K. Immunohistochemical and ultrastructural detection of advanced glycation end products in atherosclerotic lesions of human aorta with a novel specific monoclonal antibody. Am J Pathol. 1995;147:654-667

155. Baidoshvili A, Niessen HW, Stooker W, Huybregts RA, Hack CE, Rauwerda JA, Meijer CJ, Eijsman L, van Hinsbergh VW, Schalkwijk CG. N(omega)-(carboxymethyl)lysine depositions in human aortic heart valves: Similarities with atherosclerotic blood vessels. Atherosclerosis. 2004;174:287-292

156. Tikellis C, Pickering RJ, Tsorotes D, Huet O, Cooper ME, Jandeleit-Dahm K, Thomas MC. Dicarbonyl stress in the absence of hyperglycemia increases endothelial inflammation and atherogenesis similar to that observed in diabetes. Diabetes. 2014

157. Ogawa S, Nakayama K, Nakayama M, Mori T, Matsushima M, Okamura M, Senda M, Nako K, Miyata $\mathrm{T}$, Ito $\mathrm{S}$. Methylglyoxal is a predictor in type 2 diabetic patients of intima-media thickening and elevation of blood pressure. Hypertension. 2010;56:471-476

158. Schalkwijk CG, Vermeer MA, Stehouwer CD, te Koppele J, Princen HM, van Hinsbergh VW. Effect of methylglyoxal on the physico-chemical and biological properties of low-density lipoprotein. Biochimica et biophysica acta. 1998;1394:187-198

159. Rabbani N, Godfrey L, Xue M, Shaheen F, Geoffrion M, Milne R, Thornalley PJ. Glycation of Idl by methylglyoxal increases arterial atherogenicity: A possible contributor to increased risk of cardiovascular disease in diabetes. Diabetes. 2011;60:1973-1980

160. Turk Z, Cavlovic-Naglic M, Turk N. Relationship of methylglyoxal-adduct biogenesis to Idl and triglyceride levels in diabetics. Life sciences. 2011;89:485-490

161. Brown BE, Dean RT, Davies MJ. Glycation of low-density lipoproteins by methylglyoxal and glycolaldehyde gives rise to the in vitro formation of lipid-laden cells. Diabetologia. 2005;48:361-369

162. Rabbani N, Chittari MV, Bodmer CW, Zehnder D, Ceriello A, Thornalley PJ. Increased glycation and oxidative damage to apolipoprotein b100 of Idl cholesterol in patients with type 2 diabetes and effect of metformin. Diabetes. 2010;59:1038-1045

163. Rye KA, Bursill CA, Lambert G, Tabet F, Barter PJ. The metabolism and anti-atherogenic properties of hdl. J Lipid Res. 2009;50 Suppl:S195-200

164. Godfrey L, Yamada-Fowler N, Smith J, Thornalley PJ, Rabbani N. Arginine-directed glycation and decreased hdl plasma concentration and functionality. Nutr Diabetes. 2014;4:e134

165. Bacchetti T, Masciangelo S, Armeni T, Bicchiega V, Ferretti G. Glycation of human high density lipoprotein by methylglyoxal: Effect on hdl-paraoxonase activity. Metabolism: clinical and experimental. 2014;63:307-311

166. Cantero AV, Portero-Otin M, Ayala V, Auge N, Sanson M, Elbaz M, Thiers JC, Pamplona R, Salvayre R, Negre-Salvayre A. Methylglyoxal induces advanced glycation end product (ages) formation and dysfunction of pdgf receptor-beta: Implications for diabetic atherosclerosis. Faseb J. 2007;21:30963106 
167. Hanssen NM, Brouwers O, Gijbels MJ, Wouters K, Wijnands E, Cleutjens JP, De Mey JG, Miyata T, Biessen EA, Stehouwer CD, Schalkwijk CG. Glyoxalase 1 overexpression does not affect atherosclerotic lesion size and severity in apoe-/- mice with or without diabetes. Cardiovasc Res. 2014

168. Thangarajah H, Yao D, Chang El, Shi Y, Jazayeri L, Vial IN, Galiano RD, Du XL, Grogan R, Galvez MG, Januszyk M, Brownlee M, Gurtner GC. The molecular basis for impaired hypoxia-induced vegf expression in diabetic tissues. Proceedings of the National Academy of Sciences of the United States of America. 2009;106:13505-13510

169. Ceradini DJ, Yao D, Grogan RH, Callaghan MJ, Edelstein D, Brownlee M, Gurtner GC. Decreasing intracellular superoxide corrects defective ischemia-induced new vessel formation in diabetic mice. $J$ Biol Chem. 2008;283:10930-10938

170. Shao CH, Capek HL, Patel KP, Wang M, Tang K, DeSouza C, Nagai R, Mayhan W, Periasamy M, Bidasee KR. Carbonylation contributes to serca2a activity loss and diastolic dysfunction in a rat model of type 1 diabetes. Diabetes. 2011;60:947-959

171. Brouwers $\mathrm{O}$, de Vos-Houben JM, Niessen PM, Miyata T, van Nieuwenhoven F, Janssen BJ, Hageman G, Stehouwer CD, Schalkwijk CG. Mild oxidative damage in the diabetic rat heart is attenuated by glyoxalase-1 overexpression. Int J Mol Sci. 2013;14:15724-15739

172. Haslam DW, James WP. Obesity. Lancet. 2005;366:1197-1209

173. Jia X, Chang T, Wilson TW, Wu L. Methylglyoxal mediates adipocyte proliferation by increasing phosphorylation of akt1. PLoS One. 2012;7:e36610

174. Rodrigues L, Matafome P, Crisostomo J, Santos-Silva D, Sena C, Pereira P, Seica R. Advanced glycation end products and diabetic nephropathy: A comparative study using diabetic and normal rats with methylglyoxal-induced glycation. Journal of physiology and biochemistry. 2014;70:173-184

175. Crisostomo J, Matafome P, Santos-Silva D, Rodrigues L, Sena CM, Pereira P, Seica R. Methylglyoxal chronic administration promotes diabetes-like cardiac ischaemia disease in wistar normal rats. Nutrition, metabolism, and cardiovascular diseases : NMCD. 2013;23:1223-1230

176. Rodrigues T, Matafome P, Santos-Silva D, Sena C, Seica R. Reduction of methylglyoxal-induced glycation by pyridoxamine improves adipose tissue microvascular lesions. Journal of diabetes research. 2013;2013:690650

177. Rodrigues T, Matafome P, Seica R. Methylglyoxal further impairs adipose tissue metabolism after partial decrease of blood supply. Archives of physiology and biochemistry. 2013;119:209-218

178. Kim DH, Joo JI, Choi JW, Yun JW. Differential expression of skeletal muscle proteins in high-fat dietfed rats in response to capsaicin feeding. Proteomics. 2010

179. Schalkwijk CG, Brouwers O, Stehouwer CD. Modulation of insulin action by advanced glycation endproducts: A new player in the field. Horm Metab Res. 2008;40:614-619

180. Dhar A, Dhar I, Desai KM, Wu L. Methylglyoxal scavengers attenuate endothelial dysfunction induced by methylglyoxal and high concentrations of glucose. Br J Pharmacol. 2010;161:1843-1856

181. Jia X, Wu L. Accumulation of endogenous methylglyoxal impaired insulin signaling in adipose tissue of fructose-fed rats. Mol Cell Biochem. 2007;306:133-139

182. Dhar A, Dhar I, Jiang B, Desai KM, Wu L. Chronic methylglyoxal infusion by minipump causes pancreatic beta-cell dysfunction and induces type 2 diabetes in sprague-dawley rats. Diabetes. 2011;60:899-908

183. Guo Q, Mori T, Jiang Y, Hu C, Osaki Y, Yoneki Y, Sun Y, Hosoya T, Kawamata A, Ogawa S, Nakayama M, Miyata $\mathrm{T}$, Ito $\mathrm{S}$. Methylglyoxal contributes to the development of insulin resistance and salt sensitivity in sprague-dawley rats. J Hypertens. 2009;27:1664-1671

184. Maessen DEM, Scheijen JLJM, Gaens KH, Van Greevenbroek MMJ, Van der Kallen CJ, Stehouwer CD, Schalkwijk CG. Higher plasma concentrations of the methylglyoxal metabolite d-lactate are independently associated with insulin resistance: The codam study. J Diabetes Metab. 2014;5

185. Jia X, Olson DJ, Ross AR, Wu L. Structural and functional changes in human insulin induced by methylglyoxal. Faseb J. 2006;20:1555-1557

186. Riboulet-Chavey A, Pierron A, Durand I, Murdaca J, Giudicelli J, Van Obberghen E. Methylglyoxal impairs the insulin signaling pathways independently of the formation of intracellular reactive oxygen species. Diabetes. 2006;55:1289-1299

187. Fiory F, Lombardi A, Miele C, Giudicelli J, Beguinot F, Van Obberghen E. Methylglyoxal impairs insulin signalling and insulin action on glucose-induced insulin secretion in the pancreatic beta cell line ins1e. Diabetologia. 2011;54:2941-2952 
188. Nigro C, Raciti GA, Leone A, Fleming TH, Longo M, Prevenzano I, Fiory F, Mirra P, D'Esposito V, Ulianich L, Nawroth PP, Formisano P, Beguinot F, Miele C. Methylglyoxal impairs endothelial insulin sensitivity both in vitro and in vivo. Diabetologia. 2014;57:1485-1494

189. Deichen JT, Prante O, Gack M, Schmiedehausen K, Kuwert T. Uptake of [18f]fluorodeoxyglucose in human monocyte-macrophages in vitro. Eur J Nucl Med Mol Imaging. 2003;30:267-273

190. Schalkwijk CG, Vermeer MA, Stehouwer CD, te Koppele J, Princen HM, van Hinsbergh VW. Effect of methylglyoxal on the physico-chemical and biological properties of low-density lipoprotein. Biochim Biophys Acta. 1998;1394:187-198

191. Wu L, Juurlink BH. Increased methylglyoxal and oxidative stress in hypertensive rat vascular smooth muscle cells. Hypertension. 2002;39:809-814

192. Wang X, Desai K, Clausen JT, Wu L. Increased methylglyoxal and advanced glycation end products in kidney from spontaneously hypertensive rats. Kidney Int. 2004;66:2315-2321

193. Wang X, Desai K, Chang T, Wu L. Vascular methylglyoxal metabolism and the development of hypertension. J Hypertens. 2005;23:1565-1573

194. Vasdev S, Ford CA, Longerich L, Parai S, Gadag V, Wadhawan S. Aldehyde induced hypertension in rats: Prevention by n-acetyl cysteine. Artery. 1998;23:10-36

195. Dhar I, Dhar A, Wu L, Desai KM. Methylglyoxal, a reactive glucose metabolite, increases renin angiotensin aldosterone and blood pressure in male sprague-dawley rats. Am J Hypertens. 2014;27:308-316

196. Guo Q, Mori T, Jiang $Y$, Hu C, Ohsaki Y, Yoneki $Y$, Nakamichi T, Ogawa S, Sato H, Ito S. Losartan modulates muscular capillary density and reverses thiazide diuretic-exacerbated insulin resistance in fructose-fed rats. Hypertens Res. 2012;35:48-54

197. Sanchez-Lozada LG, Tapia E, Jimenez A, Bautista P, Cristobal M, Nepomuceno T, Soto V, Avila-Casado C, Nakagawa T, Johnson RJ, Herrera-Acosta J, Franco M. Fructose-induced metabolic syndrome is associated with glomerular hypertension and renal microvascular damage in rats. Am J Physiol Renal Physiol. 2007;292:F423-429

198. Chen X, Mori T, Guo Q, Hu C, Ohsaki Y, Yoneki Y, Zhu W, Jiang Y, Endo S, Nakayama K, Ogawa S, Nakayama M, Miyata T, Ito S. Carbonyl stress induces hypertension and cardio-renal vascular injury in dahl salt-sensitive rats. Hypertens Res. 2013;36:361-367

199. Wang X, Chang T, Jiang B, Desai K, Wu L. Attenuation of hypertension development by aminoguanidine in spontaneously hypertensive rats: Role of methylglyoxal. Am J Hypertens. 2007;20:629-636

200. Wang X, Jia X, Chang T, Desai K, Wu L. Attenuation of hypertension development by scavenging methylglyoxal in fructose-treated rats. J Hypertens. 2008;26:765-772

201. International agency for research on cancer. World cancer report 2014. World Health Organization; 2014.

202. Hosoda F, Arai Y, Okada N, Shimizu H, Miyamoto M, Kitagawa N, Katai H, Taniguchi H, Yanagihara K, Imoto I, Inazawa J, Ohki M, Shibata T. Integrated genomic and functional analyses reveal glyoxalase i as a novel metabolic oncogene in human gastric cancer. Oncogene. 2014

203. Antognelli C, Mezzasoma L, Fettucciari K, Mearini E, Talesa VN. Role of glyoxalase i in the proliferation and apoptosis control of human Incap and pc3 prostate cancer cells. Prostate. 2013;73:121-132

204. Loarca L, Sassi-Gaha S, Artlett CM. Two alpha-dicarbonyls downregulate migration, invasion, and adhesion of liver cancer cells in a p53-dependent manner. Dig Liver Dis. 2013;45:938-946

205. Antognelli C, Mezzasoma L, Fettucciari K, Talesa VN. A novel mechanism of methylglyoxal cytotoxicity in prostate cancer cells. Int J Biochem Cell Biol. 2013;45:836-844

206. van Heijst JW, Niessen HW, Musters RJ, van Hinsbergh VW, Hoekman K, Schalkwijk CG. Argpyrimidine-modified heat shock protein 27 in human non-small cell lung cancer: A possible mechanism for evasion of apoptosis. Cancer Lett. 2006;241:309-319

207. Ranganathan S, Walsh ES, Tew KD. Glyoxalase i in detoxification: Studies using a glyoxalase i transfectant cell line. Biochem J. 1995;309 ( Pt 1):127-131

208. Thornalley PJ, Edwards LG, Kang Y, Wyatt C, Davies N, Ladan MJ, Double J. Antitumour activity of s-pbromobenzylglutathione cyclopentyl diester in vitro and in vivo. Inhibition of glyoxalase $\mathrm{i}$ and induction of apoptosis. Biochem Pharmacol. 1996;51:1365-1372

209. Speer O, Morkunaite-Haimi S, Liobikas J, Franck M, Hensbo L, Linder MD, Kinnunen PK, Wallimann T, Eriksson $\mathrm{O}$. Rapid suppression of mitochondrial permeability transition by methylglyoxal. Role of reversible arginine modification. J Biol Chem. 2003;278:34757-34763 
210. Bartyik K, Turi S, Orosz F, Karg E. Methotrexate inhibits the glyoxalase system in vivo in children with acute lymphoid leukaemia. Eur J Cancer. 2004;40:2287-2292

211. Santel T, Pflug G, Hemdan NY, Schafer A, Hollenbach M, Buchold M, Hintersdorf A, Lindner I, Otto A, Bigl M, Oerlecke I, Hutschenreuther A, Sack U, Huse K, Groth M, Birkemeyer C, Schellenberger W, Gebhardt R, Platzer M, Weiss T, Vijayalakshmi MA, Kruger M, Birkenmeier G. Curcumin inhibits glyoxalase 1: A possible link to its anti-inflammatory and anti-tumor activity. PloS one. 2008;3:e3508

212. Yuan $M$, Luo $M$, Song $Y, X u Q$, Wang $X$, Cao $Y, B u X$, Ren $Y$, Hu X. Identification of curcumin derivatives as human glyoxalase $\mathrm{i}$ inhibitors: A combination of biological evaluation, molecular docking, 3d-qsar and molecular dynamics simulation studies. Bioorg Med Chem. 2011;19:1189-1196

213. Chen F, Wollmer MA, Hoerndli F, Munch G, Kuhla B, Rogaev El, Tsolaki M, Papassotiropoulos A, Gotz J. Role for glyoxalase i in alzheimer's disease. Proceedings of the National Academy of Sciences of the United States of America. 2004;101:7687-7692

214. Beeri MS, Moshier E, Schmeidler J, Godbold J, Uribarri J, Reddy S, Sano M, Grossman HT, Cai W, Vlassara $\mathrm{H}$, Silverman JM. Serum concentration of an inflammatory glycotoxin, methylglyoxal, is associated with increased cognitive decline in elderly individuals. Mech Ageing Dev. 2011;132:583587

215. Srikanth V, Westcott B, Forbes J, Phan TG, Beare R, Venn A, Pearson S, Greenaway T, Parameswaran $\mathrm{V}$, Munch G. Methylglyoxal, cognitive function and cerebral atrophy in older people. The journals of gerontology. Series A, Biological sciences and medical sciences. 2013;68:68-73

216. Angeloni C, Zambonin L, Hrelia S. Role of methylglyoxal in alzheimer's disease. Biomed Res Int. 2014;2014:238485

217. Ahmed N, Ahmed U, Thornalley PJ, Hager K, Fleischer G, Munch G. Protein glycation, oxidation and nitration adduct residues and free adducts of cerebrospinal fluid in alzheimer's disease and link to cognitive impairment. Journal of neurochemistry. 2005;92:255-263

218. Tajes M, Eraso-Pichot A, Rubio-Moscardo F, Guivernau B, Bosch-Morato M, Valls-Comamala V, Munoz FJ. Methylglyoxal reduces mitochondrial potential and activates bax and caspase- 3 in neurons: Implications for alzheimer's disease. Neuroscience letters. 2014;580:78-82

219. Cardoso S, Carvalho C, Marinho R, Simoes A, Sena CM, Matafome P, Santos MS, Seica RM, Moreira PI. Effects of methylglyoxal and pyridoxamine in rat brain mitochondria bioenergetics and oxidative status. J Bioenerg Biomembr. 2014;46:347-355

220. Markesbery WR. Oxidative stress hypothesis in alzheimer's disease. Free Radic Biol Med. 1997;23:134-147

221. Lloret A, Badia MC, Mora NJ, Pallardo FV, Alonso MD, Vina J. Vitamin e paradox in alzheimer's disease: It does not prevent loss of cognition and may even be detrimental. J Alzheimers Dis. 2009;17:143-149

222. Kuhla B, Boeck K, Schmidt A, Ogunlade V, Arendt T, Munch G, Luth HJ. Age- and stage-dependent glyoxalase i expression and its activity in normal and alzheimer's disease brains. Neurobiology of aging. 2007;28:29-41

223. Auburger G, Kurz A. The role of glyoxalases for sugar stress and aging, with relevance for dyskinesia, anxiety, dementia and parkinson's disease. Aging (Albany NY). 2011;3:5-9

224. Kurz A, Rabbani N, Walter M, Bonin M, Thornalley P, Auburger G, Gispert S. Alpha-synuclein deficiency leads to increased glyoxalase $\mathrm{i}$ expression and glycation stress. Cell Mol Life Sci. 2011;68:721-733

225. Hipkiss AR. Aging risk factors and parkinson's disease: Contrasting roles of common dietary constituents. Neurobiology of aging. 2014;35:1469-1472

226. Arai M, Yuzawa H, Nohara I, Ohnishi T, Obata N, Iwayama $Y$, Haga S, Toyota T, Ujike H, Ichikawa T, Nishida A, Tanaka Y, Furukawa A, Aikawa Y, Kuroda O, Niizato K, Izawa R, Nakamura K, Mori N, Matsuzawa D, Hashimoto K, Iyo M, Sora I, Matsushita M, Okazaki Y, Yoshikawa T, Miyata T, Itokawa M. Enhanced carbonyl stress in a subpopulation of schizophrenia. Arch Gen Psychiatry. 2010;67:589597

227. Toyosima M, Maekawa M, Toyota $T$, Iwayama $Y$, Arai M, Ichikawa $T$, Miyashita $M$, Arinami T, Itokawa M, Yoshikawa T. Schizophrenia with the 22q11.2 deletion and additional genetic defects: Case history. Br J Psychiatry. 2011;199:245-246

228. Kromer SA, Kessler MS, Milfay D, Birg IN, Bunck M, Czibere L, Panhuysen M, Putz B, Deussing JM, Holsboer F, Landgraf R, Turck CW. Identification of glyoxalase-i as a protein marker in a mouse model of extremes in trait anxiety. J Neurosci. 2005;25:4375-4384 
229. Hovatta I, Tennant RS, Helton R, Marr RA, Singer O, Redwine JM, Ellison JA, Schadt EE, Verma IM, Lockhart DJ, Barlow C. Glyoxalase 1 and glutathione reductase 1 regulate anxiety in mice. Nature. 2005;438:662-666

230. Ditzen C, Jastorff AM, Kessler MS, Bunck M, Teplytska L, Erhardt A, Kromer SA, Varadarajulu J, Targosz BS, Sayan-Ayata EF, Holsboer F, Landgraf R, Turck CW. Protein biomarkers in a mouse model of extremes in trait anxiety. Mol Cell Proteomics. 2006;5:1914-1920

231. Williams Rt, Lim JE, Harr B, Wing C, Walters R, Distler MG, Teschke M, Wu C, Wiltshire T, Su Al, Sokoloff G, Tarantino LM, Borevitz JO, Palmer AA. A common and unstable copy number variant is associated with differences in glo1 expression and anxiety-like behavior. PloS one. 2009;4:e4649

232. Hambsch B, Chen BG, Brenndorfer J, Meyer M, Avrabos C, Maccarrone G, Liu RH, Eder M, Turck CW, Landgraf R. Methylglyoxal-mediated anxiolysis involves increased protein modification and elevated expression of glyoxalase 1 in the brain. Journal of neurochemistry. 2010;113:1240-1251

233. Distler MG, Plant LD, Sokoloff G, Hawk AJ, Aneas I, Wuenschell GE, Termini J, Meredith SC, Nobrega MA, Palmer AA. Glyoxalase 1 increases anxiety by reducing gabaa receptor agonist methylglyoxal. $J$ Clin Invest. 2012;122:2306-2315

234. Poggioli S, Bakala H, Friguet B. Age-related increase of protein glycation in peripheral blood lymphocytes is restricted to preferential target proteins. Exp Gerontol. 2002;37:1207-1215

235. Xue M, Rabbani N, Thornalley PJ. Glyoxalase in ageing. Seminars in cell \& developmental biology. 2011;22:293-301

236. Kirk JE. The glyoxalase i activity of arterial tissue in individuals of various ages. J Gerontol. 1960;15:139-141

237. McLellan AC, Thornalley PJ. Glyoxalase activity in human red blood cells fractioned by age. Mech Ageing Dev. 1989;48:63-71

238. Kuhla B, Boeck K, Luth HJ, Schmidt A, Weigle B, Schmitz M, Ogunlade V, Munch G, Arendt T. Agedependent changes of glyoxalase $i$ expression in human brain. Neurobiology of aging. 2006;27:815822

239. Schlotterer A, Kukudov G, Bozorgmehr F, Hutter $H, D u$ X, Oikonomou D, Ibrahim $Y$, Pfisterer $F$, Rabbani N, Thornalley P, Sayed A, Fleming T, Humpert P, Schwenger V, Zeier M, Hamann A, Stern D, Brownlee $M$, Bierhaus A, Nawroth $P$, Morcos $M$. C. Elegans as model for the study of high glucosemediated life span reduction. Diabetes. 2009;58:2450-2456

240. Scheckhuber CQ, Mack SJ, Strobel I, Ricciardi F, Gispert S, Osiewacz HD. Modulation of the glyoxalase system in the aging model podospora anserina: Effects on growth and lifespan. Aging (Albany NY). 2010;2:969-980

241. Ikeda Y, Inagi R, Miyata T, Nagai R, Arai M, Miyashita M, Itokawa M, Fujita T, Nangaku M. Glyoxalase i retards renal senescence. Am J Pathol. 2011;179:2810-2821

242. Haik GM, Jr., Lo TW, Thornalley PJ. Methylglyoxal concentration and glyoxalase activities in the human lens. Exp Eye Res. 1994;59:497-500

243. Shamsi FA, Lin K, Sady C, Nagaraj RH. Methylglyoxal-derived modifications in lens aging and cataract formation. Invest Ophthalmol Vis Sci. 1998;39:2355-2364

244. Mailankot M, Padmanabha S, Pasupuleti N, Major D, Howell S, Nagaraj RH. Glyoxalase i activity and immunoreactivity in the aging human lens. Biogerontology. 2009;10:711-720

245. Fan X, Sell DR, Zhang J, Nemet I, Theves M, Lu J, Strauch C, Halushka MK, Monnier VM. Anaerobic vs aerobic pathways of carbonyl and oxidant stress in human lens and skin during aging and in diabetes: A comparative analysis. Free Radic Biol Med. 2010;49:847-856

246. Jo-Watanabe A, Ohse T, Nishimatsu H, Takahashi M, Ikeda Y, Wada T, Shirakawa J, Nagai R, Miyata T, Nagano T, Hirata $Y$, Inagi R, Nangaku M. Glyoxalase i reduces glycative and oxidative stress and prevents age-related endothelial dysfunction through modulation of endothelial nitric oxide synthase phosphorylation. Aging Cell. 2014;13:519-528

247. Fleming TH, Theilen TM, Masania J, Wunderle M, Karimi J, Vittas S, Bernauer R, Bierhaus A, Rabbani N, Thornalley PJ, Kroll J, Tyedmers J, Nawrotzki R, Herzig S, Brownlee M, Nawroth PP. Agingdependent reduction in glyoxalase 1 delays wound healing. Gerontology. 2013;59:427-437

248. Verma M, Srivastava S. Epigenetics in cancer: Implications for early detection and prevention. Lancet Oncol. 2002;3:755-763

249. El-Osta A, Brasacchio D, Yao D, Pocai A, Jones PL, Roeder RG, Cooper ME, Brownlee M. Transient high glucose causes persistent epigenetic changes and altered gene expression during subsequent normoglycemia. J Exp Med. 2008;205:2409-2417 
250. Brownlee M, Vlassara H, Kooney A, Ulrich P, Cerami A. Aminoguanidine prevents diabetes-induced arterial wall protein cross-linking. Science. 1986;232:1629-1632

251. Lo TW, Selwood T, Thornalley PJ. The reaction of methylglyoxal with aminoguanidine under physiological conditions and prevention of methylglyoxal binding to plasma proteins. Biochem Pharmacol. 1994;48:1865-1870

252. Soulis-Liparota T, Cooper M, Papazoglou D, Clarke B, Jerums G. Retardation by aminoguanidine of development of albuminuria, mesangial expansion, and tissue fluorescence in streptozocin-induced diabetic rat. Diabetes. 1991;40:1328-1334

253. Soulis T, Cooper ME, Vranes D, Bucala R, Jerums G. Effects of aminoguanidine in preventing experimental diabetic nephropathy are related to the duration of treatment. Kidney Int. 1996;50:627634

254. Hammes HP, Martin S, Federlin K, Geisen K, Brownlee M. Aminoguanidine treatment inhibits the development of experimental diabetic retinopathy. Proceedings of the National Academy of Sciences of the United States of America. 1991;88:11555-11558

255. Kihara M, Schmelzer JD, Poduslo JF, Curran GL, Nickander KK, Low PA. Aminoguanidine effects on nerve blood flow, vascular permeability, electrophysiology, and oxygen free radicals. Proceedings of the National Academy of Sciences of the United States of America. 1991;88:6107-6111

256. Bolton WK, Cattran DC, Williams ME, Adler SG, Appel GB, Cartwright K, Foiles PG, Freedman BI, Raskin P, Ratner RE, Spinowitz BS, Whittier FC, Wuerth JP. Randomized trial of an inhibitor of formation of advanced glycation end products in diabetic nephropathy. Am J Nephrol. 2004;24:32-40

257. Freedman BI, Wuerth JP, Cartwright K, Bain RP, Dippe S, Hershon K, Mooradian AD, Spinowitz BS. Design and baseline characteristics for the aminoguanidine clinical trial in overt type 2 diabetic nephropathy (action ii). Control Clin Trials. 1999;20:493-510

258. Vasan S, Foiles P, Founds $\mathrm{H}$. Therapeutic potential of breakers of advanced glycation end productprotein crosslinks. Arch Biochem Biophys. 2003;419:89-96

259. Sell DR, Monnier VM. Molecular basis of arterial stiffening: Role of glycation - a mini-review. Gerontology. 2012;58:227-237

260. Engelen L, Stehouwer CD, Schalkwijk CG. Current therapeutic interventions in the glycation pathway: Evidence from clinical studies. Diabetes Obes Metab. 2013;15:677-689

261. Kass DA, Shapiro EP, Kawaguchi M, Capriotti AR, Scuteri A, deGroof RC, Lakatta EG. Improved arterial compliance by a novel advanced glycation end-product crosslink breaker. Circulation. 2001;104:14641470

262. Hartog JW, Willemsen S, van Veldhuisen DJ, Posma JL, van Wijk LM, Hummel YM, Hillege HL, Voors AA. Effects of alagebrium, an advanced glycation endproduct breaker, on exercise tolerance and cardiac function in patients with chronic heart failure. Eur J Heart Fail. 2011;13:899-908

263. Zieman SJ, Melenovsky V, Clattenburg L, Corretti MC, Capriotti A, Gerstenblith G, Kass DA. Advanced glycation endproduct crosslink breaker (alagebrium) improves endothelial function in patients with isolated systolic hypertension. J Hypertens. 2007;25:577-583

264. Little WC, Zile MR, Kitzman DW, Hundley WG, O'Brien TX, Degroof RC. The effect of alagebrium chloride (alt-711), a novel glucose cross-link breaker, in the treatment of elderly patients with diastolic heart failure. J Card Fail. 2005;11:191-195

265. Viollet B, Guigas B, Sanz Garcia N, Leclerc J, Foretz M, Andreelli F. Cellular and molecular mechanisms of metformin: An overview. Clin Sci (Lond). 2012;122:253-270

266. Giannarelli R, Aragona M, Coppelli A, Del Prato S. Reducing insulin resistance with metformin: The evidence today. Diabetes Metab. 2003;29:6S28-35

267. Madiraju AK, Erion DM, Rahimi Y, Zhang XM, Braddock DT, Albright RA, Prigaro BJ, Wood JL, Bhanot S, MacDonald MJ, Jurczak MJ, Camporez JP, Lee HY, Cline GW, Samuel VT, Kibbey RG, Shulman GI. Metformin suppresses gluconeogenesis by inhibiting mitochondrial glycerophosphate dehydrogenase. Nature. 2014;510:542-546

268. Ruggiero-Lopez D, Lecomte M, Moinet G, Patereau G, Lagarde M, Wiernsperger N. Reaction of metformin with dicarbonyl compounds. Possible implication in the inhibition of advanced glycation end product formation. Biochem Pharmacol. 1999;58:1765-1773

269. Effect of intensive blood-glucose control with metformin on complications in overweight patients with type 2 diabetes (ukpds 34). Uk prospective diabetes study (ukpds) group. Lancet. 1998;352:854865 
270. Kender Z, Fleming T, Kopf S, Torzsa P, Grolmusz V, Herzig S, Schleicher E, Racz K, Reismann P, Nawroth PP. Effect of metformin on methylglyoxal metabolism in patients with type 2 diabetes. Exp Clin Endocrinol Diabetes. 2014;122:316-319

271. Battah S AN, Thornalley PJ. . Kinetics and mechanism of the reaction of metformin with methylglyoxal. International Congress Series. 2002;1245:355-356

272. Voziyan PA, Hudson BG. Pyridoxamine as a multifunctional pharmaceutical: Targeting pathogenic glycation and oxidative damage. Cell Mol Life Sci. 2005;62:1671-1681

273. Degenhardt TP, Alderson NL, Arrington DD, Beattie RJ, Basgen JM, Steffes MW, Thorpe SR, Baynes JW. Pyridoxamine inhibits early renal disease and dyslipidemia in the streptozotocin-diabetic rat. Kidney Int. 2002;61:939-950

274. Zhu $P$, Lin $H$, Sun $C$, Lin F, Yu H, Zhuo $X$, Zhou C, Deng Z. Synergistic effects of telmisartan and pyridoxamine on early renal damage in spontaneously hypertensive rats. Mol Med Rep. 2012;5:655662

275. Waanders F, van den Berg E, Nagai R, van Veen I, Navis G, van Goor H. Renoprotective effects of the age-inhibitor pyridoxamine in experimental chronic allograft nephropathy in rats. Nephrol Dial Transplant. 2008;23:518-524

276. Alderson NL, Chachich ME, Youssef NN, Beattie RJ, Nachtigal M, Thorpe SR, Baynes JW. The age inhibitor pyridoxamine inhibits lipemia and development of renal and vascular disease in zucker obese rats. Kidney Int. 2003;63:2123-2133

277. Tanimoto M, Gohda T, Kaneko S, Hagiwara S, Murakoshi M, Aoki T, Yamada K, Ito T, Matsumoto M, Horikoshi S, Tomino Y. Effect of pyridoxamine (k-163), an inhibitor of advanced glycation end products, on type 2 diabetic nephropathy in kk-a(y)/ta mice. Metabolism: clinical and experimental. 2007;56:160-167

278. Williams ME, Bolton WK, Khalifah RG, Degenhardt TP, Schotzinger RJ, McGill JB. Effects of pyridoxamine in combined phase 2 studies of patients with type 1 and type 2 diabetes and overt nephropathy. Am J Nephrol. 2007;27:605-614

279. Lewis EJ, Greene T, Spitalewiz S, Blumenthal S, Berl T, Hunsicker LG, Pohl MA, Rohde RD, Raz I, Yerushalmy Y, Yagil Y, Herskovits T, Atkins RC, Reutens AT, Packham DK, Lewis JB. Pyridorin in type 2 diabetic nephropathy. J Am Soc Nephrol. 2012;23:131-136

280. Garg S, Syngle A, Vohra K. Efficacy and tolerability of advanced glycation end-products inhibitor in osteoarthritis: A randomized, double-blind, placebo-controlled study. Clin J Pain. 2013;29:717-724

281. Hammes HP, Du X, Edelstein D, Taguchi T, Matsumura T, Ju Q, Lin J, Bierhaus A, Nawroth P, Hannak D, Neumaier M, Bergfeld R, Giardino I, Brownlee M. Benfotiamine blocks three major pathways of hyperglycemic damage and prevents experimental diabetic retinopathy. Nature medicine. 2003;9:294-299

282. Miller AG, Tan G, Binger KJ, Pickering RJ, Thomas MC, Nagaraj RH, Cooper ME, Wilkinson-Berka JL. Candesartan attenuates diabetic retinal vascular pathology by restoring glyoxalase-i function. Diabetes. 2010;59:3208-3215

283. Nagaraj RH, Sarkar P, Mally A, Biemel KM, Lederer MO, Padayatti PS. Effect of pyridoxamine on chemical modification of proteins by carbonyls in diabetic rats: Characterization of a major product from the reaction of pyridoxamine and methylglyoxal. Arch Biochem Biophys. 2002;402:110-119

284. Cheng AS, Cheng YH, Chiou CH, Chang TL. Resveratrol upregulates nrf2 expression to attenuate methylglyoxal-induced insulin resistance in hep g2 cells. Journal of agricultural and food chemistry. 2012;60:9180-9187

285. Maher P, Dargusch R, Ehren JL, Okada S, Sharma K, Schubert D. Fisetin lowers methylglyoxal dependent protein glycation and limits the complications of diabetes. PloS one. 2011;6:e21226

286. Xue M, Rabbani N, Momiji H, Imbasi P, Anwar MM, Kitteringham N, Park BK, Souma T, Moriguchi T, Yamamoto $\mathrm{M}$, Thornalley PJ. Transcriptional control of glyoxalase 1 by nrf2 provides a stressresponsive defence against dicarbonyl glycation. Biochem J. 2012;443:213-222

287. Das BN, Kim YW, Keum YS. Mechanisms of nrf2/keap1-dependent phase ii cytoprotective and detoxifying gene expression and potential cellular targets of chemopreventive isothiocyanates. Oxid Med Cell Longev. 2013;2013:839409

288. Mann GE, Niehueser-Saran J, Watson A, Gao L, Ishii T, de Winter P, Siow RC. Nrf2/are regulated antioxidant gene expression in endothelial and smooth muscle cells in oxidative stress: Implications for atherosclerosis and preeclampsia. Sheng Li Xue Bao. 2007;59:117-127 
289. Hsu WH, Lee BH, Chang YY, Hsu YW, Pan TM. A novel natural nrf2 activator with ppargamma-agonist (monascin) attenuates the toxicity of methylglyoxal and hyperglycemia. Toxicol Appl Pharmacol. 2013;272:842-851

290. Impellizzeri D, Esposito E, Attley J, Cuzzocrea S. Targeting inflammation: New therapeutic approaches in chronic kidney disease (ckd). Pharmacol Res. 2014;81:91-102

291. McCullough PA, Ali S. Cardiac and renal function in patients with type 2 diabetes who have chronic kidney disease: Potential effects of bardoxolone methyl. Drug Des Devel Ther. 2012;6:141-149

292. Thomas M. A preliminary evaluation of bardoxolone methyl for the treatment of diabetic nephropathy. Expert Opin Drug Metab Toxicol. 2012;8:1015-1022

293. Thomas MC. Bardoxolone: Augmenting the yin in chronic kidney disease. Diab Vasc Dis Res. 2011;8:303-304 
76 Chapter 2 


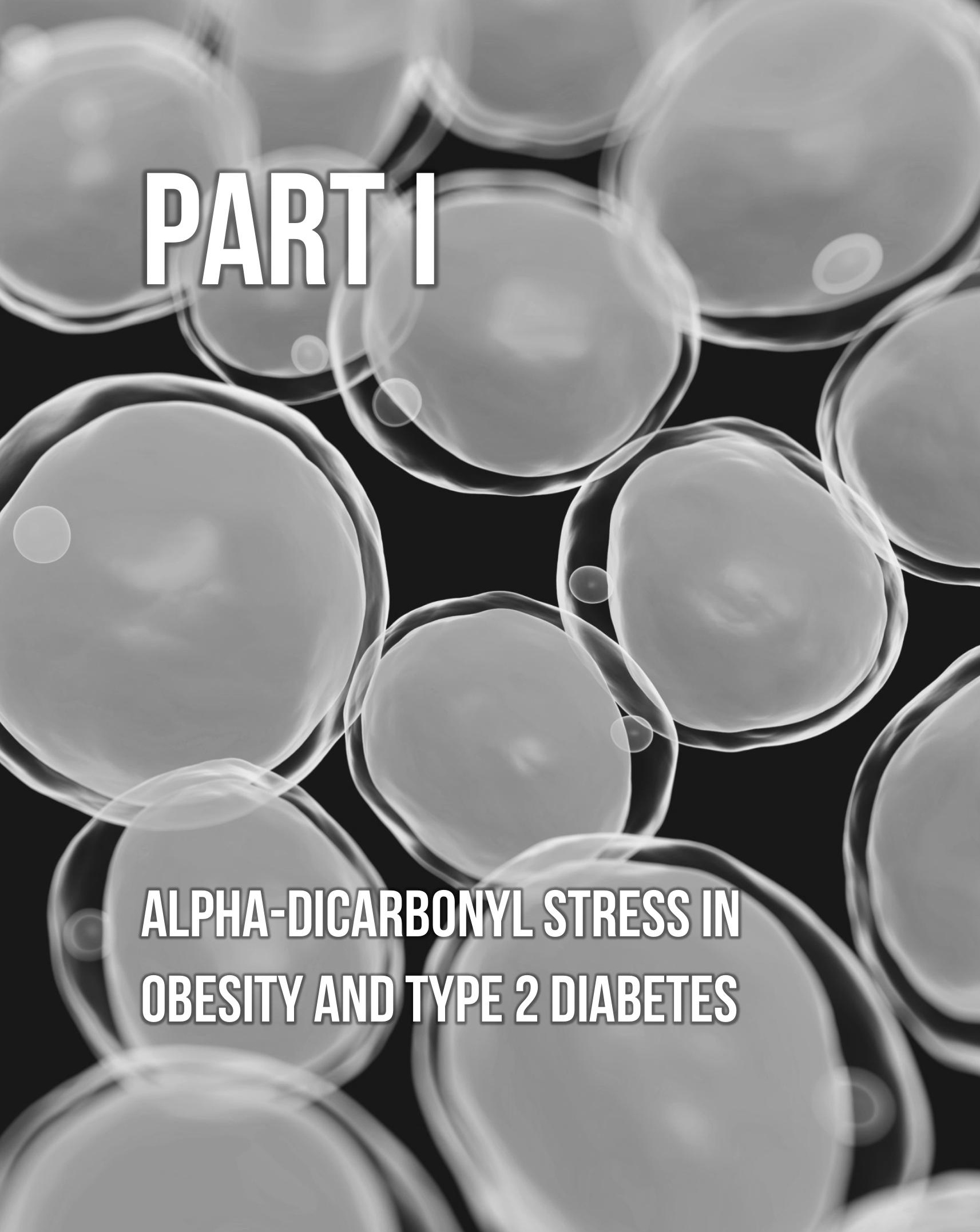




\section{HIGHER PLASMA CONCENTRATIONS OF THE METHYLGLYOXAL}

METABOLITE D-LACTATE ARE INDEPENDENTLY ASSOCIATED WITH INSULIN RESISTANCE: THE CODAM STUDY

DIONNE E.M. MAESSEN, JEAN LJ.M. SCHEIJEN, KATRIEN H. GAENS, MARLEEN M.J. VAN GREeVENBROEK, CARLA J. VAN DER KALLEN, COEN D.A. STEHOUWER AND CASPER G. SCHALKWIJK 


\section{Abstract}

Objective: Methylglyoxal (MGO), a highly reactive dicarbonyl compound generated by the spontaneous degradation of glycolytic intermediates, is a major precursor for advanced glycation endproducts and can potentially disrupt cellular functions. MGO can be detoxified by the glyoxalase system into D-lactate. Although experimental studies have shown that increased levels of MGO are associated with insulin resistance, epidemiological evidence of such an association in human studies is lacking. The aim of this study was to investigate the association between plasma Dlactate, as a reflection of plasma MGO concentrations, and insulin resistance.

Methods: Cross-sectional, complete case analyses were performed in the Cohort study on Diabetes and Atherosclerosis Maastricht (CODAM). 513 participants were included in the study population: $59.4 \pm 6.9$ years of age, $63 \%$ men, and, by design, $23 \%$ impaired glucose metabolism (IGM) and 23\% type 2 diabetes mellitus (T2DM). Plasma D-lactate was measured by UPLC-MS/MS. The main outcome measure was HOMA2-IR, as a measure of insulin resistance. The association between plasma D-lactate and HOMA2-IR was studied by multiple linear regression analysis.

Results: The prevalence of T2DM increased significantly over the tertiles of plasma Dlactate concentrations. Moreover, plasma $D$-lactate was positively associated with HOMA2-IR, when adjusted for age and sex ( $\beta=0.429 ; 95 \% \mathrm{Cl}$ : 0.350-0.507; $\mathrm{p}<0.001)$, as well as in the fully adjusted model, additionally adjusted for glucose metabolism status, smoking status, cardiovascular disease, use of medication (glucose-, lipid-, and blood-pressure-lowering), estimated glomerular filtration rate, waist circumference, glycated hemoglobin $\left(\mathrm{HbA}_{1 \mathrm{c}}\right)$ and plasma L-lactate levels $(\beta=0.145 ; 95 \% \mathrm{Cl}$ : $0.051-$ $0.239 ; p=0.003$ ). Additional data indicate that other sources of $D$-lactate can be excluded.

Conclusion: We found a positive association between plasma D-lactate and HOMA2$I R$, independently of putative confounders. These results suggest that MGO plays a role in insulin resistance, although direct measurement of MGO is necessary to confirm this. 


\section{Introduction}

Insulin resistance with respect to glucose metabolism is a metabolic condition defined by a reduced responsiveness to the action of insulin on glucose uptake, metabolism or storage. ${ }^{1}$ Recently, increased levels of advanced glycation endproducts (AGEs) have been found in association with insulin resistance. ${ }^{1-3}$

AGEs are a family of unavoidable by-products of various metabolic pathways. Methylglyoxal (MGO) has received considerable attention as the most reactive and potent AGE precursor. ${ }^{4}{ }^{5}$ MGO is a dicarbonyl compound generated by the spontaneous degradation of glycolytic intermediates during glycolysis. Under physiological circumstances, MGO can be detoxified by the glyoxalase (GLO) system. This system consists of two enzymes, glyoxalase 1 (GLO-1) and glyoxalase 2 (GLO-2), which catalyze the conversion of MGO to D-lactate. ${ }^{6}$

Although several in vitro experiments and animal studies have indicated a substantial role for MGO in the induction of insulin resistance, ${ }^{1,7}$ the association between MGO and insulin resistance in humans has not yet been studied. However, because of the high reactivity of MGO with plasma proteins, it is difficult to obtain valid and precise measurements of MGO in plasma. Since MGO is metabolized to D-lactate, we used plasma D-lactate levels as a reflection of MGO concentrations in the current analysis. ${ }^{8}$ We previously demonstrated that we are able to measure D-lactate in a very specific way that can efficiently distinguish between D-lactate and L-lactate. ${ }^{9}$ MGO degradation is the major route of D-lactate formation, although D-lactate can also originate from other sources such as the intestines. In previous work, however, we found that plasma levels of D-lactate were significantly increased in patients with type 2 diabetes mellitus (T2DM) compared to healthy controls, whereas patients suffering from inflammatory bowel disease (IBD) did not show increased levels of plasma Dlactate. ${ }^{9}$ These data underline that increased concentrations of plasma D-lactate are derived from $\mathrm{MGO}$ and are not a reflection of $\mathrm{D}$-lactate produced by the intestines. In this study, we investigated if plasma D-lactate, as a reflection of MGO concentrations, is increased in individuals with impaired glucose metabolism (IGM) and T2DM, and whether plasma D-lactate is associated with insulin resistance in a cohort study designed to investigate glucose metabolism and cardiovascular disease. 


\section{Research Design and Methods}

\section{Study population}

The study population consisted of participants from the Cohort study on Diabetes and Atherosclerosis Maastricht (CODAM). This study included 574 participants who were selected from the general population, as described in detail elsewhere. ${ }^{10}$ The cohort was enriched for impaired glucose metabolism status, as defined previously. ${ }^{11}$ Current analyses were performed on participants who were not on insulin treatment and had complete data on all variables of interest (plasma D-lactate, HOMA2-IR, age, sex, glucose metabolism status, smoking status, cardiovascular disease, use of medication (glucose-, lipid-, and blood-pressure-lowering), estimated glomerular filtration rate (eGFR), waist circumference, glycated hemoglobin $\left(\mathrm{HbA}_{1 \mathrm{C}}\right)$ and plasma L-lactate levels). Hence, the present study reports on 513 persons. The study protocol was approved by the local Medical Ethical Committee of Maastricht University Medical Centre and written informed consent was obtained from all participants.

\section{Measurement of plasma D-lactate}

Plasma D-lactate levels were measured in EDTA plasma samples from overnight fasting venous blood. Samples were analyzed by reversed phase ultra-performance liquid chromatography tandem mass spectrometry (UPLC-MS/MS), as described in detail previously. ${ }^{9}$ The intra- and inter-assay variations were 4 and $8 \%$, respectively.

\section{Measurement of insulin resistance}

Insulin resistance was estimated using the Homeostasis Model of Assessment - Insulin Resistance (HOMA2-IR) calculator from www.dtu.ox.ac.uk, as described previously. ${ }^{12}$

\section{Measurements of covariates}

Plasma L-lactate levels were measured in EDTA plasma samples from overnight fasting venous blood, using UPLC-MS/MS. ${ }^{9}$ It was measured synchronously with plasma Dlactate. Smoking behavior (never, ever or current smoker) was assessed by a questionnaire. Prior CVD and waist circumference were assessed as previously described in detail. ${ }^{13}$ Creatinine levels were measured in EDTA plasma using a Jaffe diagnostic test (Roche Diagnostics) and the Chronic Kidney Disease Epidemiology Collaboration (CKD-EPI) equation was used to calculate the eGFR. ${ }^{14}$ Finally, $\mathrm{HbA}_{1 \mathrm{C}}$ was measured using ion-exchange HPLC. ${ }^{10}$ 


\section{Use of medication}

Subjects were asked to report if they were currently using medication, and, if so, to list all the medication used. All medicines were reviewed with the use of the Dutch Pharmacological Compass 2006 (www.fk.cvz.nl) and allocated into 36 categories. Medication containing the additive polyethylene glycol (PEG) was selected using the database of College ter Beoordeling van Geneesmiddelen (www.dbg-med.nl).

\section{Definition of intestinal disease}

Diseases of study participants were self-reported by questionnaire. Intestinal disease was reported when the subject suffered from any serious intestinal disease for 3 months or longer in the past 12 months.

\section{Statistical analyses}

The general characteristics of the study population were compared across tertiles of plasma D-lactate concentrations. One-way analysis of variance (ANOVA) was used for continuous variables and chi-square tests for discrete variables. Skewed variables (plasma D-lactate, HOMA2-IR, fasting plasma glucose, plasma L-lactate and triglycerides) were compared across the plasma D-lactate tertiles by Kruskal-Wallis one-way analysis of variance and were $\log _{e}$ transformed prior to regression analyses. Multiple linear regression analysis was used to investigate the cross-sectional association between plasma D-lactate and HOMA2-IR and results are presented as standardized regression coefficients $(\beta)$. The analysis was initially adjusted for the covariates age (years) and sex (model 1), additionally adjusted for glucose metabolism status (IGM and T2DM as dummy variables), smoking status (ex-smoker and current smoker as dummy variables), prior CVD, use of medication (glucose-, lipid-, and bloodpressure-lowering) and eGFR (model 2), further adjusted for $\mathrm{HbA}_{1 \mathrm{c}}$ (model 3), and finally fully adjusted for plasma L-lactate levels (model 4). A P-value of $<0.05$ was considered statistically significant. All statistical analyses were performed with IBM SPSS Statistics Software, version 20 (IBM Corporation, Armonk, New York).

\section{Results}

General characteristics of the study population stratified according to tertiles of plasma D-lactate concentrations are shown in Table 3.1. The prevalence of IGM did not differ between the tertiles of plasma D-lactate levels (Table 3.1). However, the prevalence of T2DM increased significantly with higher plasma D-lactate levels $(p<0.001)$ (Table 3.1). Similar results were found for fasting plasma glucose levels, HOMA2-IR, and $\mathrm{HbA}_{1 \mathrm{C}}$ (all $\mathrm{p}<0.001$ ) (Table 3.1). 
Table 3.1 - General characteristics of the study population stratified according to tertiles of plasma Dlactate.

\begin{tabular}{lllll}
\hline & \multicolumn{3}{c}{ Plasma D-lactate tertiles } \\
\cline { 2 - 5 } & Lowest $(\mathrm{n}=171)$ & Middle $(\mathrm{n}=171)$ & Highest $(\mathrm{n}=171)$ & P-value \\
\hline Age, years & $59.2 \pm 6.9$ & $59.9 \pm 7.1$ & $59.1 \pm 6.8$ & 0.43 \\
Sex, \% men & 57.3 & 66.1 & 64.9 & 0.19 \\
Body mass index, kg/m ${ }^{2}$ & $27.3 \pm 3.7$ & $28.0 \pm 4.1$ & $30.0 \pm 4.4$ & $<0.001$ \\
Waist circumference, cm & $95.5 \pm 10.9$ & $98.6 \pm 11.2$ & $103.5 \pm 12.0$ & $<0.001$ \\
IGM, \% & 23.4 & 20.5 & 25.1 & 0.58 \\
T2DM, \% & 11.7 & 21.6 & 35.1 & $<0.001$ \\
Fasting plasma glucose, mmol/L & $5.4[5.0-5.8]$ & $5.6[5.2-6.1]$ & $5.9[5.4-7.1]$ & $<0.001$ \\
HOMA2-IR & $0.9[0.7-1.3]$ & $1.2[0.9-1.6]$ & $1.4[1.0-2.3]$ & $<0.001$ \\
Plasma D-lactate, $\mu$ mol/L & $5.5[4.6-6.3]$ & $8.5[7.8-9.7]$ & $14.5[12.6-17.1]$ & $<0.001$ \\
Plasma L-lactate, $\mu$ mol/L & $922[795-1054]$ & $1143[974-1315]$ & $1634[1358-1884]$ & $<0.001$ \\
HbA ${ }_{1 C}$ \% & $5.7 \pm 0.7$ & $5.9 \pm 0.7$ & $6.1 \pm 0.8$ & $<0.001$ \\
Glucose-lowering medication, \% & 5.3 & 9.4 & 17.0 & 0.002 \\
Prior CVD, \% & 21.6 & 26.9 & 32.7 & 0.07 \\
Total cholesterol, mmol/L & $4.2 \pm 1.3$ & $4.8 \pm 1.6$ & $5.2 \pm 1.7$ & $<0.001$ \\
Triglycerides, mmol/L & $1.1[0.8-1.5]$ & $1.4[1.0-1.9]$ & $1.8[1.4-2.4]$ & $<0.001$ \\
Lipid-lowering medication, \% & 15.8 & 17.0 & 20.5 & 0.50 \\
Current smoker, \% & 20.5 & 19.3 & 22.8 & 0.72 \\
Former smoker, \% & 52.0 & 51.5 & 51.5 & 0.99 \\
BP-lowering medication, \% & 28.7 & 38.0 & 46.2 & 0.004 \\
eGFR, mL/min/1.73 m ${ }^{2}$ & $90.5 \pm 11.5$ & $90.2 \pm 12.6$ & $93.8 \pm 12.1$ & 0.009 \\
\hline
\end{tabular}

Data are presented as means \pm SD, medians (interquartile range), or percentages, as appropriate; the ranges of the plasma D-lactate tertiles were [2.6-7.1], [7.1-10.7] and [10.7-32.4] $\mu \mathrm{mol} / \mathrm{L}$ respectively. IGM: impaired glucose metabolism; T2DM: type 2 diabetes mellitus; HOMA2-IR: homeostasis model assessment insulin resistance; HbA1C: glycated hemoglobin; CVD: cardiovascular disease; BP: blood-pressure; eGFR: estimated glomerular filtration rate.

Plasma D-lactate concentrations were positively associated with HOMA2-IR, in the model adjusted for age and sex (Model $1: \beta=0.429 ; 95 \% \mathrm{Cl}: 0.350-0.507 ; p<0.001$ ), as well as in a model adjusted for the additional covariates glucose metabolism status, smoking status, cardiovascular disease, use of medication, eGFR and waist circumference (Model 2: $\beta=0.214 ; 95 \% \mathrm{Cl}: 0.147-0.280 ; p<0.001$ ). After additional adjustment for $\mathrm{HbA}_{1 \mathrm{c}}$, which had a negligible effect on the regression coefficient, plasma D-lactate remained positively associated with HOMA2-IR (Model 3: $\beta=0.210$; 95\% Cl: 0.143-0.276; $p<0.001)$. Addition of plasma L-lactate levels to model 3 resulted in a relatively large decrease in the regression coefficient (Model 4: $\beta=0.145 ; 95 \% \mathrm{Cl}$ : 0.051-0.239; $p=0.003$ ), although the association between plasma $D$-lactate and HOMA2-IR remained significant (Table 3.2). 
Table 3.2 - Association between plasma D-lactate ( $\mu \mathrm{mol} / \mathrm{L})$ and HOMA2-IR.

\begin{tabular}{lllll}
\hline Dependent variable & Model & $\beta$ & $95 \% \mathrm{Cl}$ & P-value \\
\hline \multirow{3}{*}{ HOMA2-IR } & 1 & 0.429 & $0.350-0.507$ & $<0.001$ \\
& 2 & 0.214 & $0.147-0.280$ & $<0.001$ \\
& 3 & 0.210 & $0.143-0.276$ & $<0.001$ \\
& 4 & 0.145 & $0.051-0.239$ & 0.003 \\
\hline
\end{tabular}

The standardized regression coefficient $\beta$ represents one standard deviation (SD) increase in HOMA2-IR per SD increase in plasma D-lactate. Model 1: adjusted for age and sex; model 2: model $1+$ glucose metabolism status, smoking status, cardiovascular disease, use of medication (glucose-, lipid-, and blood-pressurelowering), estimated glomerular filtration rate and waist circumference; model 3: model $2+\mathrm{HbA}_{1 c}$; model 4: model 3 + plasma L-lactate levels.

Although MGO degradation is the major route of D-lactate formation, D-lactate can also be produced by other pathways. We already found in our previous study that patients suffering from IBD did not show increased levels of plasma D-lactate. However, we additionally analyzed our study population with regard to intestinal disease. There were no differences in prevalence of intestinal disease between the plasma D-lactate tertiles (T1: $1.8 \%, T 2: 4.7 \%, T 3: 2.9 \%$; $p=0.29$ ), nor was there a difference in the proportion of intestinal diseased participants treated for this disease (T1: 50\%, T2: 57\%, T3: 44\%; $p=0.88$ ).

In addition to the intestinal route, D-lactate can also be formed from PEG, which is used as an additive for several medications. To exclude PEG as a source of D-lactate production, we selected all medication in our cohort which was enriched with PEG, and analyzed whether there were more users of PEG-contaminated medication in the higher tertile of plasma D-lactate. We found that the users of PEG-contaminated medication were equally distributed between the tertiles of D-lactate (T1: $35 \%, T 2$ : 40\%, T3: 46\%; $p=0.14)$. Since PEG is often added to BP-lowering medication, we performed the same analyses for this specific group of medication. Again, no difference in amount of users was found between the D-lactate tertiles (T1: 57\%, T2: $66 \%$, T3: $60 \% ; p=0.58)$.

\section{Discussion}

In this cohort study we demonstrated that plasma D-lactate levels are increased in patients with T2DM. Additionally, we found a positive association between plasma Dlactate levels and HOMA2-IR, independently of putative confounders.

This is the first study that has examined the association between MGO and insulin resistance in a large human cohort study, using plasma D-lactate as a reflection of MGO concentrations. We observed a significantly higher prevalence of T2DM across the tertiles of plasma D-lactate concentrations. A similar trend was observed for 
fasting plasma glucose levels, HOMA2-IR, and $\mathrm{HbA} 1 \mathrm{C}$, supporting the hypothesis that persons with abnormal glucose metabolism have high plasma D-lactate levels. These positive associations are in line with our previous study, in which we demonstrated that T2DM patients have increased plasma and urine levels of D-lactate ${ }^{9}$ and with studies showing that the concentration of D-lactate typically increased in cells cultured in high glucose concentrations. ${ }^{5,8}$

We found a strong association between plasma D-lactate and HOMA2-IR, which was independent of confounders. Although adjustment for plasma L-lactate levels resulted in a relatively large decrease in the regression coefficient, the association between plasma D-lactate and HOMA2-IR remained significant, demonstrating an association between plasma D-lactate probably derived from MGO metabolism and insulin resistance. Our results are in agreement with several experimental studies showing that the major AGE-precursor MGO potentially contributes to the development of insulin resistance. It has been demonstrated that administration of MGO to rats caused impaired insulin signaling and induced insulin resistance. ${ }^{15-18}$ In addition, chronic infusion of MGO caused $\beta$-cell dysfunction. ${ }^{18}$ Next to the in vivo studies, in vitro experiments with 3 T3 adipocytes and INS-1E pancreatic cells showed that IRS-1 phosphorylation and $\mathrm{PI} 3 \mathrm{~K}$ activity were dose-dependently reduced by treatment with MGO, indicating its contribution to the pathogenesis of insulin resistance. ${ }^{17,19}$

Our finding that plasma D-lactate is positively and independently associated with insulin resistance is in line with findings from recent studies, which described a positive association between AGEs and insulin resistance. ${ }^{1-3}$ However, we cannot establish whether these associations are causal due to the cross-sectional design of the study. Further follow-up data on these or other patient groups would, of course, be invaluable, in testing whether our findings are probably due to causal relationships between MGO and insulin resistance. However, this cross-sectional study may serve as a reasonable starting point to further explore these associations. Plasma D-lactate may be, as a reflection of plasma MGO, an early marker of insulin resistance.

The main limitation of our study is that we were not able so far to measure MGO directly in these plasma samples. However, it is very likely that an increase in D-lactate concentrations is indicative of increased flux of MGO formation, as was demonstrated in erythrocytes. ${ }^{8}$ Furthermore, our additional analyses showed that we can exclude other sources than MGO for the production of D-lactate. Previous work and current results indicate that both the intestines as well as PEG-contaminated medication do not contribute to plasma D-lactate levels.

In summary, our data show for the first time that plasma D-lactate levels are associated with HOMA2-IR, independently of putative confounders. Together with findings from previous studies, our results suggest that higher levels of MGO play an important role in the etiology of insulin resistance, although this has to be confirmed in future research. 


\section{References}

1. Schalkwijk CG, Brouwers O, Stehouwer CD. Modulation of insulin action by advanced glycation endproducts: A new player in the field. Horm Metab Res. 2008;40:614-619

2. Sandu O, Song K, Cai W, Zheng F, Uribarri J, Vlassara H. Insulin resistance and type 2 diabetes in highfat-fed mice are linked to high glycotoxin intake. Diabetes. 2005;54:2314-2319

3. Forbes JM, Sourris KC, de Courten MP, Dougherty SL, Chand V, Lyons JG, Bertovic D, Coughlan MT, Schlaich MP, Soldatos G, Cooper ME, Straznicky NE, Kingwell BA, de Courten B. Advanced glycation end products (ages) are cross-sectionally associated with insulin secretion in healthy subjects. Amino Acids. 2014;46:321-326

4. Westwood ME, Thornalley PJ. Molecular characteristics of methylglyoxal-modified bovine and human serum albumins. Comparison with glucose-derived advanced glycation endproduct-modified serum albumins. J Protein Chem. 1995;14:359-372

5. Shinohara M, Thornalley PJ, Giardino I, Beisswenger P, Thorpe SR, Onorato J, Brownlee M. Overexpression of glyoxalase-i in bovine endothelial cells inhibits intracellular advanced glycation endproduct formation and prevents hyperglycemia-induced increases in macromolecular endocytosis. J Clin Invest. 1998;101:1142-1147

6. Thornalley PJ. The glyoxalase system in health and disease. Mol Aspects Med. 1993;14:287-371

7. Matafome P, Sena C, Seica R. Methylglyoxal, obesity, and diabetes. Endocrine. 2013;43:472-484

8. Thornalley PJ. Modification of the glyoxalase system in human red blood cells by glucose in vitro. Biochem J. 1988;254:751-755

9. Scheijen JL, Hanssen NM, van de Waarenburg MP, Jonkers DM, Stehouwer CD, Schalkwijk CG. L(+) and $\mathrm{d}(-)$ lactate are increased in plasma and urine samples of type 2 diabetes as measured by a simultaneous quantification of $\mathrm{I}(+)$ and $\mathrm{d}(-)$ lactate by reversed-phase liquid chromatography tandem mass spectrometry. Exp Diabetes Res. 2012;2012:234812

10. Du $H$, van der $A D$, van Bakel MM, van der Kallen $C J$, Blaak EE, van Greevenbroek MM, Jansen EH, Nijpels G, Stehouwer CD, Dekker JM, Feskens EJ. Glycemic index and glycemic load in relation to food and nutrient intake and metabolic risk factors in a dutch population. Am J Clin Nutr. 2008;87:655-661

11. Hanssen NM, Engelen L, Ferreira I, Scheijen JL, Huijberts MS, van Greevenbroek MM, van der Kallen CJ, Dekker JM, Nijpels G, Stehouwer CD, Schalkwijk CG. Plasma levels of advanced glycation endproducts nepsilon-(carboxymethyl)lysine, nepsilon-(carboxyethyl)lysine, and pentosidine are not independently associated with cardiovascular disease in individuals with or without type 2 diabetes: The hoorn and codam studies. J Clin Endocrinol Metab. 2013;98:E1369-1373

12. Wlazlo N, van Greevenbroek MM, Ferreira I, Jansen EH, Feskens EJ, van der Kallen CJ, Schalkwijk CG, Bravenboer B, Stehouwer CD. Iron metabolism is associated with adipocyte insulin resistance and plasma adiponectin: The cohort on diabetes and atherosclerosis maastricht (codam) study. Diabetes Care. 2013;36:309-315

13. van Greevenbroek MM, Jacobs M, van der Kallen CJ, Vermeulen VM, Jansen EH, Schalkwijk CG, Ferreira I, Feskens EJ, Stehouwer CD. The cross-sectional association between insulin resistance and circulating complement $\mathrm{c} 3$ is partly explained by plasma alanine aminotransferase, independent of central obesity and general inflammation (the codam study). Eur J Clin Invest. 2011;41:372-379

14. Levey AS, Stevens LA, Schmid CH, Zhang YL, Castro AF, 3rd, Feldman HI, Kusek JW, Eggers P, Van Lente $\mathrm{F}$, Greene T, Coresh J. A new equation to estimate glomerular filtration rate. Ann Intern Med. 2009;150:604-612

15. Guo Q, Mori T, Jiang Y, Hu C, Osaki Y, Yoneki Y, Sun Y, Hosoya T, Kawamata A, Ogawa S, Nakayama M, Miyata T, Ito $S$. Methylglyoxal contributes to the development of insulin resistance and salt sensitivity in sprague-dawley rats. J Hypertens. 2009;27:1664-1671

16. Dhar A, Desai KM, Wu L. Alagebrium attenuates acute methylglyoxal-induced glucose intolerance in sprague-dawley rats. Br J Pharmacol. 2010;159:166-175

17. Jia X, Wu L. Accumulation of endogenous methylglyoxal impaired insulin signaling in adipose tissue of fructose-fed rats. Mol Cell Biochem. 2007;306:133-139

18. Dhar A, Dhar I, Jiang B, Desai KM, Wu L. Chronic methylglyoxal infusion by minipump causes pancreatic beta-cell dysfunction and induces type 2 diabetes in sprague-dawley rats. Diabetes. 2011;60:899-908

19. Fiory F, Lombardi A, Miele C, Giudicelli J, Beguinot F, Van Obberghen E. Methylglyoxal impairs insulin signalling and insulin action on glucose-induced insulin secretion in the pancreatic beta cell line ins1e. Diabetologia. 2011;54:2941-2952 
88 Chapter 3 


\section{EXTRACELLULAR METHYLGLYOXAL INDUCES MUSCLE INSULIN}

RESISTANCE BY MODIFICATION OF THE INSULIN MOLECULE AND NOT BY INTRAMUSCULAR ACCUMULATION

DIONNE E.M. MAESSEN, MATTHIJS K.C. HESSELINK, PATRICK SCHRAUWEN, COEN D.A. STEHOUWER AND CASPER G. SCHALKWIJK 


\section{DELAYED INTERVENTION WITH PYRIDOXAMINE IMPROVES}

METABOLIC FUNCTION AND PREVENTS ADIPOSE TISSUE INFLAMMATION AND INSULIN RESISTANCE IN HIGH-FAT DIETINDUCED OBESE MICE

DIONNE E.M. MAESSEN, OLAF BROUWERS, KATRIEN H. GAENS, KRISTIAAN WOUTERS, JACK P. CLEUTJENS, BEN J. JANSSEN, TOSHIO MIYATA, COEN D.A. STEHOUWER, AND CASPER G. SCHALKWIJK 


\section{Abstract}

Obesity is associated with an increased risk for development of type 2 diabetes and vascular complications. Advanced glycation endproducts are increased in adipose tissue and have been associated with insulin resistance, vascular dysfunction and inflammation of adipose tissue. Here, we report that delayed intervention with pyridoxamine (PM), a vitamin B6 analogue which has been identified as an antiglycating agent, protected against high-fat diet (HFD)-induced body weight gain, hyperglycemia and hypercholesterolemia, as compared to those who were not treated. In both HFD-induced and $\mathrm{db} / \mathrm{db}$ obese mice, impaired glucose metabolism and insulin resistance were prevented by PM supplementation. PM inhibited expansion of adipose tissue and adipocyte hypertrophy in mice. In addition, adipogenesis of murine 3T3-L1 and human SGBS preadipocytes was dose- and timedependently reduced by $\mathrm{PM}$, as demonstrated by Oil Red $\mathrm{O}$ staining and reduced expression of adipogenic differentiation genes. No ectopic fat deposition was found in the liver of HFD mice. The high expression of pro-inflammatory genes in visceral adipose tissue of the HFD group was significantly attenuated by PM. Treatment with PM partially prevented HFD-induced mild vascular dysfunction. Altogether, these findings highlight the potential of PM to serve as an intervention strategy in obesity. 


\section{Introduction}

Obesity is characterized by dysregulation of adipokine production, ${ }^{1}$ which predisposes obese individuals to development of cardiovascular and metabolic complications. Recently, we and others demonstrated accumulation of advanced glycation endproducts (AGEs) in adipose tissue, ${ }^{2,3}$ and have identified that they play an important role in obesity-induced insulin resistance and dysregulation of adipokine expression, such as interleukin-6 (IL-6) and adiponectin. ${ }^{2,} 4,5$ AGEs are a heterogeneous family of non-enzymatically, post-translationally modified proteins and can be formed rapidly by the intracellular $\alpha$-dicarbonyl compounds methylglyoxal (MGO), glyoxal (GO) and 3-deoxyglucosone (3-DG). ${ }^{6}$ Because of harmful effects elicited by AGEs, several inhibitors have been designed to inhibit their formation. ${ }^{7}$

Currently, pyridoxamine (PM) is receiving considerable attention as a highly potent AGE inhibitor. PM, a vitamin B6 analogue, has been identified as an anti-glycating agent, ${ }^{8}$ possibly through trapping of $\alpha$-dicarbonyl compounds. ${ }^{9}$ Previous data have shown that PM inhibits AGE formation and retards the development of diabetic nephropathy and retinopathy in animal models of diabetes. ${ }^{10}$ Two trials in patients with diabetic nephropathy demonstrated no adverse effects of PM and thus a favorable safety profile. ${ }^{11,12}$

Because of accumulation of AGEs in obese adipose tissue and the link with insulin resistance and vascular complications, we postulate that inhibiting AGE formation will improve the metabolic and vascular profile in obesity. In the present study, we examine the effect of a delayed PM intervention on metabolic and vascular function in high-fat diet (HFD)-induced obese mice. By delaying PM treatment with 6 weeks after the start of HFD feeding, we mimic the clinical situation of obesity in which metabolic dysfunction has already developed. This delayed intervention enables us to investigate the capacity of PM to treat obesity-associated complications, rather than to prevent them.

\section{Research Design and Methods}

\section{Animals}

Male C57BL/6J mice were purchased from Jackson Laboratory (Charles River) and were maintained in a temperature-controlled room on a $12 \mathrm{~h}$ light-dark cycle. They were housed with 2-3 mice per cage and had free access to food and drinking water. After a 6 week run-in period on low-fat diet (LFD, 10\% fat, Research Diets D12450H), 12 week old mice were divided into three groups. The LFD group $(n=15)$ continued on 
the same diet, whereas the other two groups ( $n=15$ per group) switched to the HFD (45\% kcal\% fat, Research Diets D12451). After 6 weeks of HFD, one group started to receive PM ( $2 \mathrm{~g} / \mathrm{L})$ in the drinking water (HFD + PM) and 18 weeks later, all mice were sacrificed by means of $\mathrm{CO}_{2}$ inhalation and subsequent exsanguination by cardiac puncture.

Male $\mathrm{db} / \mathrm{db}$ mice were also purchased from Jackson Laboratory (Charles River) and were included in the study at an age of 6 weeks. They were treated with PM in their drinking water for 18 weeks. $\mathrm{db} / \mathrm{db}$ mice were housed and sacrificed in the same way as described for the LFD and HFD fed C57BL/6J mice.

The experimental protocol was approved by the institutional Animal Experiments Committee of Maastricht University and all experiments were performed by licensed users according to international guidelines. PM was kindly provided by Prof. T. Miyata (Tohoku University, Sendai, Japan).

\section{In vivo glucose tolerance and insulin tolerance tests}

Intraperitoneal glucose tolerance tests (IPGTT) were performed in all mice 13 weeks after the start of the study. Following a 16-h overnight fasting period, whole blood glucose was measured with a glucometer (Contour, Bayer, Leverkusen, Germany). After intraperitoneal glucose injection $(2.0 \mathrm{~g} / \mathrm{kg}$ body weight, Sigma-Aldrich, Saint Louis, United States), blood glucose levels were measured at 15, 30, 60, 90 and 120 minutes. One week later, intraperitoneal insulin tolerance tests (IPITT) were performed. To this end, mice were fasted for 4-h and insulin was injected intraperitoneally at a dose of $0.5 \mathrm{U} / \mathrm{kg}$ body weight (Actrapid Penfill, Novo Nordisk, Bagsuærd, Denmark). Blood samples were taken at the same time points as during the IPGTT and blood glucose levels were assessed. In addition, the IPGTT and IPITT were also performed in $\mathrm{db} / \mathrm{db}$ mice.

\section{Biochemical characterisation}

Fasted plasma total cholesterol and liver triglyceride levels were determined with enzymatic colorimetric tests using CHOD-PAP and GPO-PAP reagents methods respectively (Instruchemie, Delfszijl, The Netherlands). Fasted plasma insulin and leptin levels were measured in a multiplexed sandwich immunoassay of Meso Scale Discovery (K15124-C, Rockville, MD, USA). Plasma biomarkers were measured with a 7-plex multiarray biomarker assay of Meso Scale Discovery (K15012-C, Rockville, MD, USA). The $\alpha$-dicarbonyls MGO, GO and 3-DG were measured using ultra performance liquid chromatography tandem mass spectrometry (UPLC-MS/MS, Waters, Milford Massachusetts, USA), as described previously. ${ }^{13}$ 
GLO1 activity was measured in protein lysates of visceral adipose tissue (VAT), according to the method of McLellan and Thornalley. ${ }^{14}$ In short, GLO1 activity was assayed by spectrophotometry (Synergy, BioTek, Winooski, VT, USA), by measuring the increase in absorbance at $240 \mathrm{~nm}$ as a result of formation of S-Dlactoylglutathione for $20 \mathrm{~min}$.

\section{Immunohistochemical tissue characterization}

During dissection of the mice, visceral, epididymal fat depots and livers were isolated, weighed and stored for further analyses. After overnight fixation in $4 \%$ formaldehyde, tissues were embedded in paraffin and $4 \mu \mathrm{m}$ sections were collected and stained with haematoxylin and eosin (H\&E). Digital images were taken at a magnification of 20x using a Leica DFC320 digital camera (Leica Microsystems, Wetzlar, Germany). Adipocyte cell size and cell diameter were quantified with morphometric analysis software (Leica QWin V3, Leica Microsystems, Wetzlar, Germany). Macrophage infiltration in VAT was scored based on the presence of crown-like structures with the following scores: 0: no crown-like structures, 1: 1 or 2 crown-like structures, 2: 3 to 9 crown-like structures, $3: 10$ to 20 crown-like structures, 4: more than 20 crown-like structures. Fat content of the liver was scored based on the presence of fat droplets with the following scores: 0: no fat droplets, 1: very few fat droplets 2: few fat droplets 3: multiple fat droplets and 4: many fat droplets.

\section{Preadipocyte culture and differentiation}

Murine 3T3-L1 and human Simpson-Golabi-Behmel-Syndrome (SGBS) preadipocytes were cultured and differentiated into adipocytes according to the appropriate protocol. In short, murine 3T3-L1 preadipocytes were maintained in DMEM high glucose $(25 \mathrm{mM})$ containing $10 \%$ FCS and $1 \%$ glutamine-penicillin/streptozotocin. After reaching $80 \%$ confluency, differentiation was induced with the standard culture medium supplemented with $0.5 \mathrm{mM}$ 3-isobutyl-1-methylxanthine, $10 \mu \mathrm{g} / \mathrm{mL}$ insulin, and $0.444 \mu \mathrm{g} / \mathrm{mL}$ dexamethasone. After two days, the first adipogenic differentiation medium was substituted by the standard culture medium supplemented with 2.5 $\mu \mathrm{g} / \mathrm{ml}$ insulin until day 12 . Human SGBS preadipocytes were maintained in DMEM/HAM's F12 culture medium supplemented with $10 \% \mathrm{FCS}, 8 \mu \mathrm{g} / \mathrm{mL}$ biotin, 4 $\mu \mathrm{g} / \mathrm{mL}$ pantothenate and $1 \%$ glutamine-penicillin/streptozotocin, and were grown to confluence. Adipogenic differentiation was induced by incubating preadipocytes with serum-free culture medium containing $10 \mu \mathrm{g} / \mathrm{mL}$ human transferrin, $20 \mathrm{nM}$ insulin, $100 \mathrm{nM}$ cortisol and $0.2 \mathrm{nM}$ triiodothyronine for 12 days. After 6 days of differentiation, this adipogenic differentiation medium was additionally supplemented 
with $25 \mathrm{nM}$ dexamethasone, $500 \mu \mathrm{M}$ 3-isobutyl-1-methylxanthine and $2 \mu \mathrm{M}$ rosiglitazone (GlaxoSmithKline, London, UK). For both SGBS and 3T3-L1 cells, media were refreshed every other day. In addition to the normal differentiation condition, cells were also differentiated in the presence of 2 and/or 5 mM PM. RNA was extracted from cells at day 0, 2, 5 and 7. Oil Red 0 staining (Sigma Aldrich) and triglyceride measurements of both 3T3-L1 and SGBS cells during differentiation were performed following the manufacturer's instructions to determine adiposity. Cell count was determined using a Bürker-Türk counting chamber.

\section{Real-time polymerase chain reaction}

Total RNA was extracted from cells and VAT using TRIzol ${ }^{\circledR}$ (Invitrogen, Bleiswijk, The Netherlands), and reversed transcribed with the iScript cDNA synthesis kit (Biorad, Veenendaal, The Netherlands). Expression of target genes was measured quantitatively by real time PCR using SYBR Green mix (Bioline, London, United Kingdom). All primer sets used are listed in Supplementary Table 5.1. mRNA expression levels were normalised to two reference genes (cyclophilin A and $\beta 2$ microglobulin) and data were analysed with the $\Delta C T$ method. Data are expressed as normalized gene expression levels relative to control.

\section{Assessment of cardiac function, vascular stiffness, blood pressure and vascular function}

Cardiac dimensions and function were assessed under 2-3\% isoflurane anesthesia. Briefly, echocardiographic recordings were made in parasternal long-axis using a Vevo2100 imaging platform (Visual Sonics, Toronto, Canada). Data were derived from left ventricular (LV) images in end-diastole and peak systole, and average values over at least three different cycles were used for analyses. Stroke volume was calculated from subtracting peak systolic LV from end-diastolic LV and multiplied with heart rate to obtain cardiac output. Pulse wave velocity (PWV) was assessed using the Vevo2100 Ultrasound Machine. By visualizing the aortic arch, we measured the time frame of the forward wave (ECG triggered) between two aortic points and calculated the PWV. In a subset of mice, blood pressure was measured under isoflurane anesthesia by insertion of a PE-10 catheter in the abdominal aorta via the femoral artery and connected to a pressure transducer (Miller Instruments, Houston, TX, USA). The pressure signal was digitally sampled at $2 \mathrm{kHz}$ and systolic and diastolic blood pressures were calculated over a 10-15 min time period after stabilization of hemodynamic variables. 
After careful dissection of the aorta, an aortic segment of the descending thoracic aorta was excised just above the diaphragm. These segments were then mounted in a myograph organ bath (model 610M; Danish Myo Technology, Aarhus, Denmark) with two steel $40-\mu \mathrm{m}$ wires inserted through the lumen of the segments. The organ bath contained fresh Krebs-Ringer bicarbonate solution (KRB) consisting of $118 \mathrm{mM} \mathrm{NaCl}$; $4.7 \mathrm{mM} \mathrm{KCl} ; 1.2 \mathrm{mM} \mathrm{KH}_{2} \mathrm{PO}_{4} ; 25 \mathrm{mM} \mathrm{NaHCO}_{3} ; 1.1 \mathrm{mM} \mathrm{MgSO}_{4} ; 2.5 \mathrm{mM} \mathrm{CaCl}_{2}$ and 5.0 $\mathrm{mM}$ glucose, was maintained at $37{ }^{\circ} \mathrm{C}$ and was gassed continuously with $95 \% \mathrm{O}_{2}$ and $5 \% \mathrm{CO}_{2}$ ( $\mathrm{pH}$ 7.4). The internal diameter of each aorta was normalized by stretching the vessel to a diameter that yielded a wall tension equivalent to a transmural pressure of $100 \mathrm{mmHg}$. The isometric tension generated by the vessels was recorded using Powerlab 4/25 (ADInstruments, Oxford, U.K.), connected to the Myo Interface. Maximum contraction was measured by incubation with $125 \mathrm{mM} \mathrm{K}^{+}$plus $10 \mu \mathrm{M}$ phenylephrine (Sigma-Aldrich). Endothelium-independent vasorelaxation was tested with cumulative concentrations of acetylcholine (ACh, 0.001-10 $\mu \mathrm{M}$, Sigma Aldrich) during contraction, induced by $10 \mu \mathrm{M}$ phenylephrine, with pre-incubation of $10 \mu \mathrm{M}$ indomethacin (Sigma-Aldrich) to block the synthesis of prostaglandins, and $100 \mu \mathrm{M} \mathrm{L-}$ NAME (Sigma-Aldrich) to block eNOS.

\section{Statistical analyses}

All data are presented as means \pm standard error of the mean (SEM). Statistical analyses were performed with IBM SPSS Statistics Software, version 20 (IBM Corporation, Armonk, New York). One-way ANOVA was used to compare continuous variables between groups. Two-way repeated measures ANOVA was used to compare groups or conditions over time. A p-value $<0.05$ was considered statistically significant.

\section{Results}

\section{Delayed intervention with PM prevents body weight gain and improves} metabolic characteristics in HFD-induced obese mice

Six weeks of HFD feeding resulted in significantly increased body weight, plasma glucose and total cholesterol levels as compared with LFD control mice (Table 5.1). Water intake and urine production were not altered due to HFD. Thus, when we started PM intervention after the first 6 weeks, metabolic function of the HFD mice was already impaired. 
Table 5.1. Characteristics of the mice before intervention with PM.

\begin{tabular}{lll}
\hline Variable & LFD & HFD \\
\hline Body weight $(\mathrm{g})$ & $25.3 \pm 0.3$ & $28.2 \pm 0.4^{* * *}$ \\
Calorie intake (kcal/day) & $9.9 \pm 0.2$ & $11.1 \pm 0.3^{* *}$ \\
Fasting plasma glucose $(\mathrm{mM})$ & $8.0 \pm 0.4$ & $10.5 \pm 0.4^{* * *}$ \\
Fasting total cholesterol $(\mathrm{mM})$ & $1.8 \pm 0.1$ & $2.4 \pm 0.1^{* * *}$ \\
Water intake $(\mathrm{mL} /$ day) & $2.5 \pm 0.1$ & $2.6 \pm 0.04$ \\
Urine production $(\mu \mathrm{L} /$ day) & $456 \pm 134$ & $659 \pm 90$ \\
\hline
\end{tabular}

Data are presented as means \pm SEM. ${ }^{* * *} \mathrm{p}<0.001,{ }^{* *} \mathrm{p}<0.01$ compared to LFD. $\mathrm{N}=15$ and 30 mice for LFD and HFD, respectively.

Metabolic characteristics of the mice at the end of the study are shown in Figure 5.1. Administration of PM to the drinking water for 18 weeks inhibited body weight gain in HFD mice (Figure 5.1A and B), despite equal calorie intake (Figure 5.1C). In addition, we observed a trend towards metabolic improvement by PM supplementation for plasma glucose and cholesterol (Figure 5.1D and E), whereas plasma insulin and leptin levels were significantly reduced by PM treatment in HFD-fed mice (Figure 5.1F and $\mathrm{G})$. There were no differences in water intake and urine production between the groups HFD and HFD + PM (data not shown).

A

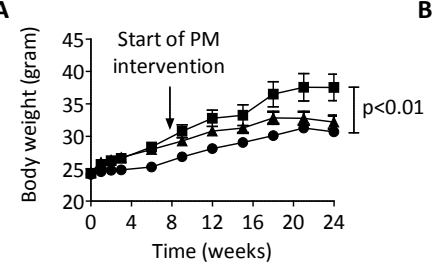

D

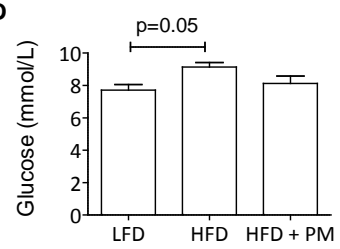

F

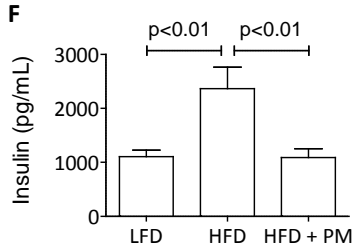

B

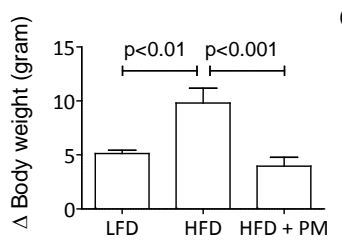

E

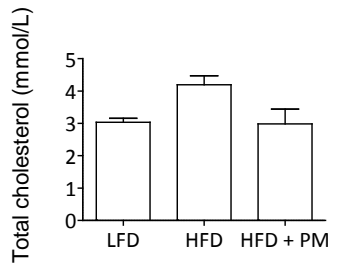

G

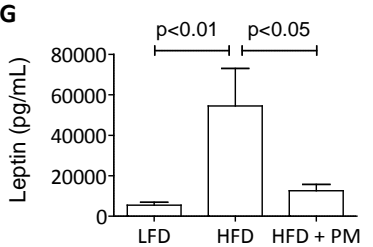

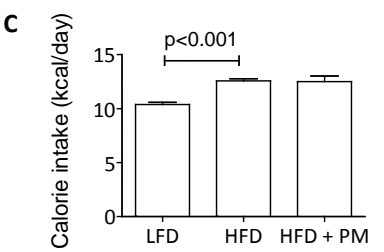

Figure 5.1 - Metabolic parameters of the mice at the end of the study. (A) Progress of body weight over time. (B) Body weight gain during the study. (C) Average calorie intake during the study. (D) Fasting plasma glucose, $(E)$ cholesterol, $(F)$ insulin and $(G)$ leptin levels. Data represent means \pm SEM. $N=11-15$ mice per group. Circles $=$ LFD, squares $=$ HFD, triangles $=$ HFD + PM. 


\section{Glucose tolerance and insulin sensitivity are improved by PM in both}

\section{HFD-induced and db/db obese mice}

We further studied the effect of PM on metabolic function with both an IPGTT and an IPITT after 13 weeks of PM treatment. Results of the IPGTT demonstrated that HFD mice had significantly lower glucose tolerance compared to LFD mice, which was improved by PM (Figure 5.2A). After insulin injection, we found an impaired decline in glucose in the HFD group in comparison to the LFD group with an attenuation of this impairment by PM (Figure 5.2B). These results demonstrate that treatment with PM is associated with general improvement in glucose tolerance and insulin sensitivity. We also performed the IPGTT and IPITT in obese $\mathrm{db} / \mathrm{db}$ mice, treated and not treated with PM. In line with our data from the HFD mice, PM also improved both glucose tolerance (Figure 5.2C) and insulin sensitivity (Figure 5.2D) in $\mathrm{db} / \mathrm{db}$ mice.

A

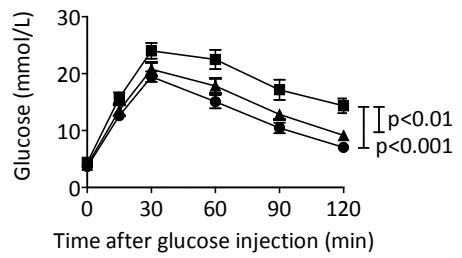

C

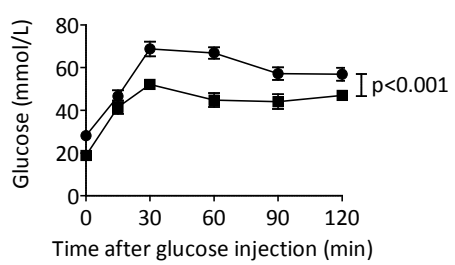

B

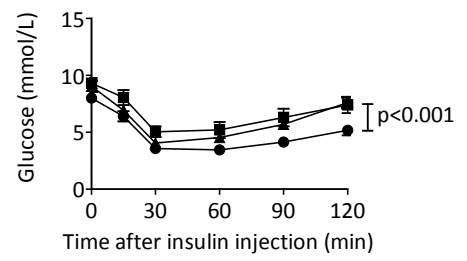

D

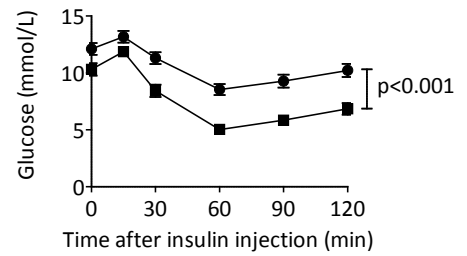

Figure 5.2 - PM prevents insulin resistance in HFD-induced and $\mathbf{d b} / \mathbf{d b}$ obese mice. Glucose homeostasis was assessed by an IPGTT (A) and an IPITT (B) in LFD mice, HFD mice and HFD + PM mice. In addition, the IPGTT (C) and IPITT (D) were also performed in $\mathrm{db} / \mathrm{db}$ mice, either or not treated with PM. Data represent means \pm SEM. For $A$ and $B$ : circles $=L F D$, squares $=H F D$, triangles $=H F D+P M$. For $C$ and $D$ : circles $=d b / d b$, squares $=d b / d b+P M$. For $A+B, n=13-15$ mice per group. For $C+D, n=7-15$ mice per group. IPGTT, intraperitoneal glucose tolerance test; IPITT, intraperitoneal insulin tolerance test. 


\section{PM prevents adipose tissue expansion and hypertrophy by inhibiting}

\section{adipogenesis}

Histochemistry demonstrated enlarged adipocytes in VAT of HFD mice in comparison to LFD mice (Figure 5.3A). Morphometric analysis demonstrated an increased cell size and adipocyte diameter in the HFD group compared to the LFD control group (Figure 5.3B and C). Both the HFD-induced increase in adipocyte diameter and cell size were attenuated by PM. In addition, the HFD-induced increase in mass of VAT was attenuated by PM (Figure 5.3D). To investigate the potential of PM to inhibit glycation in VAT, we assessed levels of the $\alpha$-dicarbonyls MGO, GO and 3-DG (Figure 5.3E-G). We observed a trend towards increased $\alpha$-dicarbonyl levels in VAT of the HFD group, which was reduced by PM. Activity of the GLO1, the major enzyme for the detoxification of $\alpha$-dicarbonyls, was reduced in VAT in the HFD group, although not statistically significant, and was improved by PM (Figure 5.3H). The $\alpha$-dicarbonyl levels, as well as GLO-1 activity, did not differ between LFD and HFD in the subcutaneous adipose tissue (data not shown).

To elucidate the mechanism behind PM-induced improvements of adiposity, we used two in vitro models of adipogenesis: murine 3T3-L1 and human SGBS preadipocytes. Both cell lines were differentiated by the appropriate differentiation mix, in the presence or absence of 2 and/or $5 \mathrm{mM}$ PM. Pictures of 3T3-L1 adipocytes demonstrated that cells differentiated in the presence of $5 \mathrm{mM}$ PM contained less fat droplets compared to untreated adipocytes (Figure 5.4A). Inhibition of adipogenesis by $\mathrm{PM}$ was confirmed by Oil Red $\mathrm{O}$ staining (Figure $5.4 \mathrm{~B}$ ), triglyceride quantification (Figure $5.4 \mathrm{C}$ ), and quantitative analysis of expression of the adipogenic markers peroxisome proliferator-activated receptor $\gamma$ (PPAR $\gamma)$, CCAAT/enhancer-binding protein $\alpha(C / E B P \alpha)$, sterol regulatory element binding protein $1 C$ (SREBP-1C), fatty acid synthase (FASN), lipoprotein lipase (LPL) and cluster of differentiation 36 (CD36) (Figure 5.4D-I). Gene expression levels of SREBP cleavage-activating protein (SCAP) were neither affected by HFD, nor by PM (data not shown). Oil Red O staining and triglyceride quantification demonstrated a dose-dependent effect of PM on adipogenesis. These findings were all confirmed in human SGBS adipocytes (data not shown). We also investigated whether incubation with PM had already an effect on adipogenesis of 3T3-L1 cells in the first two days of the differentiation process, in which the preadipocytes still have the capacity to proliferate. To study this, 3T3-L1 preadipocytes were differentiated into adipocytes and $5 \mathrm{mM}$ PM was added from upon the start of the differentiation process $(T=0)$ or two days later $(T=2)$. We found that treatment with $\mathrm{PM}$ from upon $\mathrm{T}=0$ inhibited adipogenesis even more than when PM was added from upon $\mathrm{T}=2$, as reflected by Oil Red $\mathrm{O}$ absorbance and PPARY MRNA expression (Supplementary Figure 5.1A and B). Moreover, incubation with $5 \mathrm{mM}$ PM had no effect on proliferation of the 3T3-L1 preadipocytes during the first two days of the differentiation process (Supplementary Figure 5.1C). 
B

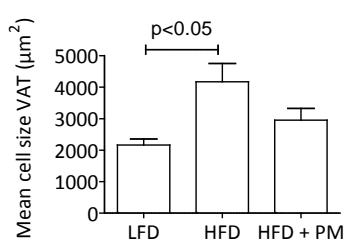

E

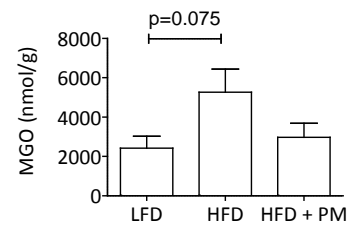

H

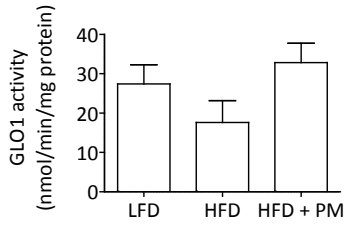

C $\bar{\varepsilon}$

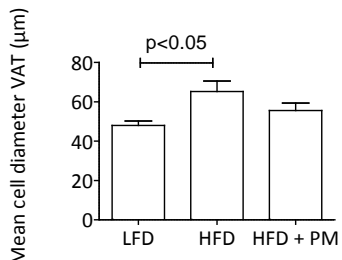

$\mathbf{F}$

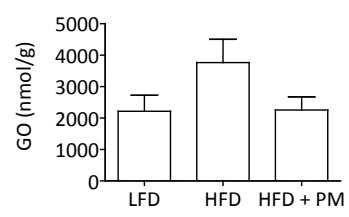

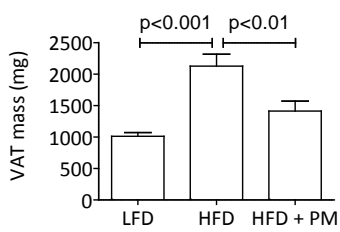

G

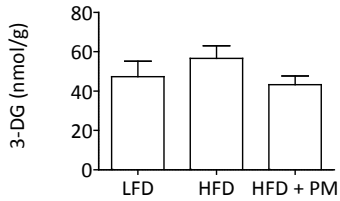

Figure 5.3 - PM reduces obesity-related adiposity and partially prevents formation of $\alpha$-dicarbonyls in adipose tissue. (A) Representative pictures of histochemical haematoxylin and eosin stainings of visceral adipose tissue, used for quantification of cell size (B) and diameter of individual adipocytes (C). (D) Weight of visceral adipose mass. (E) MGO, (F) GO and (G) 3-DG levels in visceral adipose tissue. (H) Activity of the GLO1 enzyme in visceral adipose tissue. Data represent means \pm SEM. $\mathrm{N}=11-15$ mice per group. VAT, visceral adipose tissue; MGO, methylglyoxal; GO, glyoxal; 3-DG, 3-deoxyglucosone; GLO1, glyoxalase 1.

\section{Lipid content in the liver of HFD-induced obese mice is reduced by PM}

As the liver often serves as an ectopic site of fat deposition, we investigated whether a reduction in adiposity by PM would lead to a flux of fat to the liver of HFD mice. H\&E staining of liver sections demonstrated that livers of HFD mice contained more fat droplets (Figure 5.5A and B). Treatment with PM in HFD mice resulted in less fat droplets in the liver. In line, triglyceride content was increased in the liver of HFD mice, but this was reduced by treatment with PM (Figure 5.5C). Thus, reduction in white adipose tissue by PM did not lead to ectopic fat deposition in the liver. 
A
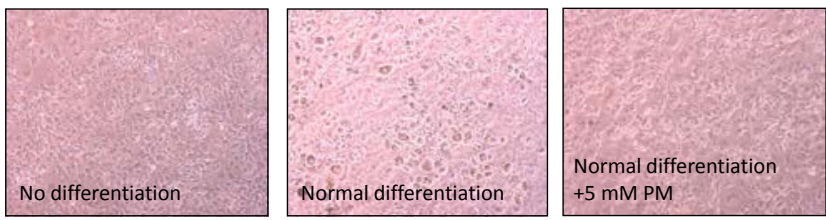

B
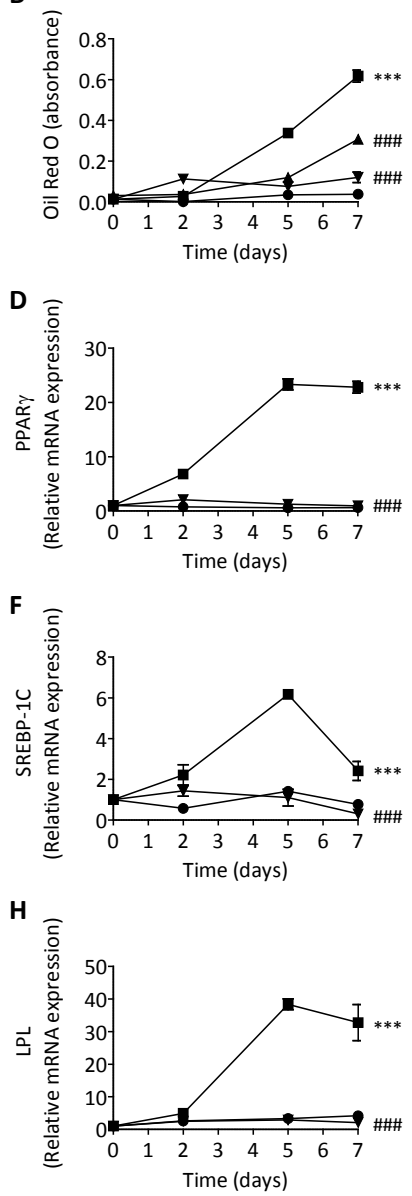

C

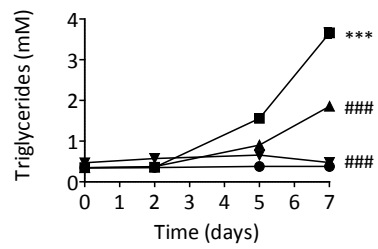

E

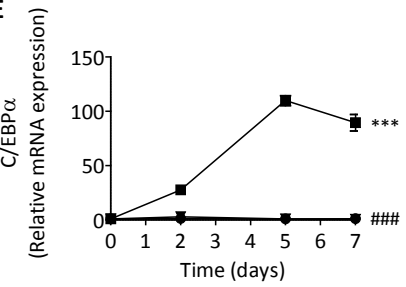

G

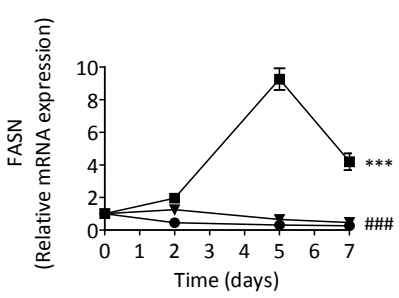

I

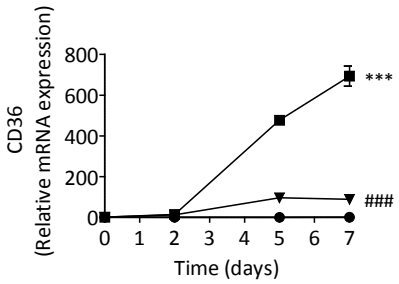

Figure 5.4 - PM inhibits adipogenesis in vitro in a dose-dependent way. (A and B) Oil Red O staining of differentiating 3T3-L1 adipocytes. (C) Triglyceride content in 3T3-L1 adipocytes during 7 days of adipogenic differentiation. (D-I) Gene expression levels of adipogenic markers in differentiating murine 3T3-L1 adipocytes. Data represent means \pm SEM. ${ }^{* * *} p<0.001$ : normal differentiation compared to no differentiation and \#\#\#p<0.001: normal differentiation + 2 or 5 mM PM compared to normal differentiation. For B-C: Circles $=$ no differentiation, squares $=$ normal differentiation, tiles $=$ normal differentiation $+2 \mathrm{mM}$ $\mathrm{PM}$, triangles $=$ normal differentiation $+5 \mathrm{mM}$ PM. For D-I: circles = no differentiation, squares = normal differentiation, triangles $=$ normal differentiation $+5 \mathrm{mM}$ PM. PPAR $\gamma$, peroxisome proliferator-activated

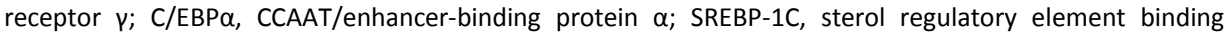
protein 1C; FASN, fatty acid synthase; LPL, lipoprotein lipase; CD36, cluster of differentiation 36. 
A
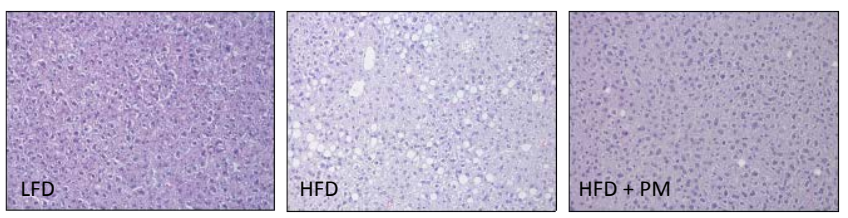

B

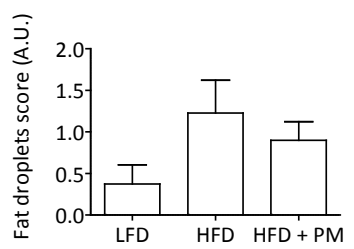

C

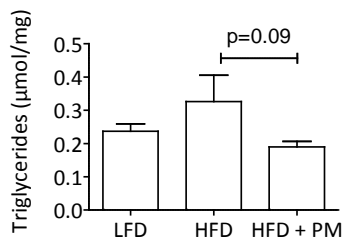

Figure 5.5 - PM reduces HFD-induced moderate fat deposition in the liver. (A) Representative pictures of haematoxylin and eosin stainings of the liver, showing fat droplets. (B) Quantification of the liver fat droplets as shown in $A$. (C) Triglyceride content in the liver. Data represent means \pm SEM. $N=11-15$ mice per group. A.U., arbitrary units.

\section{PM prevents HFD-induced adipose tissue inflammation}

To further examine the effect of PM on HFD-induced metabolic dysfunction in mice, we first characterised the VAT on the level of inflammation. Histochemical staining revealed increased accumulation of macrophages in VAT of HFD mice, compared to that of LFD mice (Figure 5.6A and B). The formation of these so-called crown-like structures was ameliorated by PM. Quantitative analyses of inflammatory gene expression levels demonstrated that HFD-induced gene expression levels of tumor necrosis factor $\alpha$ (TNF $\alpha)$, monocyte chemotactic protein 1 (MCP-1), CD11c and major histocompatibility complex II (MHC-II), and HFD-induced reduction of adiponectin were attenuated by PM treatment (Figure 5.6C-G). In plasma, however, we did not find any differences in the concentration of IFN- $\gamma$, interleukin (IL)-1 $\beta$, IL-10, IL-12, IL-2, IL-6, TNF $\alpha$ and mouse keratinocyte-derived chemokine (mKC) between the groups (data not shown).

\section{HFD-induced mild vascular dysfunction is partially prevented by PM}

Acetylcholine-induced endothelium-independent vasorelaxation of mouse aortas was slightly impaired in HFD mice (Figure 5.7A). This was improved when mice were treated with $\mathrm{PM}$, although not statistically significant. The $\log \mathrm{EC}_{50}$ of acetylcholine to achieve $50 \%$ of the maximal vasorelaxation was reduced in the HFD group, which was prevented by PM (Figure 5.7B). Neither HFD, nor PM had an effect on other vascular parameters including systolic blood pressure, diastolic blood pressure, heart rate, cardiac output, ejection fraction and pulse wave velocity (Supplementary Figure 5.2). 
A

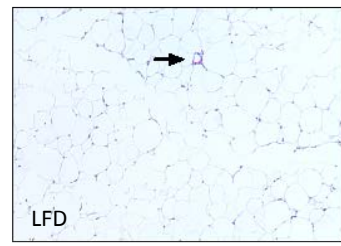

B
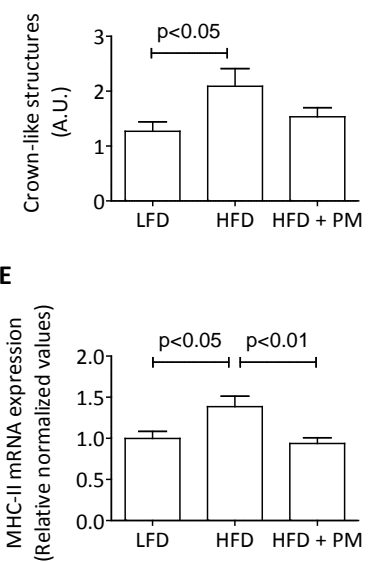
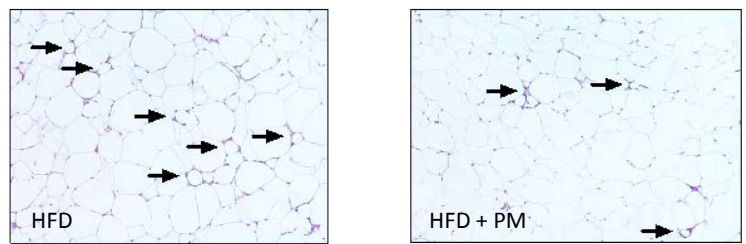

C
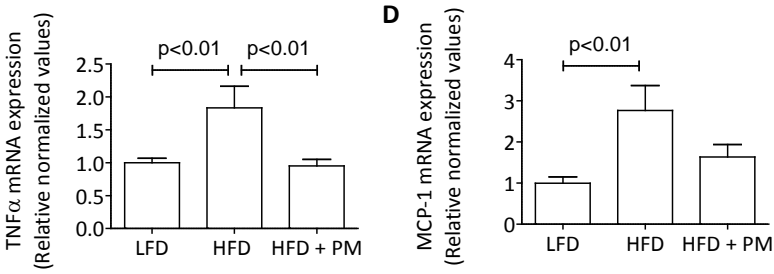

G

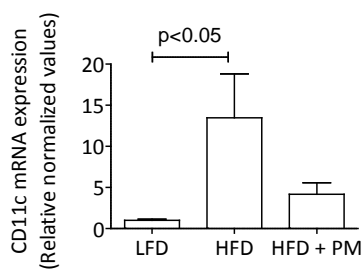

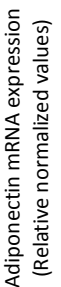

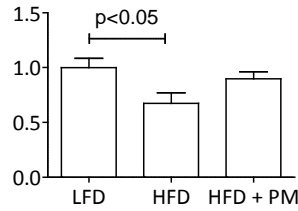

Figure 5.6 - HFD-induced inflammation in visceral adipose tissue is prevented by PM. (A) Representative pictures of haematoxylin and eosin stainings of visceral adipose tissue, showing crown-like structures. (B) Quantification of crown-like structures as shown in A. qPCR is used for quantification of gene expression of the inflammatory markers TNF $\alpha$ (C), MCP-1 (D), MHC-II (E), CD11C (F) and adiponectin (G). Data represent means \pm SEM. $N=11-15$ mice per group. TNF $\alpha$, tumor necrosis factor $\alpha$; MCP-1, monocyte chemotactic protein 1; MHC-II, major histocompatibility complex II.

\section{Discussion}

In the present study, we investigated the effects of PM on obesity and its related complications. We have shown that obesity-associated metabolic dysfunction and complications in obese mice were ameliorated by a delayed intervention with PM. HFD-induced increases in body weight, hyperglycemia, hypercholesterolemia and levels of leptin and insulin were all reduced by PM. In addition, PM is associated with a general increase in glucose tolerance and insulin sensitivity. Furthermore, expansion of adipose tissue and hypertrophy of adipocytes in obese mice were inhibited by PM, most likely via inhibition of adipogenesis. PM improved vasorelaxation of the aorta, but it had no observable effect on other vascular parameters.

By feeding mice a HFD, we induced a state of metabolic dysfunction, as indicated by an increase in body weight and severe hyperglycemia and hypercholesterolemia, and increased plasma levels of insulin and leptin. We have shown, in a delayed 
intervention study with PM, that PM was able to improve these metabolic dysfunctions, including a reduction in insulin resistance in both HFD mice and $\mathrm{db} / \mathrm{db}$ mice.

A

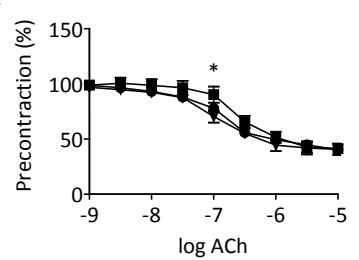

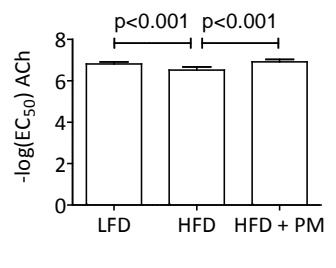

Figure 5.7 - PM partially prevents mild HFD-induced vascular dysfunction. (A) Acetylcholine (ACh)-induced endothelium-independent vasorelaxation of isolated aortas. (B) $-\operatorname{LogEC}_{50}$ of $A C h$ in endotheliumindependent vasorelaxation of the aorta. Data represent means \pm SEM. ${ }^{*} p<0.05$, HFD compared to LFD. $\mathrm{N}=11-14$ mice per group. Circles $=$ LFD, squares $=$ HFD, triangles $=$ HFD + PM. ACh, acetylcholine .

The beneficial effect of PM on metabolic function was also reflected by a reduction of the VAT mass, most likely via inhibition of adipogenesis. This concept was demonstrated in vitro by reduced Oil Red $\mathrm{O}$ staining and triglyceride content in differentiating murine 3T3-L1 and human SGBS cells. In addition, we found that PM limited the induction of important adipogenic differentiation genes such as PPAR $\gamma$, C/EBP $\alpha$, SREBP-1C, FASN, LPL and CD36. SREBP-1C is a transcription factor which is known to induce expression of adipogenic genes such as LPL and FASN, but it also induces PPARy expression, which enhances adipogenic genes expression even more. ${ }^{15}$ ${ }^{16}$ As both SREBP-1C and PPARY expression and expression of their target genes are decreased, this suggests an inhibitory effect of PM on adipogenesis, possibly via inhibition of SREBP-1C. In the literature, it has been described that the AGE $N(\varepsilon)$ (carboxymethyl)lysine (CML) interferes with the SREBP cleavage-activating protein (SCAP)/SREBP-1C pathway. ${ }^{17,18}$ In our study, we did not find any effect of PM on mRNA expression levels of SCAP in adipocytes. However, in different cell types CML has been described to co-localize with SCAP, ${ }^{17-19}$ suggesting a considerable glycation of SCAP, and consequently leading to altered function of SCAP. Therefore, the glycation of SCAP, along with the possible direct effects of PM, may be a possible mechanism by which AGEs enhance adipogenesis. The dangerous reverse side of smaller fat depots in obesity is ectopic fat deposition. The most important organ that is known to be at risk for ectopic fat deposition is the liver. However, in this study, we demonstrated that the inhibition of adipogenesis by PM in HFD mice did not lead to fatty liver disease. On the contrary, PM treatment resulted in less fat content in HFD livers. 
Obesity is associated with a dysregulated expression of adipocytokines. ${ }^{2,}{ }^{20}$ We and others have very recently demonstrated that AGEs are implicated herein. ${ }^{2,21,22}$ In the current study, the accumulation of macrophages, the so-called crown-like structures, and increased pro-inflammatory gene expression levels in VAT of HFD mice were observed and the number of crown-like structures and expression of proinflammatory cytokines TNF $\alpha, \mathrm{MCP}-1, \mathrm{CD} 11 \mathrm{c}$ and MHC-II were strongly reduced by PM; whereas, the expression of the anti-inflammatory cytokine adiponectin was increased. Thus, supplementation with PM was associated with a normalization of the inflammatory phenotype of VAT in HFD mice. These results are in line with our previous work, in which we demonstrated that CML accumulation in adipose tissue of obese $\mathrm{db} / \mathrm{db}$ mice was associated with a pro-inflammatory phenotype of the adipose tissue. When the receptor for AGEs (RAGE) was absent, inflammation levels were normalized. $^{2}$ Together, these data form a strong body of evidence that the accumulation of AGEs in adipose tissue plays a key role in the pathogenesis of adipose tissue inflammation.

In VAT of HFD mice, we found a trend toward decreased GLO1 activity. Because inflammation reduces GLO1 activity, ${ }^{23}$ the pro-inflammatory phenotype of VAT in HFD mice is most likely responsible for the reduction in GLO1 activity. In line with this, PM reduces adipose tissue inflammation and, thus, causes normalization of GLO1 activity in VAT of HFD mice.

Some of our findings regarding PM have previously been described in comparable studies. ${ }^{24,}{ }^{25}$ However, in those studies, PM had been administered to mice from the start of the HFD, implying that metabolic function at the start of PM treatment was not comparable to that of obesity. Because we hypothesize that PM might be a potential treatment for obesity and its comorbidities, we mimicked the human situation by starting treatment with PM when obesity had already developed. To the best of our knowledge, our study is the first study to use PM in such a delayed intervention.

Although AGEs have been described in relation to vascular complications, ${ }^{26}$ we only found an improvement in aortic vasorelaxation, while improvements of additional vascular parameters were lacking. These findings are in line with those of Hagiwara et al., ${ }^{24}$ who similarly found no effect of PM on blood pressure in HFD-induced obese mice. In aged mice, however, it has been noted that PM prevents age-related aortic stiffening and vascular resistance in association with reduced collagen glycation. ${ }^{27}$ Since we did not see large effects of HFD on development of serious (cardio)vascular complications within 24 weeks of HFD, age-related AGE accumulation may be more relevant for vascular complications than obesity-related AGE accumulation. It might 
be that our animals were not old enough to develop (cardio)vascular complications at HFD.

In clinical trials, treatment with PM has mainly been described in the setting of diabetic nephropathy. Several preclinical studies in animal models of diabetic nephropathy have demonstrated that oral supplementation of PM is effective in preserving renal function. ${ }^{28-32}$ In a combined multicenter phase II trial involving type 2 diabetic patients with overt nephropathy, PM was demonstrated to be generally safe and to have a potential effect in preserving diabetic kidney function. ${ }^{11}$ In contrast, a second clinical trial reported no beneficial effect of PM in reducing creatinine levels, although it suggested that patients with less advanced renal impairment might benefit. ${ }^{12}$ A third clinical trial addressed the efficacy and tolerability of PM in osteoarthritis. ${ }^{33}$ It reported no adverse effects after 6 months of PM treatment, while a combined treatment with PM significantly decreased AGEs, inflammation and pain in patients with osteoarthritis.

In conclusion, we have demonstrated that a delayed intervention with PM is associated with improvement of several aspects of obesity including metabolic dysfunction, insulin resistance and adipose tissue inflammation. These findings indicate that PM may be a potential novel treatment for obesity-associated metabolic dysfunction and complications. A clinical trial with PM in obese individuals would elucidate the efficacy of PM in human obesity complications. 


\section{References}

1. Cao H. Adipocytokines in obesity and metabolic disease. J Endocrinol. 2014;220:T47-59

2. Gaens KH, Goossens GH, Niessen PM, van Greevenbroek MM, van der Kallen CJ, Niessen HW, Rensen SS, Buurman WA, Greve JW, Blaak EE, van Zandvoort MA, Bierhaus A, Stehouwer CD, Schalkwijk CG. Nepsilon-(carboxymethyl)lysine-receptor for advanced glycation end product axis is a key modulator of obesity-induced dysregulation of adipokine expression and insulin resistance. Arterioscler Thromb Vasc Biol. 2014;34:1199-1208

3. Song F, Hurtado del Pozo C, Rosario R, Zou YS, Ananthakrishnan R, Xu X, Patel PR, Benoit VM, Yan SF, Li H, Friedman RA, Kim JK, Ramasamy R, Ferrante AW, Jr., Schmidt AM. Rage regulates the metabolic and inflammatory response to high-fat feeding in mice. Diabetes. 2014;63:1948-1965

4. Schalkwijk CG, Brouwers O, Stehouwer CD. Modulation of insulin action by advanced glycation endproducts: A new player in the field. Horm Metab Res. 2008;40:614-619

5. Sandu O, Song K, Cai W, Zheng F, Uribarri J, Vlassara H. Insulin resistance and type 2 diabetes in highfat-fed mice are linked to high glycotoxin intake. Diabetes. 2005;54:2314-2319

6. Thornalley PJ, Langborg A, Minhas HS. Formation of glyoxal, methylglyoxal and 3-deoxyglucosone in the glycation of proteins by glucose. Biochem J. 1999;344 Pt 1:109-116

7. Schalkwijk CG, Miyata T. Early- and advanced non-enzymatic glycation in diabetic vascular complications: The search for therapeutics. Amino Acids. 2012;42:1193-1204

8. Booth AA, Khalifah RG, Hudson BG. Thiamine pyrophosphate and pyridoxamine inhibit the formation of antigenic advanced glycation end-products: Comparison with aminoguanidine. Biochem Biophys Res Commun. 1996;220:113-119

9. Voziyan PA, Hudson BG. Pyridoxamine as a multifunctional pharmaceutical: Targeting pathogenic glycation and oxidative damage. Cell Mol Life Sci. 2005;62:1671-1681

10. Engelen L, Stehouwer CD, Schalkwijk CG. Current therapeutic interventions in the glycation pathway: Evidence from clinical studies. Diabetes Obes Metab. 2013;15:677-689

11. Williams ME, Bolton WK, Khalifah RG, Degenhardt TP, Schotzinger RJ, McGill JB. Effects of pyridoxamine in combined phase 2 studies of patients with type 1 and type 2 diabetes and overt nephropathy. Am J Nephrol. 2007;27:605-614

12. Lewis EJ, Greene T, Spitalewiz S, Blumenthal S, Berl T, Hunsicker LG, Pohl MA, Rohde RD, Raz I, Yerushalmy Y, Yagil Y, Herskovits T, Atkins RC, Reutens AT, Packham DK, Lewis JB. Pyridorin in type 2 diabetic nephropathy. J Am Soc Nephrol. 2012;23:131-136

13. Scheijen JL, Schalkwijk CG. Quantification of glyoxal, methylglyoxal and 3-deoxyglucosone in blood and plasma by ultra performance liquid chromatography tandem mass spectrometry: Evaluation of blood specimen. Clin Chem Lab Med. 2014;52:85-91

14. McLellan AC, Phillips SA, Thornalley PJ. The assay of s-d-lactoylglutathione in biological systems. Anal Biochem. 1993;211:37-43

15. Kim JB, Spiegelman BM. Add1/srebp1 promotes adipocyte differentiation and gene expression linked to fatty acid metabolism. Genes Dev. 1996;10:1096-1107

16. Fajas L, Schoonjans K, Gelman L, Kim JB, Najib J, Martin G, Fruchart JC, Briggs M, Spiegelman BM, Auwerx J. Regulation of peroxisome proliferator-activated receptor gamma expression by adipocyte differentiation and determination factor 1 /sterol regulatory element binding protein 1: Implications for adipocyte differentiation and metabolism. Mol Cell Biol. 1999;19:5495-5503

17. Mastrocola R, Collino M, Nigro D, Chiazza F, D'Antona G, Aragno M, Minetto MA. Accumulation of advanced glycation end-products and activation of the scap/srebp lipogenetic pathway occur in dietinduced obese mouse skeletal muscle. PLoS One. 2015;10:e0119587

18. Mastrocola R, Collino M, Rogazzo M, Medana C, Nigro D, Boccuzzi G, Aragno M. Advanced glycation end products promote hepatosteatosis by interfering with scap-srebp pathway in fructose-drinking mice. Am J Physiol Gastrointest Liver Physiol. 2013;305:G398-407

19. Yuan Y, Zhao L, Chen Y, Moorhead JF, Varghese Z, Powis SH, Minogue S, Sun Z, Ruan XZ. Advanced glycation end products (ages) increase human mesangial foam cell formation by increasing golgi scap glycosylation in vitro. Am J Physiol Renal Physiol. 2011;301:F236-243

20. Leal Vde O, Mafra D. Adipokines in obesity. Clin Chim Acta. 2013;419:87-94

21. Stirban A, Negrean M, Gotting C, Uribarri J, Gawlowski T, Stratmann B, Kleesiek K, Koschinsky T, Vlassara H, Tschoepe D. Dietary advanced glycation endproducts and oxidative stress: In vivo effects on endothelial function and adipokines. Ann N Y Acad Sci. 2008;1126:276-279 
22. Gaens KH, Stehouwer CD, Schalkwijk CG. Advanced glycation endproducts and its receptor for advanced glycation endproducts in obesity. Curr Opin Lipidol. 2013;24:4-11

23. Hanssen NM, Wouters K, Huijberts MS, Gijbels MJ, Sluimer JC, Scheijen JL, Heeneman S, Biessen EA, Daemen MJ, Brownlee M, de Kleijn DP, Stehouwer CD, Pasterkamp G, Schalkwijk CG. Higher levels of advanced glycation endproducts in human carotid atherosclerotic plaques are associated with a rupture-prone phenotype. Eur Heart J. 2014;35:1137-1146

24. Hagiwara S, Gohda T, Tanimoto M, Ito T, Murakoshi M, Ohara I, Yamazaki T, Matsumoto M, Horikoshi $\mathrm{S}$, Funabiki K, Tomino Y. Effects of pyridoxamine (k-163) on glucose intolerance and obesity in highfat diet c57bl/6j mice. Metabolism. 2009;58:934-945

25. Unoki-Kubota H, Yamagishi S, Takeuchi M, Bujo H, Saito Y. Pyridoxamine, an inhibitor of advanced glycation end product (age) formation ameliorates insulin resistance in obese, type 2 diabetic mice. Protein Pept Lett. 2010;17:1177-1181

26. Stirban A, Gawlowski T, Roden M. Vascular effects of advanced glycation endproducts: Clinical effects and molecular mechanisms. Mol Metab. 2014;3:94-108

27. Wu ET, Liang JT, Wu MS, Chang KC. Pyridoxamine prevents age-related aortic stiffening and vascular resistance in association with reduced collagen glycation. Exp Gerontol. 2011;46:482-488

28. Degenhardt TP, Alderson NL, Arrington DD, Beattie RJ, Basgen JM, Steffes MW, Thorpe SR, Baynes JW. Pyridoxamine inhibits early renal disease and dyslipidemia in the streptozotocin-diabetic rat. Kidney Int. 2002;61:939-950

29. Zhu P, Lin H, Sun C, Lin F, Yu H, Zhuo X, Zhou C, Deng Z. Synergistic effects of telmisartan and pyridoxamine on early renal damage in spontaneously hypertensive rats. Mol Med Rep. 2012;5:655662

30. Waanders F, van den Berg E, Nagai R, van Veen I, Navis G, van Goor H. Renoprotective effects of the age-inhibitor pyridoxamine in experimental chronic allograft nephropathy in rats. Nephrol Dial Transplant. 2008;23:518-524

31. Alderson NL, Chachich ME, Youssef NN, Beattie RJ, Nachtigal M, Thorpe SR, Baynes JW. The age inhibitor pyridoxamine inhibits lipemia and development of renal and vascular disease in zucker obese rats. Kidney Int. 2003;63:2123-2133

32. Tanimoto M, Gohda T, Kaneko S, Hagiwara S, Murakoshi M, Aoki T, Yamada K, Ito T, Matsumoto M, Horikoshi S, Tomino Y. Effect of pyridoxamine (k-163), an inhibitor of advanced glycation end products, on type 2 diabetic nephropathy in kk-a(y)/ta mice. Metabolism. 2007;56:160-167

33. Garg S, Syngle A, Vohra K. Efficacy and tolerability of advanced glycation end-products inhibitor in osteoarthritis: A randomized, double-blind, placebo-controlled study. Clin J Pain. 2013;29:717-724 
124 Chapter 5 
SUPPLEMENTARY DATA

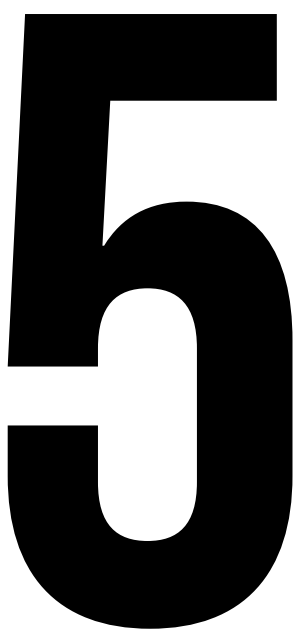


Supplementary Table 5.1 - Sequences of primers used for qPCR

\begin{tabular}{lll}
\hline Gene & Forward primer & Reverse primer \\
\hline PPAR $(\mathrm{m})$ & GCCCTGTCCCAGAGTGAAAG & GCATGTAGCGAATGAGCTGTA \\
C/EBP $\alpha(\mathrm{m})$ & GCGGGAACGCAACAACATC & GTCACTGGTCAACTCCAGCAC \\
SREBP-1C $(\mathrm{m})$ & ACTTTTCCTTAACGTGGGCCT & GCTGGAGCATGTCTTCGATGT \\
SCAP $(\mathrm{m})$ & ACTGGACTGAAGGCAGGTCAA & GCCTCTAGTCTAGGTCCAAAGAGTTG \\
FASN $(\mathrm{m})$ & AGAGATCCCGAGACGCTTCT & GCTTGGTCCTTTGAAGTCGAAGA \\
CD36 $(\mathrm{m})$ & GGAGCCATCTTTGAGCCTTCA & GAACCAAACTGAGGAATGGATCT \\
LPL $(\mathrm{m})$ & TGGCGTAGCAGGAAGTCTGA & TGCCTCCATTGGGATAAATGTC \\
TNF $\alpha(\mathrm{m})$ & TGGGAGTAGACAAGGTACAACCC & CATCTTCTCAAAATTCGAGTGACAA \\
MCP-1 $(\mathrm{m})$ & TTAAAAACCTGGATCGGAACCAA & GCATTAGCTTCAGATTTACGGGT \\
CD11c $(\mathrm{m})$ & GGGAGAAAACAAGGGGACA & GTATTCATGGGAAGGCATCG \\
MHC-II $(\mathrm{m})$ & CCTGGTGACTGCCATTACCT & GTAGCACTCGCCCATGAACT \\
Adiponectin $(\mathrm{m})$ & AAGGAGATGCAGGTCTTCTTGGT & CCCCGTGGCCCTTCAG \\
$\beta 2-$ microglobulin $(\mathrm{m})$ & CTTTCTGGTGCTTGTCTCACTGA & GTATGTTCGGCTTCCCATTCTC \\
Cyclophilin A $(\mathrm{m})$ & TTCCTCCTTTCACAGAATTATTCCA & CCGCCAGTGCCATTATGG \\
\hline
\end{tabular}

PPAR $\gamma$, peroxisome proliferator-activated receptor $\gamma$; C/EBP $\alpha$, CCAAT/enhancer-binding protein $\alpha$; SREBP$1 C$, sterol regulatory element binding protein $1 C$; SCAP, sterol regulatory element-binding protein cleavageactivating protein; FASN, fatty acid synthase; CD36, cluster of differentiation 36; LPL, lipoprotein lipase; TNF $\alpha$, Tumor necrosis factor $\alpha$; MCP-1, monocyte chemotactic protein 1; MHC-II, major histocompatibility complex II. $(\mathrm{m})$ indicates mouse primers.
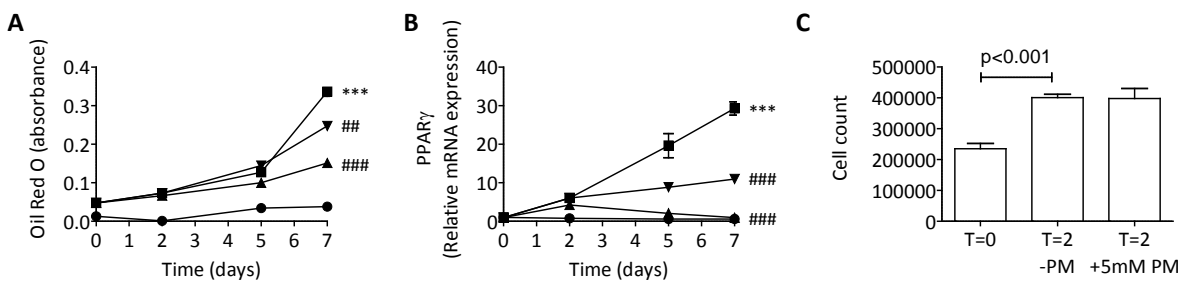

Supplementary Figure 5.1 - PM has a time-dependent effect on 3T3-L1 adipogenesis but does not influence proliferation during the first two days of differentiation. (A) Oil Red $O$ and (B) PPARY mRNA expression during differentiation with $5 \mathrm{mM}$ PM from upon $\mathrm{T}=0$ or $\mathrm{T}=2$. (C) Cell count of 3T3-L1 cells with or without $\mathrm{PM}$ at $\mathrm{T}=2$. Data represent means $\pm \mathrm{SEM}$. ${ }^{* * *} \mathrm{p}<0.001$ : normal differentiation compared to no differentiation and \#\#p<0.01, \#\#\#p<0.001: normal differentiation + $5 \mathrm{mM} P M$ from upon $\mathrm{T}=0$ or $\mathrm{T}=2$. Circles $=$ no differentiation, squares $=$ normal differentiation, tiles $=$ normal differentiation $+5 \mathrm{mM}$ PM from upon $\mathrm{T}=0$, triangles $=$ normal differentiation $+5 \mathrm{mM}$ PM from upon $\mathrm{T}=2$. PPAR $\gamma$, peroxisome proliferatoractivated receptor $\gamma$. 
A

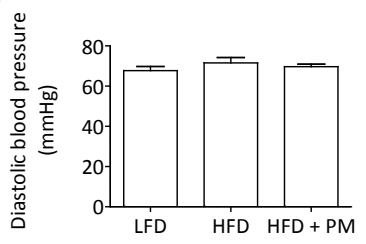

D

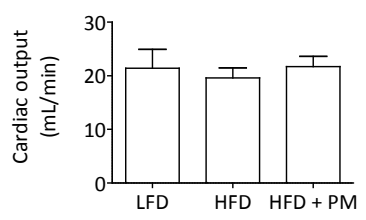

B

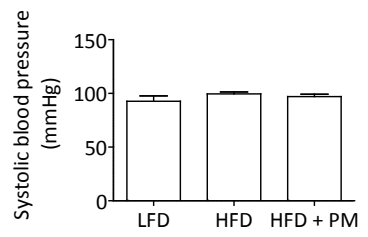

E

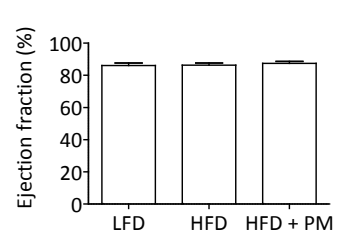

C

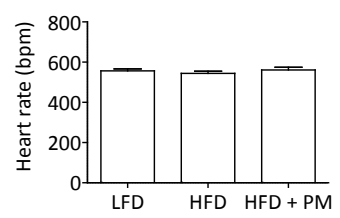

$F$

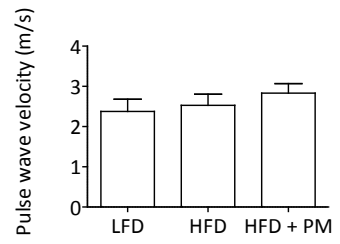

Supplementary Figure 5.2 - PM has no effect on several vascular parameters in HFD-induced obese mice. (A) Systolic blood pressure, (B) diastolic blood pressure and (C) heart rate measured with an inter-arterial Millar catheter, (D) cardiac output, (E) ejection fraction and (F) pulse wave velocity. Data represent means \pm SEM. for $A-C, n=6-7$ mice per group; for $D-F, n=11-15$ mice per group. 
128 Chapter 5 
This chapter is embargoed at request

GLYOXALASE-1 OVEREXPRESSION INHIBITS BODY WEIGHT GAIN AND GLUCOSE INTOLERANCE IN MICE WITH HIGH-FAT DIETINDUCED OBESITY

DIONNE E.M. MAESSEN, OLAF BROUWERS, JACK P.M. CLEUTJENS, KRISTIAAN WOUTERS, TOSHIO MIYATA, COEN D.A. STEHOUWER AND CASPER G. SCHALKWIJK 
SUPPLEMENTARY DATA

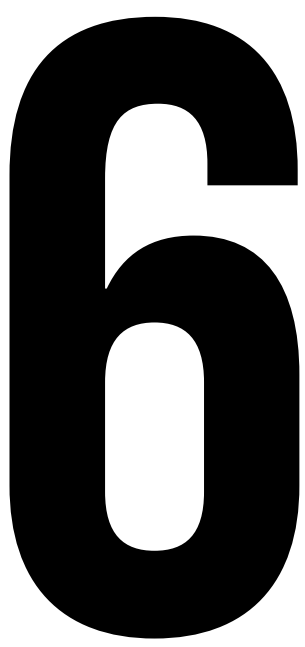


Supplementary Table 6.1 - Sequences of primers used for qPCR

\begin{tabular}{lll}
\hline Gene & Forward primer & Reverse primer \\
\hline TNF $\alpha$ & TGGGAGTAGACAAGGTACAACCC & CATCTTCTCAAAATTCGAGTGACAA \\
IL-6 & TTCAACCAAGAGGTAAAAGATTTACATAA & CACTCCTTCTGTGACTCCAGCTT \\
CD11C & GGGAGAAAACAAGGGGACA & GTATTCATGGGAAGGCATCG \\
Leptin & CCAAAACCCTCATCAAGACC & GGTGAAGCCCAGGAATGAAG \\
F4/80 & GGATGTACAGATGGGGGATG & TCTGTGGTGTCAGTGCAGGT \\
MCP-1 & TTAAAAACCTGGATCGGAACCAA & GCATTAGCTTCAGATTTACGGGT \\
MHC-II & CCTGGTGACTGCCATTACCT & GTAGCACTCGCCCATGAACT \\
Mannose receptor & TGCCAAAAATTATTGATCCTGTAACT & CGCCGGCACCTATCACA \\
\hline
\end{tabular}

TNF $\alpha$, tumor necrosis factor $\alpha$; IL-6, interleukin-6; MCP-1, monocyte chemotactic protein 1; MHC-II, major histocompatibility complex II. 


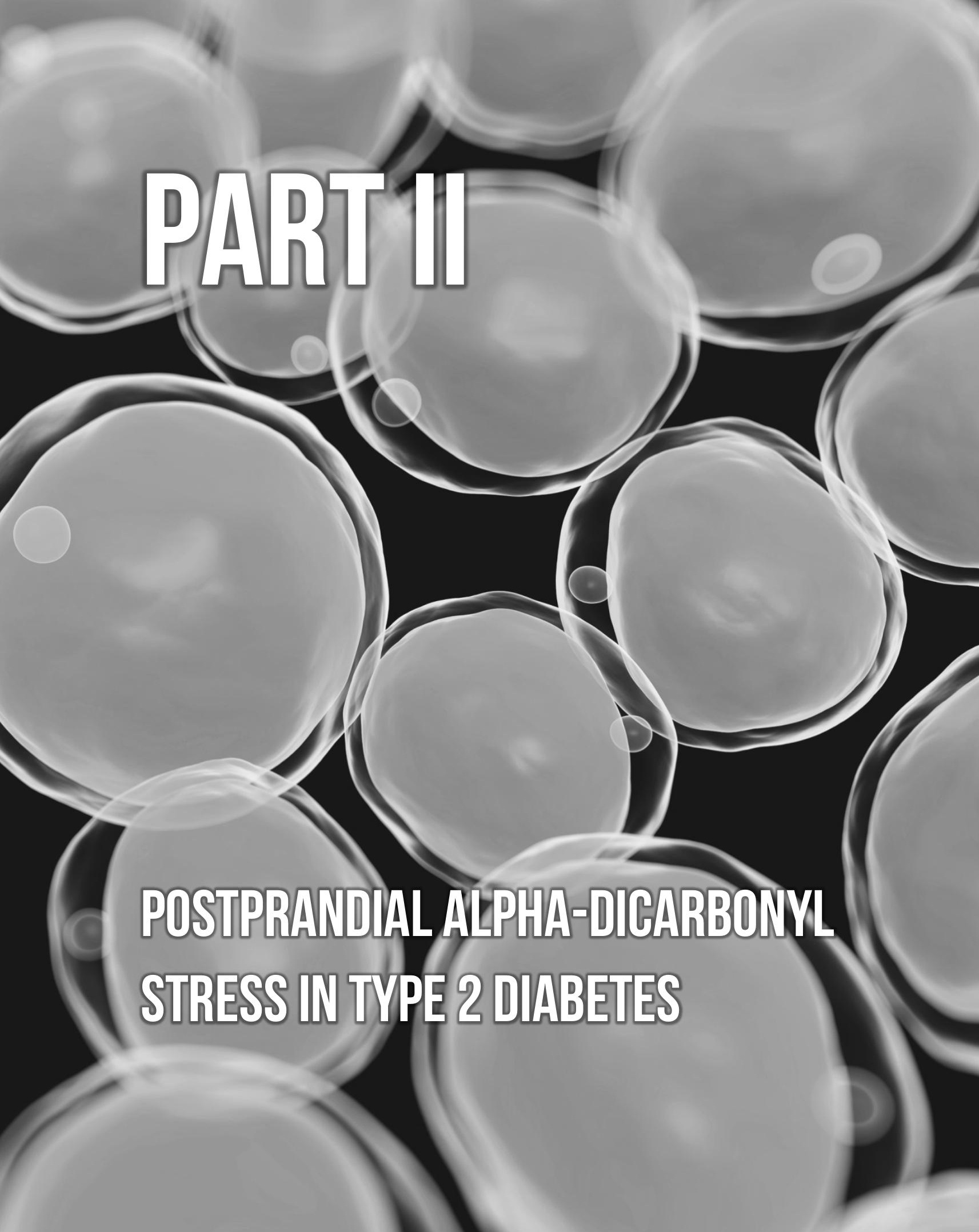




\section{POST-GLUCOSE LOAD PLASMA ALPHA-DICARBONYL CONCENTRATIONS ARE INCREASED IN INDIVIDUALS WITH IMPAIRED GLUCOSE METABOLISM AND TYPE 2 DIABETES: THE CODAM STUDY}

DIONNE E.M. MAESSEN, OLAF BROUWERS, JACK P.M. CLEUTJENS, KRISTIAAN WOUTERS, TOSHIO MIYATA, COEN D.A. STEHOUWER AND CASPER G. SCHALKWIJK 


\section{Abstract}

Objective: There is increasing evidence that postprandial glucose excursions play an important role in the development of vascular complications. The underlying mechanism is unknown, but glucose-derived formation of reactive $\alpha$-dicarbonyl compounds may explain why acute hyperglycemia leads to increased risk for diabetic complications. In the current study, we investigated whether $\alpha$-dicarbonyls are increased after a glucose load in individuals without and with impaired glucose metabolism (IGM) and type 2 diabetes.

Research Design and Methods: Cross-sectional, linear analyses were performed in the Cohort study on Diabetes and Atherosclerosis Maastricht (CODAM, $n=574,61 \%$ men, 60 years old). Individuals with normal glucose metabolism ( $n=279)$, IGM ( $n=120)$ and type 2 diabetes ( $n=92$ ) who had complete data on an oral glucose tolerance test (OGTT) and were not on insulin treatment were included in the study population. Plasma $\alpha$-dicarbonyl (methylglyoxal (MGO), glyoxal (GO) and 3-deoxyglucosone (3DG)) levels were measured in the fasting state and in samples of the OGTT by UPLCMS/MS.

Results: The presence of both IGM and type 2 diabetes was significantly associated with higher $\alpha$-dicarbonyl incremental area under the curves (iAUC), as calculated from the OGTT (for IGM: MGO $\beta=0.190,95 \% \mathrm{Cl}=0.106-0.274$; GO $\beta=0.287,95 \% \mathrm{Cl}=0.172$ 0.401 ; 3-DG $\beta=0.285,95 \% \mathrm{Cl}=0.221-0.349$; for type 2 diabetes: $M G O \beta=0.293,95 \%$ $\mathrm{Cl}=0.180-0.405$; GO $\beta=0.536,95 \% \mathrm{Cl}=0.382-0.689 ; 3-\mathrm{DG} \beta=0.542,95 \% \mathrm{Cl}=0.456$ 0.628). Adjustment for glucose iAUC attenuated these associations. iAUCs of the $\alpha$ dicarbonyls correlated highly with glucose iAUC, but not with fasting glucose levels and $\mathrm{HbA}_{1 \mathrm{C}}$.

Conclusions: The increased levels of $\alpha$-dicarbonyls during an OGTT in individuals with IGM and type 2 diabetes underline the potential importance of $\alpha$-dicarbonyl stress as a candidate to explain the increased risk of diabetic complications in individuals with postprandial hyperglycemia. 


\section{Introduction}

Type 2 diabetes and impaired glucose metabolism (IGM) are associated with the development of microvascular complications and cardiovascular disease (CVD). ${ }^{1}$ Prospective studies in diabetes have shown a strong correlation between mean glucose levels, as reflected by $\mathrm{HbA}_{1 \mathrm{c}}$, and diabetic complications. However, in recent years, postprandial glucose excursions, rather than fasting glucose concentrations or mean glucose levels, have increasingly been recognized as a contributing factor to the increased risk of vascular complications. ${ }^{2,3}$ Controlled clinical trials, such as the Diabetes Control and Complications Trial (DCCT) in type 1 diabetes, ${ }^{4}$ and the United Kingdom Prospective Diabetes Study (UKPDS) in type 2 diabetes, ${ }^{5}$ have established that intensive therapies which reduce $\mathrm{HbA}_{\mathrm{C}}$ levels, reduce and delay the development and progression of diabetes-related long-term vascular complications. Post-trial analyses of the DCCT revealed that post-meal glucose levels contribute more to $\mathrm{HbA}_{\mathrm{c}}$ than fasting plasma levels, ${ }^{6}$ suggesting that postprandial hyperglycemic spikes may accelerate the onset of diabetic complications. Moreover, many epidemiological data support this concept, showing that glucose levels after an oral glucose tolerance test (OGTT) are an independent risk factor for CVD, while fasting glucose levels are not or less so. ${ }^{2,}{ }^{7-11}$ In addition, postprandial glucose in type 2 diabetes predicts myocardial infarctions ${ }^{12}$ and is a risk factor for CVD. ${ }^{13}$ However, it is largely unknown how these postprandial glucose peaks cause the increased risk for diabetic complications. A possible mechanism through which they have a more damaging effect than high fasting or mean glucose levels might be via the formation of $\alpha$-dicarbonyls.

The $\alpha$-dicarbonyls, methylglyoxal (MGO), glyoxal (GO) and 3-deoxyglucoseone (3-DG), are mainly formed as glycolytic intermediates by metabolic conversion of glucose. We and others have shown the importance of $\alpha$-dicarbonyls in the development of nephropathy, ${ }^{14,}{ }^{15}$ retinopathy ${ }^{16}$ and neuropathy, ${ }^{17,18}$ and in macrovascular complications, ${ }^{19}$ using rodent models of diabetes.

We hypothesized that the postprandial glucose concentrations, rather than fasting plasma glucose, determine $\alpha$-dicarbonyl levels. Although Beisswenger et al. already demonstrated, in a small study of 21 individuals with type 1 diabetes, that both MGO and 3-DG plasma levels increase after postprandial glycemic excursions, ${ }^{20}$ the question whether $\alpha$-dicarbonyl levels are elevated in individuals with impaired glucose metabolism (IGM) and type 2 diabetes remains unanswered.

In the present study, we investigated, in a large cohort study, whether plasma levels of $\alpha$-dicarbonyls are elevated in individuals with IGM and type 2 diabetes. Both fasting levels and incremental area under the curves (iAUC) obtained from an OGTT were analyzed. 


\section{Research Design and Methods}

\section{Study population}

The present study comprises participants from the Cohort study on Diabetes and Atherosclerosis Maastricht (CODAM), which included 574 participants who were selected from the general population as described in detail elsewhere. ${ }^{21}$ The CODAM study was designed to investigate cardiovascular and metabolic function, and was enriched for IGM status, as described previously. ${ }^{22}$ Current main analyses were performed on 491 participants who underwent a full OGTT and were not on insulin treatment. The study was approved by the local Medical Ethical Committee of Maastricht University Medical Centre and all participants gave written informed consent.

\section{Definition of glucose metabolism status}

The glucose tolerance status of the participants was determined by an OGTT. After an overnight fasting period (10-12 hours), study participants underwent a standard $75 \mathrm{~g}$ OGTT (82 g dextrose monohydrate, Avebe, The Netherlands) and venous blood was obtained prior to, and at 30,60 and 120 minutes after the glucose load. Fasting and post-load plasma glucose concentrations (in $\mathrm{mmol} / \mathrm{L}$ ) were measured with a hexokinase glucose- 6 phosphate dehydrogenase method (ABX Diagnosis, Montpellier, France). Fasting and $2 \mathrm{~h}$ post-load glucose concentrations were used to classify the study participants' glucose metabolism status (GMS) according to the World Health Organization (WHO) criteria. Briefly, individuals were classified as having normal glucose metabolism (NGM) when they had normal fasting ( $<6.1 \mathrm{mmol} / \mathrm{L})$ and $2 \mathrm{~h}$ postload ( $<7.8 \mathrm{mmol} / \mathrm{L}$ ) glucose concentrations. Individuals with impaired fasting glucose (6.1-7.0 $\mathrm{mmol} / \mathrm{L})$, impaired $2 \mathrm{~h}$ post-load glucose levels $(7.8-11.1 \mathrm{mmol} / \mathrm{L})$, or both were classified as having IGM. When individuals had high fasting plasma glucose levels $(\geq 7.0 \mathrm{mmol} / \mathrm{L})$ and/or high $2 \mathrm{~h}$ post-load glucose levels $(\geq 11.1 \mathrm{mmol} / \mathrm{L})$, or when they used glucose-lowering medication or insulin, they were classified as having type 2 diabetes. ${ }^{22}$ Individuals with known type 2 diabetes, or those with fasting glucose levels $>8.5 \mathrm{mmol} / \mathrm{L}$ were excluded from undergoing an OGTT.

\section{Measurements of plasma $\alpha$-dicarbonyls}

Plasma levels of $\alpha$-dicarbonyls were measured in EDTA plasma samples from the OGTT at baseline and 30, 60 and 120 minutes after the glucose load. Blood samples were collected in EDTA tubes which were stored on ice prior to blood sampling to ensure 
rapid cooling of the blood. After withdrawal of the blood sample, tubes were stored on ice immediately, and were spun within two hours at $3000 \mathrm{rpm}, 4^{\circ} \mathrm{C}$. Plasma samples have been stored at $-80^{\circ} \mathrm{C}$ until analysis. Reversed phase ultra-performance liquid chromatography tandem mass spectrometry (UPLC-MS/MS) was used to analyze the plasma samples for MGO, GO and 3-DG, as described previously. ${ }^{23}$ The inter-assay variations for MGO, GO and 3-DG were 4.3, 5.1 and 2.2\%, respectively. Current analyses were performed with fasting $\alpha$-dicarbonyl levels and OGTT iAUCs.

\section{Calculation of the OGTT incremental area under the curve}

The area under the curve (AUC) for the OGTT levels of the $\alpha$-dicarbonyls and glucose was calculated according to the trapezoidal method, ${ }^{24}$ where baseline (fasting) levels were subtracted from each individual data point to specify the post-glucose load increases. These data are referred to as the iAUC.

\section{Covariates}

Waist circumference and prior CVD were assessed as described previously. ${ }^{25}$ Questionnaires were used to asses smoking behavior (never, ever or current smoker) and use of medication (lipid-, glucose- and blood pressure-lowering medication). Plasma creatinine levels were measured with the Jaffé diagnostic test (Roche Diagnostics, Mannheim, Germany) and the estimated glomerular filtration rate (eGFR) was calculated using the Chronic Kidney Disease Epidemiology Collaboration (CKD-EPI) equation. ${ }^{26}$ Systolic blood pressures were measured in the brachial arteries and twice in both the tibialis posterior and dorsalis pedis arteries of the lower extremities with a standard Doppler device (Mini Dopplex D900, Huntleigh Diagnostics Ltd, Harmelen, The Netherlands). ${ }^{27}$ Total and HDL-cholesterol and triglycerides were measured in EDTA plasma by enzymatic methods (Roche Diagnostics, Mannheim, Germany). ${ }^{27}$

\section{Statistical analyses}

The general characteristics of the study population were compared across the three groups of GMS. Continuous variables were analyzed with one-way ANOVA and discrete variables were analyzed with chi-square tests. Fasting levels and iAUCs from the OGTT were normally distributed for all $\alpha$-dicarbonyls. To increase statistical power, missing values on $\mathrm{HbA}_{1 \mathrm{C}}$ (3.7\% missings), eGFR (0.8\% missings) and $\mathrm{BMI}(0.2 \%$ missings) were imputed by creating 5 datasets using multiple imputation. Skewed variables (fasting plasma glucose, fasting plasma insulin, HOMA-IR and triglycerides) were $\log _{e}$ transformed prior to analyses. Two-way repeated measures ANOVA with 
Bonferroni correction was used to compare the curves of the $\alpha$-dicarbonyls during the OGTT between NGM, IGM and type 2 diabetes over time. Fasting levels and iAUCs of the $\alpha$-dicarbonyls were compared between the groups using one-way ANOVA with Bonferroni correction. Multiple linear regression analysis was used to investigate potential influence of confounding factors on the association between GMS and $\alpha$ dicarbonyl levels. The main independent variables were GMS, analyzed as dummies for IGM and type 2 diabetes, fasting glucose levels, iAUC glucose and $\mathrm{HbA}_{1 \mathrm{C}}$, and the main dependent variables were fasting levels and iAUCs of the $\alpha$-dicarbonyls. Data are presented as standardized regression coefficients $(\beta)$. Analyses were initially adjusted for age and sex, and for analyses with fasting glucose levels, iAUC glucose and $\mathrm{HbA}_{1 \mathrm{C}}$, also for GMS (model 1). Analyses were further adjusted for smoking status, eGFR, $\log _{e}$ triglycerides, total-to-HDL cholesterol ratio, waist circumference, prior CVD, systolic blood pressure and use of medication (lipid-, glucose- and blood pressure-lowering medication) (model 2). Finally, analyses for GMS were additionally adjusted for glucose (fasting or iAUC glucose, appropriate to the $\alpha$-dicarbonyl measure), as a potential source of $\alpha$-dicarbonyl formation (model 3), and to investigate to which extent iAUCs were dependent on fasting $\alpha$-dicarbonyl levels, model 2 was additionally adjusted for fasting plasma levels of the appropriate $\alpha$-dicarbonyl (model 4). A p-value of $<0.05$ was considered statistically significant.

As increased levels of $\alpha$-dicarbonyls can be a result of both increased formation as well as decreased detoxification, we investigated whether individuals with IGM or type 2 diabetes had a decreased capacity to detoxify $\alpha$-dicarbonyls. To test this, we analyzed whether the association between post-load glucose excursions and $\alpha$ dicarbonyl iAUCs differed between individuals with NGM, IGM and type 2 diabetes. To this end, the interaction terms IGM*iAUC glucose and type 2 diabetes*iAUC glucose were added to the linear regression model (adjusted for covariates in model 2). $p_{\text {interaction }}<0.1$ was considered statistically significant. Significant $p$-values for interaction would indicate a different detoxification capacity of $\alpha$-dicarbonyls in individuals with IGM or type 2 diabetes, for the same change in glucose concentration. All statistical analyses were performed with IBM SPSS Statistics Software, version 20 (IBM Corporation, Armonk, New York). 


\section{Results}

General characteristics of the study population stratified according to GMS are shown in table 7.1. Overall, participants with type 2 diabetes were slightly older, had a higher $\mathrm{BMI}$, higher blood pressure, lower HDL-cholesterol and more often CVD and microalbuminuria. Curves of the OGTT in Figure 7.1 demonstrate increased levels of glucose and MGO, GO and 3-DG after the glucose load. Plasma glucose levels were approximately 5,000-fold higher compared to the plasma $\alpha$-dicarbonyl levels.

\section{Univariate associations between GMS and both fasting plasma $\alpha$ - dicarbonyls and the OGTT IAUC of the plasma $\alpha$-dicarbonyls}

When we analyzed the fasting $\alpha$-dicarbonyl levels, we found approximately 1.1 -fold higher plasma concentrations of MGO in individuals with type 2 diabetes, but not with IGM (Table 7.1, p<0.001), as compared to NGM. Fasting levels of 3-DG were increased in both individuals with IGM and type 2 diabetes compared to those with NGM (Table 7.1, both $p<0.001$ ). GO levels at baseline did not differ between the groups (Table 7.1). When we additionally included individuals with known type 2 diabetes who were not allowed to undergo an OGTT, we observed significantly higher fasting levels of plasma $\alpha$-dicarbonyls, compared to levels from those who did undergo the OGTT (Supplementary Figure 7.1).

iAUCs for the a-dicarbonyls MGO, GO, and 3-DG were significantly higher (1.6-, 2.3and 1.8-fold change, respectively) in participants with IGM (all $p<0.001$ ) and were even higher (2.1-, 3.4-, and 2.6-fold change, respectively) in those with type 2 diabetes (all $p<0.001$ ) (Figure 7.1B, D, and F) compared with NGM. For glucose, both fasting levels and IAUC of the OGTT were increased in individuals with IGM and type 2 diabetes (Table 7.1 and Figure $7.1 \mathrm{H}$ ) (all $\mathrm{p}<0.001$ ).

\section{Multivariate associations between GMS and fasting plasma $\alpha$ - dicarbonyl levels}

The presence of IGM was not associated with higher fasting plasma levels of MGO and GO after adjustment for age and sex (Table 7.2, model 1). Fasting plasma 3-DG levels in individuals with IGM were 0.255 standard deviations higher than in those with NGM $(\beta=0.255 ; 95 \% \mathrm{Cl}: 0.136-0.375 ; p<0.001)$. Additional adjustment for smoking, eGFR, triglycerides, total-to-HDL cholesterol ratio, waist circumference, medication, prior CVD and systolic blood pressure did not materially change this association (Table 7.2, model 2). 
Table 7.1 - General characteristics of the CODAM study population stratified according to glucose metabolism status.

\begin{tabular}{|c|c|c|c|c|}
\hline & $\operatorname{NGM}(n=279)$ & IGM $(n=120)$ & T2DM $(n=92)$ & $P_{\text {trend }}$ \\
\hline Age (years) & $58.8 \pm 7.4$ & $59.9 \pm 6.7$ & $60.4 \pm 6.2$ & 0.056 \\
\hline Sex (\% men) & 58.8 & 60.0 & 64.1 & 0.386 \\
\hline BMI $\left(\mathrm{kg} / \mathrm{m}^{2}\right)$ & $27.5 \pm 3.9$ & $29.0 \pm 4.3$ & $30.1 \pm 4.5$ & $<0.001$ \\
\hline Waist (cm) & $96.0 \pm 10.9$ & $100.9 \pm 11.9$ & $104.2 \pm 11.5$ & $<0.001$ \\
\hline $\mathrm{HbA}_{1 \mathrm{c}}(\%)$ & $5.6 \pm 0.4$ & $5.8 \pm 0.4$ & $6.6 \pm 0.9$ & $<0.001$ \\
\hline $\mathrm{HbA}_{1 \mathrm{c}}(\mathrm{mmol} / \mathrm{mol})$ & $38.0 \pm 4.8$ & $40.3 \pm 4.7$ & $48.4 \pm 9.9$ & $<0.001$ \\
\hline Fasting plasma MGO (nmol/L) & $350 \pm 71$ & $353 \pm 57$ & $392 \pm 72$ & $<0.001$ \\
\hline Fasting plasma GO (nmol/L) & $1087 \pm 287$ & $1107 \pm 279$ & $1057 \pm 280$ & 0.442 \\
\hline Fasting plasma 3-DG (nmol/L) & $1102 \pm 156$ & $1191 \pm 136$ & $1619 \pm 300$ & $<0.001$ \\
\hline Fasting plasma glucose (mmol/L) & $5.3[5.0-5.5]$ & $6.0[5.5-6.3]$ & $7.3[6.9-8.2]$ & $<0.001$ \\
\hline Fasting plasma insulin (pmol/L) & $52.0[41.0-69.0]$ & $67.0[46.0-100.0]$ & $85.5[56.5-124.8]$ & $<0.001$ \\
\hline HOMA-IR & $0.98[0.78-1.29]$ & $1.30[0.89-1.91]$ & $1.72[1.14-2.49]$ & $<0.001$ \\
\hline Glucose-lowering medication (\%) & 0.0 & 2.5 & 33.7 & $<0.001$ \\
\hline Systolic blood pressure (mmHg) & $135.6 \pm 17.5$ & $143.8 \pm 19.3$ & $147.9 \pm 18.6$ & $<0.001$ \\
\hline Diastolic blood pressure (mmHg) & $80.1 \pm 8.1$ & $84.1 \pm 9.8$ & $85.4 \pm 10.3$ & $<0.001$ \\
\hline Mean arterial pressure $(\mathrm{mmHg})$ & $98.6 \pm 10.3$ & $104.0 \pm 12.0$ & $106.2 \pm 11.5$ & $<0.001$ \\
\hline Anti-hypertensive medication (\%) & 28.3 & 43.3 & 51.1 & $<0.001$ \\
\hline Prior CVD (\%) & 22.9 & 27.5 & 37.0 & 0.009 \\
\hline Ex-smokers (\%) & 46.6 & 53.3 & 59.8 & 0.072 \\
\hline Current smokers (\%) & 19.7 & 19.2 & 18.5 & 0.791 \\
\hline eGFR (mL/min $\left./ 1.73 \mathrm{~m}^{2}\right)$ & $90.8 \pm 11.7$ & $91.5 \pm 11.6$ & $92.3 \pm 13.5$ & 0.310 \\
\hline Microalbuminuria (\%) & 3.9 & 4.2 & 9.8 & 0.048 \\
\hline Macroalbuminuria (\%) & 0.4 & 0.8 & 2.2 & 0.105 \\
\hline Total cholesterol (mmol/L) & $5.2 \pm 0.9$ & $5.3 \pm 0.9$ & $5.4 \pm 1.1$ & 0.058 \\
\hline HDL cholesterol (mmol/L) & $1.3 \pm 0.4$ & $1.2 \pm 0.3$ & $1.1 \pm 0.3$ & $<0.001$ \\
\hline LDL cholesterol (mmol/L) & $3.4 \pm 0.9$ & $3.3 \pm 0.9$ & $3.2 \pm 1.1$ & 0.309 \\
\hline Triglycerides (mmol/L) & $1.2[0.9-1.6]$ & $1.6[1.1-2.2]$ & $2.0[1.3-2.6]$ & $<0.001$ \\
\hline Lipid-lowering medication (\%) & 15.1 & 20.0 & 19.6 & 0.221 \\
\hline
\end{tabular}

Data are presented as means \pm standard deviations, medians (interquartile range), or percentages, as appropriate. 3-DG, 3-deoxyglucosone; CVD, cardiovascular disease; eGFR, estimated glomerular filtration rate; GO, glyoxal; $\mathrm{HbA}_{1 \mathrm{c}}$, glycated hemoglobin; $\mathrm{HDL}$, high-density lipoprotein; $\mathrm{HOMA}-\mathrm{IR}$, homeostasis model assessment insulin resistance; LDL, low-density lipoprotein; MGO, methylglyoxal. Linear trend was tested with one-way ANOVA for continuous variables and with chi-square for discrete variables, as appropriate.

Addition of fasting glucose levels to the regression model completely attenuated the association between the presence of IGM and higher fasting levels of 3-DG (Table 7.2, model 3). In contrast, the presence of type 2 diabetes was associated with higher fasting levels of both MGO ( $\beta=0.542 ; 95 \% \mathrm{Cl}: 0.322-0.761 ; p<0.001)$ and 3-DG $(\beta=$ 1.517; $95 \% \mathrm{Cl}: 1.385-1.649 ; \mathrm{p}<0.001)$ after adjustment for age and sex, as compared to NGM. 
A

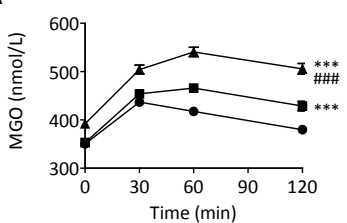

C

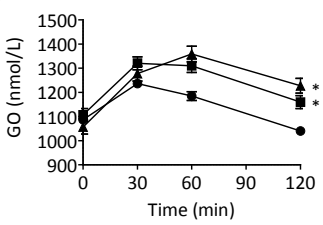

$\mathbf{E}$

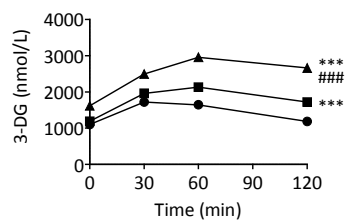

G

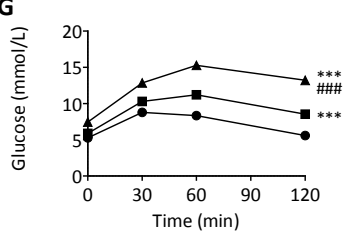

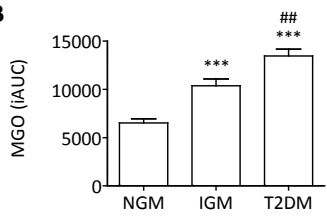

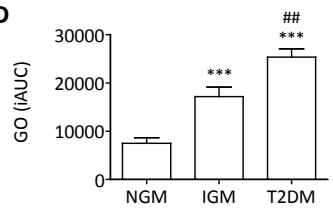

$\mathbf{F}$
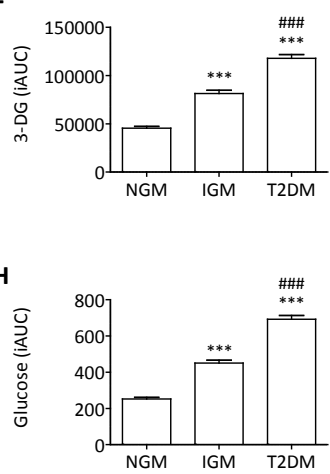

Figure 7.1 - Plasma $\alpha$-dicarbonyl and glucose levels during an oral glucose tolerance test. (A) shows MGO levels during an OGTT over time and (B) demonstrates these data calculated as an iAUC. (C-D) shows the same for GO levels, (E-F) for 3-DG levels and (G-H) for glucose levels. Data are shown as means \pm standard error of the means. Circles $=$ NGM, squares $=I G M$ and triangles $=$ type 2 diabetes. Differences in OGTT curves between the groups of GMS were tested with repeated measures two-way ANOVA with Bonferroni correction. Differences in iAUCs between the groups were tested with one-way ANOVA with Bonferroni

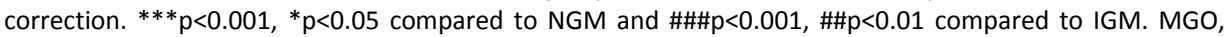
methylglyoxal; GO, glyoxal; 3-DG, 3-deoxyglucosone; OGTT, oral glucose tolerance test; iAUC, incremental area under the curve; NGM, normal glucose metabolism; IGM, impaired glucose metabolism.

After additional adjustment for multiple covariates in model 2, associations between the presence of type 2 diabetes and higher fasting levels of $\mathrm{MGO}(\beta=0.492 ; 95 \% \mathrm{Cl}$ : $0.216-0.769 ; p<0.001)$ and 3-DG $(\beta=1.376 ; 95 \% \mathrm{Cl}: 1.211-1.542 ; p<0.001)$ were largely unchanged. Further adjustment for fasting glucose levels resulted in an $82 \%$ attenuation of the association between type 2 diabetes and fasting MGO levels (Table 7.2, model 3). In line, the association between type 2 diabetes and fasting 3-DG levels was attenuated by $61 \%$, but remained statistically significant (Table 7.2 , model 3 ). Also after adjustment for potential confounders, we found no associations between either IGM or type 2 diabetes and fasting GO levels. 
Table 7.2 - Associations between glucose metabolism status and fasting and iAUC measures of plasma $\alpha$ dicarbonyls during an OGTT.

\begin{tabular}{|c|c|c|c|c|c|c|c|}
\hline \multirow{2}{*}{ Determinant } & \multirow{2}{*}{ Model } & \multicolumn{3}{|c|}{ IGM vs NGM } & \multicolumn{3}{|c|}{ T2DM vs NGM } \\
\hline & & $\beta$ & $95 \% \mathrm{Cl}$ & $p$-value & $\beta$ & $95 \% \mathrm{Cl}$ & $\mathrm{p}$-value \\
\hline \multirow{3}{*}{ Fasting MGO } & 1 & 0.011 & $-0.188-0.209$ & 0.917 & 0.542 & $0.322-0.761$ & $<0.001$ \\
\hline & 2 & -0.019 & $-0.226-0.188$ & 0.855 & 0.492 & $0.216-0.769$ & $<0.001$ \\
\hline & 3 & -0.129 & $-0.343-0.085$ & 0.236 & 0.089 & $-0.268-0.447$ & 0.624 \\
\hline \multirow{3}{*}{ Fasting GO } & 1 & 0.030 & $-0.142-0.202$ & 0.735 & -0.112 & $-0.303-0.078$ & 0.247 \\
\hline & 2 & 0.063 & $-0.114-0.240$ & 0.486 & -0.088 & $-0.326-0.149$ & 0.465 \\
\hline & 3 & 0.013 & $-0.172-0.198$ & 0.891 & -0.272 & $-0.581-0.037$ & 0.085 \\
\hline \multirow{3}{*}{ Fasting 3-DG } & 1 & 0.255 & $0.136-0.375$ & $<0.001$ & 1.517 & $1.385-1.649$ & $<0.001$ \\
\hline & 2 & 0.216 & $0.092-0.341$ & $<0.001$ & 1.376 & $1.211-1.542$ & $<0.001$ \\
\hline & 3 & -0.013 & $-0.122-0.096$ & 0.815 & 0.536 & $0.354-0.718$ & $<0.001$ \\
\hline \multirow{4}{*}{ ¡AUC MGO } & 1 & 0.203 & $0.123-0.283$ & $<0.001$ & 0.359 & $0.271-0.448$ & $<0.001$ \\
\hline & 2 & 0.190 & $0.106-0.274$ & $<0.001$ & 0.293 & $0.180-0.405$ & $<0.001$ \\
\hline & 3 & 0.044 & $-0.043-0.130$ & 0.321 & -0.008 & $-0.137-0.120$ & 0.897 \\
\hline & 4 & 0.187 & $0.108-0.266$ & $<0.001$ & 0.362 & $0.255-0.469$ & $<0.001$ \\
\hline \multirow{4}{*}{ ¡AUC GO } & 1 & 0.268 & $0.160-0.377$ & $<0.001$ & 0.486 & $0.366-0.606$ & $<0.001$ \\
\hline & 2 & 0.287 & $0.172-0.401$ & $<0.001$ & 0.536 & $0.382-0.689$ & $<0.001$ \\
\hline & 3 & 0.114 & $-0.006-0.234$ & 0.064 & 0.180 & $0.001-0.358$ & 0.049 \\
\hline & 4 & 0.302 & $0.196-0.408$ & $<0.001$ & 0.514 & $0.372-0.656$ & $<0.001$ \\
\hline \multirow{4}{*}{ iAUC 3-DG } & 1 & 0.319 & $0.257-0.382$ & $<0.001$ & 0.645 & $0.576-0.714$ & $<0.001$ \\
\hline & 2 & 0.285 & $0.221-0.349$ & $<0.001$ & 0.542 & $0.456-0.628$ & $<0.001$ \\
\hline & 3 & 0.030 & $-0.013-0.072$ & 0.176 & 0.015 & $-0.048-0.079$ & 0.640 \\
\hline & 4 & 0.295 & $0.231-0.360$ & $<0.001$ & 0.607 & $0.500-0.714$ & $<0.001$ \\
\hline
\end{tabular}

Data were analyzed using linear regression analysis. The standardized regression coefficient $\beta$ represents the increase of $\alpha$-dicarbonyl concentrations expressed in standard deviations, compared to NGM. MGO, methylglyoxal; GO, glyoxal; 3-DG, 3-deoxyglucosone; NGM, normal glucose metabolism; IGM, impaired glucose metabolism; $\mathrm{Cl}$, confidence interval; iAUC, incremental area under the curve. Model 1: adjusted for age + sex; model 2 : model 1 + smoking + eGFR + triglycerides + total-to-HDL cholesterol ratio + waist circumference + prior CVD + systolic blood pressure + medication (lipid-lowering, glucose-lowering and blood pressure-lowering medication); model 3: model $2+$ glucose (fasting glucose for fasting $\alpha$-dicarbonyls and iAUC glucose for iAUC $\alpha$-dicarbonyls); model 4: model $2+$ fasting levels of corresponding $\alpha$-dicarbonyls.

\section{Multivariate associations between GMS and iAUCs of a-dicarbonyls}

In age- and sex-adjusted analyses, the presence of IGM was associated with significantly higher iAUCs for all three $\alpha$-dicarbonyls (MGO: $\beta=0.203$; $95 \% \mathrm{Cl}$ : 0.123 0.283; $p<0.001$, GO: $\beta=0.268$; 95\% Cl: 0.160-0.377; $p<0.001$ and 3-DG: $\beta=0.319 ; 95 \%$ $\mathrm{Cl}: 0.257-0.382 ; \mathrm{p}<0.001)$, as compared to NGM. For type 2 diabetes, the associations with higher iAUCs of all three $\alpha$-dicarbonyls appeared to be even stronger (MGO: $\beta=$ $0.359 ; 95 \% \mathrm{Cl}: 0.271-0.448 ; \mathrm{p}<0.001, \mathrm{GO}: \beta=0.486 ; 95 \% \mathrm{Cl}: 0.366-0.606 ; \mathrm{p}<0.001$ and 3-DG: $\beta=0.645 ; 95 \% \mathrm{Cl}: 0.576-0.714 ; \mathrm{p}<0.001)$. After further adjustment for the 
covariates in model 2, both IGM and type 2 diabetes remained significantly associated with higher iAUCs of all three $\alpha$-dicarbonyls (Table 7.2, model 2), compared to iAUCs of individuals with NGM. However, when analyses were further adjusted for the iAUC from glucose, the associations of both IGM and type 2 diabetes with MGO and 3-DG iAUCs disappeared completely (Table 7.2, model 3). Similarly, although the association between type 2 diabetes and higher iAUC of GO ( $\beta=0.180 ; 95 \% \mathrm{Cl}: 0.001-0.358 ; \mathrm{p}=$ 0.049 ) remained significant, it was also attenuated by $66 \%$. Adjustment for fasting levels of the appropriate $\alpha$-dicarbonyls in model 4 did not change the strength of the association compared to model 2 (Table 7.3, model 4 vs 2 ).

Since the associations between IGM and type 2 diabetes and higher $\alpha$-dicarbonyl iAUCs almost completely disappeared after adjustment for glucose, we hypothesized that the higher iAUCs of MGO, GO and 3-DG were a direct result of higher iAUCs of glucose in IGM and type 2 diabetes, rather than a decreased capacity to detoxify $\alpha$ dicarbonyls. Indeed, when adjusted for all covariates in model 2, the glucose iAUC was strongly associated with the iAUC of all three $\alpha$-dicarbonyls (Table 7.3; MGO: $\beta=$ 0.195; 95\% Cl: 0.148-0.243; $\mathrm{p}<0.001, \mathrm{GO}: \beta=0.231 ; 95 \% \mathrm{Cl}: 0.165-0.297 ; \mathrm{p}<0.001$ and 3-DG: $\beta=0.342 ; 95 \% \mathrm{Cl}: 0.318-0.365 ; \mathrm{p}<0.001)$. These associations did not differ between NGM, IGM or type 2 diabetes for all three $\alpha$-dicarbonyls ( $p_{\text {interaction }}>0.1$ ). Overall, associations between the iAUC of glucose and the iAUC of $\alpha$-dicarbonyls were stronger than associations between $\mathrm{HbA}_{1 \mathrm{C}}$ or fasting plasma glucose and the iAUC of a-dicarbonyls (Table 7.3).

\section{Discussion}

This study demonstrated that iAUCs of the $\alpha$-dicarbonyls MGO, GO and 3-DG, as calculated from an OGTT, were higher in individuals with IGM and type 2 diabetes, independently of potential confounders. Fasting plasma levels of $\alpha$-dicarbonyls were predominantly higher in individuals with type 2 diabetes, although fasting 3-DG levels were also slightly increased in individuals with IGM.

After adjustment for glucose, these associations disappeared almost completely for MGO and 3-DG, and to a large, but slightly lesser extent, for GO, indicating that glucose is the major source of $\alpha$-dicarbonyls. To our knowledge, this is the first time that $\alpha$-dicarbonyls have been measured in a post-glucose load setting in individuals with NGM, IGM and type 2 diabetes. 


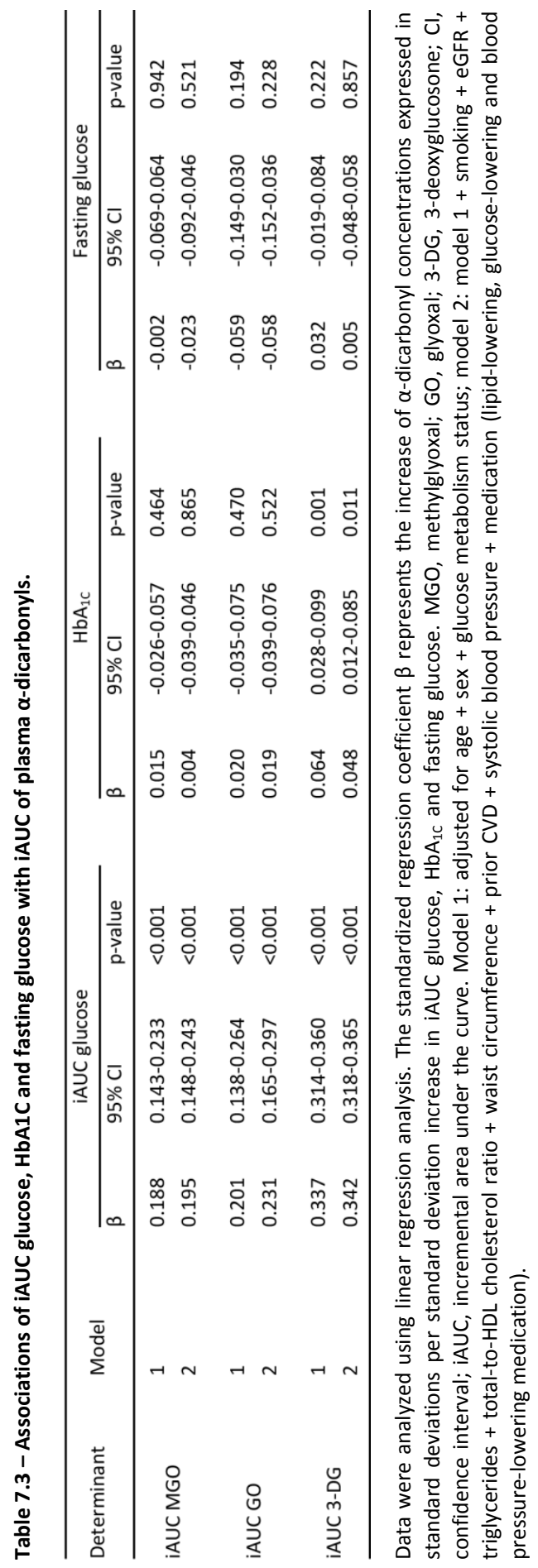


In the present study, we found that iAUCs of MGO, GO and 3-DG, as calculated from an OGTT, were higher in individuals with IGM and type 2 diabetes, independently of potential confounders. Our data are in accordance with findings from a previous study by Beisswenger et al, in which they showed increased MGO and 3-DG levels during the postprandial period in patients with type 1 diabetes. ${ }^{20}$ As glucose serves as a primary source for the formation of $\alpha$-dicarbonyls, transient glucose excursions during the postprandial period may give rise to increases of $\alpha$-dicarbonyl levels, which in turn may induce long-term damage to the vasculature. Indeed, El-Osta et al. demonstrated that even transient exposures to high glucose levels induce persistent changes in cultured endothelial cells, which could be prevented by an overexpression of glyoxalase I (GLO1), the major enzyme detoxifying MGO and GO. ${ }^{28}$ We and others demonstrated that increased levels of $\alpha$-dicarbonyl compounds are directly associated with vascular complications. ${ }^{14,29}$ MGO particularly has attracted a lot of attention as a key player in vascular dysfunction, due to its capacity to induce oxidative stress, ${ }^{29}$ cell death ${ }^{30}$ and endothelial dysfunction. ${ }^{14}$ Therefore, the observed increased levels of $\alpha$ dicarbonyls with post-challenge glucose excursions in IGM and type 2 diabetes may link fluctuations in blood glucose levels in these patients with persistent increases in risk of vascular complications and CVD.

The $\alpha$-dicarbonyls in the plasma can originate from various sources, including in situ formation in the plasma, release from cells and external sources. ${ }^{31}$ Due to their rapid increase during the OGTT, the post-load plasma $\alpha$-dicarbonyl levels most likely originate from intracellular compartments which come directly into contact with plasma glucose. As we found the largest increase in $\alpha$-dicarbonyls in the individuals with IGM and with type 2 diabetes, it is likely that plasma $\alpha$-dicarbonyls originate from insulin-independent cells, specifically red blood cells and endothelial cells. Indeed, we demonstrated in human endothelial cells that hyperglycemia produced higher levels of $\mathrm{MGO}^{32}$ and that $\alpha$-dicarbonyl levels are much higher in circulating cells than in plasma. $^{23}$ We assume that $\alpha$-dicarbonyl levels after a glucose challenge would increase even further in circulating cells and endothelial cells, as only a small percentage of dicarbonyl compounds leaks into the circulation. ${ }^{23}$ To what extent this increase of dicarbonyls in plasma is similar in other tissues that are sensitive to diabetic complications, such as the kidney, nerves, retina and atherosclerotic plaques, remains to be elucidated. Next to release from cells, plasma $\alpha$-dicarbonyls may also be a result of autoxidation of glucose in the plasma, but it is not known to which extent this process contributes to plasma levels of $\alpha$-dicarbonyls. It is unlikely however that the iAUCs reflect any autoxidation, as this is a slow process and we observed an increase of $\alpha$-dicarbonyls already 30 minutes after the glucose load. In addition, dicarbonyl compounds can also originate from exogenous sources, ${ }^{31}$ for example from 
the glucose drink we used in this study. However, we previously observed no increased plasma MGO levels in a healthy volunteer within two hours after drinking coffee, a drink with very high levels of MGO (55 $\mu \mathrm{mol} / \mathrm{L})$ but without any glucose. As the glucose drink used for the OGTT only contained $1.6 \mu \mathrm{mol} / \mathrm{L} \mathrm{MGO}$, it is highly unlikely that the low levels of $\alpha$-dicarbonyls in the glucose drink contribute to their plasma levels after the glucose challenge. The question remains whether the increased $\alpha$-dicarbonyl iAUCs are a reflection of decreased detoxification potency in IGM and type 2 diabetes. The glyoxalase system is the major pathway to detoxify MGO and GO. ${ }^{33}$ This system consists of the rate-limiting enzyme glyoxalase- 1 and glyoxalase-2. These enzymes convert MGO and GO, with the involvement of reduced glutathione, to their end product D-lactate. ${ }^{33}$ Several experimental studies have linked the presence of diabetes to dysfunction of the glyoxalase system. ${ }^{34}$ However, additional adjustment for glucose in our analyses attenuated the associations between GMS and the iAUC of $\alpha$-dicarbonyls by $60-97 \%$, suggesting that the elevated post-challenge dicarbonyl levels are the result of increased formation from its substrate glucose. Although dysfunction of $\alpha$-dicarbonyl detoxification cannot be eliminated as a contributor to increased plasma $\alpha$-dicarbonyl levels, the lack of interaction between dicarbonyl iAUCs and GMS indicates that detoxification mechanisms are not differently active in any of the three GMS groups.

Our new observation that post-load glucose levels are closely associated with $\alpha$ dicarbonyl formation is of high clinical relevance because of the current developments in the field of glucose-lowering therapies. Dipeptidyl-peptidase-4 (DPP-4) inhibitors form a very new treatment strategy which has been shown to regulate postprandial glucose concentrations. ${ }^{35}$ Whether DPP-4 inhibitors can reduce $\alpha$-dicarbonyls is unknown. In addition, the bionic pancreas is a state of the art intervention which has been demonstrated to regulate glycemic control very strictly in type 1 diabetes, ${ }^{36}$ and may prove valuable in type 2 diabetes as well. Directly lowering $\alpha$-dicarbonyl levels may also be a mechanism to reduce postprandial carbonyl stress and the putative association with vascular damage at long term. One intervention which is currently highly under investigation is pyridoxamine. Pyridoxamine is a chemical scavenger of reactive $\alpha$-dicarbonyls and has been shown to inhibit formation of AGEs. Several experimental and clinical studies have already demonstrated beneficial effects of pyridoxamine with regard to diabetic microvascular complications. ${ }^{37-39}$

The major strengths of this study are that we were able to perform our analyses in a large and well-defined cohort study, and, in addition, we measured plasma $\alpha$ dicarbonyls with state of the art techniques based on UPLC-MS/MS. There are also a few limitations of this study. First, individuals with known type 2 diabetes did not undergo an OGTT, while they had higher fasting levels of $\alpha$-dicarbonyl compounds 
compared to the type 2 diabetes patients who did undergo a full OGTT. Therefore, their $\alpha$-dicarbonyl levels during the OGTT are expected to increase even more than in newly diagnosed subjects, indicating that our observations may be an underestimation of the true effect in type 2 diabetes. Furthermore, the glucose load in the OGTT is not completely comparable to postprandial glucose excursions. To investigate the effect of postprandial glucose excursions on $\alpha$-dicarbonyl levels, a mixed meal test needs to be done, although it has been described that the level of glycemia $2 \mathrm{~h}$ after an OGTT is closely related to the level of glycemia after a standardized meal. ${ }^{40}$ Moreover, a major advantage of the OGTT used in this study is that it allowed us to specifically investigate the hypothesis that glucose spikes cause formation of MGO, without confounding of postprandial changes in lipid and protein levels.

In conclusion, we found that significant increases of MGO, GO and 3-DG levels occurred during an OGTT in individuals with IGM and type 2 diabetes in comparison to controls. These increases were strongly associated with post-load glucose excursions. These findings, together with the known harmful biological effects of these $\alpha$ dicarbonyls, underline the potential importance of dicarbonyl stress as a functional candidate to explain the increased risk of diabetic complications in individuals with postprandial hyperglycemia. Prospective analyses on micro- and macrovascular complications are necessary to associate our current findings with vascular outcome. 


\section{References}

1. Forbes JM, Cooper ME. Mechanisms of diabetic complications. Physiol Rev. 2013;93:137-188

2. de Vegt F, Dekker JM, Ruhe HG, Stehouwer CD, Nijpels G, Bouter LM, Heine RJ. Hyperglycaemia is associated with all-cause and cardiovascular mortality in the hoorn population: The hoorn study. Diabetologia. 1999;42:926-931

3. Beisswenger P, Heine RJ, Leiter LA, Moses A, Tuomilehto J. Prandial glucose regulation in the glucose triad: Emerging evidence and insights. Endocrine. 2004;25:195-202

4. The effect of intensive treatment of diabetes on the development and progression of long-term complications in insulin-dependent diabetes mellitus. The diabetes control and complications trial research group. N Engl J Med. 1993;329:977-986

5. Intensive blood-glucose control with sulphonylureas or insulin compared with conventional treatment and risk of complications in patients with type 2 diabetes (ukpds 33). Uk prospective diabetes study (ukpds) group. Lancet. 1998;352:837-853

6. Rohlfing CL, Wiedmeyer HM, Little RR, England JD, Tennill A, Goldstein DE. Defining the relationship between plasma glucose and $\mathrm{hba}(\mathrm{lc})$ : Analysis of glucose profiles and $\mathrm{hba}(\mathrm{cc})$ in the diabetes control and complications trial. Diabetes Care. 2002;25:275-278

7. Donahue RP, Abbott RD, Reed DM, Yano K. Postchallenge glucose concentration and coronary heart disease in men of japanese ancestry. Honolulu heart program. Diabetes. 1987;36:689-692

8. Lowe LP, Liu K, Greenland P, Metzger BE, Dyer AR, Stamler J. Diabetes, asymptomatic hyperglycemia, and 22-year mortality in black and white men. The chicago heart association detection project in industry study. Diabetes Care. 1997;20:163-169

9. Glucose tolerance and mortality: Comparison of who and american diabetes association diagnostic criteria. The decode study group. European diabetes epidemiology group. Diabetes epidemiology: Collaborative analysis of diagnostic criteria in europe. Lancet. 1999;354:617-621

10. Coutinho M, Gerstein HC, Wang Y, Yusuf S. The relationship between glucose and incident cardiovascular events. A metaregression analysis of published data from 20 studies of 95,783 individuals followed for 12.4 years. Diabetes Care. 1999;22:233-240

11. Balkau B, Shipley M, Jarrett RJ, Pyorala K, Pyorala M, Forhan A, Eschwege E. High blood glucose concentration is a risk factor for mortality in middle-aged nondiabetic men. 20-year follow-up in the whitehall study, the paris prospective study, and the helsinki policemen study. Diabetes Care. 1998;21:360-367

12. Hanefeld M, Fischer S, Julius U, Schulze J, Schwanebeck U, Schmechel H, Ziegelasch HJ, Lindner J. Risk factors for myocardial infarction and death in newly detected niddm: The diabetes intervention study, 11-year follow-up. Diabetologia. 1996;39:1577-1583

13. Cavalot F, Petrelli A, Traversa M, Bonomo K, Fiora E, Conti M, Anfossi G, Costa G, Trovati M. Postprandial blood glucose is a stronger predictor of cardiovascular events than fasting blood glucose in type 2 diabetes mellitus, particularly in women: Lessons from the san luigi gonzaga diabetes study. J Clin Endocrinol Metab. 2006;91:813-819

14. Brouwers O, Niessen PM, Miyata T, Ostergaard JA, Flyvbjerg A, Peutz-Kootstra CJ, Sieber J, Mundel PH, Brownlee M, Janssen BJ, De Mey JG, Stehouwer CD, Schalkwijk CG. Glyoxalase-1 overexpression reduces endothelial dysfunction and attenuates early renal impairment in a rat model of diabetes. Diabetologia. 2014;57:224-235

15. Giacco F, Du X, D'Agati VD, Milne R, Sui G, Geoffrion M, Brownlee M. Knockdown of glyoxalase 1 mimics diabetic nephropathy in nondiabetic mice. Diabetes. 2014;63:291-299

16. Berner AK, Brouwers O, Pringle R, Klaassen I, Colhoun L, McVicar C, Brockbank S, Curry JW, Miyata T, Brownlee M, Schlingemann RO, Schalkwijk C, Stitt AW. Protection against methylglyoxal-derived ages by regulation of glyoxalase 1 prevents retinal neuroglial and vasodegenerative pathology. Diabetologia. 2012;55:845-854

17. Duran-Jimenez B, Dobler D, Moffatt S, Rabbani N, Streuli CH, Thornalley PJ, Tomlinson DR, Gardiner NJ. Advanced glycation end products in extracellular matrix proteins contribute to the failure of sensory nerve regeneration in diabetes. Diabetes. 2009;58:2893-2903 
18. Bierhaus A, Fleming T, Stoyanov S, Leffler A, Babes A, Neacsu C, Sauer SK, Eberhardt M, Schnolzer M, Lasitschka F, Neuhuber WL, Kichko TI, Konrade I, Elvert R, Mier W, Pirags V, Lukic IK, Morcos M, Dehmer T, Rabbani N, Thornalley PJ, Edelstein D, Nau C, Forbes J, Humpert PM, Schwaninger M, Ziegler D, Stern DM, Cooper ME, Haberkorn U, Brownlee M, Reeh PW, Nawroth PP. Methylglyoxal modification of nav1.8 facilitates nociceptive neuron firing and causes hyperalgesia in diabetic neuropathy. Nat Med. 2012;18:926-933

19. Tikellis C, Pickering RJ, Tsorotes D, Huet O, Cooper ME, Jandeleit-Dahm K, Thomas MC. Dicarbonyl stress in the absence of hyperglycemia increases endothelial inflammation and atherogenesis similar to that observed in diabetes. Diabetes. 2014

20. Beisswenger PJ, Howell SK, O'Dell RM, Wood ME, Touchette AD, Szwergold BS. Alpha-dicarbonyls increase in the postprandial period and reflect the degree of hyperglycemia. Diabetes Care. 2001;24:726-732

21. Du $H$, van der $A D$, van Bakel MM, van der Kallen CJ, Blaak EE, van Greevenbroek MM, Jansen EH, Nijpels G, Stehouwer CD, Dekker JM, Feskens EJ. Glycemic index and glycemic load in relation to food and nutrient intake and metabolic risk factors in a dutch population. Am J Clin Nutr. 2008;87:655-661

22. Hanssen NM, Engelen L, Ferreira I, Scheijen JL, Huijberts MS, van Greevenbroek MM, van der Kallen CJ, Dekker JM, Nijpels G, Stehouwer CD, Schalkwijk CG. Plasma levels of advanced glycation endproducts nepsilon-(carboxymethyl)lysine, nepsilon-(carboxyethyl)lysine, and pentosidine are not independently associated with cardiovascular disease in individuals with or without type 2 diabetes: The hoorn and codam studies. J Clin Endocrinol Metab. 2013;98:E1369-1373

23. Scheijen JL, Schalkwijk CG. Quantification of glyoxal, methylglyoxal and 3-deoxyglucosone in blood and plasma by ultra performance liquid chromatography tandem mass spectrometry: Evaluation of blood specimen. Clin Chem Lab Med. 2014;52:85-91

24. Allison DB, Paultre F, Maggio C, Mezzitis N, Pi-Sunyer FX. The use of areas under curves in diabetes research. Diabetes Care. 1995;18:245-250

25. van Greevenbroek MM, Jacobs M, van der Kallen CJ, Vermeulen VM, Jansen EH, Schalkwijk CG, Ferreira I, Feskens EJ, Stehouwer CD. The cross-sectional association between insulin resistance and circulating complement $\mathrm{c} 3$ is partly explained by plasma alanine aminotransferase, independent of central obesity and general inflammation (the codam study). Eur J Clin Invest. 2011;41:372-379

26. Levey AS, Stevens LA, Schmid CH, Zhang YL, Castro AF, 3rd, Feldman HI, Kusek JW, Eggers P, Van Lente F, Greene T, Coresh J. A new equation to estimate glomerular filtration rate. Ann Intern Med. 2009;150:604-612

27. Jacobs $M$, van Greevenbroek MM, van der Kallen CJ, Ferreira I, Blaak EE, Feskens EJ, Jansen EH, Schalkwijk CG, Stehouwer CD. Low-grade inflammation can partly explain the association between the metabolic syndrome and either coronary artery disease or severity of peripheral arterial disease: The codam study. Eur J Clin Invest. 2009;39:437-444

28. El-Osta A, Brasacchio D, Yao D, Pocai A, Jones PL, Roeder RG, Cooper ME, Brownlee M. Transient high glucose causes persistent epigenetic changes and altered gene expression during subsequent normoglycemia. J Exp Med. 2008;205:2409-2417

29. Brouwers O, Niessen PM, Ferreira I, Miyata T, Scheffer PG, Teerlink T, Schrauwen P, Brownlee M, Stehouwer CD, Schalkwijk CG. Overexpression of glyoxalase-i reduces hyperglycemia-induced levels of advanced glycation end products and oxidative stress in diabetic rats. J Biol Chem. 2011;286:13741380

30. Kang Y, Edwards LG, Thornalley PJ. Effect of methylglyoxal on human leukaemia 60 cell growth: Modification of DNA g1 growth arrest and induction of apoptosis. Leuk Res. 1996;20:397-405

31. Kalapos MP. Where does plasma methylglyoxal originate from? Diabetes Res Clin Pract. 2013;99:260271

32. Schalkwijk CG, van Bezu J, van der Schors RC, Uchida K, Stehouwer CD, van Hinsbergh VW. Heatshock protein 27 is a major methylglyoxal-modified protein in endothelial cells. FEBS Lett. 2006;580:1565-1570

33. Thornalley PJ. The glyoxalase system in health and disease. Mol Aspects Med. 1993;14:287-371

34. Rabbani N, Thornalley PJ. Glyoxalase in diabetes, obesity and related disorders. Semin Cell Dev Biol. 2011;22:309-317

35. Vora J, Bain SC, Damci T, Dzida G, Hollander P, Meneghini LF, Ross SA. Incretin-based therapy in combination with basal insulin: A promising tactic for the treatment of type 2 diabetes. Diabetes Metab. 2013;39:6-15 
36. Russell SJ, El-Khatib FH, Sinha M, Magyar KL, McKeon K, Goergen LG, Balliro C, Hillard MA, Nathan DM, Damiano ER. Outpatient glycemic control with a bionic pancreas in type 1 diabetes. $N$ Engl J Med. 2014;371:313-325

37. Williams ME, Bolton WK, Khalifah RG, Degenhardt TP, Schotzinger RJ, McGill JB. Effects of pyridoxamine in combined phase 2 studies of patients with type 1 and type 2 diabetes and overt nephropathy. Am J Nephrol. 2007;27:605-614

38. Tanimoto M, Gohda T, Kaneko S, Hagiwara S, Murakoshi M, Aoki T, Yamada K, Ito T, Matsumoto M, Horikoshi S, Tomino Y. Effect of pyridoxamine (k-163), an inhibitor of advanced glycation end products, on type 2 diabetic nephropathy in kk-a(y)/ta mice. Metabolism. 2007;56:160-167

39. Degenhardt TP, Alderson NL, Arrington DD, Beattie RJ, Basgen JM, Steffes MW, Thorpe SR, Baynes JW. Pyridoxamine inhibits early renal disease and dyslipidemia in the streptozotocin-diabetic rat. Kidney Int. 2002;61:939-950

40. Wolever TM, Chiasson JL, Csima A, Hunt JA, Palmason C, Ross SA, Ryan EA. Variation of postprandial plasma glucose, palatability, and symptoms associated with a standardized mixed test meal versus 75 g oral glucose. Diabetes Care. 1998;21:336-340 
SUPPLEMENTARY DATA

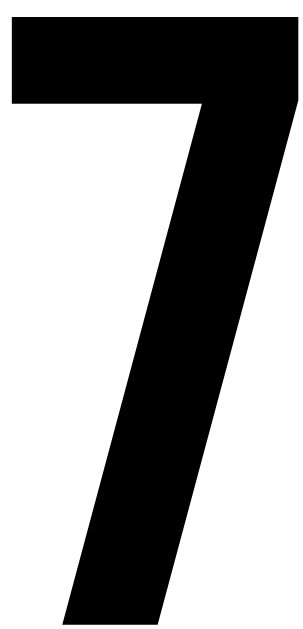


A

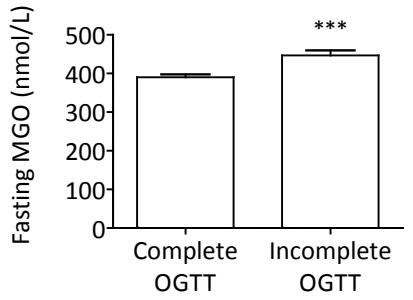

C

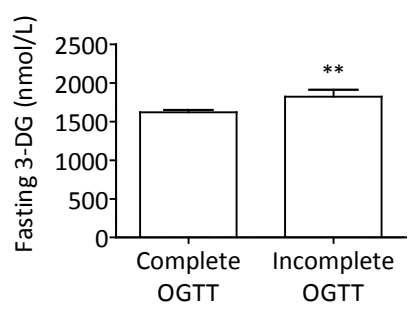

B

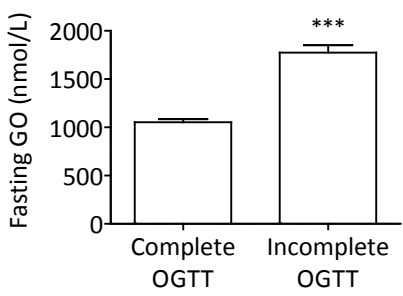

D

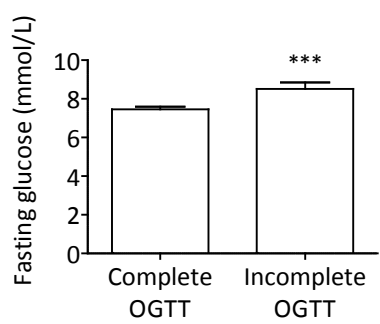

Supplementary Figure 7.1 - Fasting plasma $\alpha$-dicarbonyl levels of individuals without and with a complete OGTT. Fasting plasma levels of (A) MGO, (B) GO, (C) 3-DG and (D) glucose in individuals who underwent a complete OGTT and individuals who were not able to undergo a complete OGTT. Analyses were performed in all individuals with type 2 diabetes who were not on insulin treatment. Data are shown as means \pm standard error of the means. Differences between the two groups were tested with an independent samples t-test. ${ }^{* *} p<0.01$ and ${ }^{* * *} p<0.001$. MGO, methylglyoxal; GO, glyoxal; 3-DG, 3deoxyglucosone; OGTT, oral glucose tolerance test. 
ENERGY RESTRICTION AND ROUX-EN-Y GASTRIC BYPASS REDUCE POSTPRANDIAL ALPHA-DICARBONYL STRESS IN OBESE WOMEN WITH TYPE 2 DIABETES

DIONNE E.M. MAESSEN, NORDIN M.J. HANSSEN, MIRJAM A. LIPS, JEAN L.J.M. SCHEIJEN, K. WILLEMS VAN DIJK, H. PIJL, COEN D.A. STEHOUWER AND CASPER G. SCHALKWIJK 


\section{Abstract}

Aims and hypothesis: Dicarbonyl compounds are formed rapidly as byproducts of glycolysis and are a key mediator of diabetic complications. However, evidence of postprandial $\alpha$-dicarbonyl formation in humans is lacking, and interventions to reduce $\alpha$-dicarbonyls have not yet been investigated. Therefore, we investigated postprandial $\alpha$-dicarbonyl levels in obese women without and with type 2 diabetes. Furthermore, we evaluated whether a diet very low in energy (very low calorie diet [VLCD]) or Rouxen-Y gastric bypass (RYGB) reduces $\alpha$-dicarbonyl stress in obese women with type 2 diabetes.

Methods: In lean $(n=12)$ and obese women without $(n=27)$ or with type 2 diabetes ( $n=27$ ), we measured the $\alpha$-dicarbonyls, methylglyoxal (MGO), glyoxal (GO) and 3deoxyglucosone (3-DG), and glucose in fasting and postprandial plasma samples obtained during a mixed meal test. Obese women with type 2 diabetes underwent either a VLCD or RYGB. Three weeks after the intervention, individuals underwent a second mixed meal test.

Results: Obese women with type 2 diabetes had higher fasting and particularly higher postprandial plasma $\alpha$-dicarbonyl levels, compared with those without diabetes. After three weeks of a VLCD, postprandial $\alpha$-dicarbonyl levels in diabetic women were significantly reduced (AUC MGO -14\%, GO -16\%, 3-DG -25\%), mainly through reduction of fasting plasma $\alpha$-dicarbonyls (MGO -13\%, GO -13\%, 3-DG -33\%). Similar results were found after RYGB.

Conclusions and interpretation: This study shows that type 2 diabetes is characterized by increased fasting and postprandial plasma $\alpha$-dicarbonyl stress, which can be reduced by improving glucose metabolism through a VLCD or RYGB. These data highlight the potential to reduce reactive $\alpha$-dicarbonyls in obese individuals with type 2 diabetes.

Trial registration: ClinicalTrials.gov NCT01167959 


\section{Introduction}

Postprandial glucose excursions are a detrimental factor in diabetic complications. ${ }^{1,2}$ An important mechanism for postprandial glucose peaks contributing to increased risk of diabetic complications may be the formation of $\alpha$-dicarbonyls, ${ }^{3,4}$ which have been linked to a range of detrimental effects on cellular function., 3,6

We recently showed that individuals with impaired glucose metabolism or type 2 diabetes have higher plasma levels of the $\alpha$-dicarbonyls methylglyoxal (MGO), glyoxal (GO) and 3-deoxyglucosone (3-DG) during an oral glucose tolerance test (OGTT), compared to individuals with normal glucose metabolism. ${ }^{1}$ These highly reactive $\alpha$ dicarbonyls are mainly formed as glycolytic intermediates during metabolism of glucose. ${ }^{7}$ They rapidly interact with protein residues, forming advanced glycation endproducts and reactive oxygen species, which are known to impair vascular function. ${ }^{8}$ Increased $\alpha$-dicarbonyl stress has been associated with the development of diabetic neuropathy, nephropathy and atherosclerosis. ${ }^{3,5,9,10}$ Together, these data underline the potential importance of postprandial $\alpha$-dicarbonyl stress as a new target for treatment of diabetic complications. However, whether type 2 diabetes is associated with higher plasma $\alpha$-dicarbonyl levels after a meal is unknown.

Weight loss interventions could reduce the development of diabetic complications by improving glucose metabolism. ${ }^{11}$ Particularly energy restriction and bariatric surgery have been linked to improved glucose metabolism and reduction of diabetic complications and cardiovascular disease. ${ }^{12,13}$ Interestingly, beneficial effects of energy restriction and bariatric surgery on insulin resistance seem to occur rapidly. ${ }^{14-16}$ Thus, it is likely that $\alpha$-dicarbonyls will be rapidly reduced by these interventions.

Therefore, we investigated whether type 2 diabetes is associated with higher fasting and particularly higher postprandial plasma $\alpha$-dicarbonyl levels compared with lean and obese women with normal glucose tolerance (NGT) and whether a diet very low in energy or Roux-en-Y gastric bypass (RYGB) reduces plasma $\alpha$-dicarbonyl levels in obese women with type 2 diabetes.

\section{Methods}

\section{Study design and population}

The research design and methods of this study have been described in detail previously. ${ }^{16}$ In short, we included obese women with either NGT $(n=27)$ or type 2 diabetes $(n=27)$ who were eligible for dietary or surgical treatment. Age-matched, healthy women with normal BMI $\left(<25 \mathrm{~kg} / \mathrm{m}^{2}, n=12\right)$ were included as controls for 
baseline comparisons. All individuals were characterized at baseline ( 1 month before intervention) and obese individuals were additionally characterized 3 weeks after intervention. The study protocol (clinical trial registration no. NCT01167959) was approved by the medical ethical committee of the Leiden University Medical Center and all participants provided written informed consent. All analyses were performed blind.

Initially, we intended to subject obese individuals with NGT or type 2 diabetes to either gastric banding (GB) or RYGB. However, since RYGB was reported to have superior metabolic effects in individuals with type 2 diabetes, surgeons were reluctant to treat these individuals with GB. Therefore, we treated individuals with type 2 diabetes who were eligible for bariatric surgery with a diet very low in energy (very low calorie diet [VLCD]). As the effects of GB mainly result from a restriction in energy intake, we reasoned that the VLCD might mimic the effects of GB. Eventually, NGT obese individuals underwent either GB $(n=11)$ or RYGB $(n=16)$. Obese individuals with type 2 diabetes either underwent a $\operatorname{VLCD}(n=12)$ or $\operatorname{RYGB}(n=15)$.

Standard operating procedures were followed for GB and RYGB, and after surgery, patients were prescribed a staged meal plan. ${ }^{16}$ Individuals who underwent a VLCD were prescribed commercially available liquid Prodimed (Prodimed Benelux BV, Valkenswaard, The Netherlands). During this intervention, study participants were allowed four to five sachets per day and an additional choice of selected vegetables. ${ }^{16}$ Effects of the different interventions on weight loss and glucose metabolism after three weeks have been reported previously. ${ }^{16}$

\section{Mixed meal test}

All antidiabetic medications were discontinued $48 \mathrm{~h}$ before the study days. After overnight fasting $(\geq 10 \mathrm{~h})$ at both study days, participants underwent a liquid mixed meal test (MMT) which consisted of $266 \mathrm{ml}$ (1673.6 kJ [400 kcal]) Nutridrink (Nutricia, Zoetermeer, The Netherlands). Both fasting and multiple postprandial (10, 20, 30, 60, 90, 120, 150 and 180 minutes) EDTA blood samples were taken. Plasma levels of $\alpha$ dicarbonyls and glucose during the mixed meal test are referred to as postprandial plasma levels.

\section{Measurements of plasma $\alpha$-dicarbonyls}

Reversed phase ultra-performance liquid chromatography tandem mass spectrometry (UPLC-MS/MS) was used to measure plasma levels of MGO, GO and 3-DG in EDTA plasma samples, as described in detail previously. ${ }^{17}$ The inter-assay variations for MGO, GO and 3-DG were 4.6, 4.8 and 3.4\%, respectively. 


\section{Biochemical characterization}

Serum levels of total cholesterol, high-density lipoprotein (HDL) cholesterol, triglycerides and free fatty acids were measured as described previously. ${ }^{18} \mathrm{HbA}_{1 \mathrm{C}}$ was measured in whole blood samples using a high performance liquid chromatography Integra 800 analyzer (Roche Diagnostics, Mannheim, Germany). Serum glucose levels were measured using a Modular P800 chemistry analyzer (Roche Diagnostics, Mannheim, Germany). Insulin levels were assessed with an immunometric assay on an automated Immulite 2500 (Siemens, Breda, The Netherlands). Insulin resistance was estimated using the Homeostasis Model of Assessment - Insulin Resistance (HOMA-IR), as described elsewhere. ${ }^{16}$

\section{Calculation of the postprandial incremental area under the curve}

The area under the curve (AUC) for $\alpha$-dicarbonyls and glucose levels measured during the MMT was calculated using the trapezoidal rule, ${ }^{19}$ where fasting levels were subtracted from each individual data point to specify postprandial excursions (incremental AUC, iAUC [nmol/l $\times \min$ for $\alpha$-dicarbonyls and $\mathrm{mmol} / \mathrm{l} \times \mathrm{min}$ for glucose]).

\section{Statistics}

Baseline characteristics of the study population, as well as fasting $\alpha$-dicarbonyl and glucose levels and corresponding iAUCs at baseline, were compared using one-way ANOVA with Bonferroni correction. Adjustment for plasma glucose levels was performed with one-way ANCOVA with Bonferroni correction. Two-way repeated measures ANOVA with Bonferroni correction was used to compare the three groups regarding postprandial plasma $\alpha$-dicarbonyl and glucose levels at baseline during the mixed meal test. Paired two-sided sample $t$ tests were used to compare fasting and iAUC $\alpha$-dicarbonyl and glucose levels between baseline and three weeks after intervention within the four intervention groups. All statistical analyses were performed with IBM SPSS Statistics Software, version 20 (IBM Corporation, Armonk, New York) and a two-sided $p$ value of $<0.05$ was considered statistically significant.

\section{Results}

Baseline characteristics of the study population are reported in Table 8.1. Overall, as compared with lean individuals, obese NGT individuals had lower HDL cholesterol levels and higher HOMA-IR. In obese individuals with type 2 diabetes, HOMA-IR, $\mathrm{HbA} 1 \mathrm{C}$ and plasma triglyceride levels were higher compared to the obese NGT individuals. 
174 Chapter 8

Table 8.1 - Baseline characteristics of the study population

\begin{tabular}{llll}
\hline Characteristic & Lean $(n=12)$ & Obese NGT $(n=27)$ & Obese T2DM $(n=27)$ \\
\hline Age (years) & $49.2 \pm 6.2$ & $47.7 \pm 6.4$ & $51.0 \pm 7.1$ \\
Weight $(\mathrm{kg})$ & $64.4 \pm 7.2$ & $124.3 \pm 11.7^{* * *}$ & $117.2 \pm 17.1$ \\
$\mathrm{BMI}\left(\mathrm{kg} / \mathrm{m}^{2}\right)$ & $21.7 \pm 1.6$ & $43.8 \pm 3.2^{* * *}$ & $42.0 \pm 5.5$ \\
Waist $(\mathrm{cm})$ & $78.0 \pm 6.0$ & $122.3 \pm 9.2^{* * *}$ & $123.2 \pm 11.0$ \\
Fat mass $(\%)$ & $35.5 \pm 2.4$ & $56.3 \pm 2.2^{* * *}$ & $55.7 \pm 4.4$ \\
$\mathrm{HbA}_{1 \mathrm{C}}(\mathrm{mmol} / \mathrm{mol})$ & $31.9 \pm 2.5$ & $36.1 \pm 7.8$ & $49.6 \pm 12.0^{\dagger+\dagger}$ \\
$\mathrm{HbA}_{1 \mathrm{C}}(\%)$ & $5.1 \pm 0.2$ & $5.5 \pm 0.7$ & $6.7 \pm 1.1^{\dagger+\dagger}$ \\
Triglycerides (mmol/L) & $1.0 \pm 0.3$ & $1.4 \pm 0.6$ & $1.8 \pm 0.7^{\dagger}$ \\
Free fatty acids (mmol/L) & $0.9 \pm 0.3$ & $1.0 \pm 0.4$ & $1.2 \pm 0.3$ \\
Total cholesterol (mmol/L) & $5.0 \pm 0.9$ & $4.6 \pm 1.0$ & $4.4 \pm 0.8$ \\
HDL cholesterol (mmol/L) & $1.7 \pm 0.3$ & $1.1 \pm 0.3^{* * *}$ & $1.1 \pm 0.3$ \\
LDL cholesterol (mmol/L) & $2.9 \pm 0.9$ & $2.9 \pm 0.9$ & $2.5 \pm 0.6$ \\
HOMA-IR & $0.3 \pm 0.1$ & $3.2 \pm 2.3^{* *}$ & $5.4 \pm 3.6^{\dagger}$ \\
\hline
\end{tabular}

Data are presented as means \pm SD. Differences between the groups were tested using one-way ANOVA with Bonferroni correction. ${ }^{* *} p<0.01$ and ${ }^{* *} p<0.001$ for lean vs obese NGT individuals. $+p<0.05$ and $+++p<0.001$ for obese NGT vs. obese type 2 diabetes individuals. NGT, normal glucose tolerance; T2DM, type 2 diabetes mellitus; HDL, high-density lipoprotein; LDL, low-density lipoprotein; HOMA-IR, homeostasis model of assessment - insulin resistance.

\section{Fasting plasma MGO levels are higher in obese NGT women}

Fasting plasma MGO levels were higher in obese NGT individuals compared with lean individuals (Supplementary Table 8.1). Because glucose is considered a major substrate for $\alpha$-dicarbonyl formation, we adjusted our analyses for fasting plasma glucose levels. Interestingly, the elevated fasting MGO levels in obese NGT individuals remained significant after adjustment for glucose (Supplementary Table 8.1). None of the other fasting $\alpha$-dicarbonyls were increased in obese NGT individuals. Furthermore, iAUCs of all plasma $\alpha$-dicarbonyls and glucose did not differ between lean and obese NGT individuals (Figure 8.1B, D, F and $H$ ).

\section{Fasting and postprandial $\alpha$-dicarbonyl stress is higher in obese women with type 2 diabetes}

When we compared obese individuals with NGT and those with type 2 diabetes at baseline, we found significantly higher fasting plasma levels of $\alpha$-dicarbonyls and glucose (Supplementary Table 8.1, $p<0.01$ for all) in those with type 2 diabetes. Particularly, the postprandial iAUCs of MGO, 3-DG and glucose of the mixed meal test were significantly higher ( $p<0.01$ for all) in obese individuals with type 2 diabetes compared with obese NGT individuals (Figure 8.1B, F and H). We observed a similar, yet non-significant difference between obese NGT and type 2 diabetic individuals for 
the iAUC of GO (Figure 8.1D). After adjustment for glucose, all significant differences between obese individuals without and with type 2 diabetes were attenuated (Supplementary Table 8.1).

A

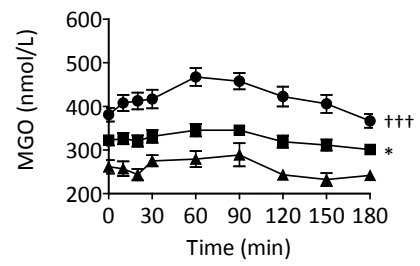

C

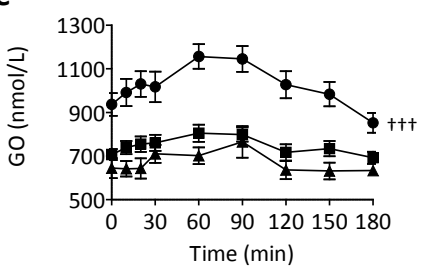

$\mathbf{E}$

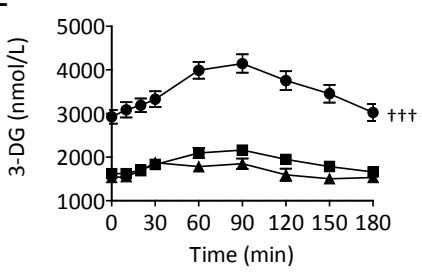

G

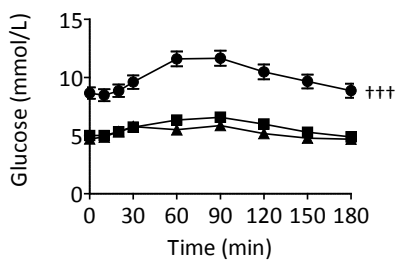

B

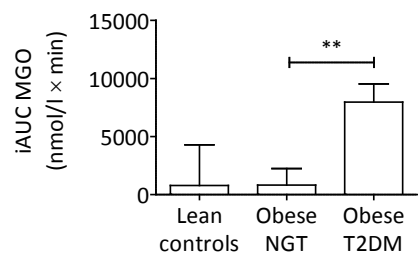

D

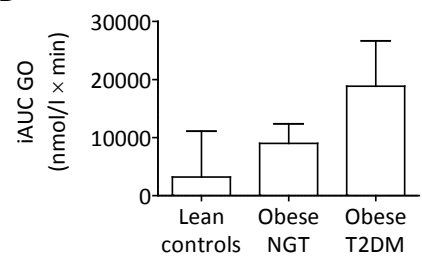

$\mathbf{F}$

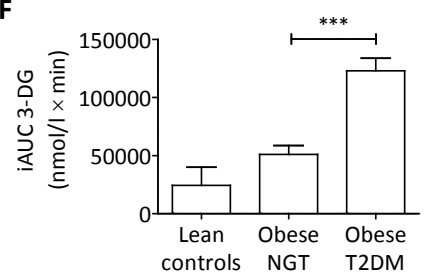

H

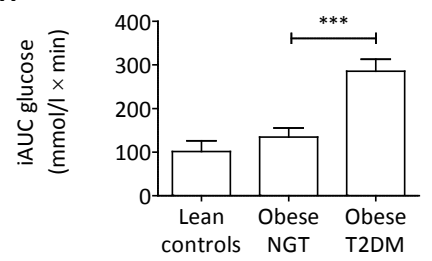

Figure 8.1 - Baseline plasma levels of $\alpha$-dicarbonyls and glucose before and during a mixed meal test. Plasma levels during the MMT of (A) MGO, (C) GO, (E) 3-DG and (G) glucose and iAUC, as calculated from the MMT of (B) MGO, (D) GO, (F) 3-DG and (H) glucose. Data are shown as means (SEM). Triangles, lean, $n=12$; squares, obese NGT, $n=27$; circles, obese type 2 diabetic individuals, $n=27$. Differences in postprandial curves during the mixed meal between the groups were tested with repeated-measures two-way ANOVA with Bonferroni correction. Differences in the iAUCs of MGO, GO, 3-DG and glucose between the groups were tested with one-way ANOVA with Bonferroni correction. ${ }^{*} p<0.05,{ }^{* *} p<0.01$ and ${ }^{* * *} p<0.001$ compared with lean individuals and ${ }^{t+\dagger} p<0.001$ compared with obese NGT individuals. 


\section{Fasting plasma MGO levels are reduced by RYGB in obese NGT women within three weeks}

In obese NGT individuals, we observed reduced fasting MGO levels after RYGB $(p<0.05)$, but no significant reduction in other $\alpha$-dicarbonyls (Supplementary Figure 8.1). Weight loss through GB in obese NGT individuals did not lead to changes in $\alpha$ dicarbonyl stress (Supplementary Figure 8.2).

\section{CR and RYGB reduce fasting and postprandial plasma $\alpha$-dicarbonyl stress in obese women with type 2 diabetes}

In obese type 2 diabetic individuals, postprandial levels of $\alpha$-dicarbonyls and glucose were decreased after 3 weeks of a VLCD (Figure 8.2A, C, E and G). Indeed, the total load of $\alpha$-dicarbonyls and glucose after a meal, as reflected by the AUC, was substantially decreased by the VLCD (data not shown, $p<0.05$ for all). This effect was mostly attributable to decreased fasting $\alpha$-dicarbonyl levels (MGO and 3-DG, $p<0.05$ for both), as the postprandial $\alpha$-dicarbonyl excursions (iAUC) after a meal were similar before and after the VLCD (Figure 8.2B, D, F and H). Fasting plasma GO levels did not change significantly after 3 weeks of the VLCD, but a non-significant $(p=0.11)$ reduction was observed. Comparable findings regarding the effect on postprandial $\alpha$ dicarbonyl stress in obese type 2 diabetic individuals were found 3 weeks after RYGB (Figure 8.3).

\section{Discussion}

This study shows that obese individuals with type 2 diabetes have higher fasting and particularly higher postprandial plasma $\alpha$-dicarbonyl levels than individuals without diabetes. Moreover, a VLCD and RYGB reduced plasma $\alpha$-dicarbonyl stress in obese type 2 diabetic individuals, mainly through reduction of fasting plasma $\alpha$-dicarbonyls. In obese individuals with NGT, we found higher fasting plasma MGO levels compared with lean individuals, but we observed no further postprandial increase. Interestingly, these increased fasting MGO levels were reduced by RYGB. The elevated fasting MGO levels in obese individuals compared with healthy individuals remained significant after adjustment for glucose. Therefore, other pathways may contribute to increased MGO formation in obese NGT individuals, such as catabolism of threonine and acetone, lipid peroxidation and degradation of glycated proteins. ${ }^{3}$ In contrast, fasting and postprandial plasma levels of the other $\alpha$-dicarbonyls were not affected by the presence of obesity. 
A

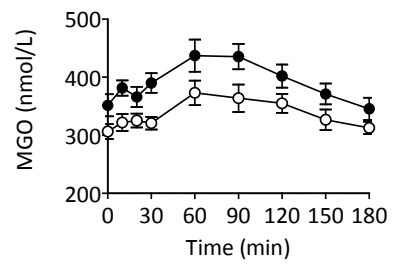

C

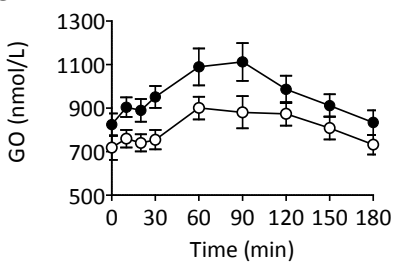

E

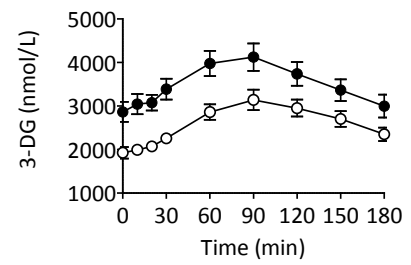

G

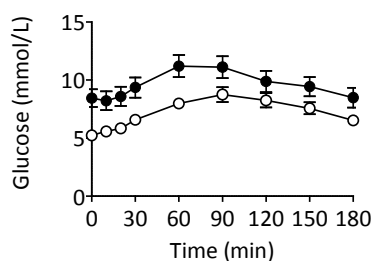

B

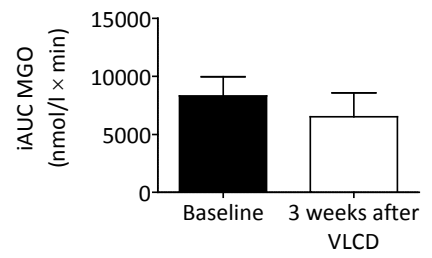

D

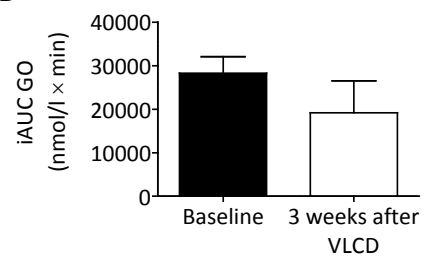

$\mathbf{F}$

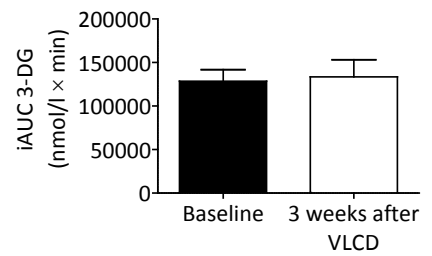

H

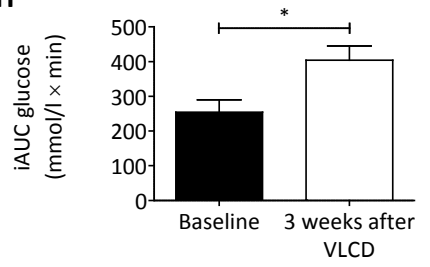

Figure 8.2 - Plasma levels of $\alpha$-dicarbonyls and glucose in obese individuals with type $\mathbf{2}$ diabetes after $\mathbf{3}$ weeks of a VLCD. Plasma levels during the MMT of (A) MGO, (C) GO, (E) 3-DG and (G) glucose and iAUC, as calculated from the MMT, of (B) MGO, (D) GO, (F) 3-DG and (H) glucose. Data are shown as means (SEM). Black circles, obese type 2 diabetic individuals before the VLCD; open circles, obese type 2 diabetic individuals 3 weeks after the VLCD, $n=12$. Differences in fasting levels and the iAUCs of MGO, GO, 3-DG and glucose were tested with paired two-sided samples $t$ tests. ${ }^{*} p<0.05$ compared with baseline.

Our current findings on increased postprandial $\alpha$-dicarbonyl stress in type 2 diabetes, together with similar findings in type 1 diabetes, ${ }^{20}$ are in line with our previous work, in which we demonstrated increased $\alpha$-dicarbonyl stress in type 2 diabetic individuals after an oral glucose load. ${ }^{1}$ Therefore, it is likely that the increased $\alpha$-dicarbonyl levels after a meal result from increased postprandial glucose levels. However, the possible role of other substrates for $\alpha$-dicarbonyl formation, such as reduced lipid oxidation and reactive oxygen species, cannot be excluded. ROS are known to increase 
postprandially in type 2 diabetes $^{21}$ and, therefore, reduction of ROS by weight loss could also be responsible for lower postprandial MGO stress, but this phenomenon deserves further investigation. Additionally, a VLCD may reduce MGO via induction of nuclear factor (erythroid-derived 2)-like 2 (Nrf2), an inducer of the MGO-detoxifying enzyme glyoxalase- $1 .^{22}$

A

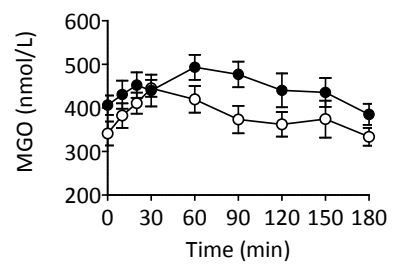

C

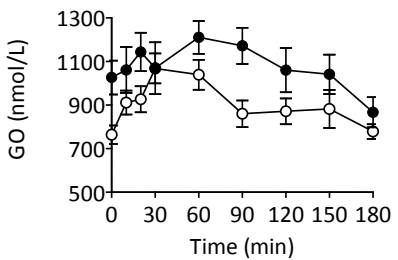

E

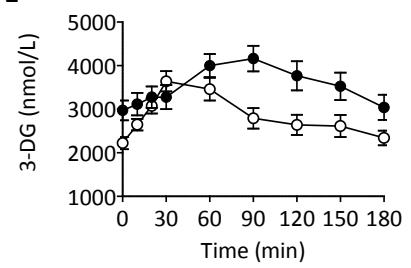

G

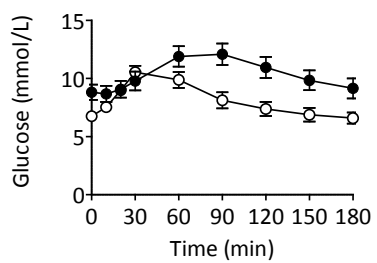

B

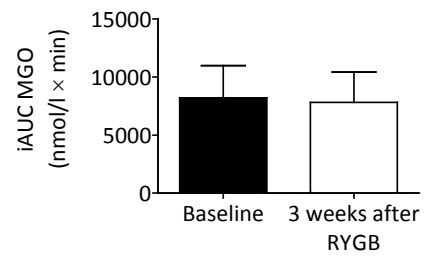

D

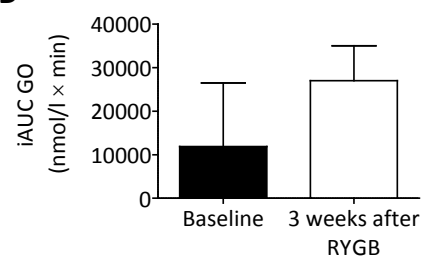

$\mathbf{F}$

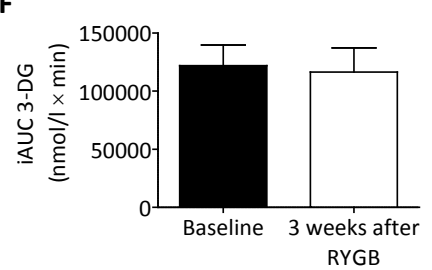

H

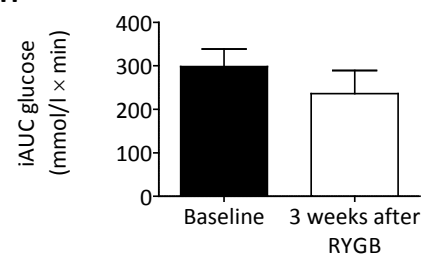

Figure 8.3 - Plasma levels of $\alpha$-dicarbonyls and glucose in obese individuals with type 2 diabetes $\mathbf{3}$ weeks after Roux-en-Y gastric bypass. Plasma levels during the MMT of (A) MGO, (C) GO, (E) 3-DG and (G) glucose and iAUC, as calculated from the MMT, of (B) MGO, (D) GO, (F) 3-DG and (H) glucose. Data are shown as means (SEM). Black circles, obese type 2 diabetic individuals before RYGB; open circles, obese type 2 diabetic individuals 3 weeks after RYGB, $n=15$. Differences in fasting levels and the iAUCs of MGO, GO, 3-DG and glucose were tested with paired two-sided samples $t$ tests. 
Our current findings are of potential clinical importance, since $\alpha$-dicarbonyl compounds have been identified as potential key mediators of diabetic complications. Of the three major $\alpha$-dicarbonyls, MGO has been described as the most potent glycating agent in the generation of glycation adducts on cellular and short-lived extracellular proteins, lipids and DNA. ${ }^{3}$ Multiple studies have shown that MGO plays a crucial role in the development of diabetic complications, particularly via induction of endothelial dysfunction. ${ }^{24}$ In addition, MGO has been linked to hypertension, ${ }^{25}$ atherosclerosis, $^{10}$ epigenetic changes ${ }^{26}$ and many other age-related diseases. ${ }^{3}$ Therefore, excursions in MGO at the fasting and postprandial level in patients with type 2 diabetes are a potential target for prevention and treatment of diabetic complications. For example, quenching of $\alpha$-dicarbonyls may be possible with the vitamin B6 analogue, pyridoxamine. ${ }^{27,28}$ Furthermore, MGO may be reduced via induction of glyoxalase-1, using inducers of Nrf2. ${ }^{22}$

This is the first study that describes increased postprandial $\alpha$-dicarbonyl stress in obese type 2 diabetic individuals, and its reduction by weight loss. Future work should investigate whether a VLCD and RYBG achieve health improvements and lower cardiovascular risk through reduced $\alpha$-dicarbonyl stress. A limitation of this study was that we could not include a control group that remained weight-stable. Nevertheless, we report on two distinct interventions that aimed to induce weight loss, showing comparable results. Another limitation was that we lacked statistical power to investigate mediating factors through which $\alpha$-dicarbonyl levels were improved by the VLCD and RYGB. Additionally, we investigated women only in the current study, but we have no theoretical basis to assume that our results would be different in men. Furthermore, our study does not reveal which tissues contribute to the plasma pool of $\alpha$-dicarbonyls. Although we hypothesize that plasma $\alpha$-dicarbonyls are derived from insulin-independent cells which are in close contact with blood, such as endothelial cells ${ }^{29}$ and erythrocytes, animal studies are needed to fully address this issue.

In conclusion, we demonstrated increased postprandial $\alpha$-dicarbonyl stress in obese individuals with type 2 diabetes, which can be reduced by a VLCD or RYGB. These data highlight the potential to reduce $\alpha$-dicarbonyls as a target to prevent or delay the development of complications in obese type 2 diabetic individuals. 


\section{References}

1. Maessen DE, Hanssen NM, Scheijen JL, van der Kallen CJ, van Greevenbroek MM, Stehouwer CD, Schalkwijk CG. Post-glucose load plasma alpha-dicarbonyl concentrations are increased in individuals with impaired glucose metabolism and type 2 diabetes: The codam study. Diabetes Care. 2015; 38:913-920

2. Madsbad S. Impact of postprandial glucose control on diabetes-related complications: How is the evidence evolving? J Diabetes Complications. 2015;

3. Maessen DE, Stehouwer CD, Schalkwijk CG. The role of methylglyoxal and the glyoxalase system in diabetes and other age-related diseases. Clin Sci (Lond). 2015; 128:839-861

4. Schalkwijk CG. Vascular age-ing by methylglyoxal: The past, the present and the future. Diabetologia. 2015; 58:1715-1719

5. Brownlee M. Biochemistry and molecular cell biology of diabetic complications. Nature. 2001; 414:813-820

6. Rabbani N, Thornalley PJ. Dicarbonyl stress in cell and tissue dysfunction contributing to ageing and disease. Biochem Biophys Res Commun. 2015; 458:221-226

7. Thornalley PJ, Langborg A, Minhas HS. Formation of glyoxal, methylglyoxal and 3-deoxyglucosone in the glycation of proteins by glucose. Biochem J. 1999; 344 Pt 1:109-116

8. Schalkwijk CG, Miyata T. Early- and advanced non-enzymatic glycation in diabetic vascular complications: The search for therapeutics. Amino Acids. 2012; 42:1193-1204

9. Bierhaus A, Fleming T, Stoyanov S, Leffler A, Babes A, Neacsu C, Sauer SK, Eberhardt M, Schnolzer M, Lasitschka F, Neuhuber WL, Kichko TI, Konrade I, Elvert R, Mier W, Pirags V, Lukic IK, Morcos M, Dehmer T, Rabbani N, Thornalley PJ, Edelstein D, Nau C, Forbes J, Humpert PM, Schwaninger M, Ziegler D, Stern DM, Cooper ME, Haberkorn U, Brownlee M, Reeh PW, Nawroth PP. Methylglyoxal modification of nav1.8 facilitates nociceptive neuron firing and causes hyperalgesia in diabetic neuropathy. Nat Med. 2012; 18:926-933

10. Hanssen NM, Wouters K, Huijberts MS, Gijbels MJ, Sluimer JC, Scheijen JL, Heeneman S, Biessen EA, Daemen MJ, Brownlee M, de Kleijn DP, Stehouwer CD, Pasterkamp G, Schalkwijk CG. Higher levels of advanced glycation endproducts in human carotid atherosclerotic plaques are associated with a rupture-prone phenotype. Eur Heart J. 2014; 35:1137-1146

11. Knowler WC, Fowler SE, Hamman RF, Christophi CA, Hoffman HJ, Brenneman AT, Brown-Friday JO, Goldberg R, Venditti E, Nathan DM. 10-year follow-up of diabetes incidence and weight loss in the diabetes prevention program outcomes study. Lancet. 2009; 374:1677-1686

12. Colman RJ, Anderson RM, Johnson SC, Kastman EK, Kosmatka KJ, Beasley TM, Allison DB, Cruzen C, Simmons HA, Kemnitz JW, Weindruch R. Caloric restriction delays disease onset and mortality in rhesus monkeys. Science. 2009; 325:201-204

13. Schauer PR, Bhatt DL, Kirwan JP, Wolski K, Brethauer SA, Navaneethan SD, Aminian A, Pothier CE, Kim ES, Nissen SE, Kashyap SR. Bariatric surgery versus intensive medical therapy for diabetes--3-year outcomes. N Engl J Med. 2014; 370:2002-2013

14. Jazet IM, Pijl H, Frolich M, Romijn JA, Meinders AE. Two days of a very low calorie diet reduces endogenous glucose production in obese type 2 diabetic patients despite the withdrawal of blood glucose-lowering therapies including insulin. Metabolism. 2005; 54:705-712

15. Jazet IM, Ouwens DM, Schaart G, Pijl H, Keizer H, Maassen JA, Meinders AE. Effect of a 2-day very low-energy diet on skeletal muscle insulin sensitivity in obese type 2 diabetic patients on insulin therapy. Metabolism. 2005; 54:1669-1678

16. Lips MA, de Groot GH, van Klinken JB, Aarts E, Berends FJ, Janssen IM, Van Ramshorst B, Van Wagensveld BA, Swank DJ, Van Dielen F, Willems van Dijk K, Pijl H. Calorie restriction is a major determinant of the short-term metabolic effects of gastric bypass surgery in obese type 2 diabetic patients. Clin Endocrinol (Oxf). 2014; 80:834-842

17. Scheijen JL, Schalkwijk CG. Quantification of glyoxal, methylglyoxal and 3-deoxyglucosone in blood and plasma by ultra performance liquid chromatography tandem mass spectrometry: Evaluation of blood specimen. Clin Chem Lab Med. 2014; 52:85-91

18. Lips MA, de Groot GH, Berends FJ, Wiezer R, van Wagensveld BA, Swank DJ, Luijten A, van Dijk KW, $\mathrm{Pijl} \mathrm{H}$, Jansen PL, Schaap FG. Calorie restriction and roux-en-y gastric bypass have opposing effects on circulating fgf21 in morbidly obese subjects. Clin Endocrinol (Oxf). 2014; 81:862-870 
19. Allison DB, Paultre F, Maggio C, Mezzitis N, Pi-Sunyer FX. The use of areas under curves in diabetes research. Diabetes Care. 1995; 18:245-250

20. Beisswenger PJ, Howell SK, O'Dell RM, Wood ME, Touchette AD, Szwergold BS. Alpha-dicarbonyls increase in the postprandial period and reflect the degree of hyperglycemia. Diabetes Care. 2001; 24:726-732

21. Ceriello A, Bortolotti N, Motz E, Pieri C, Marra M, Tonutti L, Lizzio S, Feletto F, Catone B, Taboga C. Meal-induced oxidative stress and low-density lipoprotein oxidation in diabetes: The possible role of hyperglycemia. Metabolism. 1999; 48:1503-1508

22. Xue M, Rabbani N, Momiji H, Imbasi P, Anwar MM, Kitteringham N, Park BK, Souma T, Moriguchi T, Yamamoto M, Thornalley PJ. Transcriptional control of glyoxalase 1 by nrf2 provides a stressresponsive defence against dicarbonyl glycation. Biochem J. 2012; 443:213-222

23. Martin-Montalvo A, Villalba JM, Navas P, de Cabo R. Nrf2, cancer and calorie restriction. Oncogene. 2011; 30:505-520

24. Brouwers O, Niessen PM, Miyata T, Ostergaard JA, Flyvbjerg A, Peutz-Kootstra CJ, Sieber J, Mundel $\mathrm{PH}$, Brownlee M, Janssen BJ, De Mey JG, Stehouwer CD, Schalkwijk CG. Glyoxalase-1 overexpression reduces endothelial dysfunction and attenuates early renal impairment in a rat model of diabetes. Diabetologia. 2014; 57:224-235

25. Dhar I, Dhar A, Wu L, Desai KM. Methylglyoxal, a reactive glucose metabolite, increases renin angiotensin aldosterone and blood pressure in male sprague-dawley rats. Am J Hypertens. 2014; 27:308-316

26. El-Osta A, Brasacchio D, Yao D, Pocai A, Jones PL, Roeder RG, Cooper ME, Brownlee M. Transient high glucose causes persistent epigenetic changes and altered gene expression during subsequent normoglycemia. J Exp Med. 2008; 205:2409-2417

27. Degenhardt TP, Alderson NL, Arrington DD, Beattie RJ, Basgen JM, Steffes MW, Thorpe SR, Baynes JW. Pyridoxamine inhibits early renal disease and dyslipidemia in the streptozotocin-diabetic rat. Kidney Int. 2002; 61:939-950

28. Maessen DE, Brouwers O, Gaens KH, Wouters K, Cleutjens JP, Janssen BJ, Miyata T, Stehouwer CD, Schalkwijk CG. Delayed intervention with pyridoxamine improves metabolic function and prevents adipose tissue inflammation and insulin resistance in high-fat diet-induced obese mice. Diabetes. 2015;

29. Shinohara M, Thornalley PJ, Giardino I, Beisswenger P, Thorpe SR, Onorato J, Brownlee M. Overexpression of glyoxalase-i in bovine endothelial cells inhibits intracellular advanced glycation endproduct formation and prevents hyperglycemia-induced increases in macromolecular endocytosis. J Clin Invest. 1998; 101:1142-1147 
182 Chapter 8 
SUPPLEMENTARY DATA 
Supplementary Table 8.1 - Plasma levels of fasting and postprandial $\alpha$-dicarbonyl levels at baseline without and with adjustment for glucose

\begin{tabular}{|c|c|c|}
\hline & Unadjusted means & Adjusted means (adjusted for glucose) \\
\hline \multicolumn{3}{|c|}{ Fasting MGO (nmol/l) } \\
\hline Lean & $262 \pm 15$ & $290 \pm 19$ \\
\hline Obese NGT & $322 \pm 12^{*}$ & $346 \pm 14^{*}$ \\
\hline Obese T2DM & $381 \pm 16^{\dagger+}$ & $344 \pm 16$ \\
\hline \multicolumn{3}{|c|}{ Fasting GO (nmol/l) } \\
\hline Lean & $645 \pm 46$ & $729 \pm 60$ \\
\hline Obese NGT & $707 \pm 25$ & $777 \pm 42$ \\
\hline Obese T2DM & $937 \pm 52^{t+t}$ & $829 \pm 48$ \\
\hline \multicolumn{3}{|c|}{ Fasting 3-DG (nmol/l) } \\
\hline Lean & $1531 \pm 53$ & $2061 \pm 81$ \\
\hline Obese NGT & $1620 \pm 61$ & $2063 \pm 57$ \\
\hline Obese T2DM & $2926 \pm 159^{t+\dagger}$ & $2247 \pm 65$ \\
\hline \multicolumn{3}{|l|}{ IAUCMGO } \\
\hline Lean & $795 \pm 3487$ & $2057 \pm 2718$ \\
\hline Obese NGT & $823 \pm 1424$ & $1542 \pm 1673$ \\
\hline Obese T2DM & $7963 \pm 1571^{+t}$ & $6759 \pm 1795$ \\
\hline \multicolumn{3}{|l|}{$\overline{i A \cup C G O}$} \\
\hline Lean & $3211 \pm 7872$ & $6500 \pm 10170$ \\
\hline Obese NGT & $9006 \pm 3368$ & $10925 \pm 6270$ \\
\hline Obese T2DM & $18837 \pm 7809$ & $15771 \pm 6601$ \\
\hline \multicolumn{3}{|l|}{ IAUC 3-DG } \\
\hline Lean & $24434 \pm 15607$ & $39639 \pm 15229$ \\
\hline Obese NGT & $51074 \pm 7604$ & $59945 \pm 9389$ \\
\hline Obese T2DM & $123027 \pm 10922^{t+t}$ & $108853 \pm 9884$ \\
\hline
\end{tabular}

Lean, $n=12$; obese NGT, $n=27$; obese type 2 diabetes, $n=27$. Data are presented as unadjusted and adjusted means (SEM). Without correction for glucose, differences between the groups were tested with one-way ANOVA with Bonferroni correction. To compare the groups after adjustment for glucose, one-way ANCOVA with Bonferroni correction was used. ${ }^{*} p<0.05$ for lean vs obese NGT individuals. ${ }^{++} p<0.01$ and ${ }^{+++} p<0.001$ for obese NGT vs. obese type 2 diabetic individuals. 
A

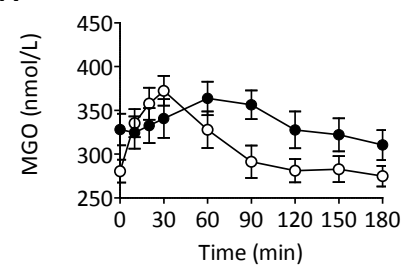

C

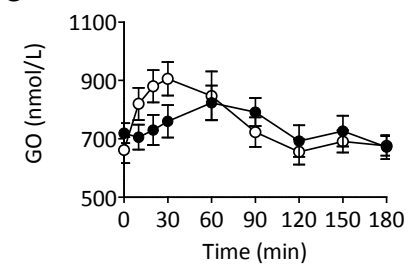

E

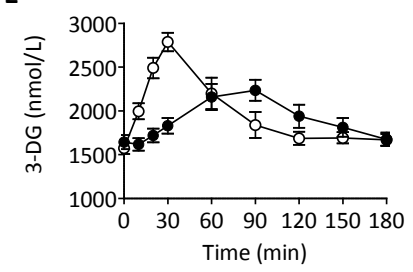

G

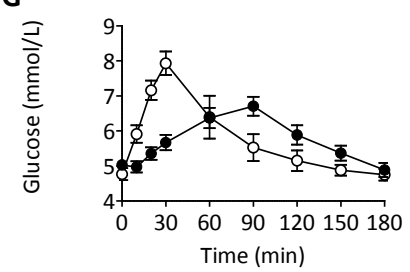

B

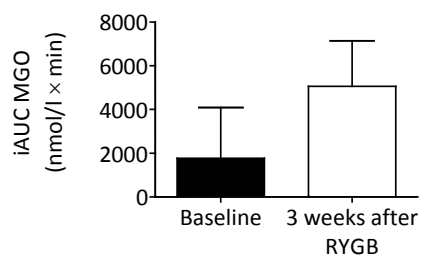

D

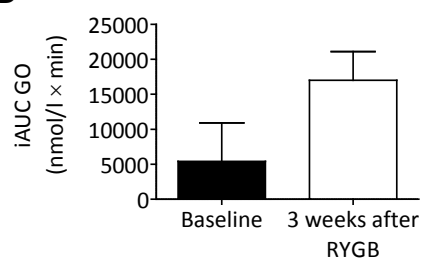

$\mathbf{F}$

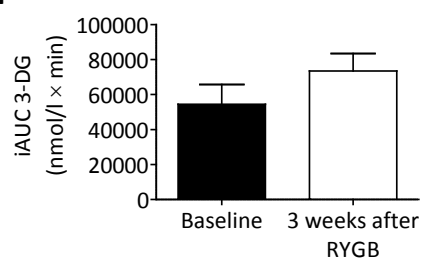

H

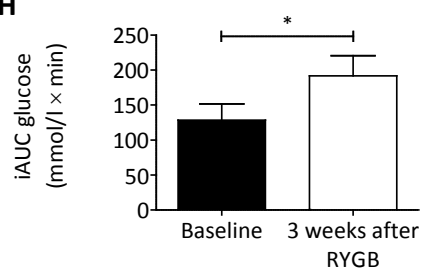

Supplementary Figure 8.1 - Plasma levels of $\alpha$-dicarbonyls and glucose in obese NGT individuals 3 weeks after Roux-en-Y gastric bypass. Plasma levels during the MMT of (A) MGO, (B) GO, (E) 3-DG and (G) glucose. iAUC as calculated from the MMT of (B) MGO, (D) GO, (F) 3-DG and (H) glucose. Data are shown as means (SEM). Black circles, obese NGT individuals before RYGB; open circles, obese NGT individuals three weeks after RYGB, $n=16$. Differences in the iAUCs of MGO, GO, 3-DG and glucose were tested with paired twosided samples $t$ tests. 
A

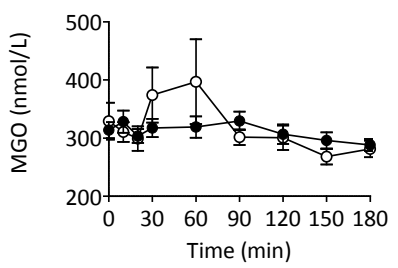

C

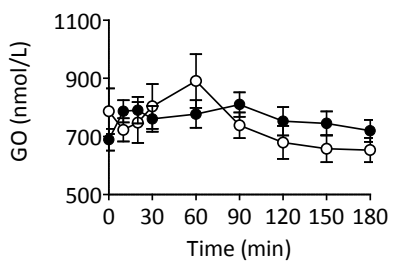

E

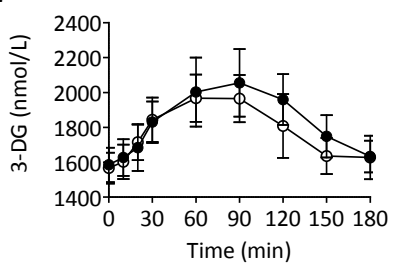

G

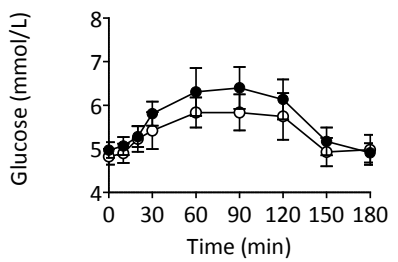

B

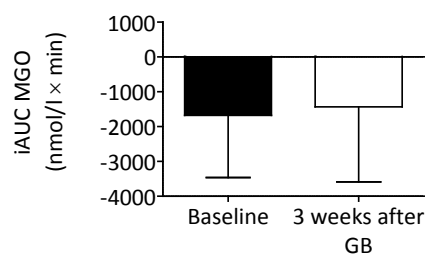

D

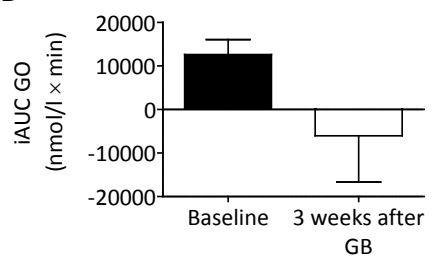

$\mathbf{F}$

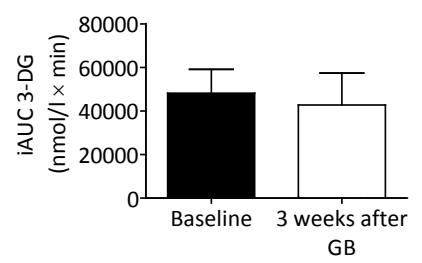

H

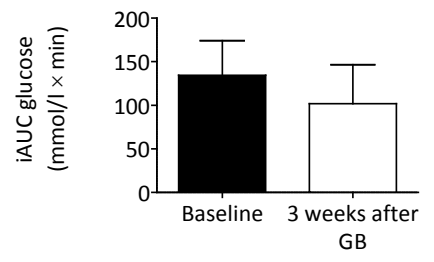

Supplementary Figure 8.2 - Plasma levels of $\alpha$-dicarbonyls and glucose in obese NGT individuals 3 weeks after gastric banding. Plasma levels during the MMT of (A) MGO, (B) GO, (E) 3-DG and (G) glucose. iAUC as calculated from the MMT of (B) MGO, (D) GO, (F) 3-DG and (H) glucose. Data are shown as means (SEM). Black circles, obese NGT individuals before GB; open circles, obese NGT individuals three weeks after GB, $n=11$. Differences in the iAUCs of MGO, GO, 3-DG and glucose were tested with paired two-sided samples $t$ tests. 
GENERAL DISCUSSION 


\section{Discussion}

In recent years, emerging evidence indicates a significant role of reactive $\alpha$ dicarbonyls and advanced glycation endproducts (AGEs) in the associations between obesity, insulin resistance, type 2 diabetes and cardiovascular complications. In order to study the exact mechanisms through which $\alpha$-dicarbonyls and AGEs contribute to these etiologies, the present thesis focused on the role of $\alpha$-dicarbonyl stress and AGEs in the development of obesity, insulin resistance and type 2 diabetes, by using a combination of in vivo studies, in vitro studies and epidemiological studies. This chapter discusses, in light of current knowledge, the key findings of this thesis and directions for future research.

\section{a-Dicarbonyls are directly involved in the development of obesity and adipose tissue inflammation}

Obesity is characterized by expansion of the adipose tissue which predisposes obese individuals to a wide range of diseases. ${ }^{1}$ Previous experimental studies from our lab have demonstrated that levels of the AGE $N^{\varepsilon}$-(carboxymethyl)lysine (CML) are increased during adipocyte lipid accumulation and suggested a role for advanced glycation in adipogenesis. ${ }^{2}$ To unravel the detailed role of $\alpha$-dicarbonyls and AGEs in obesity and adipose tissue expansion, we targeted $\alpha$-dicarbonyl stress in two high-fat diet (HFD)-induced obese mouse models, by pyridoxamine (chapter 5) or overexpression of the glyoxalase 1 (GLO1) enzyme (chapter 6). In both studies, we found inhibition of body weight gain during the period of HFD feeding. Decreased adiposity upon inhibition of $\alpha$-dicarbonyl stress, as was found in both studies, is a possible explanation for this observation. Both pyridoxamine and GLO1 overexpression resulted in decreased size of the individual adipocyte, and our study with pyridoxamine supplementation demonstrated decreased absolute mass of the visceral adipose tissue. These findings implicate that $\alpha$-dicarbonyls are involved in HFD-induced adipocyte maturation. Indeed, in vitro experiments revealed that the beneficial effects of targeting $\alpha$-dicarbonyls found in adipose tissue were most likely due to inhibition of adipogenesis, as Oil Red $\mathrm{O}$ staining and triglyceride content in both murine 3T3-L1 and human SGBS adipocytes were reduced by pyridoxamine. Decreased expression of adipogenic differentiation genes upon pyridoxamine stimulation strengthened this observation. Especially reduced SREBP-1C mRNA expression is in line with previous research, which demonstrated an interaction between CML and the SREBP cleavage-activating protein (SCAP)/SREBP-1C pathway. ${ }^{3,4}$ In addition, $\mathrm{CML}$ has been described to co-localize with SCAP, ${ }^{3-5}$ suggesting glycation 
of the SCAP protein. From our current observations, we concluded that inhibition of $\alpha$-dicarbonyls has beneficial effects on the prevention of HFD-induced development of obesity, due to decreased adiposity. Although previous findings suggest that this observation can be explained by interaction of $\alpha$-dicarbonyls or AGEs with the adipogenic SCAP/SREBP-1C pathway, other underlying mechanisms that lead to decreased adipogenesis cannot be excluded. Our telemetry measurements in an obese mouse model described in chapter 6 demonstrated that increased physical activity upon $\alpha$-dicarbonyl inhibition was not responsible for the decrease in adiposity. Therefore, future studies are needed to provide insight into the exact role of $\alpha$ dicarbonyls or AGEs in adipogenesis and associated weight gain in obesity.

Hypertrophy of the adipocyte in obese individuals leads to dysfunction of the adipose tissue. ${ }^{6}$ An important hallmark of hypertrophic adipocytes in obesity is increased adipokine secretion, ${ }^{7}$ resulting in a pro-inflammatory phenotype of the adipose tissue increasing the risk for developing type 2 diabetes and cardiovascular disease. ${ }^{7}$ In animal models of obesity, described in chapter $\mathbf{5}$ and $\mathbf{6}$, we found an inhibitory effect of pyridoxamine and GLO1 overexpression on mRNA expression levels of proinflammatory genes in visceral adipose tissue. Our data are in line with previous research, demonstrating the implication of advanced glycation in increased adipokine production in obesity via knockout of the main AGE receptor RAGE. ${ }^{2}$

In addition to the direct effects of pyridoxamine via inhibition of $\alpha$-dicarbonyls, this vitamin B6 analogue may also improve adipose tissue inflammation and metabolic function via reduction of oxidative stress. ${ }^{9}$ Pyridoxamine potentially traps oxygen radicals directly, ${ }^{10}$ but it also inhibits ROS generation via post-Amadori oxidative reactions. $^{11,12}$

In conclusion, current data form a strong body of evidence that $\alpha$-dicarbonyls and AGEs play a significant role in the dysregulation of the adipokine profile in obesity. Inhibition of $\alpha$-dicarbonyl stress and AGEs via pyridoxamine or induction of GLO1 seems to be a potential intervention strategy in the treatment of obesity and obesityrelated adipose tissue inflammation.

\section{a-Dicarbonyls induce insulin resistance through modification of the} insulin molecule

Obesity, and specifically obesity-induced adipose tissue inflammation, represents a major risk factor for the development of insulin resistance. ${ }^{13}$ As we demonstrated that $\alpha$-dicarbonyls are involved both directly in obesity, as well as in the induction of adipose tissue inflammation, it is evident to speculate that these compounds also play a substantial role in the etiology of insulin resistance. Indeed, several experimental 
studies indicated the involvement of $\alpha$-dicarbonyls herein, ${ }^{2,}{ }^{14-16}$ via e.g. $\beta$-cell dysfunction ${ }^{17-19}$ or apoptosis, ${ }^{20}$ oxidative stress, ${ }^{21}$ and structural and functional changes of insulin. ${ }^{22}$ However, evidence in humans was lacking. As described in chapter 3, we investigated the association between $\alpha$-dicarbonyls, and in particular $\mathrm{MGO}$, and insulin resistance in a large human cohort study. Because of the high reactivity of MGO with plasma proteins, valid and precise measurements for MGO in plasma were not available yet for this study. Since MGO is metabolized into D-lactate via the glyoxalase system, ${ }^{23}$ we therefore measured plasma D-lactate levels as an estimate of plasma MGO levels with state of the art technique UPLC-MS/MS. We found a positive association between plasma D-lactate levels and HOMA-IR, as a measure of insulin resistance, providing for the first time evidence in humans of a possible link between MGO and insulin resistance. Later, we achieved to develop a method to measure plasma levels of reactive MGO, and also other $\alpha$-dicarbonyls including GO and 3-DG, with UPLC-MS/MS. ${ }^{24}$ The study described in chapter 4 confirmed our hypothesis that plasma MGO, but also GO and 3-DG, are significantly higher in insulin resistant individuals. In contrast, plasma levels of AGEs were not different between individuals with or without insulin resistance. Furthermore, increased plasma levels of $\alpha$-dicarbonyls were not reflected by intramuscular accumulation of $\alpha$-dicarbonyls and AGEs. The lack of an association between intramuscular $\alpha$-dicarbonyl levels and insulin resistance implicated that specifically extracellular $\alpha$-dicarbonyls are involved in insulin resistance. In chapter 4 , we further elucidated how these reactive compounds contribute to the development of insulin resistance. We found strong evidence that a modification of insulin by MGO is likely to impair normal functioning of the insulin signaling cascade. MGO-modification has previously been identified on arginine residues of human insulin, after a 3-day incubation of insulin with MGO in vitro. ${ }^{22}$ However, due to the very short half-life of insulin in plasma $(\sim 4-6 \mathrm{~min}),{ }^{25}$ such a long-term incubation probably reflects the situation in the pancreas, in which insulin is packaged inside clustered granules of the $\beta$-cell. ${ }^{26}$ Therefore, we performed a short-term incubation of insulin with MGO in vitro and we found a dose-dependent arginine modification of insulin by MGO after 1-h. Stimulation of cultured skeletal muscle cells with MGO-modified insulin revealed impairment of function, as indicated by decreased phosphorylation of AKT downstream the insulin receptor. Together, these data implicate that increased plasma $\alpha$-dicarbonyl stress, and particularly increased plasma MGO, contributes directly to the etiology of muscle insulin resistance, most likely via modification of the insulin molecule and impairment of its function. This result provided perspective for prevention and treatment of insulin resistance in at-risk obese individuals. Indeed, we found that targeting of $\alpha$-dicarbonyls via pyridoxamine supplementation (chapter 5 ) 
prevented the development of insulin resistance in HFD-induced obese mice, and that GLO1 overexpression (chapter 6) improved glucose metabolism. In addition, previous experimental studies demonstrated beneficial effects of insulin sensitivity in an obese mouse model with knockout of the major AGE receptor AGE, implicating the involvement of advanced glycation in insulin resistance. ${ }^{2,8}$

The effect of GLO1 induction has recently been investigated in a human study, in which a dietary GLO1 inducer demonstrated synergistic stimulation of GLO1 expression by trans-resveratrol (tRES) and hesperetin (HESP), via activation of nuclear factor (erythroid-derived 2)-like 2 (Nrf2). ${ }^{27} \mathrm{Nrf2}$ mediates anti-oxidant responsive element (ARE)-dependent induction of anti-oxidant enzymes and previous studies have identified an ARE-responsive element in the promotor of GLO1. ${ }^{28,}{ }^{29}$ The combination of tRES and HESP demonstrated improved glycemic control and vascular function in overweight and obese subjects as a result of GLO1 stimulation. ${ }^{27}$

In conclusion, evidence from both experimental and clinical studies highlight the association between increased $\alpha$-dicarbonyl stress and insulin resistance. This relation is most likely explained by modification of the insulin protein by $\alpha$-dicarbonyl compounds, particularly by highly reactive MGO. Future studies are needed to identify MGO-modifications on circulating and pancreatic insulin in vivo.

\section{Postprandial $\alpha$-dicarbonyl stress in type 2 diabetes}

In case of diabetes, chronic hyperglycemia is the one of the major risk factors for the development of vascular complications. ${ }^{30}$ Largely based on outcome studies including the Diabetes Control and Complications Trial (DCCT) and the United Kingdom Prospective Diabetes Study (UKPDS), ${ }^{31,32}$ lowering glycosylated hemoglobin $\left(\mathrm{HbA}_{1 \mathrm{c}}\right)$ has become the primary treatment goal in the management of chronic hyperglycemia. ${ }^{33}$ However, postprandial glucose excursions are currently of considerable interest in view of strict overall glycemic control. Multiple studies have described an association between postprandial hyperglycemia and increased risk for diabetic vascular complications. ${ }^{33-44}$ A possible explanation for the contribution of postprandial glucose excursions to vascular complications in diabetes is increased $\alpha$ dicarbonyl stress. Several experimental studies have identified an association between increased $\alpha$-dicarbonyl stress and both micro- and macrovascular complications in diabetes, as described in detail in chapter 2. However, whether $\alpha-$ dicarbonyls were also increased in the postprandial setting had not been elucidated yet. 
In this thesis, we found increased plasma concentrations of $\alpha$-dicarbonyls in individuals with impaired glucose metabolism (IGM) and type 2 diabetes during an oral glucose tolerance test (chapter 7). These associations were completely independent of putative confounders. However, adjustment for post-load glucose excursions attenuated the associations, indicating that glucose is the major source for $\alpha$-dicarbonyl formation in this setting. Although the level of glycemia 2 -h after an oral glucose tolerance test is known to be closely related to glucose levels after a standardized meal, ${ }^{45}$ direct evidence for increased postprandial $\alpha$-dicarbonyl stress was not yet provided with this study. Our study described in chapter 8 provided proof of concept, showing that both fasting and postprandial plasma $\alpha$-dicarbonyl levels are indeed significantly higher in obese women with type 2 diabetes, compared to obese women without diabetes. We also found an effect of obesity itself on fasting plasma MGO levels, but not on GO and 3-DG. Since this association remained significant after adjustment for glucose, it is likely that increased fasting plasma levels of MGO in obesity originate from other sources than glucose. One explanation may be increased lipid peroxidation, which is an important source for the formation of MGO. ${ }^{46,47}$ Moreover, our studies described in chapter $\mathbf{5}$ and chapter $\mathbf{6}$ demonstrated decreased GLO1 activity in visceral adipose tissue of obese mice, which might give a second possible explanation for increased fasting plasma MGO levels in obese women without diabetes. Future studies should unravel to what extent these increased plasma $\alpha$-dicarbonyl excursions after a meal contribute to the development of diabetic vascular complications.

Importantly, our study described in chapter $\mathbf{8}$ demonstrated that increased postprandial plasma $\alpha$-dicarbonyl stress in obese women with type 2 diabetes was reversible by weight loss interventions. Both energy restriction by a very low calorie diet and Roux-en-Y gastric bypass (RYGB) proved to be effective in lowering $\alpha$ dicarbonyl stress, already within 3 weeks. Thus, in addition to pyridoxamine and GLO1 induction, weight loss seems to be a third intervention strategy to lower diabetesinduced increases in $\alpha$-dicarbonyl stress, at least in individuals with obesity.

\section{Conclusion and future perspectives}

In this thesis, we identified the critical role of $\alpha$-dicarbonyl compounds in the etiology of obesity and insulin resistance, by using a strong combination of large cohort studies, animal studies and in vitro studies. In addition, we demonstrated for the first time the existence of postprandial $\alpha$-dicarbonyl excursions in individuals with type 2 diabetes, which might explain the increased risk for diabetic vascular complications. 
Figure 9.1 summarizes the main results described in this thesis and demonstrates the current working hypothesis. Altogether, we can conclude that $\alpha$-dicarbonyls form a potential target in the treatment of obesity and obesity-induced insulin resistance and type 2 diabetes.

This thesis provided important directions for future research in the field of glycation and type 2 diabetes. Our observations about the beneficial effects of pyridoxamine on obesity, inflammation, insulin resistance and also partially vascular function have created high expectations for clinical use. To date, several clinical studies have already demonstrated favorable effects of pyridoxamine, predominantly on diabetic nephropathy. ${ }^{48,49}$ With respect to research findings from the current thesis, a clinical study investigating the effect of pyridoxamine intervention in obese individuals on insulin resistance, inflammation and both micro- and macrovascular dysfunction is of high interest and such a study is currently in preparation. Furthermore, it is highly relevant to study the impact of postprandial $\alpha$-dicarbonyl excursions on clinical outcome. Intravenous spikes of $\alpha$-dicarbonyls in an animal model could give us insight into the biological effect of such excursions on e.g. insulin sensitivity and vascular function.

Another direction for future research could be found in the identification of insulinmodifications by $\alpha$-dicarbonyls in both the circulation and the pancreas, being the residual site of native insulin. A combination of these experimental and clinical studies would enable us to unravel the exact role of $\alpha$-dicarbonyl stress in the etiology of type 2 diabetes, ranging from obesity as a major risk factor, to the development of vascular complications in its most advanced stage. 


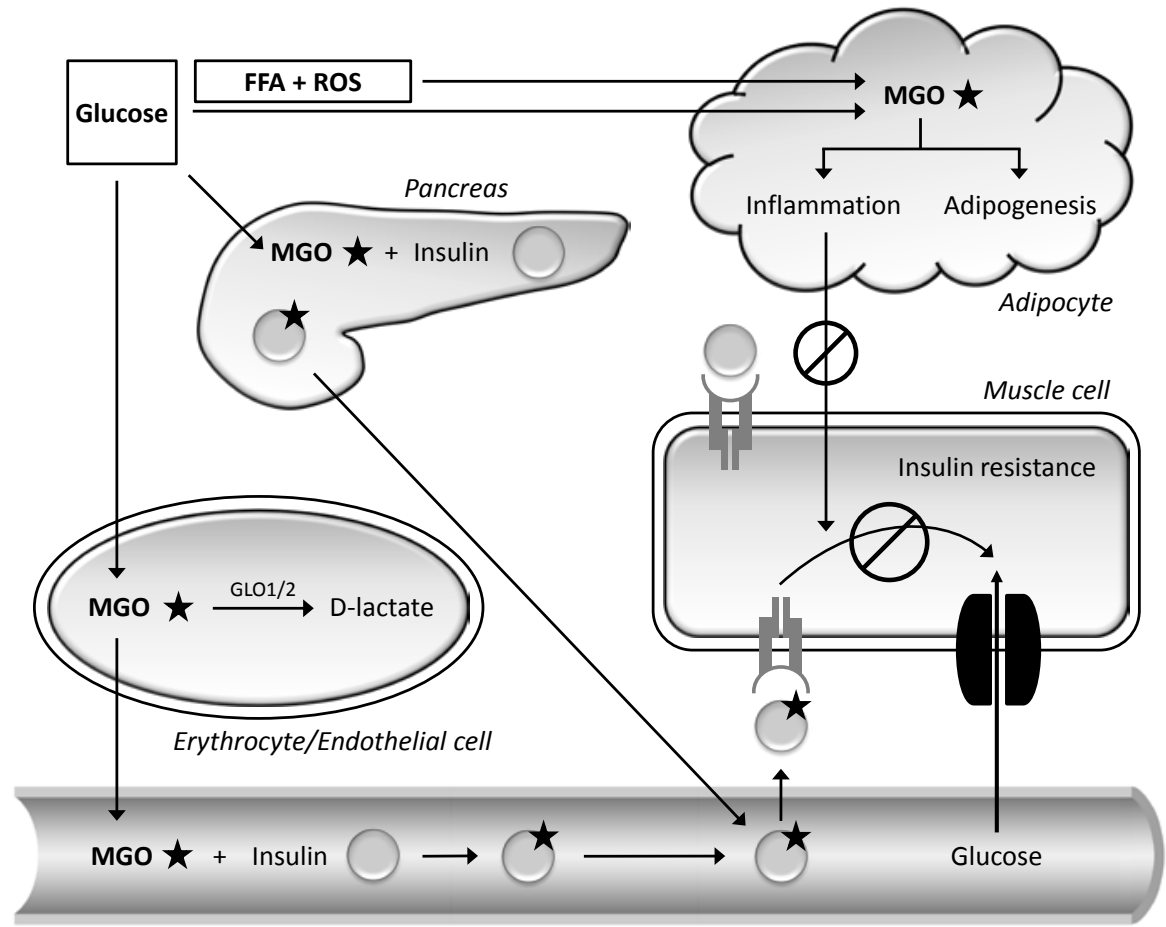

Circulation

Figure 9.1 - Schematic overview of the main findings of this thesis and the current working hypothesis. Glucose enters the endothelial cell or erythrocyte in which glycolysis gives rise to the formation of MGO and other $\alpha$-dicarbonyls. The glyoxalase system metabolizes MGO into D-lactate, which has been found to be associated with insulin resistance (chapter 3). When postprandial formation of MGO exceeds the detoxification capacity of glyoxalase, MGO accumulates and enters the circulation, as is the case in individuals with type 2 diabetes (chapter 7 and 8). In the circulation, MGO may bind to arginine residues of insulin, causing formation of MG-H1 modifications on circulating insulin (chapter 4). In addition to modification of insulin in the circulation, it is hypothesized that this phenomenon may also occur in the pancreas. Modified insulin loses its normal function upon modification by MGO, and the intracellular insulin signaling cascade in the muscle cell is not activated properly, causing insulin resistance and thus reduced glucose uptake from the circulation (chapter 4). In addition to glucose, free fatty acids (FFAs) and reactive oxygen species (ROS) may also lead to the formation of MGO. Accumulation of MGO in the adipocyte results in adipose tissue inflammation and increased adipogenesis, which enhances body weight gain in obesity (chapter 5 and 6). In addition, adipose tissue inflammation increases the risk of developing insulin resistance in obese individuals. 


\section{References}

1. Haslam DW, James WP. Obesity. Lancet. 2005; 366:1197-1209

2. Gaens $\mathrm{KH}$, Goossens GH, Niessen PM, van Greevenbroek MM, van der Kallen CJ, Niessen HW, Rensen SS, Buurman WA, Greve JW, Blaak EE, van Zandvoort MA, Bierhaus A, Stehouwer CD, Schalkwijk CG. Nepsilon-(carboxymethyl)lysine-receptor for advanced glycation end product axis is a key modulator of obesity-induced dysregulation of adipokine expression and insulin resistance. Arterioscler Thromb Vasc Biol. 2014; 34:1199-1208

3. Mastrocola R, Collino M, Nigro D, Chiazza F, D'Antona G, Aragno M, Minetto MA. Accumulation of advanced glycation end-products and activation of the scap/srebp lipogenetic pathway occur in dietinduced obese mouse skeletal muscle. PLoS One. 2015; 10:e0119587

4. Mastrocola R, Collino M, Rogazzo M, Medana C, Nigro D, Boccuzzi G, Aragno M. Advanced glycation end products promote hepatosteatosis by interfering with scap-srebp pathway in fructose-drinking mice. Am J Physiol Gastrointest Liver Physiol. 2013; 305:G398-407

5. Yuan Y, Zhao L, Chen Y, Moorhead JF, Varghese Z, Powis SH, Minogue S, Sun Z, Ruan XZ. Advanced glycation end products (ages) increase human mesangial foam cell formation by increasing golgi scap glycosylation in vitro. Am J Physiol Renal Physiol. 2011; 301:F236-243

6. Zhang Y, Proenca R, Maffei M, Barone M, Leopold L, Friedman JM. Positional cloning of the mouse obese gene and its human homologue. Nature. 1994; 372:425-432

7. Fasshauer M, Bluher M. Adipokines in health and disease. Trends Pharmacol Sci. 2015; 36:461-470

8. Song F, Hurtado del Pozo C, Rosario R, Zou YS, Ananthakrishnan R, Xu X, Patel PR, Benoit VM, Yan SF, Li H, Friedman RA, Kim JK, Ramasamy R, Ferrante AW, Jr., Schmidt AM. Rage regulates the metabolic and inflammatory response to high-fat feeding in mice. Diabetes. 2014; 63:1948-1965

9. Voziyan PA, Hudson BG. Pyridoxamine as a multifunctional pharmaceutical: Targeting pathogenic glycation and oxidative damage. Cell Mol Life Sci. 2005; 62:1671-1681

10. Onorato JM, Jenkins AJ, Thorpe SR, Baynes JW. Pyridoxamine, an inhibitor of advanced glycation reactions, also inhibits advanced lipoxidation reactions. Mechanism of action of pyridoxamine. J Biol Chem. 2000; 275:21177-21184

11. Mossine VV, Linetsky M, Glinsky GV, Ortwerth BJ, Feather MS. Superoxide free radical generation by amadori compounds: The role of acyclic forms and metal ions. Chem Res Toxicol. 1999; 12:230-236

12. Smith PR, Thornalley PJ. Mechanism of the degradation of non-enzymatically glycated proteins under physiological conditions. Studies with the model fructosamine, $\mathrm{n}$ epsilon-(1-deoxy-d-fructos-1yl)hippuryl-lysine. Eur J Biochem. 1992; 210:729-739

13. Xu H, Barnes GT, Yang Q, Tan G, Yang D, Chou CJ, Sole J, Nichols A, Ross JS, Tartaglia LA, Chen H. Chronic inflammation in fat plays a crucial role in the development of obesity-related insulin resistance. J Clin Invest. 2003; 112:1821-1830

14. Song F, Schmidt AM. Glycation and insulin resistance: Novel mechanisms and unique targets? Arterioscler Thromb Vasc Biol. 2012; 32:1760-1765

15. Unoki-Kubota H, Yamagishi S, Takeuchi M, Bujo H, Saito Y. Pyridoxamine, an inhibitor of advanced glycation end product (age) formation ameliorates insulin resistance in obese, type 2 diabetic mice. Protein Pept Lett. 2010; 17:1177-1181

16. Jia X, Wu L. Accumulation of endogenous methylglyoxal impaired insulin signaling in adipose tissue of fructose-fed rats. Mol Cell Biochem. 2007; 306:133-139

17. Kooptiwut S, Kebede M, Zraika S, Visinoni S, Aston-Mourney K, Favaloro J, Tikellis C, Thomas MC, Forbes JM, Cooper ME, Dunlop M, Proietto J, Andrikopoulos S. High glucose-induced impairment in insulin secretion is associated with reduction in islet glucokinase in a mouse model of susceptibility to islet dysfunction. J Mol Endocrinol. 2005; 35:39-48

18. Dhar A, Dhar I, Jiang B, Desai KM, Wu L. Chronic methylglyoxal infusion by minipump causes pancreatic beta-cell dysfunction and induces type 2 diabetes in sprague-dawley rats. Diabetes. 2011; 60:899-908

19. Fiory F, Lombardi A, Miele C, Giudicelli J, Beguinot F, Van Obberghen E. Methylglyoxal impairs insulin signalling and insulin action on glucose-induced insulin secretion in the pancreatic beta cell line ins1e. Diabetologia. 2011; 54:2941-2952

20. Chang TJ, Tseng HC, Liu MW, Chang YC, Hsieh ML, Chuang LM. Glucagon-like peptide-1 prevents methylglyoxal-induced apoptosis of beta cells through improving mitochondrial function and suppressing prolonged ampk activation. Sci Rep. 2016; 6:23403 
21. Guo Q, Mori T, Jiang Y, Hu C, Osaki Y, Yoneki Y, Sun Y, Hosoya T, Kawamata A, Ogawa S, Nakayama M, Miyata $\mathrm{T}$, Ito $\mathrm{S}$. Methylglyoxal contributes to the development of insulin resistance and salt sensitivity in sprague-dawley rats. J Hypertens. 2009; 27:1664-1671

22. Jia $\mathrm{X}$, Olson DJ, Ross $A R, \mathrm{Wu}$ L. Structural and functional changes in human insulin induced by methylglyoxal. Faseb J. 2006; 20:1555-1557

23. Thornalley PJ. The glyoxalase system in health and disease. Mol Aspects Med. 1993; 14:287-371

24. Scheijen JL, Schalkwijk CG. Quantification of glyoxal, methylglyoxal and 3-deoxyglucosone in blood and plasma by ultra performance liquid chromatography tandem mass spectrometry: Evaluation of blood specimen. Clin Chem Lab Med. 2014; 52:85-91

25. Duckworth WC, Bennett RG, Hamel FG. Insulin degradation: Progress and potential. Endocr Rev. 1998; 19:608-624

26. Li YV. Zinc and insulin in pancreatic beta-cells. Endocrine. 2014; 45:178-189

27. Xue M, Weickert MO, Qureshi S, Kandala NB, Anwar A, Waldron M, Shafie A, Messenger D, Fowler M, Jenkins G, Rabbani N, Thornalley PJ. Improved glycemic control and vascular function in overweight and obese subjects by glyoxalase 1 inducer formulation. Diabetes. 2016;

28. Mann GE, Niehueser-Saran J, Watson A, Gao L, Ishii T, de Winter P, Siow RC. Nrf2/are regulated antioxidant gene expression in endothelial and smooth muscle cells in oxidative stress: Implications for atherosclerosis and preeclampsia. Sheng Li Xue Bao. 2007; 59:117-127

29. Xue M, Rabbani N, Momiji H, Imbasi P, Anwar MM, Kitteringham N, Park BK, Souma T, Moriguchi T, Yamamoto $\mathrm{M}$, Thornalley PJ. Transcriptional control of glyoxalase 1 by nrf2 provides a stressresponsive defence against dicarbonyl glycation. Biochem J. 2012; 443:213-222

30. Suh S, Kim JH. Glycemic variability: How do we measure it and why is it important? Diabetes Metab J. 2015; 39:273-282

31. The effect of intensive treatment of diabetes on the development and progression of long-term complications in insulin-dependent diabetes mellitus. The diabetes control and complications trial research group. N Engl J Med. 1993; 329:977-986

32. Intensive blood-glucose control with sulphonylureas or insulin compared with conventional treatment and risk of complications in patients with type 2 diabetes (ukpds 33). Uk prospective diabetes study (ukpds) group. Lancet. 1998; 352:837-853

33. Madsbad S. Impact of postprandial glucose control on diabetes-related complications: How is the evidence evolving? J Diabetes Complications. 2016; 30:374-385

34. Glucose tolerance and mortality: Comparison of who and american diabetes association diagnostic criteria. The decode study group. European diabetes epidemiology group. Diabetes epidemiology: Collaborative analysis of diagnostic criteria in europe. Lancet. 1999; 354:617-621

35. Is the current definition for diabetes relevant to mortality risk from all causes and cardiovascular and noncardiovascular diseases? Diabetes Care. 2003; 26:688-696

36. Glucose tolerance and cardiovascular mortality: Comparison of fasting and 2-hour diagnostic criteria. Arch Intern Med. 2001; 161:397-405

37. Meigs JB, Nathan DM, D'Agostino RB, Sr., Wilson PW. Fasting and postchallenge glycemia and cardiovascular disease risk: The framingham offspring study. Diabetes Care. 2002; 25:1845-1850

38. Coutinho $M$, Gerstein HC, Wang Y, Yusuf $S$. The relationship between glucose and incident cardiovascular events. A metaregression analysis of published data from 20 studies of 95,783 individuals followed for 12.4 years. Diabetes Care. 1999; 22:233-240

39. Temelkova-Kurktschiev TS, Koehler C, Henkel E, Leonhardt W, Fuecker K, Hanefeld M. Postchallenge plasma glucose and glycemic spikes are more strongly associated with atherosclerosis than fasting glucose or hba1c level. Diabetes Care. 2000; 23:1830-1834

40. Nakamura N, Ueno Y, Tsuchiyama Y, Koike Y, Gohda M, Satani O. Isolated post-challenge hyperglycemia in patients with normal fasting glucose concentration exaggerates neointimal hyperplasia after coronary stent implantation. Circ J. 2003; 67:61-67

41. Sasso FC, Carbonara O, Nasti R, Campana B, Marfella R, Torella M, Nappi G, Torella R, Cozzolino D. Glucose metabolism and coronary heart disease in patients with normal glucose tolerance. Jama. 2004; 291:1857-1863

42. Esposito K, Giugliano D, Nappo F, Marfella R. Regression of carotid atherosclerosis by control of postprandial hyperglycemia in type 2 diabetes mellitus. Circulation. 2004; 110:214-219

43. Chiasson JL, Josse RG, Gomis R, Hanefeld M, Karasik A, Laakso M. Acarbose treatment and the risk of cardiovascular disease and hypertension in patients with impaired glucose tolerance: The stop-niddm trial. Jama. 2003; 290:486-494 
44. Hanefeld M, Fischer S, Julius U, Schulze J, Schwanebeck U, Schmechel H, Ziegelasch HJ, Lindner J. Risk factors for myocardial infarction and death in newly detected niddm: The diabetes intervention study, 11-year follow-up. Diabetologia. 1996; 39:1577-1583

45. Wolever TM, Chiasson JL, Csima A, Hunt JA, Palmason C, Ross SA, Ryan EA. Variation of postprandial plasma glucose, palatability, and symptoms associated with a standardized mixed test meal versus 75 g oral glucose. Diabetes Care. 1998; 21:336-340

46. Gaens $\mathrm{KH}$, Stehouwer CD, Schalkwijk CG. Advanced glycation endproducts and its receptor for advanced glycation endproducts in obesity. Curr Opin Lipidol. 2013; 24:4-11

47. Negre-Salvayre A, Coatrieux C, Ingueneau C, Salvayre R. Advanced lipid peroxidation end products in oxidative damage to proteins. Potential role in diseases and therapeutic prospects for the inhibitors. Br J Pharmacol. 2008; 153:6-20

48. Lewis EJ, Greene T, Spitalewiz S, Blumenthal S, Berl T, Hunsicker LG, Pohl MA, Rohde RD, Raz I, Yerushalmy Y, Yagil Y, Herskovits T, Atkins RC, Reutens AT, Packham DK, Lewis JB. Pyridorin in type 2 diabetic nephropathy. J Am Soc Nephrol. 2012; 23:131-136

49. Williams ME, Bolton WK, Khalifah RG, Degenhardt TP, Schotzinger RJ, McGill JB. Effects of pyridoxamine in combined phase 2 studies of patients with type 1 and type 2 diabetes and overt nephropathy. Am J Nephrol. 2007; 27:605-614 
198 | Chapter 9 


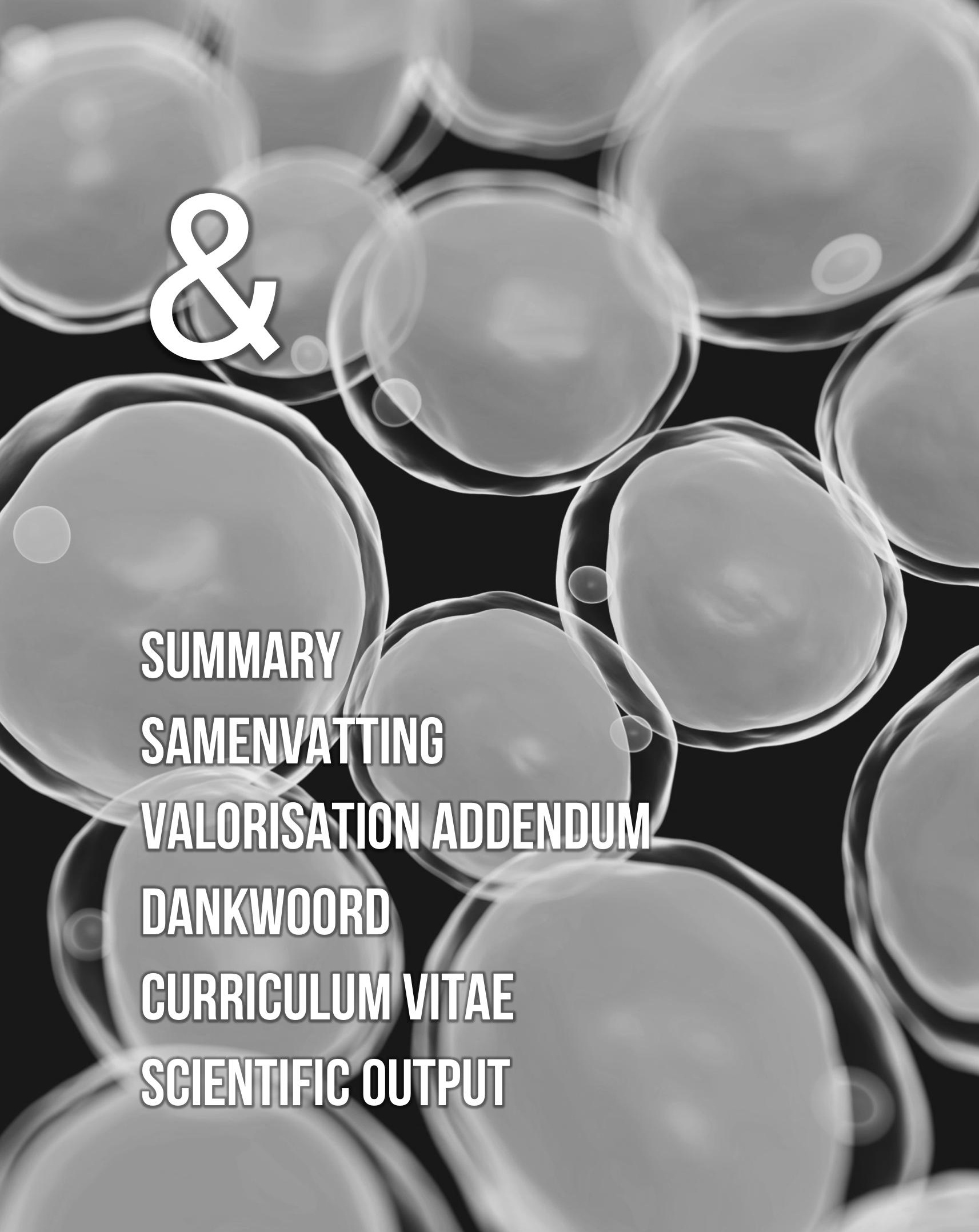


SUMMARY 


\section{Summary}

Obesity is a major health concern worldwide and is an important risk factor for the development of insulin resistance, type 2 diabetes and related cardiovascular complications. However, the underlying mechanism through which obesity contributes to the burden of these conditions remained largely unknown. From previous studies, there is increasing evidence that advanced glycation endproducts (AGEs) and their precursors, the so-called $\alpha$-dicarbonyls, are important players in the development of insulin resistance and type 2 diabetes. The reactive $\alpha$-dicarbonyls are predominantly formed during metabolism of glucose and fatty acids, and can react with amino acids in proteins, forming stable AGEs. Thus, given their sources, it was reasonable to hypothesize that formation of these compounds is increased under hyperglycemic and hyperlipidaemic conditions. Therefore, the central aim of this thesis was to identify the detailed role of $\alpha$-dicarbonyl stress and AGEs in the etiology of obesity, insulin resistance and type 2 diabetes.

The topics covered in this thesis are introduced in the general introduction, described in chapter 1 . This chapter highlights the glycation pathway, including formation, metabolism and biological effects of $\alpha$-dicarbonyls and AGEs, and their role in obesity, insulin resistance and hyperglycemia. Furthermore, the general introduction reveals current knowledge gaps and describes the aim and outline of this thesis.

The most reactive $\alpha$-dicarbonyl is methylglyoxal (MGO) and is therefore considered to be the most important precursor in the formation of AGEs. Under physiological circumstances, the accumulation of MGO is prevented by the glyoxalase system, which metabolizes MGO into D-lactate. In chapter 2, we reviewed the biology of MGO and the glyoxalase system and their importance in diabetes and other age-related diseases, such as cardiovascular disease, cancer and disorders of the central nervous system.

Chapter 3 suggests for the first time a link between MGO and insulin resistance in humans. Since MGO is highly reactive and therefore difficult to measure, we measured plasma levels of the MGO metabolite D-lactate in participants of the Cohort Study on Diabetes and Atherosclerosis Maastricht (CODAM). In this study, we demonstrated a higher prevalence of type 2 diabetes over the tertiles of plasma Dlactate concentrations. Furthermore, we found a positive association between plasma D-lactate and HOMA-IR, as a measure of insulin resistance. Although direct measurement of MGO was required for future studies, these results suggested that MGO plays an important role in insulin resistance. 
The potential role of $\mathrm{MGO}$ in insulin resistance and possible underlying mechanisms were investigated in chapter 4 . In this chapter, we focused on the muscle, being the primary organ for insulin-dependent uptake of glucose from the circulation. We found increased plasma levels of the three $\alpha$-dicarbonyls MGO, glyoxal (GO) and 3deoxyglucosone (3-DG), but not AGEs, in insulin resistant individuals compared to healthy controls. Intramuscular levels of $\alpha$-dicarbonyls and AGEs were similar between the two groups. With in vitro experiments using mature $\mathrm{C} 2 \mathrm{C} 12$ mouse myotubes, we aimed to unravel underlying mechanisms linking MGO and muscular insulin resistance. Extracellular supplementation of AGEs or MGO to $\mathrm{C} 2 \mathrm{C} 12$ myotubes did not affect insulin-induced phosphorylation of AKT. However, we found that MGO modifies insulin directly, resulting in impaired insulin-induced phosphorylation of AKT. These data confirmed the link between MGO and impaired insulin sensitivity, in particular in the muscle, and demonstrated that this can be explained by modification of insulin and impairment of insulin function.

An important risk factor for the development of insulin resistance is obesity. In Chapter 5, I have studied the role of MGO in development of obesity and associated complications, including insulin resistance, in an animal model of obesity. To investigate this, HFD-fed mice were supplemented with the anti-glycating agent pyridoxamine. This vitamin B6 analogue protected against high-fat diet (HFD)-induced body weight gain, hyperglycaemia and hypercholesterolaemia. In addition, pyridoxamine proved to be successful in preventing HFD-induced insulin resistance and impairment of glucose metabolism. Expansion of the adipose tissue as a result of the HFD was also prevented by pyridoxamine, likely due to inhibited expression of adipogenic differentiation genes. An important mechanism through which excessive adipose tissue predisposes the obese individual to complications is adipose tissue inflammation. Supplementation with pyridoxamine in the HFD-induced obese mouse model attenuated the expression of pro-inflammatory genes in the visceral adipose tissue. Together, this chapter highlights pyridoxamine as a potential intervention strategy in obesity.

Chapter 6 describes the inhibition of $M G O$ in an obese mouse model by overexpression of the glyoxalase-1 enzyme (GLO1). GLO1 is the rate-limiting enzyme in the glyoxalase defense system and metabolizes MGO into the intermediate product S-D-lactoylglutathione, which is further metabolized into D-lactate by the glyoxalase-2 enzyme. In line with the study using pyridoxamine, GLO1 overexpression prevented body weight gain and decreased plasma levels of insulin and leptin in HFD-induced obese mice. Furthermore, HFD-induced glucose intolerance was improved by GLO1 
overexpression. Hallmarks of obesity, including adipocyte hypertrophy and adipose tissue inflammation, were also partly reduced by GLO1 overexpression. These data suggest that modulating the MGO-GLO1 pathway may be a novel intervention strategy in obesity and its related complications.

Chronic hyperglycaemia is an important risk factor for the development of diabetic complications. Emerging evidence demonstrates that postprandial glucose fluctuations may contribute even more to the development of these complications in diabetes than elevated fasting glucose levels, although it is not clear yet which mechanism is responsible for the link between postprandial hyperglycemia and diabetic complications. Given the fact that $\alpha$-dicarbonyls are rapidly formed during glycolysis, we hypothesized that these compounds might play an important role in this process. Chapter 7 demonstrates increased plasma levels of $\alpha$-dicarbonyls in individuals with impaired glucose metabolism (IGM) and type 2 diabetes during an oral glucose tolerance test (OGTT).

In line, a mixed meal test described in chapter 8 confirmed the increased formation of $\alpha$-dicarbonyls in the postprandial period in obese women with type 2 diabetes. Importantly, energy restriction and Roux-en-Y gastric bypass significantly reduced postprandial plasma $\alpha$-dicarbonyl stress in these women within three weeks. Together, these studies underline the potential importance of postprandial $\alpha$ dicarbonyl stress as a risk factor for diabetic complications and the potential to reduce these compounds by weight loss interventions.

The main findings of this thesis are discussed in chapter 9. In light of current knowledge, this chapter discussed the role of $\alpha$-dicarbonyls in obesity and adipose tissue inflammation, and related insulin resistance. In addition, the possible role of postprandial $\alpha$-dicarbonyl stress in diabetic complications is discussed. Based on results of this thesis, we conclude that $\alpha$-dicarbonyls form a potential target in the treatment of obesity and obesity-induced insulin resistance and type 2 diabetes. Investigating the applicability of pyridoxamine in an obese human population and unraveling the impact of postprandial $\alpha$-dicarbonyl stress on vascular function would be highly relevant for future studies. In addition, identification of MGO-modifications at the insulin molecule in vivo would create new possibilities for intervention strategies in insulin resistance. 
SAMENVATTING 


\section{Samenvatting}

Obesitas is een wereldwijd gezondheidsprobleem en is een belangrijke risicofactor voor de ontwikkeling van insulineresistentie, type 2 diabetes en gerelateerde hart- en vaatziekten. Echter, het onderliggende mechanisme dat verantwoordelijk is voor de link tussen obesitas en deze complicaties was tot op heden onbekend. Uit eerdere studies waren er steeds meer aanwijzingen dat geavanceerde glyceringsproducten (AGE's) en hun voorlopers, de zogenaamde $\alpha$-dicarbonyls, een belangrijke rol spelen in de ontwikkeling van insulineresistentie en type 2 diabetes. De zeer reactieve $\alpha$ dicarbonyls worden voornamelijk gevormd tijdens metabolisme van glucose en vetzuren, en kunnen vervolgens een reactie aangaan met aminozuren in eiwitten wat leidt tot de vorming van stabiele AGE's. Gezien hun bron was onze hypothese dat de vorming van $\alpha$-dicarbonyls verhoogd is onder hyperglycemische en hyperlipidemische condities. Het doel van deze thesis was dan ook het identificeren van de rol van $\alpha$ dicarbonyl stress en AGE's in de etiologie van obesitas, insulineresistentie en type 2 diabetes.

Hoofdstuk 1 is een algemene introductie waarin de onderwerpen van deze thesis geïntroduceerd worden. Dit hoofdstuk beschrijft uitgebreid de biologie van $\alpha$ dicarbonyls en AGE's, waaronder hun vorming, afbraak en biologische effecten. Daarnaast wordt ingegaan op hun rol in obesitas, insulineresistentie en hyperglycemie. Verder behandelt de algemene introductie de huidige kenniskloven en beschrijft dit hoofdstuk het doel en de opzet van deze thesis.

Methylglyoxaal (MGO) is de meest reactieve $\alpha$-dicarbonyl en wordt daarom gezien als de meest belangrijke voorloper in de vorming van AGE's. Onder normale omstandigheden wordt de opstapeling van MGO voorkomen door het glyoxalase systeem, wat MGO omzet naar D-lactaat. Hoofdstuk 2 geeft een uitgebreid overzicht van de biologie van MGO en het glyoxalase systeem en hun rol in diabetes en andere leeftijd gerelateerde ziekten, zoals cardiovasculaire ziekten, kanker en aandoeningen aan het centraal zenuwstelsel.

In hoofdstuk 3 wordt voor het eerst een mogelijke link gemaakt tussen MGO en insulineresistentie in een humane studie. Omdat MGO zeer reactief is en daardoor moeilijk te meten, hebben we destijds de MGO-metaboliet D-lactaat gemeten in plasma van deelnemers aan de Cohort Study on Diabetes and Atherosclerosis Maastricht (CODAM), welke verrijkt is met patiënten met type 2 diabetes. In deze studie hebben we aangetoond dat de prevalentie van type 2 diabetes significant 
toeneemt naarmate de plasmawaarden van D-lactaat hoger liggen. Verder hebben we een positieve associatie gevonden tussen plasma D-lactaat waarden en HOMA-IR, welke een maat is voor insulineresistentie. Hoewel het direct meten van MGO in plasma wenselijk werd bevonden voor toekomstige studies, suggereerden deze data dat MGO een belangrijke rol speelt in insulineresistentie.

De potentiële rol van $\mathrm{MGO}$ in insulineresistentie en mogelijke onderliggende mechanismen worden verder besproken in hoofdstuk 4. In dit hoofdstuk ligt de focus op de spier, welke het primaire orgaan is dat afhankelijk is van insuline voor glucoseopname uit de circulatie. We vonden toegenomen plasmaspiegels van de drie $\alpha$-dicarbonyls MGO, glyoxaal (GO) en 3-deoxyglucosoon (3-DG) in individuen met insulineresistentie, vergeleken met gezonde controles. Plasmaspiegels van AGE's waren niet verhoogd. Daarnaast was er geen verschil in waarden van $\alpha$-dicarbonyls en AGE's in de spier tussen de twee groepen. Met in vitro experimenten, waarbij we gebruik gemaakt hebben van gedifferentieerde C2C12 spiercellen van een muis, hebben we getracht een onderliggend mechanisme te ontrafelen wat de link verklaart tussen MGO en insulineresistentie in de spier. Extracellulaire toediening van MGO of AGE's aan C2C12 spiercellen had geen effect op de insuline-geïnduceerde fosforylering van AKT. Echter, additionele experimenten hebben aangetoond dat MGO het insulinemolecuul modificeert, wat resulteert in verminderde insulinegeïnduceerde fosforylering van AKT. Deze data bevestigden de link tussen MGO en insulineresistentie, in het bijzonder in de spier, via een modificatie van insuline en als gevolg een verstoring van de normale insulinefunctie.

Een belangrijke risicofactor voor de ontwikkeling van insulineresistentie is obesitas. Hoofdstuk 5 bediscussieert de rol van MGO in obesitas en gerelateerde complicaties, waaronder insulineresistentie. Om dit te onderzoeken hebben we gebruik gemaakt van een muismodel welke obesitas ontwikkelde naar aanleiding van een hoog-vet dieet (HFD). Deze muizen kregen via het drinkwater pyridoxamine toegediend. Pyridoxamine is een vitamine B6 analoog met anti-glyceringscapaciteiten. De studie beschreven in hoofdstuk 5 heeft aangetoond dat pyridoxamine beschermt tegen HFDgeïnduceerde toename in lichaamsgewicht, hyperglycemie en hypercholesterolemie. Daarnaast is pyridoxamine succesvol gebleken in het voorkomen van insulineresistentie en glucose-intolerantie als gevolg van het HFD. Vergroting van het vetweefsel in deze muizen werd eveneens voorkomen door pyridoxamine, hoogstwaarschijnlijk door een verminderde expressie van genen die bijdragen aan differentiatie tot volwaardige vetcellen. Een belangrijk mechanisme waarlangs overmatig vetweefsel de obese individu vatbaar maakt voor complicaties is de 
inductie van vetweefselinflammatie. Het toedienen van pyridoxamine aan de HFDgeïnduceerde obese muizen verminderde de expressie van pro-inflammatoire genen in het visceraal vetweefsel. Samengevat toonden deze data aan dat pyridoxamine een zeer potentiële interventie zou zijn in de behandeling van obesitas.

Hoofdstuk 6 rapporteert een vergelijkbare studie, waarin accumulatie van MGO in een obees muismodel werd voorkomen door overexpressie van het glyoxalase-1 (GLO1) enzym. GLO1 is het snelheidsbeperkende enzym van het glyoxalase systeem en zet MGO om in het tussenproduct S-D-lactoylglutathion, wat verder gemetaboliseerd wordt tot D-lactaat door het glyoxalase-2 enzym. In lijn met de vorige studie remde ook overexpressie van GLO1 de HFD-geïnduceerde toename in lichaamsgewicht in muizen. Daarnaast verlaagde het plasmaspiegels van insuline en leptine in de obese muizen en werd glucose-intolerantie als gevolg van obesitas verminderd door GLO1 overexpressie. Daarnaast werden karakteristieke kenmerken van obesitas, zoals hypertrofie van adipocyten en vetweefselinflammatie, gereduceerd in dit model. Deze studie toonde aan dat naast pyridoxamine ook het aangrijpen op de MGO-GLO1 pathway een mogelijke nieuwe interventiestrategie zou kunnen zijn in obesitas en gerelateerde complicaties.

Chronische hyperglycemie is een belangrijke risicofactor voor diabetische complicaties. Er zijn steeds meer aanwijzingen uit de literatuur dat postprandiale schommelingen in glucose wellicht een belangrijkere rol spelen in de ontwikkeling van deze complicaties dan een verhoogd $\mathrm{HbA}_{1 \mathrm{c}}$, hoewel er nog geen mechanisme bekend was dat deze link maakte. Aangezien $\alpha$-dicarbonyls voornamelijk tijdens de glycolyse gevormd worden, was onze hypothese dat deze componenten mogelijk een rol spelen in deze link. De studie die beschreven staat in hoofdstuk 7 laat zien dat individuen met een verstoord glucosemetabolisme of type 2 diabetes significant hogere plasmawaarden van $\alpha$-dicarbonyls hebben tijdens een orale glucose tolerantietest. Deze bevindingen werden bevestigd in hoofdstuk 8, waarin verhoogde plasmawaarden van $\alpha$-dicarbonyls werden aangetoond in obese vrouwen met type 2 diabetes tijdens een mixed meal test. Daarnaast hebben we met deze studie aangetoond dat energiebeperking en Roux-en-Y gastric bypass deze postprandiale $\alpha$ dicarbonyl stress significant kunnen reduceren binnen drie weken. Samen benadrukken deze twee studies het potentiële belang van postprandiale $\alpha$-dicarbonyl stress als een mogelijke risicofactor voor diabetische complicaties en de mogelijkheid om deze componenten te reduceren door interventies gericht op gewichtsverlies.

De belangrijkste bevindingen van deze thesis worden bediscussieerd in hoofdstuk 9 . Met kennis van de huidige studies beschrijft dit hoofdstuk de rol van $\alpha$-dicarbonyls in 
obesitas en vetweefselinflammatie, en gerelateerde insulineresistentie. Daarnaast wordt de mogelijke rol van postprandiale $\alpha$-dicarbonyl stress in diabetische complicaties bediscussieerd. Gebaseerd op de resultaten van deze thesis hebben we geconcludeerd dat $\alpha$-dicarbonyls een potentiële target vormen in de behandeling van obesitas en obesitas-gerelateerde insulineresistentie en type 2 diabetes. Het bestuderen van de toepasbaarheid van pyridoxamine in een klinische trial met obese mensen en het beoordelen van de impact van postprandiale $\alpha$-dicarbonyl stress op (cardio)vasculaire functie zou zeer relevant zijn voor toekomstige studies. Daarnaast zou identificatie van MGO-modificaties op het insulinemolecuul in vivo nieuwe mogelijkheden creëren voor interventiestrategieën in insulineresistentie. 


\section{VALORISATION ADDENDUM}




\section{Valorisation}

The burden of obesity is one of the largest health problems in modern-time society and affects over 600 million adults worldwide. An elevated BMI increases the risk of developing insulin resistance, type 2 diabetes and related complications. This poses an enormous emotional and social economic burden on obese individuals and health care systems. The ever-increasing prevalence of obesity and, as a result, type 2 diabetes shows the growing need to better understand their link and the need for new therapeutics. The work presented in this thesis aimed to unravel the intermediate step linking central obesity to type 2 diabetes and related complications. Our main findings were that $\alpha$-dicarbonyl stress is 1 ) implicated in the development of obesity and insulin resistance and 2) increased in individuals with type 2 diabetes and 3 ) that this is reversible by weight loss interventions. This chapter describes how these current findings may be applied in order to prevent or reverse the obesity-induced development of insulin resistance and type 2 diabetes and provides a perspective on potential future research steps to translate current findings into clinical practice.

\section{Identification of new treatment targets}

This thesis extensively investigated the role of $\alpha$-dicarbonyl stress in obesity, insulin resistance and type 2 diabetes and underlines the potential of $\alpha$-dicarbonyls as potential treatment targets.

Two independent studies in a mouse model of obesity, as described in chapter 5 and 6 , demonstrated that $\alpha$-dicarbonyls are implicated in the development of obesity and obesity-related complications including adipose tissue inflammation and insulin resistance. Predominantly body weight gain and insulin resistance were improved upon $\alpha$-dicarbonyl inhibition, but also adipocyte hypertrophy and adipose tissue inflammation were significantly improved when $\alpha$-dicarbonyl stress was reduced. These findings highlight $\alpha$-dicarbonyl stress as an exciting potential treatment target for the burden of obesity and the related development of insulin resistance.

In the field of insulin resistance, this thesis also provided new insights into modifications of the insulin protein. In vitro studies demonstrated that MGO can form adducts on insulin, which consequently leads to an impairment of the normal insulin signalling cascade. Although future studies are needed to identify such modifications on insulin in vivo, these findings provide possible new therapeutic windows for insulin resistance. 
Another major finding of this thesis was that postprandial $\alpha$-dicarbonyl stress in plasma is increased in patients with type 2 diabetes. Previous studies have revealed the importance of postprandial glucose excursions in the development of (cardio)vascular diabetic complications. Based on literature, from which it is known that increased fasting $\alpha$-dicarbonyl stress is associated with the development of diabetic complications, and our current findings on postprandial $\alpha$-dicarbonyl stress, we hypothesize that these compounds could make the link between glucose excursions after a meal and (cardio)vascular disease in patients with type 2 diabetes. Our finding that these postprandial $\alpha$-dicarbonyl excursions are reversible by weight loss interventions underline $\alpha$-dicarbonyl compounds even more as potential treatment targets in the reduction or prevention of severe diabetic complications.

\section{Options for new treatment strategies}

In this thesis, several treatment strategies, all aimed to reduce $\alpha$-dicarbonyl stress, were explored and showed promising effects: 1) Quenching of $\alpha$-dicarbonyls by pyridoxamine, 2) Increased metabolism of MGO and GO by glyoxalase-1 (GLO1) overexpression and 3 ) Reduction of $\alpha$-dicarbonyls by weight loss interventions.

\section{Pyridoxamine}

Pyridoxamine is a vitamin B6 analogue with anti-glycating properties through quenching of $\alpha$-dicarbonyls. Several clinical trials have already demonstrated the efficacy of pyridoxamine as a treatment of diabetic nephropathy. As described in this thesis, extensive research in an animal model of obesity demonstrated that pyridoxamine is a very successful compound in the reduction of obesity itself and obesity-induced complications. Characteristic features of obesity, including body weight gain, adipocyte hypertrophy, adipose tissue inflammation and severe insulin resistance were improved by pyridoxamine. These findings created high expectations for clinical use of pyridoxamine and make it thus worth testing pyridoxamine as an effective treatment candidate in human obesity. A randomized controlled clinical trial with pyridoxamine in obese individuals would provide insight into the applicability of this compound in the treatment of obesity and obesity-associated complications, including micro- and macrovascular complications, insulin resistance and inflammation.

\section{Induction of GLO1}

In addition to pyridoxamine, this thesis has also demonstrated the efficacy of GLO1 overexpression in an obese mouse model. This genetic modification not only reduced high-fat diet (HFD)-induced body weight gain, but also reduced glucose intolerance, 
adipocyte hypertrophy and adipose tissue inflammation. Previous studies described multiple ways to induce GLO1 gene expression. Synthetic drugs like candesartan, but also more naturally available compounds have been demonstrated to possess GLO1stimulating properties. Polyphenols such as resveratrol and flavonoids are known to upregulate GLO1 expression. A very recent study revealed a successful combination of two polyphenols, trans-resveratrol and hesperetin, resulting in improved glycemic control and vascular function in obese subjects through induction of the GLO1 enzyme. In addition, isothiocyanates, like phenethyl isothiocyanate and sulforaphane, which can be found in cruciferous vegetables, are known to stimulate GLO-I by activating the cell-defense master switch nuclear factor-erythroid 2 (Nrf2). Previous research showed that GLO1 has an Nrf2-responsive element in its promoter, and that exposure to sulforaphane induced expression and activity of GLO1, with consequently a decrease in MGO.

\section{Weight loss interventions}

A third intervention strategy to reduce $\alpha$-dicarbonyl stress that has been documented in this thesis is based on weight loss interventions. We demonstrated that patients with type 2 diabetes are characterized by postprandial increases of plasma $\alpha$ dicarbonyls. In obese women, these excursions were reversible within three weeks of weight loss, either by energy restriction or Roux-en-Y gastric bypass. We hypothesize that other lifestyle interventions, such as increasing the level of physical activity, would also decrease (postprandial) $\alpha$-dicarbonyl stress.

\section{a-Dicarbonyls as biomarkers}

Biomarkers are of large clinical value in the prevention, diagnosis and treatment of diseases. Based on findings of this thesis, indicating the involvement of $\alpha$-dicarbonyls in obesity, insulin resistance and type 2 diabetes, we hypothesize that plasma measurement of $\alpha$-dicarbonyl stress may therefore serve as an excellent marker of deranged glucose metabolism, and may thus serve as a marker of increased risk of type 2 diabetes and possibly also for diabetic complications. Nowadays, UPLC-MS/MS is used for valid and precise measurements of $\alpha$-dicarbonyls. However, this technique is expensive, time-consuming and it requires too much plasma to use it as a tool for biomarker measurement. Therefore, development of a new, quick diagnostic tool to measure $\alpha$-dicarbonyls in small blood samples would be of significant value for the social and economic burden of type 2 diabetes. The use of $\alpha$-dicarbonyls as biomarkers and risk predictors of type 2 diabetes and related complications would enable clinical doctors to make a diagnosis at an early stage of the disease and to set up an adequate treatment strategy, amongst other things aimed to reduce plasma $\alpha$ dicarbonyl stress. 


\section{DANKWOORD}




\section{Dankwoord}

$\mathrm{Na} 4$ jaar is er een einde gekomen aan mijn promotie bij Interne Geneeskunde. Ik kijk terug op een fantastische tijd in een geweldig team waarin ik vrienden en herinneringen voor het leven heb gemaakt. Dit proefschrift was er uiteraard niet gekomen zonder de hulp van velen. Ik wil daarom iedereen bedanken die ook maar enigszins heeft bijgedragen aan de totstandkoming van dit proefschrift. Een aantal mensen wil ik graag in het bijzonder bedanken.

Prof. Dr. C.G. Schalkwijk. Beste Casper, als er een award bestond voor de beste promotor zou jij hem verdienen. Ik ben je enorm dankbaar voor de persoonlijke begeleiding de afgelopen vier jaar en je betrokkenheid bij mijn promotie. Je toegankelijkheid en de prettige manier waarop je het lab aanstuurt zorgen voor een fantastische sfeer op de afdeling en maken dat ik me vanaf dag één thuis heb gevoeld. Je hebt me ontzettend veel geleerd en ik ben je zeer dankbaar voor alle kansen die je me geboden hebt, zoals het bezoeken van de vele (buitenlandse) congressen en het volgen van verschillende cursussen. Ik wil jou, samen met Hermine, ook bedanken voor jullie gastvrijheid tijdens labuitjes en kerstdiners. Daar heb ik écht van genoten en ik zal het gaan missen. Ik wens je alle goeds voor de toekomst en hopelijk ga je nog veel moois ontdekken op het gebied van glycering!

Prof. Dr. C.D.A. Stehouwer. Beste Coen, ik heb grote bewondering voor de wijze waarop jij betrokken bent bij de vele promovendi die je begeleidt. Het is uitzonderlijk hoe snel jij een manuscript kritisch beoordeelt en de puntjes op de $i$ weet te zetten. Door jouw enorme kennis van het vak en wetenschappelijke integriteit ben je een groot voorbeeld voor velen. Ik vind het een eer dat ik onder jouw supervisie mijn promotieonderzoek heb mogen doen.

Dr. N.M.J. Hanssen. Beste Nordin, een betere copromotor had ik me niet kunnen wensen. Jouw hulp bij de epidemiologische hoofdstukken, maar zeker ook de experimentele hoofdstukken, zijn van onschatbare waarde geweest voor dit proefschrift. Je eeuwige enthousiasme en enorme drive voor je werk verdienen een groot compliment. Ik wens je heel veel succes in de kliniek en hopelijk mogen we in de toekomst nog een keer samenwerken.

Graag bedank ik de leden van de beoordelingscommissie, Prof. Dr. H.A.J. StruijkerBoudier, Prof. Dr. E.E. Blaak, Prof. Dr. P.C. Dagnelie, Prof. Dr. A.J. Smit en Prof. Dr. C.C.J. Tack, voor het beoordelen van dit proefschrift. 
Lieve paranimfen, kamergenootjes en vooral fijne collega's: lieve Monica en Katrien. Wat ben ik blij dat jullie vandaag naast mij willen staan. Jullie waren de fijnste kamergenoten die ik kon bedenken en mede dankzij jullie kwam ik elke dag met veel plezier naar mijn werk. Naast het feit dat we ook écht wetenschappelijke discussies gehad hebben, was er op onze kamer vooral ook heel erg veel gezelligheid (ook voor veel mensen van andere kamers ;)). Lieve Monica, het feit dat we aan een blik over onze beeldschermen heen al genoeg hebben zegt eigenlijk alles. Jouw humor en nuchtere kijk op alles vind ik gewoon heerlijk. Met welke collega kan ik ooit nog een kantoor delen terwijl we het foute uur van Q-music luisteren? Dankjewel voor de ontzettend gezellige tijd en de nodige afleiding. Succes met de laatste maanden van je $\mathrm{PhD}$ ! Lieve Katrien, naast het feit dat jij mijn vraagbaak bent over alles wat met glycering te maken heeft, kan ik met jou ook eindeloos kletsen. De vele keren dat we een kamer (en soms ook een bed) hebben gedeeld op congressen waren supergezellig. Dankjewel voor al je hulp, luisterend oor, en vooral de leuke tijd. Ik vind het bijzonder dat jij mij op mijn allereerste werkdag ontvangen hebt en vandaag, op de belangrijkste dag van deze vier jaar, naast mij wil staan als paranimf! Meiden, jullie zijn toppers, ik hoop dat we elkaar nog veel blijven zien!

Voor het tot stand komen van dit proefschrift heb ik ook met mensen van andere afdelingen en universiteiten samengewerkt. Graag wil ik hen hartelijk danken voor hun wetenschappelijke bijdrage en fijne samenwerking.

A special word of thanks to Prof. T. Miyata, for kindly providing the pyridoxamine and constructing the GLO1 transgenic mice. Our visit to Japan to attend the $12^{\text {th }}$ IMARS meeting made me a big fan of your homeland.

Prof. Dr. M.K.C. Hesselink en Prof. Dr. P. Schrauwen. Beste Matthijs en Patrick, hartelijk dank voor de fijne samenwerking en het feit dat ik gebruik heb mogen maken van materialen uit jullie studies. Ik waardeer jullie betrokkenheid en vond het erg fijn om af en toe samen te zitten en de voortgang van zaken te bespreken. Ik weet zeker dat dit hoofdstuk een mooi vervolg gaat krijgen. Ook ben ik hier dank verschuldigd aan Dr. G. Schaart. Gert, dank voor het 'graven' naar de samples, ik weet dat het geen makkelijke klus was.

Dr. M.A. Lips, Prof. Dr. K. Willems van Dijk en Prof. Dr. H. Pijl. Beste Mirjam, Ko en Hanno, ik wil jullie bedanken dat ik gebruik heb mogen maken van plasmasamples uit jullie studie en jullie bijdrage aan het manuscript. Dit hoofdstuk heeft de kers op de taart gevormd voor het tweede deel van dit proefschrift. 
Dr. J.P.M. Cleutjens en Dr. B.J. Janssen. Jack, bedankt voor je hulp bij de morfometrische analyse van de vetcellen in de twee dierstudies van dit proefschrift. Ben, ik wil je hartelijk danken voor het opzetten van de cardiovasculaire metingen bij de proefdieren.

De twee dierexperimentele studies die in dit proefschrift beschreven staan had ik niet uit kunnen voeren zonder de hulp van velen. Graag wil ik de mensen van het CPV, in het bijzonder Richard, Saskia, Rik, Clarice, Harry, Pauline en Mandy, bedanken voor hun bijdragen. Daarnaast ook mijn dank voor Helma van Essen voor haar hulp bij het telemetrie experiment. Helma, het was een spannend experiment maar het heeft met recht dit proefschrift gehaald!

Jean, jij kunt eigenlijk onder alle kopjes beschreven worden: collega's, vrienden, coauteurs, vormgever, en nog veel meer. Een eervolle (en eerste) vernoeming is hier daarom meer dan op zijn plaats. Zonder de duizenden metingen die je voor me gedaan hebt was dit proefschrift er niet gekomen. Jouw inzet, creativiteit, enthousiasme, en humor zijn werkelijk fantastisch. Bedankt voor alle fenomenale stapavondjes, etentjes, congressen, dagjes weg, koffiepauzes en nog veel meer, ik zal ze nooit (maar dan ook echt nooit;)) vergeten. Een groot woord van dank ook voor de prachtige foto's van onze bruiloft. Dankzij jou hebben we onvergetelijke herinneringen aan deze bijzondere dag. Ik wens je ontzettend veel succes met het afronden van je proefschrift, hopelijk ben jij de volgende die aan de beurt is!

Marjo, voor jou geldt hetzelfde. Ook jij bent meer dan een collega en daarom wil ik je in het bijzonder bedanken. Je bent een kei op het lab, maar naast het feit dat jij veel MSD-metingen voor mij hebt gedaan, wil ik je ook bedanken voor alle extracurriculaire activiteiten. De koffiemomentjes en stapavondjes waren soms memorabel. Ik hoop dat ik nog vaak mee mag en ook altijd die innige omhelzingen van je krijg als het tijd is om te gaan!

Veel dank ben ik ook verontschuldigd aan mijn overige collega's van Interne Geneeskunde (in alfabetische volgorde) voor de fantastische tijd die ik dankzij hen gehad heb:

Ad, van mijn docent werd je mijn collega. Jouw inzet voor het onderwijs is van grote waarde en zal vanaf volgend jaar zeker gemist worden. Geniet van je laatste jaar bij de Universiteit en daarna van je welverdiende pensioen! Annemieke, het feit dat we elkaar bijna niet tegen komen op de afdeling bewijst hoe betrokken jij bent bij het onderwijs. Veel succes voor de toekomst! Bas, 8 maanden lang heb ik je met veel plezier begeleid. Dankjewel voor je ondersteuning. Ik ben trots om te zien dat je nu 
zo'n leuke baan hebt gevonden. Ik wens je alle succes voor de toekomst! Boy, ons enige gezamenlijke, maar daardoor zeker niet minder belangrijk, project was UIL+. Bedankt voor de leuke zittingen en ga vooral zo door! Dennis, hopelijk zijn de capillairen inmiddels van je netvlies versleten, respect voor hoe veel werk je daarin verzet hebt. Bedankt voor alle leuke momenten! Elisabeth, jouw verdediging heeft de lat hoog gelegd voor mij. Je hebt een prachtig proefschrift afgeleverd en hebt de deur geopend voor verder onderzoek naar het complement systeem en cardiovasculaire ziekten. Veel succes gewenst met je nieuwe carrière bij Synthon. Hanneke, niets is voor jou te veel en alles loopt als een geoliede machine. Mede dankzij jou ben ik aan de slag mogen gaan bij Medtronic, bedankt! Ik wens je veel succes voor de toekomst en ik vind het leuk dat we collega's blijven! José, onze enige samenwerking was tijdens het opofferen van mijn muizen, maar daarvan weet ik dat jij een keiharde werker bent met een berg ervaring waar iedereen profijt van heeft. Bedankt daarvoor! Kristiaan, dank voor je bijdragen aan mijn twee dierexperimentele hoofdstukken. Het is fijn om iemand op de afdeling te hebben met zo veel kennis van dierwetenschappelijk onderzoek. Ik wens je heel veel succes met je tenure track en je verdere wetenschappelijke carrière! Lian, jij was mijn Wikipedia op het gebied van epidemiologie. Wat heb ik vaak gebruik mogen maken van jouw kennis over statistische analyses, dankjewel daarvoor! Marcelle, hopelijk vind je tussen je drukke opleiding door toch nog wat momentjes om de laatste loodjes van je proefschrift af te ronden. Ik weet in ieder geval zeker dat je een fantastische huisarts zult worden! Margee, jij hebt talloze experimenten voor mij gedaan op het lab. Je zult vast geen Western Blot meer kunnen zien. Dankjewel voor al je hulp. Maria, helaas hebben we nooit samen experimenten kunnen doen, maar ik weet hoe gedreven en enthousiast jij in je werk bent en anderen daarmee helpt. Onze gezamenlijke treinreizen en carpoolritjes naar Elsloo en Geleen waren altijd gezellig! Marleen en Carla, dank voor al jullie hulp bij de CODAM manuscripten. Het is fijn dat er altijd iemand is die zoveel van een cohort weet en je kan helpen met een vraag over een specifieke bepaling uit 2001. Marleen, jij in het bijzonder bedankt voor je tijd wanneer ik een vraag had over statistische analyses en de wetenschappelijke discussies tijdens werkbesprekingen. Ik vind het bewonderenswaardig hoe goed $\mathrm{jij}$ op de hoogte bent van alle individuele experimenten en daar altijd zeer bruikbare input voor weet te geven. Mathias, ik vind het geweldig dat jij het dierexperimentele werk met pyridoxamine gaat vertalen naar de mens! Ik wens je heel veel succes met de klinische trial en ik duim ervoor dat je fantastische resultaten zult verkrijgen. Hopelijk zijn we nog vaak samen in de Maastrichtse cafeetjes te vinden. Mitchell en Suzan, van gedreven studenten werden jullie talentvolle AIO's. Het is mooi om te zien hoe goed het jullie vergaat. Veel succes met de rest van jullie PhD! Nynke, ik vind het erg leuk dat jij als student ons team in 
bent gerold en AlO bent geworden. Met een Diabetes Care paper als start van je PhD kan er alleen nog maar veel meer moois komen, succes! Olaf, jij bent degene die mij op weg heeft geholpen. Een eerste werkweek vol opofferingen van muizen en myograafexperimenten was een goede start. Dankjewel voor je hulp en begeleiding in de eerste twee jaar van mijn PhD en de gezellige momenten tijdens congressen. Ik wens je een mooie toekomst bij Zuyd Hogeschool. Paul, we have only been working together for a very short period of time. I am sure that you are the one who is going to unravel the glycation of insulin. Good luck! Petra, ik heb zelden iemand gezien die zo vrolijk is als jij. Het feit dat jij enorm behulpzaam bent en heel veel ervaring hebt (zowel met technieken op het lab als met promoveren) maakt samenwerken met jou ontzettend fijn. Ik wens je veel succes bij de Maastricht Studie! Stijn, dankjewel voor de leuke tijd. Ik zal ons momentje voor de camera nooit vergeten. Zo'n groene jas staat je goed! Heel veel succes gewenst met het afronden van je boekje. Vicky, jij bent van alle markten thuis. Dotblotten of een verbouwing coördineren, je draait je hand er niet voor om. Petje af, hoor! Ying, it's incredible how quickly you mastered the tricks of epidemiology. I wish you all the best for the future and I'm sure you're going to publish many beautiful papers about the complement system. Yvo, mijn kamergenoot voor twee jaar. Ik vond het erg fijn dat je altijd interesse had in mijn onderzoek. Van data blinderen heb ik niet veel kaas gegeten maar met jouw zeer gedetailleerde SOP's kon zelfs ik met het programma overweg. Ik wens je heel veel succes met het afronden van je boekje en je carrière in de kliniek.

I would also like to thank my new colleagues at Medtronic for the very warm welcome to the Safety department. I am looking forward to my future at the company and the collaboration with all of you!

Lieve vrienden, jullie hebben ervoor gezorgd dat er altijd genoeg afleiding was. Dank jullie wel voor de eeuwige gezelligheid. Dat er nog vele etentjes, weekendjes en uitjes mogen volgen!

Lieve familie, ook al was het soms best lastig om te begrijpen waar ik mee bezig was, ik vond het ontzettend leuk dat jullie altijd zo veel interesse hadden. Dank jullie wel voor alle fijne momenten, jullie zijn onmisbaar en ik vind het fijn dat we zo vaak samen zijn. Lieve schoonfamilie, in het bijzonder Enny, Nöl, Monique, Sean, Teun en Koos, dank aan jullie allemaal voor de gezellige momenten. Het voelt bij jullie als een tweede thuis. 
Lieve papa en mama, zonder jullie was dit boekje er niet gekomen. Jullie hebben ons altijd gestimuleerd om eruit te halen wat erin zit en hebben ons daartoe alle kansen geboden. Het feit dat ik zo ver ben gekomen, heb ik grotendeels aan jullie te danken. Dank jullie wel voor de fijne thuisbasis, jullie onvoorwaardelijke steun en liefde, en het feit dat jullie altijd voor Rianne en mij klaar staan. Jullie zijn mijn grote voorbeeld. Lieve Rianne, een betere zus kan ik me niet wensen. Ik ben ongelooflijk trots op jou en weet zeker dat je een fantastische toekomst tegemoet gaat. Dankjewel voor alle fijne momenten die we samen gehad hebben en zeker nog zullen krijgen. Je bent een zus uit duizenden.

Als laatste mijn grote steun en toeverlaat. Lieve Bram, jij bent mijn alles. Je bent een geweldig persoon en ik ben ontzettend trots dat ik je vrouw mag zijn. Dankjewel voor je onvoorwaardelijke liefde, steun, en humor. Jouw betrokkenheid bij dit boekje is van onschatbare waarde geweest. Er zijn niet genoeg woorden om je daarvoor te bedanken. Ik vind het heerlijk om met jou van het leven te genieten en ik kijk uit naar een geweldige toekomst samen. Ik houd onbeschrijflijk veel van jou!

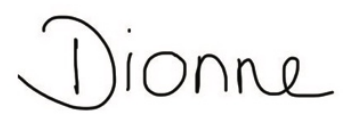




\section{Curriculum vitae}

Dionne Maessen was born on August 20, 1989 in Geleen, The Netherlands. She graduated from secondary school (Gymnasium, Graaf Huyn College, Geleen) in 2007. That same year she started her study Biomedical Sciences at Maastricht University. In 2012, a seven-month internship at the department of Maastricht Radiation Oncology at the same university resulted in obtaining her Master's degree in Biomedical Sciences (cum laude). During her study and the internship, Dionne got interested in the world of scientific research. Therefore, in 2012, she started her PhD at the department of Internal Medicine, Laboratory of Metabolism and Vascular Medicine, Maastricht University. Under supervision of Prof. C.G. Schalkwijk, Prof. C.D.A. Stehouwer and Dr. N.M.J. Hanssen, she worked on the role of $\alpha$-dicarbonyl stress in obesity and type 2 diabetes. The results of her research are presented in this thesis. Since October 2016, Dionne works as a Clinical Safety Specialist at Medtronic, Maastricht. 


\section{Scientific output}

\section{List of publications}

- Maessen DEM, Hanssen NMJ, Lips MA, Scheijen JLM, Willems van Dijk K, Pijl H, Stehouwer CDA, Schalkwijk CG. Energy restriction and roux-en-y gastric bypass reduce postprandial alpha-dicarbonyl stress in obese women with type 2 diabetes. Diabetologia. 2016; 59: 2013-2017

- Maessen DEM, Brouwers O, Gaens KH, Wouters K, Cleutjens JP, Janssen BJ, Miyata T, Stehouwer CDA, Schalkwijk CG. Delayed intervention with pyridoxamine improves metabolic function and prevents adipose tissue inflammation and insulin resistance in high-fat diet-induced obese mice. Diabetes. 2016; 65: 956-966

- Maessen DEM, Stehouwer CDA, Schalkwijk CG. The role of methylglyoxal and the glyoxalase system in diabetes and other age-related diseases. Clin Sci (Lond). 2015; 128: 839-861

- Maessen DEM, Hanssen NMJ, Scheijen JLJM, van der Kallen CJ, van Greevenbroek MM, Stehouwer CDA, Schalkwijk CG. Post-glucose load plasma alpha-dicarbonyl concentrations are increased in individuals with impaired glucose metabolism and type 2 diabetes: The codam study. Diabetes Care. 2015; 38: $913-920$

- Maessen DEM, Scheijen JL, Gaens KH, van Greevenbroek MM, van der Kallen CJ, Stehouwer CD, Schalkwijk CG. Higher plasma concentrations of the methylglyoxal metabolite D-lactate are independently associated with insulin resistance: The CODAM study. J Diabetes Metab. 2014; 5:11

\section{Oral presentations}

- Diabetes and Metabolism Research Symposium - 2016 (Lille, France): Calorie restriction reduces postprandial $\alpha$-dicarbonyl stress in obese women with type 2 diabetes

- International Symposium on Diabetic Complications - 2015 (Heidelberg, Germany): Post-glucose load plasma $\alpha$-dicarbonyl concentrations are increased in individuals with impaired glucose metabolism and type 2 diabetes: the CODAM study 
- Science Day Internal Medicine - 2015 (Maastricht, The Netherlands): Postglucose load plasma $\alpha$-dicarbonyl concentrations are increased in individuals with impaired glucose metabolism and type 2 diabetes: the CODAM study

- International Symposium on the Maillard Reaction - 2015 (Tokyo, Japan): Pyridoxamine: a putative compound for treatment of obesity-associated complications

- International Symposium on the Maillard Reaction - 2015 (Tokyo, Japan): Postglucose load plasma $\alpha$-dicarbonyl concentrations are increased in individuals with impaired glucose metabolism and type 2 diabetes: the CODAM study

- Annual Dutch Diabetes Research Meeting - 2015 (Oosterbeek, The Netherlands): Post-glucose load plasma $\alpha$-dicarbonyl concentrations are increased in individuals with impaired glucose metabolism and type 2 diabetes: the CODAM study

- Annual Dutch Diabetes Research Meeting - 2015 (Oosterbeek, The Netherlands): Glyoxalase-1 overexpression reduces obesity-induced complications

\section{Poster presentations}

- $\quad$ Annual Meeting of the European Association for the Study of Diabetes - 2014 (Vienna, Austria): Glyoxalase-1 overexpression reduces body weight and adipokine expression, and improves insulin sensitivity in high-fat diet-induced obese mice

- Glyoxalase Centennial - 2013 (Warwick, United Kingdom): Delayed intervention with pyridoxamine improves the metabolic profile and insulin sensitivity in highfat diet-induced obese mice

- Glyoxalase Centennial - 2013 (Warwick, United Kingdom): Plasma concentrations of the methylglyoxal metabolite D-lactate are independently associated with insulin resistance: the CODAM study

- Annual Meeting of the European Association for the Study of Diabetes - 2013 (Barcelona, Spain): Plasma concentrations of the methylglyoxal metabolite Dlactate are independently associated with insulin resistance: the CODAM study 